\title{
POLITÉCNICA
}

Universidad Politécnica de Madrid

Escuela Técnica Superior de

Ingenieros Informáticos

\section{Investigación y Caracterización de Modelos de Calidad de Componentes Web}

\author{
Tesis Doctoral
}

Autor: Andrés-Leonardo Martínez-Ortiz

Licenciado en Informática

Directores: Genoveva López Gómez

David Lizcano Casas

Doctores en Informática 
Copyright (C) 2020 Andrés-Leonardo Martínez-Ortiz 
Departamento de Lenguajes y Sistemas Informáticos e Ingeniería del Software

Escuela Técnica Superior de Ingenieros Informáticos

\section{Investigación y Caracterización de Modelos de Calidad de} Componentes Web

Autor: Andrés-Leonardo Martínez-Ortiz

Licenciado en Informática

Directora: Genoveva López Gómez

Doctora en Informática

Director: David Lizcano Casas

Doctor en Informática 
Las tecnologías web son el pilar del desarrollo de Internet, haciendo de la red una de las mayores contribuciones a la innovación social, económica y cultural, y sin duda también tecnológica, de la historia de la humanidad. Desde la introducción en 1991 del protocolo http [1] y el lenguaje de etiquetado html [2], seguidos muy pronto de las primeras aplicaciones web, la tecnología ha facilitado el desarrollo y validación de novedosas propuestas. Estas no solo han trasladado a la red ideas preexistentes, sino que han creado toda una plétora de nuevas formas de uso y, lo que es más importante desde el punto de vista de la ingeniería del software, nuevos modelos de desarrollo de la tecnología. Siguiendo una aproximación ágil, y aun a costa de introducir deuda técnica, la propuesta y evaluación de nuevos productos web se ha priorizado, convirtiendo el "release soon, release often", el desarrollo en ecosistemas abiertos y la distribución en repositorios públicos bajo licenciamiento libre, en los principios que rigen la innovación y el desarrollo web, y que lo sitúa en muchos aspectos en extremos alejados de la ingeniería del software más convencional.

A lo largo de las dos últimas décadas se ha producido un acercamiento entre ambas posturas: por un lado, la investigación dentro del campo de la ingeniería del software ha proporcionado un mejor entendimiento de las técnicas ágiles y los ecosistemas de desarrollo abierto, recibiendo el reconocimiento y la adopción por parte de la industria; por otro, la labor llevada a cabo por el World Wide Web Consurtium (W3C) [3], coordinando el esfuerzo conjunto de empresas, academia y otros agentes del mundo de Internet como la Fundación Mozilla [4], ha conducido, entre otras cosas, a la estandarización de ECMAScript [5], aportaciones destacadas de la industria como TypeScript [6], o la introducción de tecnologías como los componentes web [7], donde resulta clara la influencia de paradigmas adoptados desde hace décadas en el mundo de la ingeniería del software. Los componentes, de reciente introducción, mejoran la cohesión y el acoplamiento de los elementos declarativos (html), lógicos (JavaScript) y de estilo (css) de las aplicaciones web, facilitando su reusabilidad y distribución. No obstante, la proliferación de librerías de componentes web distribuidas en repositorios públicos ha visto limitada su adopción por parte de la industria debido a la ausencia de modelos que permitan evaluar las características de calidad de producto y calidad en uso de acuerdo con los estándares al uso. La ausencia de garantía de calidad es tal, que gran parte de la industria limita o incluso prohíbe el uso repositorios de componentes tan populares como Github [8], Bower [9] o Npm [10].

Esta tesis aporta como novedad el desarrollo de un modelo de calidad de componentes web resultado del uso de técnicas mixtas que combinan investigación cualitativa y cuantitativa y que, aplicadas a la calidad software, introducen elementos de valoración objetiva y reproducibles en la definición de modelos, la validación de métricas software, estáticas (intrínsecas) y dinámicas (extrínsecas), y la evaluación de la cobertura que estas proporcionan de las características de calidad de producto y calidad de uso definidas en el estándar ISO/IEC 25000 [11].

La primera contribución introduce un paradigma de investigación mixta [12] aplicado al ámbito de los modelos de calidad software, para, a continuación, adaptarlo al caso particular de los componentes web. La combinación de técnicas de investigación cualitativa permite acotar los elementos de valoración subjetiva siempre presentes en los modelos de calidad, produciendo instrumentos de validación cuantitativa, requisito ineludible en el desarrollo de software moderno y que, desbordando el ámbito académico, impactará de manera significativa en los escenarios industriales de desarrollo de aplicaciones web.

Como segunda contribución, se presentan un conjunto de técnicas que, mejorando el Método Delphi [13], permiten una mayor comprensión analítica de los procesos de formación de consenso entre expertos, y que facilitan los métodos cualitativos para el desarrollo y validación de un modelo de calidad de componentes web. Fruto de esta aproximación se presentan 
técnicas obtenidas de valoración analítica del nivel de cobertura de características de calidad de producto y calidad en uso por parte de métricas intrínsecas y extrínsecas, el análisis diferencial entre iteraciones y la técnica que denominamos de conglomerados de Kendall y que permite la caracterización de los procesos de formación de consenso, categorizando los contextos posibles de aplicación alternativa de los modelos de calidad.

Como tercera contribución, se presenta el modelo de calidad de componentes web obtenido mediante las técnicas ya mencionadas. La importancia del modelo reside en varios puntos: por un lado, se trata de un modelo que, sustanciado a partir de la experiencia de expertos web, ofrece cobertura en términos de métricas de las características de calidad contempladas por el estándar ISO/IEC 25000 y, por tanto, en este sentido introduce la calidad de los componentes web en un lenguaje reconocido por la industria. Por otro, las métricas identificadas permiten el análisis automatizado de componentes web alojados en repositorios públicos que, traducidos en umbrales (benchmarks) de calidad, facilitarán sin duda la adopción a nivel masivo.

Por último, la cuarta contribución la constituye el desarrollo de un entorno de evaluación experimental que emplea algunas de las métricas de cobertura señaladas, para llevar a cabo procesos de validación automatizada de componentes web. La plataforma, utilizada en un proceso experimental con usuarios reales, ha permitido obtener evidencia estadística cuantitativa que relaciona la calidad percibida por usuario final con la evaluación realizada a partir de la aplicación de las métricas. Esta parte final aborda la evaluación cuantitativa, completando el proceso de investigación mixto, y sienta las bases de plataformas de evaluación automatizada de componentes web.

En resumen, las contribuciones realizadas por esta tesis validan la idoneidad de las técnicas mixtas de investigación aplicadas al dominio de la calidad software, refutan la imposibilidad de conectar estándares de calidad con aproximaciones ágiles y presentan las bases para facilitar la adopción de tecnología desarrollada en ecosistemas abiertos. 


\section{Abstract}

Web technologies are the mainstay of Internet development, making the network one of the greatest contributions to social, economic and cultural, but certainly also technological, innovation in human history. Since the introduction of the http [1] protocol and the html [2] mark-up language in 1991, soon followed by the first web applications, the technology has facilitated the development and validation of novel products and online services. These have not only transferred pre-existing ideas to the network but have created a whole plethora of new ways of use, and what is more important from the point of view of software engineering, new models of technology development. Following an agile approach, and even at the cost of introducing technical debt, the proposal and evaluation of new web products has been prioritized, turning "release soon, release often", development into open ecosystems and distribution into public repositories under free licensing., in the principles that govern innovation and web development, and that places it in many aspects at extremes far from the most conventional software engineering.

Over the past two decades, there has been an approach between both positions: on the one hand, research within the field of software engineering has provided a better understanding of agile techniques and open development ecosystems, receiving recognition and adoption by the industry; on the other, the work carried out by the World Wide Web Consortium (W3C) [3], coordinating the joint effort of companies, academia and other agents in the world of the Internet such as the Mozilla Foundation [4], has led, among other things, to the standardization of ECMAScript [5], outstanding contributions from the industry such as TypeScript [6] or the introduction of technologies such as web components [7], where the influence of paradigms adopted for decades in the world of software engineering is clear. The recently introduced components improve the cohesion and coupling of declarative (html), logical (JavaScript) and style (css) elements of web applications, facilitating their reusability and distribution. However, the proliferation of web component libraries distributed in public repositories has limited their adoption by the industry due to the absence of models that allow evaluating the characteristics of product quality and quality in use according to standards use. The lack of quality assurance is to such an extent that much of the industry limits or even prohibits the use of such popular component repositories as Github [8], Bower [9] or Npm [10].

This thesis contributes as a novelty the development of a quality model of web components resulting from the use of mixed techniques that combine qualitative and quantitative research, and that applied to software quality, introduce objective and reproducible evaluation elements in the definition of models, the validation of software metrics, static (intrinsic) and dynamic (extrinsic), and the evaluation of the coverage they provide of the characteristics of product quality and quality of use included in the ISO / IEC 25000 standard [11].

The first contribution introduces a mixed research paradigm [12] applied to the field of software quality models, and then adapts it to the particular case of web components. The combination of qualitative research techniques allows to limit the elements of subjective assessment always present in quality models, producing quantitative validation instruments, an inescapable requirement in the development of modern software and that, exceeding the academic field, will significantly impact on industrial scenarios of web application development.

As a second contribution, a set of techniques are presented that, improving the Delphi Method [13], allow a greater analytical understanding of the consensus-building processes among experts, and that facilitate qualitative techniques for the development and validation of a model of quality of web components. As a result of this approach, techniques obtained from analytical assessment of the level of coverage of product quality characteristics and quality in use by intrinsic and extrinsic metrics, the differential analysis between iterations and the technique 
that we call Kendall conglomerates are presented, allowing the characterization of consensusbuilding processes, categorizing the possible contexts of alternative application of quality models.

As a third contribution, the web component quality model obtained using the aforementioned techniques is presented. The importance of the model lies in several points: on the one hand, it is a model that, based on the experience of web experts, offers coverage in terms of metrics of the quality characteristics contemplated by the ISO / IEC 25000 standard, and therefore in this sense it introduces the quality of web components in a language recognized by the industry. On the other hand, the identified metrics allow the automated analysis of web components hosted in public repositories, which translated into quality benchmarks, will undoubtedly facilitate mass adoption.

Finally, the fourth contribution is the development of an experimental evaluation environment that uses some of the coverage metrics indicated, to carry out automated validation processes for web components. The platform, used in an experimental process with real users, has made it possible to obtain quantitative statistical evidence that relates the quality perceived by the end user with the evaluation made from the application of the metrics. This final part addresses quantitative evaluation, completing the mixed research process, and lays the foundation for automated web component evaluation platforms.

In summary, the contributions made by this thesis validate the suitability of mixed research techniques applied to the domain of software quality, refute the impossibility of connecting quality standards with agile approaches and present the bases to facilitate the adoption of technology developed in ecosystems open. 
A Lola, mi madre, y Antonio, mi padre.

A mi familia. 
Quisiera comenzar con una especial mención a la memoria del Dr. Fernando Alonso Amo, en reconocimiento de su labor educativa e investigadora desde la Facultad de Informática de la Universidad Politécnica de Madrid.

A la Dra. Genoveva López Gómez y al Dr. David Lizcano por su apoyo inagotable durante todos estos años.

A todos los alumnos del grupo CONWET del departamento de Lenguajes y Sistemas Informáticos e Ingeniería de Software de la Facultad de Informática de la Universidad Politécnica de Madrid.

Especial agradecimiento a los veinte expertos que han formado parte del panel de evaluación Delphi. Además de contribuir desinteresadamente, ofrecieron su valioso tiempo en unos momentos especialmente complicados, confinados en casa y enfrentados en algunos casos a complicadas situaciones personales derivadas de la pandemia del COVID-19.

Agradecer a el Dr. Carlos Torrecilla-Salinas y la Dra. María José Escalona la revisión de nuestra aproximación al método Delphi y sus valiosos comentarios y sugerencias.

A Carmela Morales Martínez y Mercedes Pacetti-Navarro por su ayuda en la revisión y corrección de erratas y estilo de la memoria. 


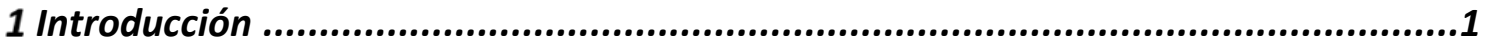

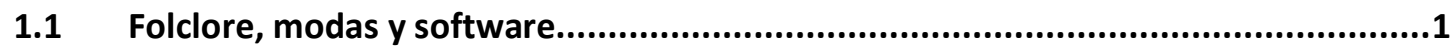

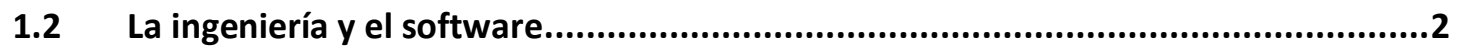

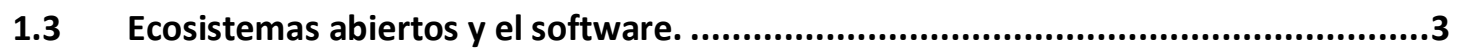

1.4 Calidad software como objetivo común..................................................................4

2 Revisión del Estado del Arte ......................................................................6

2.1 Métodos de Investigación Mixtos .........................................................................6

2.1.1 Antecedentes de los métodos mixtos de investigación .......................................................... 7

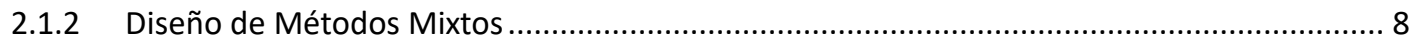

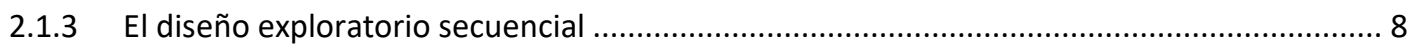

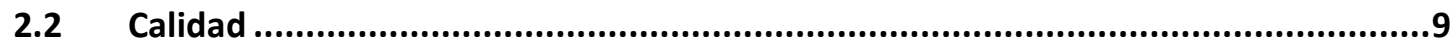

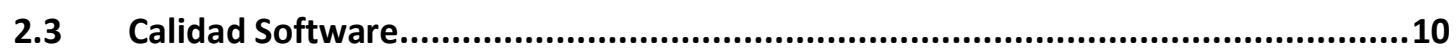

2.4 ISO/IEC 25010 Modelo de Calidad de Uso y de Producto ....................................12

2.5 ISO/IEC 25022 Medida de la Calidad en Uso....................................................14

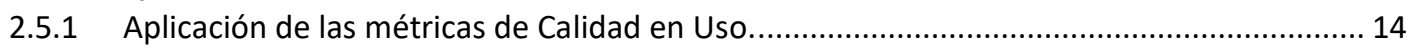

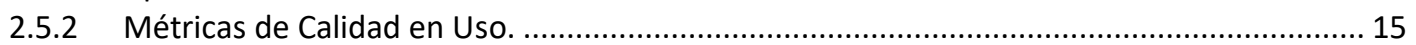

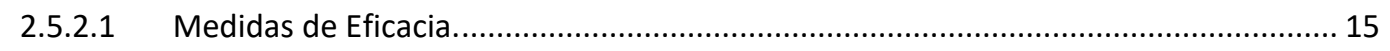

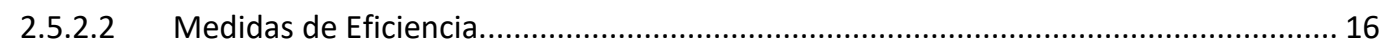

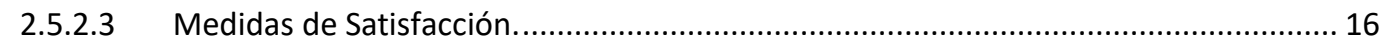

2.5.2.4 Medidas de ausencia de riesgo............................................................................. 17

2.5.2.5 Medidas de cobertura de contexto. ................................................................... 17

2.6 ISO/IEC 25023 Medida de la Calidad de Sistemas y Productos Software.................18

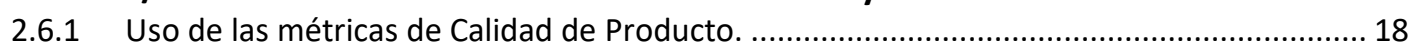

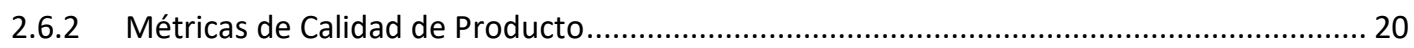

2.6.2.1 Medidas de Adecuación Funcional ..................................................................... 20

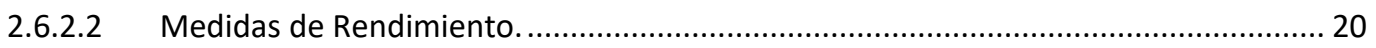

2.6.2.3 Medidas de Compatibilidad ............................................................................. 21

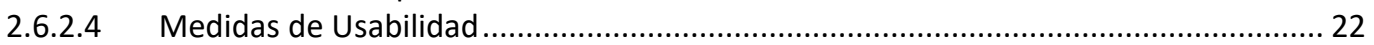

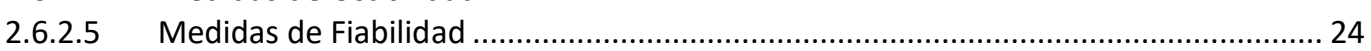

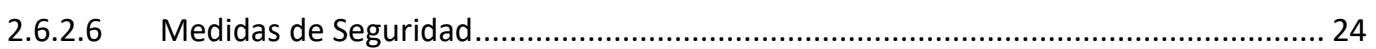

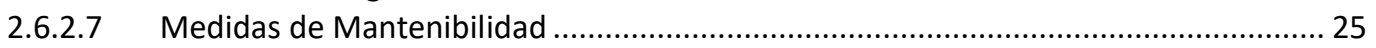

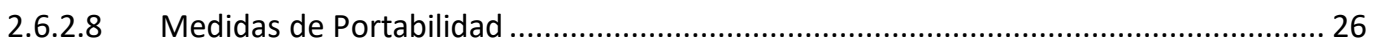

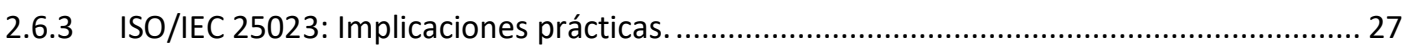

2.7 Desarrollo de Componentes en el mundo Web .....................................................27

2.8 Metodología Ágil y Desarrollos en Repositorios Abiertos ......................................29

2.9 Calidad de Componentes Web..........................................................................30

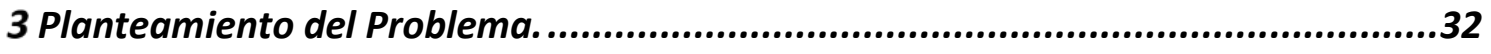

3.1 Motivación .............................................................................................................32

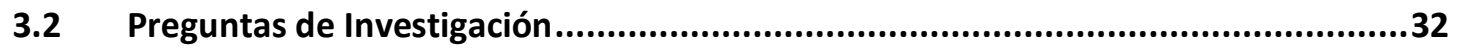

4 Descripción de la Solución Propuesta.............................................................35 
4.1 Diseño de Investigación Mixta en Ingeniería del Software.....................................35

4.1.1 Diseño e implementación de la fase cualitativa ...................................................... 36

4.1.2 Aplicación de las estrategias de diseño de fundamentos cualitativos. ............................. 36

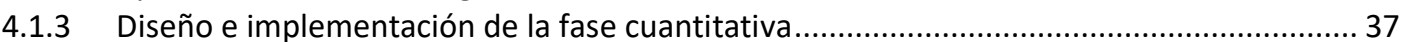

4.2 Diseño de la fase Cualitativa: Caracterización de Calidad Software ........................38

4.2.1 Conceptualización experimental del Modelo de Calidad. ................................................. 38

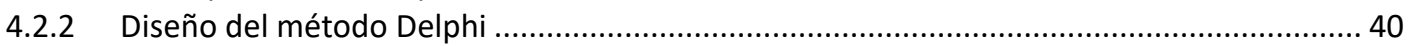

4.2.2.1 Definición de la materia de estudio ....................................................................... 40

4.2.2.2 Configuración del Panel de Expertos ..................................................................... 44

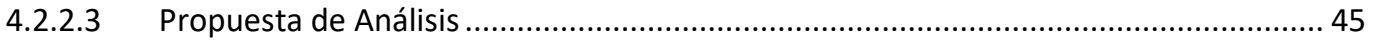

4.2.3 Conglomerados de Consenso y su Categorización ....................................................... 47

4.3 Instrumentos experimentales de fundamentos cualitativos ...............................48

4.3.1.1 Dominio de Experimentación y de Aplicación ............................................................ 48

4.3.1.2 Catalogo de Componentes Experimentales ............................................................... 49

4.3.1.3 Catálogo de Atributos de Calidad (Métricas) Experimentales .................................... 49

4.3.2 Diseño de la Plataforma de Experimentación ................................................................ 50

4.3.2.1 Módulo de Diseño de Experimentación................................................................. 51

4.4 Diseño de la Fase Cuantitativa: Experimentación y Análisis. ...............................55

5 Discusión de los Resultados ................................................................58

5.1 Exploración Cualitativa de la Calidad de Componentes Web..............................58

5.1.1 Caracterización del panel de expertos............................................................................ 58

5.1.2 Conceptualización Experimental del Modelo de Calidad de Componentes Web................ 60

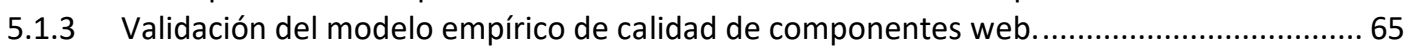

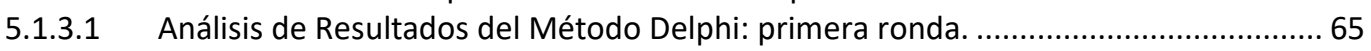

5.1.3.2 Análisis de Resultados del Método Delphi: segunda ronda. ..................................... 70

5.1.3.3 Análisis diferencial del Método Delphi ..................................................................... 74

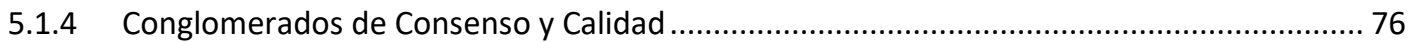

5.1.4.1 Análisis de Conglomerados: primera ronda ......................................................... 77

5.1.4.2 Análisis de Conglomerados: segunda ronda ........................................................ 81

5.2 Modelo de Calidad de Componentes Web ........................................................85

5.3 Resultados del Análisis y Experimentación Cuantitativa. ...................................86

5.3.1 Categorización de participantes del estudio cuantitativo. ................................................ 87

5.3.2 Exploración Cuantitativa a nivel de Escenario .................................................................. 88

5.3.3 Exploración Cuantitativa a nivel de Componente ......................................................... 91

5.3.4 Exploración Cuantitativa a nivel de Estudio................................................................. 97

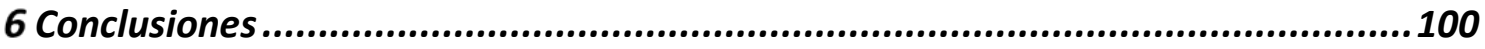

6.1 Métodos mixtos de investigación en Ingeniería del Software ..............................100

6.2 Calidad en ecosistemas abiertos ......................................................................... 101

6.3 Calidad de Componentes Web......................................................... 102

6.4 Cobertura Empírica del Estándar ISO/IEC 25010 ..............................................102

6.5 Generalización de Modelos Empíricos de Calidad ......................................... 104

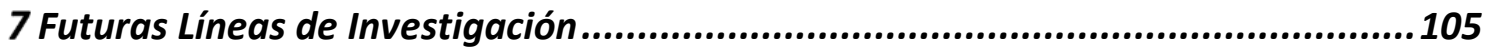

7.1 El Futuro de los Métodos mixtos en Ingeniería del Software.................................105

7.2 El Futuro de la investigación de la Calidad Software de Ecosistemas Abiertos. .... 105

7.3 El Futuro de la Evaluación de Calidad de Componentes Web...............................106

7.4 El Futuro de la Evaluación Empírica del Estándar ISO/IEC 25010.........................106 
7.5 El Futuro de la Generalización de Modelos Empíricos de Calidad. ........................106

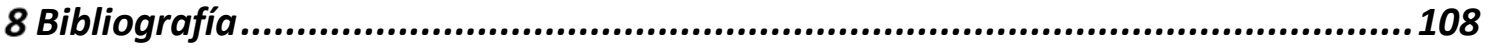

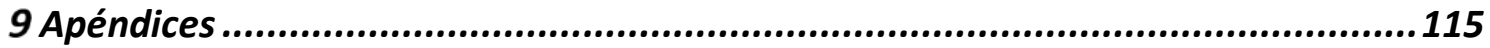

9.1 Datos Experimentales del Estudio Cualitativo .....................................................115

9.2 Distribuciones de Consenso..............................................................................117

9.3 Datos Experimentales del Estudio Cuantitativo I ..................................................119

9.4 Datos Experimentales del Estudio Cuantitativo II .................................................123

9.5 Datos Experimentales del Estudio Cuantitativo III .................................................127

9.6 Categorización del Panel de Expertos..................................................................129 


\section{Listado de Tablas}

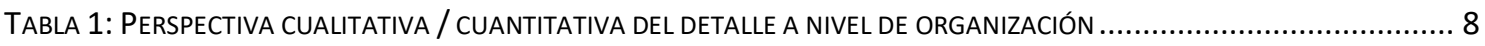

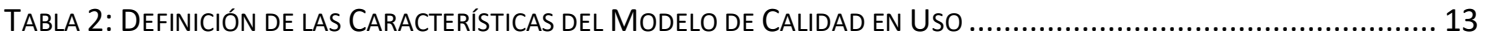

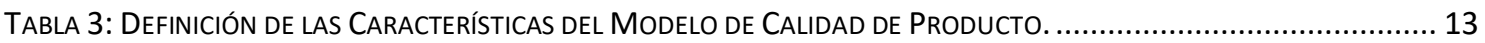

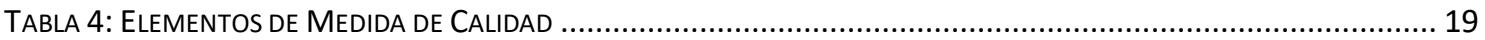

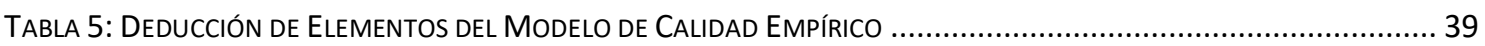

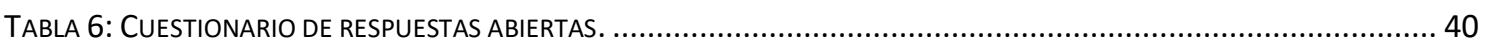

TABLA 7: CuestionaRIo Dimensión CALIdAd de Producto / MÉTRICA DE HALSTEAD. ...............................................42

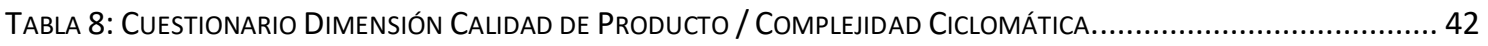

TABla 9: Cuestionario Dimensión CalidAd de Producto / Complejidad EStructural (FAN-OUT). ....................... 43

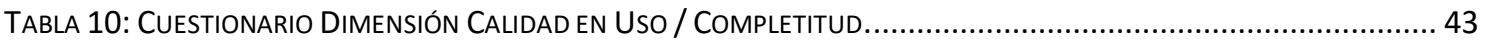

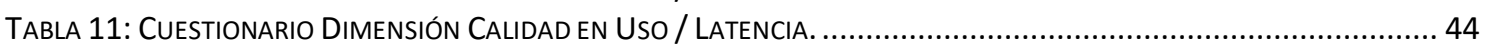

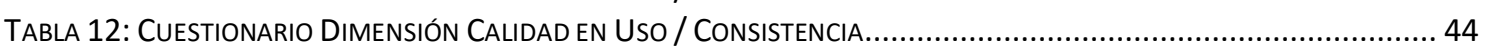

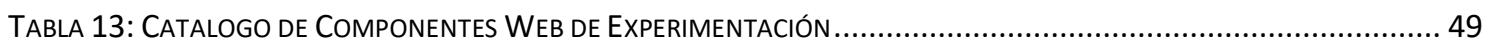

TABla 14: CATÁlogo de Atributos de Calidad (MÉTRICAS) EXPerimentales .......................................................5 50

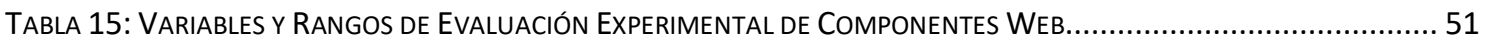

TABLA 16: ESTADÍSTICAS DESCRIPTIVAS DEL ATRIBUTO dE LA SÍNTESIS DE LA COMPLEJIDAD DE HALSTEAD ...................... 52

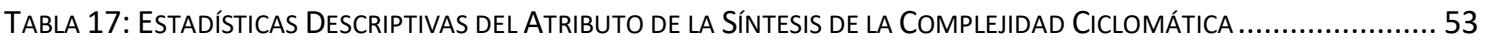

TABla 18: Estadísticas Descriptivas de la Síntesis del Atributo de la MedidA de Dependencias (fan-out)......... 54

TABLA 19: ESTADíSTICAS DESCRIPTIVAS DE LA SínTESIS DEL ATRIBUTO DE LA COMPLETITUD .........................................5 54

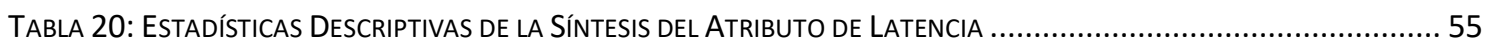

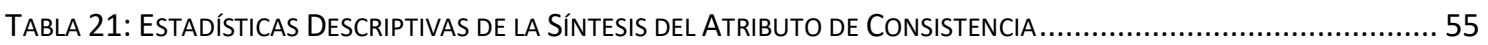

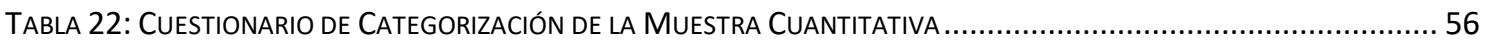

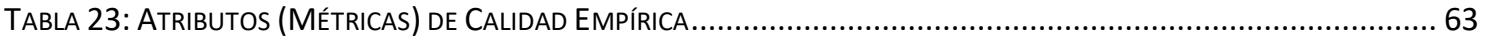

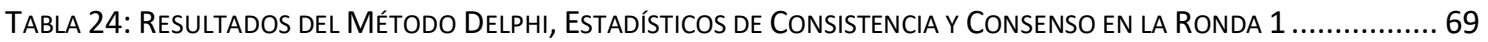

TABla 25: Resultados del MÉtodo DelPHI, Estadísticos de Consistencia y CONSENSO EN LA RondA 2 ................. 73

TABLA 26: ANÁLISIS DIFERENCIAL DE LOS RESULTADOS DEL MÉTOdO DELPHI PARA LA CALIDAD DE PRODUCTO ................... 75

TABLA 27: ANÁLISIS DIFERENCIAL DE LOS RESULTADOS DEL MÉTODO DELPHI PARA LA CALIDAD EN USO ..............................76

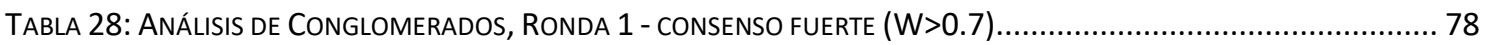

TABLA 29: ANÁLISIS DE CONGLOMERADOS, RONDA 1 - CONSENSO FUERTE MODERADO(W>0.6) .................................. 78

TABLA 30: ANÁLISIS DE CONGLOMERADOS, RONDA 1 - CONSENSO MODERADO (W=0.5) …..................................... 79

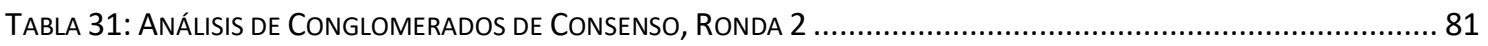

TABLA 32: ANÁLISIS DE CONGLOMERADOS, RONDA 2 - CONSENSO FUERTE $(W>0.7)$, SIN SOLAPES .............................8 82

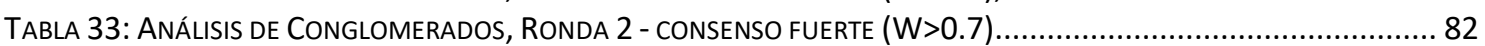

TABLA 34: ANÁLISIS de Conglomerados, RondA 2 - ConglomeradoS DE SEGUNdo NIVEL ....................................8. 84

TABLA 35: ANÁlISIS DE Conglomerados, RondA 2 - ConglomeradoS DE TERCER NIVEL........................................8 85

TABLA 36: ANÁLISIS DE Conglomerados, RondA 2 - Conglomerados DE CUARTO NIVEL .....................................8 85

TABLA 37: ANÁlisis de Conglomerados, Ronda 2 - Conglomerados DE QuINTO NiVEL ....................................85

TABLA 38: CATEgoRIZACIÓN DE LOS PARTICIPANTES en El ESTUdio CuANTITATIVO................................................ 87

TABLA 39: ESTADÍSTICAS DESCRIPTIVAS DE LA EXPLORACIÓN CUANTITATIVA A NIVEL DE ESCENARIO ...............................89

TABLA 40: TEST DE NORMALIDAD DE LA EXPLORACIÓN CUANTITATIVA A NIVEL DE ESCENARIO ......................................8 89

TABLA 41: DIAGRAMAS Q-Q DE LA EXPLORACIÓN CUANTITATIVA A NIVEL DE ESCENARIO ............................................90

TABLA 42: ANÁLISIS ANOVA DE UN FACTOR EXPLORACIÓN CUANTITATIVA A NIVEL DE ESCENARIO ................................99

TABLA 43: EstadíSTICAS DeSCRIPTIVAS DE LA EXPLoRACIÓn CUANTITATIVA A NIVEL DE COMPONENTE ............................92

TABLA 44: TEST DE NORMALIDAD DE LA EXPLORACIÓN CUANTITATIVA A NIVEL DE COMPONENTE.................................. 92

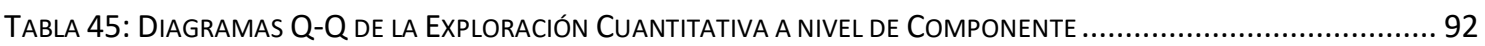

TABLA 46: ANOVA dE UN FACTOR DE LA EXPLORACIÓN CUANTITATIVA A NIVEL DE COMPONENTE ................................ 93

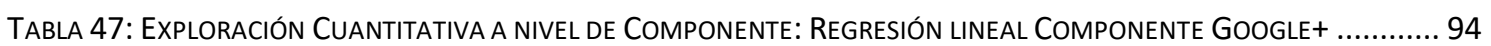

TABLA 48: EXPloración CuANTITATIVA A NIVEL DE COMPONENTE: Regresión LINEAL COMPONENTE TWITTER ...............99

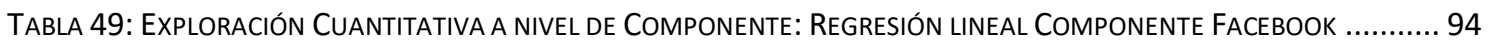

TABla 50: EXPloración CuAntitativa A nivel de Componente: Regresión lineal CoMPonente Pinterest............. 95

TABLA 51: EXPLORACIÓN CUANTITATIVA A NIVEL DE COMPONENTE: RegresIÓN LINEAL COMPONENTE BOLSA ..................95

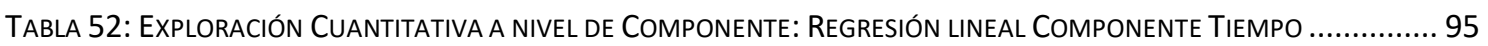

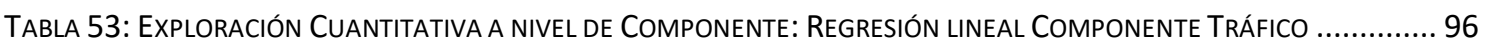

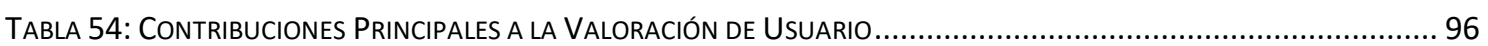


TABla 55: Estadísticas DesCRIPTIVAS de la ValoRACIÓn de Usuario a Nivel de Estudio

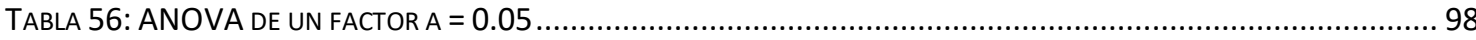

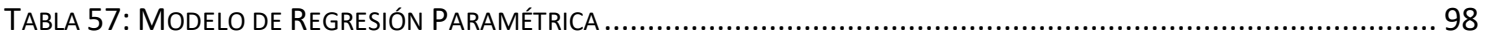

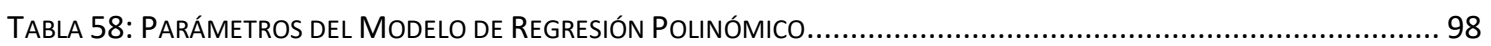

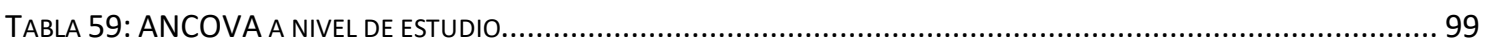




\section{Listado de llustraciones}

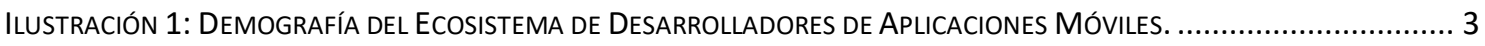

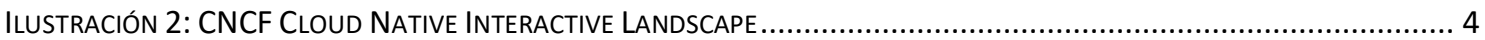

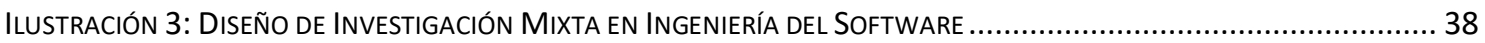

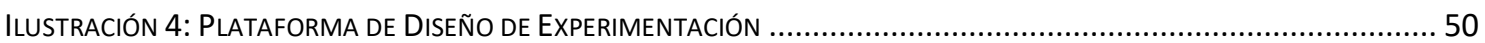

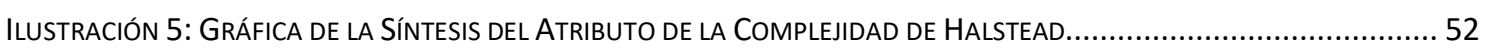

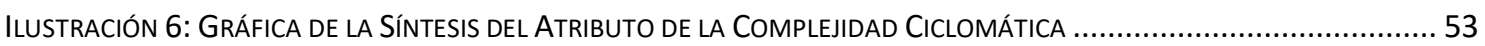

ILUSTRACIÓN 7: GRÁFICA DE LA SínTESIS DEL ATRIBUTO DE LA MEDIDA DE DEPENDENCIAS (FAN-OUT) .............................5 53

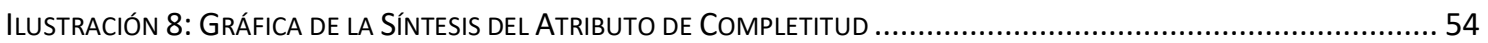

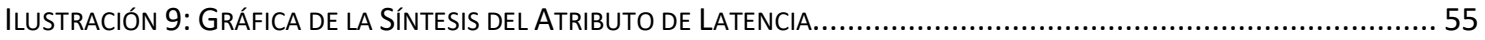

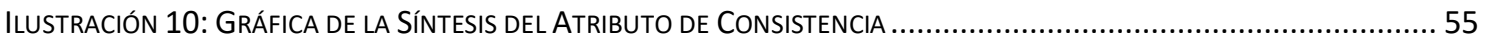

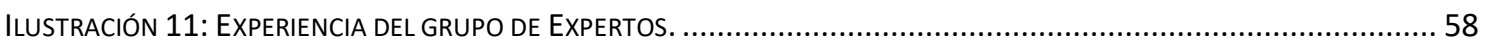

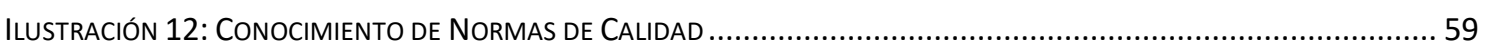

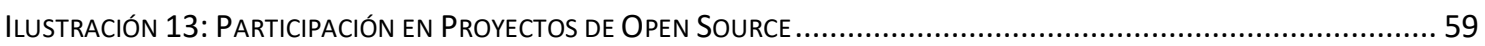

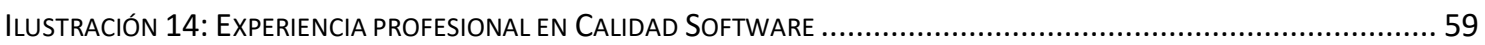

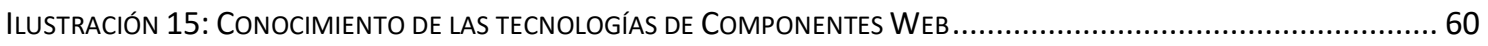

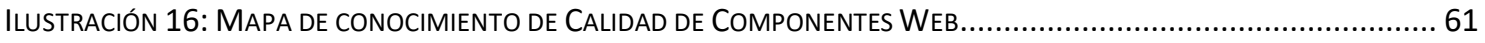

ILUSTRACIÓN 17: RESULTADOS DEL MÉTODO DELPHI, ESTADÍSTICAS DESCRIPTIVAS DE LA RONDA 1 ............................66

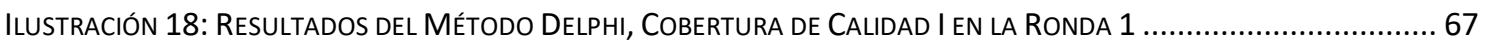

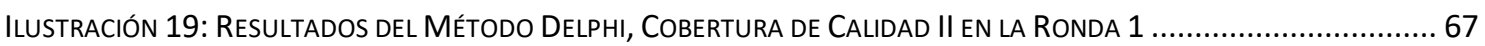

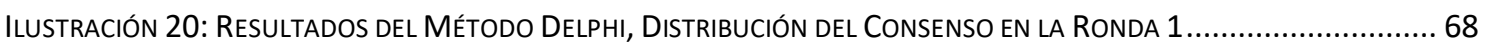

ILUSTRACIÓN 21: Resultados del MÉTOdo DelPHI, ANÁlISIS DE CORRESPONDENCIA SIMPLE EN LA RondA 1 ................70

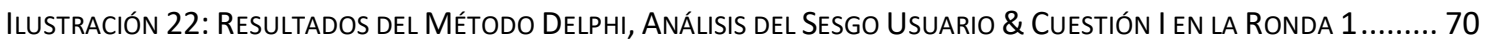

ILUSTRACIÓN 23: RESULTADOS DEL MÉTODO DELPHI, ESTADÍSTICAS DESCRIPTIVAS DE LA RONDA $2 \ldots \ldots . . . . . . . . . . . . . . . . . . . . .71$

ILUSTRACIÓn 24: Resultados del MÉTOdo DelPHI, CobertuRA de CALIDAd I EN LA RondA 2 ...................................72

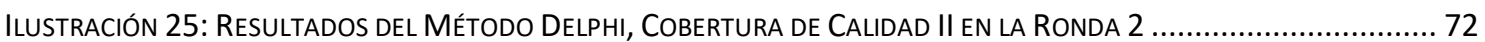

ILUSTRACIÓN 26: Resultados del MÉTOdo DelPHI, DistribuCIÓN DEL CONSENSO EN LA RONDA 2 .............................73

ILUSTRACIÓN 27: Resultados del MÉTOdo DelPHI, ANÁlISIS DE CORRESPONDENCIA SIMPLE EN LA RONDA $2 \ldots \ldots . . . . . . . .74$

ILUSTRACIÓN 28: Resultados del MÉTOdo DelPHI, ANÁLISIS DEL SESGO USUARIO \& CUESTIÓN I EN LA RONDA 2 .......... 74

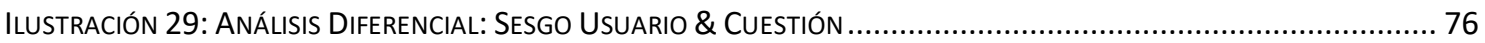

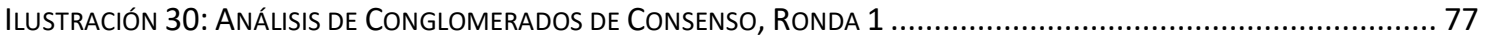

ILUSTRACIÓN 31: ANÁLISIS DE LA EVOLUCIÓN DINÁMICA DEL ESTADÍSTICO W DE KENDAL, RONDA 1..............................8 80

ILUSTRACIÓN 32: ANÁLISIS DE LA EVOLUCIÓN DINÁMICA DEL ESTADÍSTICO W DE KENDAL, RONDA 2 .............................8 83

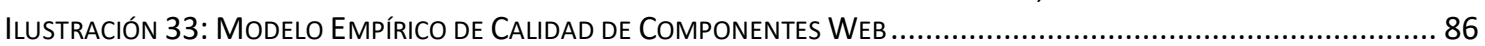

ILUSTRACIÓN 34: ORGANIZACIÓN TABULAR DE LOS RESULTADOS EXPERIMENTALES DE UN ESCENARIO ..............................8. 87

ILUSTRACIÓN 35: ORGANIZACIÓN TABULAR DE LOS RESULTADOS EXPERIMENTALES DE UN COMPONENTE .........................87

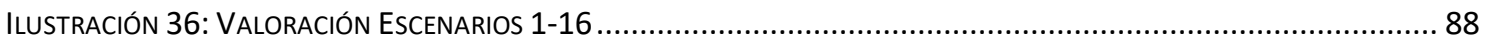

ILUSTRACIÓN 37: VALORACIÓN DE LOS COMPONENTES GOOGLE+, TWITTER, FACEBOOK Y PINTEREST............................. 91

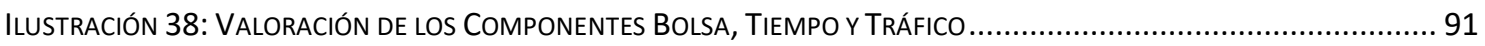

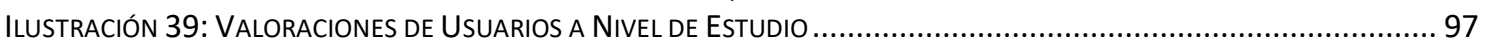

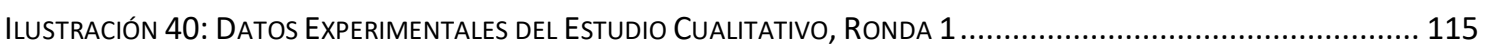

ILUSTRACIÓN 41: DATOS EXPERIMENTALES DEL ESTUDIO CUALITATIVO, RONDA 2 ................................................. 116

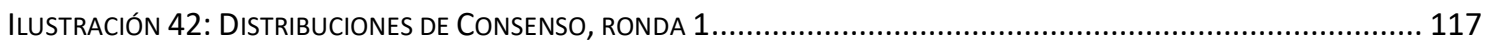

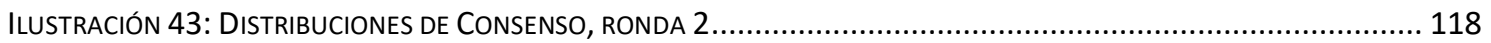

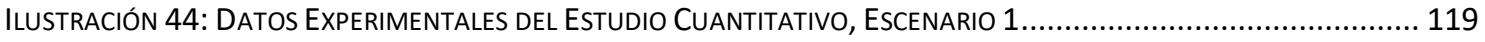

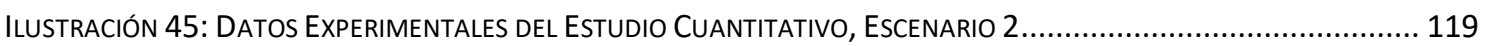

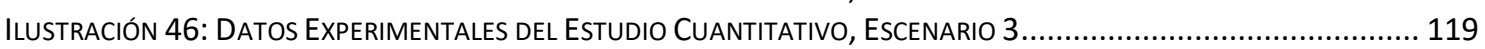

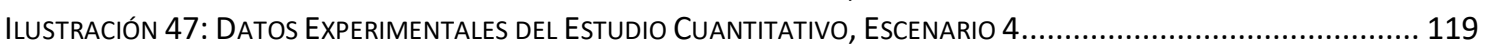

ILUSTRACIÓN 48: DATOS EXPERIMENTALES DEL ESTUDIO CUANTITATIVO, ESCENARIO 5............................................ 120

ILUSTRACIÓN 49: DATOS EXPERIMENTALES DEL ESTUDIO CUANTITATIVO, ESCENARIO 6 ............................................ 120

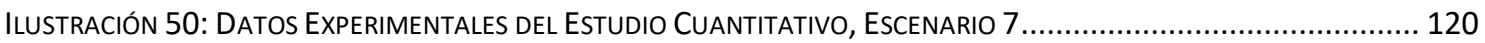

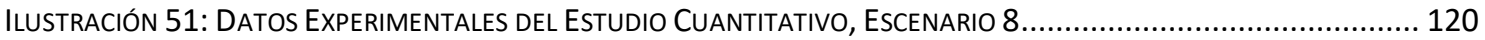

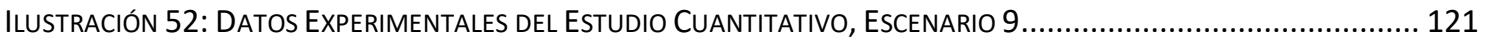

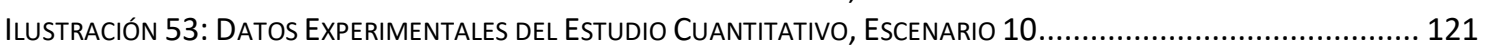

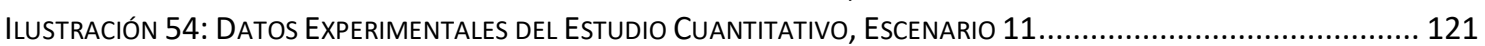


ILUSTRACIÓN 55: DATOS EXPERIMENTALES DEL ESTUDIO CUANTITATIVO, ESCENARIO 12

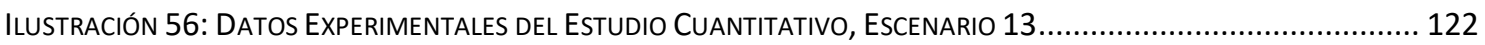

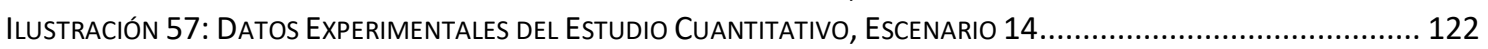

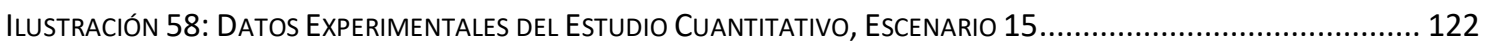

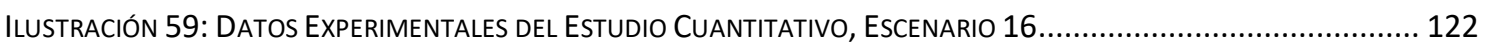

ILUSTRACIÓN 60:DATOS EXPERIMENTALES DEL Estudio CuANTITATIVO, CoMPONENTE Google+ ............................... 123

ILUSTRACIÓN 61: DATOS EXPERIMENTALES DEl Estudio CuANTITATIVO, COMPONENTE TWITTER .............................. 123

ILUSTRACIÓn 62: DATOS EXPERIMENTALES DEl Estudio CuANTITATIVO, COMPONENTE FACEBOOK............................. 124

ILUSTRACIÓN 63: DATOS EXPERIMENTALES DEL ESTUdIO CUANTITATIVO, COMPONENTE PINTEREST .............................. 124

ILUSTRACIÓN 64: DATOS EXPERIMENTALES DEl ESTUdIO CuANTITATIVO, COMPONENTE BolSA ................................. 125

ILUSTRACIÓN 65: DATOS EXPERIMENTALES DEL ESTUdio CuANTITATIVO, COMPONENTE TIEMPO................................. 125

ILUSTRACIÓN 66: DATOS EXPERIMENTALES DEL ESTUdIO CuANTITATIVO, COMPONENTE TRÁFICO................................ 126

ILUSTRACIÓN 67: RESULTAdOS EXPERIMENTALES CUANTITATIVOS AgRUPADOS A NiVEL DE ESTUdIO............................. 128

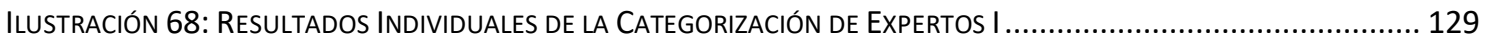

ILUSTRACIÓN 69: RESULTADOS INDIVIDUALES DE LA CATEGORIZACIÓN DE EXPERTOS II ............................................. 129 


\section{Introducción}

"No se puede ser al mismo tiempo hombre de acción y hombre de estudio, sin atentar contra la dignidad de una y otra profesión, sin faltar a la vocación de ambas. "

Max Weber

Los últimos 16 años de mi actividad profesional han estado ligados al mundo de la ingeniería del software, aunque en términos de un fenómeno de relativa novedad, el desarrollo de código en ecosistemas abiertos, y yo diría que aún no del todo entendido. Mi propia experiencia ha excluido el análisis en los términos en los que aprendí, académicamente al menos, a desarrollar software a la escala necesaria y con las garantías requeridas por los procesos de ingeniería. Pero no por esto he dejado de atestiguar la efectividad de este nuevo paradigma en la solución de complejos problemas del mundo del software y el sostenimiento de la que es, posiblemente, la mayor revolución tecnológica de la historia.

Más allá de la labor investigadora, de la que se dará cuenta en los capítulos siguientes, este trabajo ha resultado un viaje personal, que cierra la brecha entre el entendimiento que separaba los resultados que podían observarse, y las técnicas que permitía la comprensión de los procesos de innovación en ecosistemas abiertos. Y han sido, curiosamente, los métodos mixtos de investigación, que resuelven en su caso la, para muchos insalvable, brecha epistemológica existente en la combinación de las técnicas cuantitativas, que persiguen la generalización y replicación, y las técnicas cualitativas, más holísticas o culturales, las que adecuadamente adaptadas han resultado fundamentales.

Estas técnicas se han mostrado efectivas a la hora de entender cómo subyace cierto nivel de orden bajo el manto de complejidad que cubre los ecosistemas abiertos, y que habían hecho imposible aplicar las técnicas en exceso simplistas de la industria convencional. En particular, los métodos mixtos de investigación han permitido ahondar en dimensiones sociales, culturales si se quiere, de los ecosistemas software y que juegan un papel irreemplazable en la valoración de la calidad del software producido bajo este paradigma.

\subsection{Folclore, modas y software.}

La ingeniería del software es sin duda una de las más recientes y aunque su continuo desarrollo aun no permite dar por concluida su historia, las anécdotas relacionadas con las dificultades en la puesta en práctica de técnicas de ingeniería son innumerables [14]. Experiencias estudiadas y documentadas [15] de estas dificultades se remontan a los años 60 y si bien las economías de escala introducidas por la industrialización impulsaron la innovación y la calidad en sistemas y productos software, me atrevería a decir que las limitaciones ya destacadas fueron el germen 
de las sucesivas crisis y estancamientos en el desarrollo y la innovación de la producción industrial de software durante los años 90 .

De hecho, casi desde sus orígenes, pero sin duda durante los años 70 y principios de los años 80s, surgieron, de manera marginal [16] si se quiere, lo que se denominaron los bazares de desarrollo de software, en contraposición con las catedrales [17]; sólo mucho mas tarde los llamaríamos ecosistemas abiertos [18] y se abordaría el análisis de los mismos desde puntos de vista sociales, económicos y tecnológicos [19] [20]. Pero antes de llegar a este punto, no fueron pocos los que asumiendo que el desarrollo de software era más un arte que una ciencia, abordaron las formulación de tal artesanía [21] [22], hasta el punto de que el "folclore y las modas demasiado a menudo reemplazan los estándares profesionales" [23].

La creciente ubicuidad del software hace mas preocupante si cabe la brecha entre academia e industria. Los recientes ejemplos del Boeing 737 Max o el retraso en la comercialización de la nueva plataforma ID.3 de Volkswagen [24] ponen de manifiesto que, además de económico, el impacto puede llegar a poner en riesgo numerosas vidas humanas. Teniendo en cuenta que los programadores cometen entre 0,5 y 50 errores por cada 1000 líneas de código, conforme crece el tamaño de las soluciones, la garantía de sistemas libres de errores es nula. Esto explicaría por qué de media los desarrolladores dedicarían aproximadamente 21 horas semanales a procesos de reingeniería [24]. En conjunto con la rápida evolución de la tecnología, esta situación se traduce en una productividad deficiente, que explicaría las dificultades en el mantenimiento y la rápida obsolescencia reinante en el mundo del software, lo que han hecho de la arqueología del software algo más que un bonito término.

\subsection{La ingeniería y el software}

El término "ingeniería del software" se remonta a 1968 [25], y su introducción se realizó en el contexto de unas conferencias donde se abordaba la crisis del software, concepto que resumía la incapacidad ya entonces del desarrollo eficiente de grandes sistemas software. Si nos atenemos a las dificultades actuales [24], bien podría decirse que se trata de una crisis que no se encuentra en vías de ser superada completamente.

En términos actuales la ingeniería del software se define como "la aplicación de una aproximación sistemática, disciplinada y cuantificable a las estructuras, productos, sistemas o procesos" [26] y que "contempla todos los aspectos de la producción desde las fases tempranas de especificación de los sistemas, hasta su mantenimiento una vez puestos en producción" [25].

La disciplina se formula actualmente como un cuerpo de conocimiento consolidado [27], respaldado académica e industrialmente, y que cuenta con organizaciones profesionales [28] [29] [30] encargadas de la promoción de buenas prácticas, fomento de la investigación dentro del área de conocimiento y el desarrollo de estándares y códigos éticos [31] [32].

Durante los últimos cuarenta años se han introducido numerosas herramientas como la programación estructurada [33] y el paradigma de programación orientada a objetos; la necesidad de planificar el desarrollo software en términos de procesos predecibles, llevó a la introducción de modelos de estimación de esfuerzo como el modelo COCOMO [34] y la definición y estandarización de procesos y metodologías, reunidas de manera consistente en modelos de madurez como CMMi [35], introducidos como requisito habitual en pliegos de adquisición de proyectos software por gobiernos y empresas a proveedores de servicios IT. Adicionalmente, en los últimos 20 años se han realizado esfuerzos importantes en la creación y actualización de estándares en el campo de los sistemas y la ingeniería del software [36], cubriendo áreas tan importantes como arquitectura, requisitos, procesos $y$, por supuesto, calidad de producto software y calidad en uso.

La adopción de dichos modelos y estándares, sin embargo, distan mucho de ser universales y en ningún caso se asocian con desarrollos innovadores, que sin embargo parecen conectados con 
los ecosistemas de innovación abierta [37]. Es como si para conseguir los objetivos que persigue la ingeniería del software hubiese que sacrificar la innovación y la productividad derivados de la evolución trepidante de las tecnologías software.

\subsection{Ecosistemas abiertos y el software.}

Los ecosistemas han resultado ser una forma eficiente de abordar la complejidad creciente en los desarrollos de sistemas y productos software. Si a la acepción convencional [19] que presenta los ecosistemas software como un "conjunto de agentes que funcionan como una unidad, interactuando bajo un mercado común de software y servicios, así como las relaciones existentes entre ellos", se les añade como elemento de arbitrio que regula el acceso a la propiedad intelectual, los esquemas de licenciamiento abiertos [38], lo que obtenemos son ecosistemas abiertos.

Si bien las diferencias con los modelos que surgen de la ingeniería convencional pudieran no parecer insalvables, lo cierto es que estos ecosistemas son [19] sistemas sociales, económicos y tecnológicos, de dimensión enorme y naturaleza multinivel, compleja, dinámica, adaptativa, orgánica y auto organizada (emergence [39]) y global. Esta caracterización da una perspectiva de la distancia real entre la ingeniería del software introducida en la sección anterior y los ecosistemas abiertos.

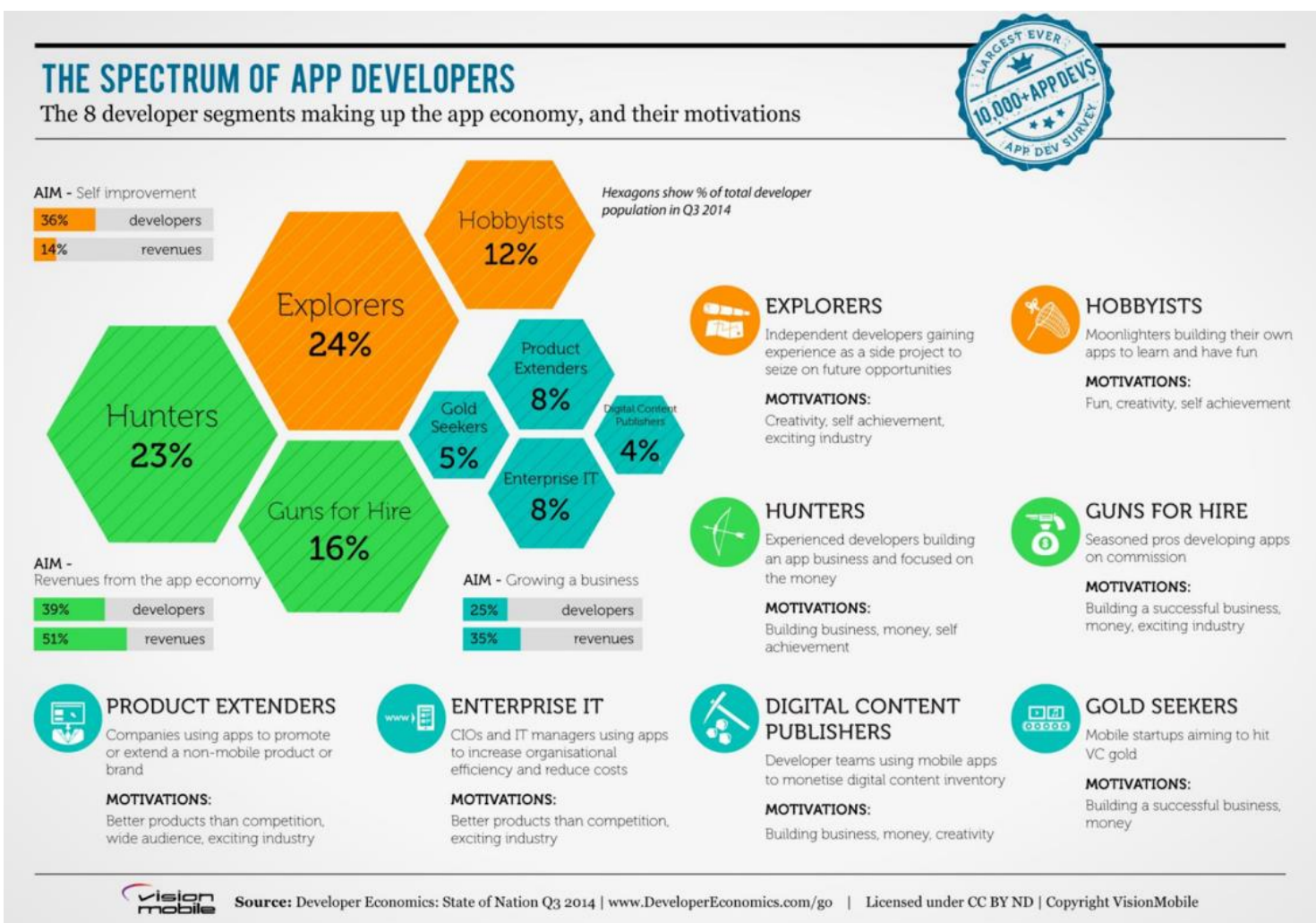

Ilustración 1: Demografía del Ecosistema de Desarrolladores de Aplicaciones Móviles.

Otras características de los ecosistemas limitan significativamente la aplicación de las prácticas de ingeniería. Por ejemplo, de acuerdo con el estudio realizado con mas de 10.000 desarrolladores de todo el mundo [40], según recoge la llustración 1, las principales motivaciones del $36 \%$ de los desarrolladores de aplicaciones móviles no son económicas, resultando ser el aprendizaje y entretenimiento. Es más, considerando también las categorías de desarrolladores independientes (Hunters y Guns for Hire) que suman otro 39\%, en conjunto un $75 \%$ de los desarrolladores de aplicaciones móviles, resultarían demasiado pequeños como para adoptar de manera eficiente prácticas de ingeniería estándar. 
Esta situación sería característica en todos aquellos ecosistemas de innovación y evolución rápida donde, como en el caso del desarrollo web, por ejemplo, la ausencia de mecanismos más convencionales de formación lleva a la autoformación de los desarrolladores. Merece la pena insistir en que este fenómeno no es en absoluto negativo, ya que, si bien excluye en gran medida procesos propios de la ingeniería, la aproximación ágil al desarrollo de software aún permite liderar procesos de innovación disruptiva, constituyendo el pilar de las tecnologías software hoy en día.

Los ejemplos actuales de ecosistemas software de éxito son innumerables e incluyen plataformas web como Chromium [41], servidores web como el servidor Apache [42], sistemas operativos distribuidos como Kubernetes [43], distribuciones software como Debian [44], navegadores web como Firefox [4], bases de datos como PostgreSQL [45], lenguajes de programación como Python [46], R [47] y TensorFlow [48], o tecnologías de componentes web como lit-elements [49].

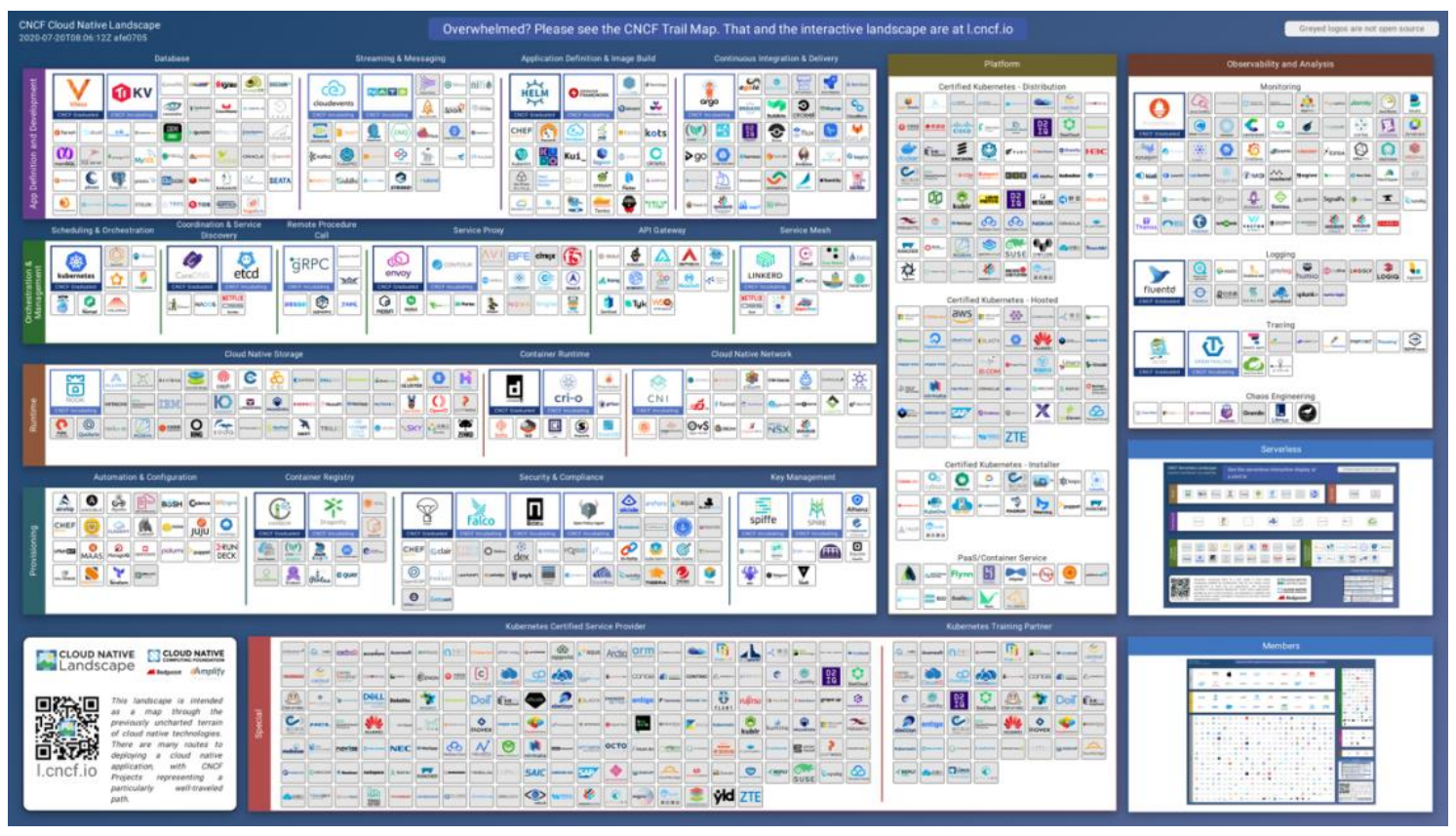

Ilustración 2: CNCF Cloud Native Interactive Landscape

El más icónico de ellos quizás sea el sistema operativo GNU/Linux, que se encuentra detrás del $95 \%$ de los dominios que se sirven actualmente en Internet, del $80 \%$ de los nuevos dispositivos móviles, de los 500 supercomputadores más potentes del mundo y es la plataforma primaria del $75 \%$ de los proveedores de computación en la nube [50]. Otro impactante ejemplo lo constituye el ecosistema representado por el denominado CNCF Cloud Native Interactive Landscape [51], recogido en la llustración 2 , que representa un ecosistema de tecnologías de computación en la nube, cuyas compañías alcanzan en conjunto una capitalización bursátil de algo más de 20 billones $\left(10^{12}\right)$ de dólares.

\subsection{Calidad software como objetivo común.}

A la vista de como he presentado los progresos en la ingeniería del software y los ecosistemas abiertos, pudiera parecer que la divergencia entre la disciplina y la práctica de la producción de software no solo ha existido desde siempre, sino que se incrementa con el paso del tiempo. Lo cierto es que según se ralentiza la innovación y mejora nuestro conocimiento, la generalización en el uso de dichas tecnologías introduce demandas que obligan a los desarrolladores de los ecosistemas abiertos a considerar elementos propios de la práctica de la ingeniería: planificación, medida, eficiencia y calidad en los resultados. 
Los principios de desarrollo ágil ya en 2001 establecieron prioridades prácticas: individuos e interacciones sobre procesos y herramientas, software funcionando sobre documentación extensiva, colaboración con el cliente sobre negociación contractual y respuesta ante el cambio sobre seguir un plan. Pero estas escuetas directrices han evolucionado desde entonces en áreas activas de investigación que, mejorando nuestra comprensión de estás técnicas de desarrollo, se han traducido en guías de buenas prácticas, metodologías, procesos y todo un conjunto de herramientas de soporte.

Si bien la calidad ha resultado ser un objetivo ineludible, parece claro que el enfoque que requieren los procesos de desarrollo de software exige una aproximación alternativa, que tendrá que continuar siendo aprendida de la experiencia obtenida en los desarrollos llevados a cabo en ecosistemas abiertos, para una vez consolidada convertirse en el cuerpo de una ingeniería del software.

En este trabajo de investigación se avanza en ese camino presentando técnicas que permiten mejorar el conocimiento sobre la forma en la que los desarrolladores que trabajan en ecosistemas abiertos evalúan la calidad de la tecnología software, en este caso de componentes web, para proponer un nexo que conecte con el cuerpo de estandarización utilizado en la industria.

El nicho tecnológico elegido presenta por sí mismo un conjunto de elementos que lo hacen atractivo: las tecnologías web han constituido un ecosistema de innovación de carácter disruptivo [52], donde aún hoy en día se prioriza la introducción de características funcionales y de producto. Pero también es de las áreas donde más reciente se ha realizado un esfuerzo de estandarización e introducción de técnicas de ingeniería. Ambas características ofrecen la oportunidad de extender el aprendizaje más allá de dicho ecosistema.

En conjunto los resultados podrían beneficiar a todos aquellos agentes que comparten la visión de que la calidad del software se traduce en un mundo mejor. 


\section{Revisión del Estado del Arte}

Te considero una gran persona, señor Bolsón, y te aprecio mucho; pero en última instancia, ieres sólo un simple individuo en un mundo enorme!

La presente investigación contribuye con resultados en áreas que van desde la metodología de la investigación al análisis de consenso en grupos de expertos, la calidad software, las tecnologías de componentes web y la definición de métricas de software.

Esta variedad de resultados requiere una revisión del estado del arte y la bibliografía asociada de claro perfil heterogéneo que se organiza en secciones más o menos auto contenidas.

\subsection{Métodos de Investigación Mixtos}

La metodología de la investigación científica se ha visto sacudida en los últimos veinte años con una corriente que, si bien habría de verse como inevitable, ha removido los cimientos de la ortodoxia. Esta afirmación que podría parecer exagerada pensando en el dominio de las ciencias sociales, sin duda no pasará por extrema a poco que se reflexione en el impacto que habrá de tener en el mundo de las ingenierías.

De acuerdo con el análisis recogido en J.W. Creswell y V.L. Plano Clark [12], los antecedentes históricos se remontan a finales de los años cincuenta, cuando la publicación de D.T. Campbell y D.W. Friske [53] ya valoraba la inclusión de múltiples fuentes de datos cuantitativos, aspecto también recogido ya en 1978 en Denzin [54], década en la que reputados representantes de la investigación cuantitativa como Campbell [55] o Cronbach [56] ya abogaban por la inclusión de datos cualitativos como parte de estudios experimentales cuantitativos.

Como resultado de estos trabajos preliminares, durante la década de los años ochenta se reprodujeron los artículos y libros que presentaban métodos mixtos en dominios que van desde la sociología [57], la gestión empresarial [58] o a la educación [59]. El principal signo distintivo de estos trabajos resultó ser la determinación de ir más allá de la mera utilización de métodos cuantitativos y cualitativos en procesos de investigación para, yendo un paso más lejos, explorar la integración y aproximación conjunta de preguntas de investigación, recogida de datos y análisis de los resultados.

Para la elaboración de este apartado, se ha seguido un par de referencias bibliográficas que presentan los métodos de investigación en general [60] y los métodos mixtos en particular [12]. Las principales referencias que hacen mención explícita a estas técnicas aplicadas al campo de la ingeniería se encuentran de forma abrumadora dentro del campo del análisis de los procesos educativos [61] [62], lo que resulta completamente normal, dado que el origen de dichas técnicas se encuadra en el área de las ciencias sociales.

Dentro de la ingeniería del software, con el enfoque que se ha seguido en esta investigación con la caracterización de las componentes culturales, o subjetivas como la calidad, la búsqueda de 
artículos en los que se aplican dichas técnicas resulta en extremo complicado, ya que no existe un consenso claro en como denominar los trabajos que hacen uso de los métodos mixtos para facilitar su localización, y así trabajos en los que se aplican tales técnicas [63] pueden pasar completamente desapercibidos, existiendo, qué duda cabe, honrosas excepciones [64] [65]. Hasta donde alcanza nuestro conocimiento, no existen trabajos previos de caracterización de la calidad siguiendo métodos mixtos de investigación.

Aunque en primera instancia, estos planteamientos pueden resultar ajenos a la ingeniería del software, la componente cultural o social de los procesos de creación de software, presentes en ecosistemas abiertos, pero también en compañías con un gran número de ingenieros y desarrolladores de software, ofrece una justificación plausible de la aplicación de los métodos de investigación mixtos.

Es más, la definición de la naturaleza de estas técnicas, la revisión y caracterización de los problemas que son abordables por ellas, y las ventajas que se derivan de su aplicación aportarán indicios de su potencial para ahondar en las raíces epistemológicas de nuestra labor científica. Antes de que salten las alarmas alertando de la llegada del post modernismo epistemológico a la ingeniería del software, procedamos a la definición de los métodos mixtos de investigación.

\subsubsection{Antecedentes de los métodos mixtos de investigación}

Las técnicas de investigación mixtas son fruto de una evolución acaecida en los últimos cincuenta años; su conceptualización es solo reciente y responde a la madurez de una tendencia que surgió de manera fragmentada en estudios diversos, pero siempre dentro de las ciencias sociales.

En la actualidad la definición de métodos mixtos hace énfasis en la aproximación metodológica, así como en el objeto de la de investigación [12]:

- La obtención y análisis de datos cuantitativos y cualitativos responde rigurosamente a hipótesis y cuestiones de investigación.

- El proceso combina, integrando datos y resultados, las técnicas de investigación cuantitativas y cualitativas.

- Fruto de la madurez de la disciplina, la actividad se organiza bajo un diseño de investigación que ofrece soporte lógico y procedimental para la realización de los estudios.

- De igual forma, se ha realizado una labor epistemológica que encuadra teórica y filosóficamente los métodos mixtos dentro de los principales paradigmas de investigación.

Este mejor entendimiento de los fundamentos de los métodos mixtos permite discriminar las situaciones que requieren dichas técnicas de aquellos casos en los que la exploración del problema, visibilidad de los actores del estudio, la caracterización de la complejidad o la armonización de múltiples perspectivas, dan prevalencia a las técnicas cualitativas o bien aquellos otros casos donde la necesidad de entender la relación entre variables, el análisis de grupos o la ambición generalizadora de los resultados hacen prevalecer las técnicas cuantitativas.

En general, los métodos mixtos serán necesarios allí donde una única fuente de datos sea insuficiente (diseño convergente), los resultados cuantitativos requieran explicación (diseño secuencial explicativo), los resultados cualitativos de generalización (diseño secuencia exploratorio), se requiera la expansión de un diseño experimental, o que múltiples casos tengan que ser comparados o contrastados, los actores tengan que involucrarse en la investigación o resulte imprescindible evaluar un programa. Estos últimos cuatro escenarios corresponden a diseños avanzados que no se describirán en este trabajo. 
En todos los escenarios mencionados, la combinación de técnicas cualitativas y cuantitativas proporciona un mejor entendimiento del problema; los datos cualitativos sustentan un entendimiento detallado del problema, mientras que la información cuantitativa facilita el entendimiento más general. Los principales beneficios de los métodos mixtos consisten, por tanto, en la provisión extra de evidencia para la investigación, facilitando resolver aquellos problemas que no pueden responderse desde un enfoque cualitativo o cuantitativo exclusivamente, proporcionando una visión más allá de ambas técnicas por separado al aunar múltiples paradigmas.

Resulta revelador presentar las técnicas cualitativas/cuantitativas según el foco diferente de cada aproximación en conexión con el ámbito de aplicación a nivel de organización (Tabla 1). Esto permite entender el beneficio que las técnicas mixtas proporcionan desde el punto de vista de la comprensión de organizaciones y ecosistemas.

\begin{tabular}{|l|l|l|l|}
\hline Paradigma & Alcance & \# Individuos & Ámbito Organizativo \\
\hline Cualitativo & Detallado & Reducido & Dirección \\
\hline Cuantitativo & Focalizado & Elevado & Clientes \\
\hline
\end{tabular}

Tabla 1: Perspectiva cualitativa / cuantitativa del detalle a nivel de organización

\subsubsection{Diseño de Métodos Mixtos}

El diseño establece los procesos de recogida, análisis, interpretación e informe de actividades de investigación. Los diseños pueden establecerse a priori, como parte de la planificación de las actividades de investigación, aunque con frecuencia son el resultado emergente de un proceso que es fruto de prueba y error ante la respuesta de problemas que surgen durante la labor investigadora.

No obstante, resultado de la experiencia acumulada, se han categorizado un conjunto de diseños frecuentes con objeto de establecer un marco de referencia que guíe la implementación de los métodos de investigación garantizando la calidad de los resultados. Los principales diseños son el convergente, el explicativo secuencial y exploratorio secuencial.

El diseño convergente reúne los resultados del análisis de los datos cuantitativos y cualitativos con objeto de compararlos o combinarlos, proporcionando una mejor comprensión del problema, validando unos resultados con otros, permitiendo comprobar si los participantes responden de manera similar a las escalas cuantitativas y los cuestionarios abiertos.

El diseño explicativo secuencial cuenta con dos fases, comenzando con la recogida y análisis de datos cuantitativos, para a continuación obtener y analizar datos cualitativos que explican o expanden los resultados de la primera fase cuantitativa.

El diseño exploratorio secuencial cuenta con tres fases, comenzando con una fase en la que se recogen y analizan datos cualitativos; estos resultados permiten realizar una fase exploratoria en la que se generan nuevas variables, el diseño de instrumentos o experimentos cuantitativos o herramientas digitales como aplicaciones móviles o web dirigidos a la generalización de los resultados cualitativos. Por último, en la tercera fase se lleva a cabo la validación: a) explicando cómo los datos cuantitativos pueden ser interpretados a partir de los resultados cualitativos o b) cómo los datos cuantitativos proporcionan un mejor entendimiento a partir de la perspectiva cualitativa de los participantes del estudio. Será el diseño que se utilizará en esta investigación.

\subsubsection{El diseño exploratorio secuencial}

El objeto principal del diseño exploratorio secuencial es el desarrollo y aplicación de medidas cuantitativas, ya sean cuestionarios, diseños experimentales, herramientas digitales o variables, que estén fundamentadas en datos cualitativos. Este diseño resulta conveniente ante la ausencia de medidas, instrumentos o actividades experimentales, cuando las variables son 
desconocidas o no existe marco teórico de referencia o cuando se persigue generalizar los resultados cualitativos a un grupo mayor.

En términos más concretos, el diseño exploratorio secuencial resulta adecuado cuando:

- El objeto de la investigación cuantitativa se encuentra imbricado en elementos culturales, careciendo de formalización.

- Se persigue el desarrollo de un producto o resultado relevante y a la vez culturalmente significativo.

- Se persigue la transmisibilidad y generalización de un nuevo resultado.

- Siguiendo un proceso emergente que, partiendo de la identificación de preguntas de investigación, resultado de la exploración cualitativa para un grupo pequeño de participantes, se evalúan con una muestra cuantitativa mayor.

Para aquellos que se pregunten como se encuadran estos métodos dentro de la epistemología, Creswell \& Plano-Clark [12] aclaran:

Desde un punto de vista filosófico, los investigadores comienzan a partir de principios constructivistas, desarrollando inductivamente el estudio para evaluar diversas perspectivas, obteniendo una mejor comprensión. Una vez que la investigación se mueve a la fase cuantitativa, los supuestos subyacentes se desplazan al post positivismo, identificando y midiendo deductivamente variables y tendencias estadísticas. La interpretación conjunta final de los resultados residiría en la perspectiva dialéctica de ambos enfoques.

Si bien existen variantes que responden a necesidades más específicas, el diseño explicativo secuencial se implementa ejecutando los siguientes pasos:

1. Diseño e implementación de la fase cualitativa, en la que se establecen las preguntas de investigación cualitativas y cómo se abordarán. Esto requiere la identificación de la muestra cualitativa, los protocolos de recogida de datos en entrevistas abiertas, así como el análisis de los datos cualitativos y procesos de selección de temas de interés. Como resultado, se obtendrán las cuestiones de investigación cuantitativa.

2. Aplicación de las estrategias de diseño de fundamentos cualitativos, en la que se diseña y desarrollan prototipos de evaluación de datos cuantitativos, instrumentos digitales o medidas, mejorando en conjunto tanto las cuestiones de investigación cuantitativa como las hipótesis generales del estudio. En esta fase también se determinarían la forma en la que los participantes de la fase cuantitativa serán seleccionados.

3. Diseño e implementación de la fase cuantitativa, en la que se establece la muestra cuantitativa que generaliza o evalúa los resultados cualitativos y las preguntas de investigación cuantitativas, obteniéndose los resultados de entrevistas cerradas haciendo uso de los instrumentos diseñados, para finalmente analizar los datos con técnicas estadísticas.

4. Interpretación de los resultados conjuntos, en la que se resumen e interpretan los resultados cuantitativos y cualitativos, valorándose hasta qué punto y de qué formas los resultados cuantitativos generalizan los resultados cualitativos.

Estos serán los pasos contemplados en el diseño de la presente investigación. A continuación, la revisión del estado del arte y la bibliografía asociada a la calidad software resaltará los elementos subjetivos de la calidad software y la desconexión de los estándares actuales con el mundo del desarrollo web.

\subsection{Calidad}

El concepto de calidad, existente en ámbitos más allá de la ingeniería del software, presenta de manera intrínseca elementos de subjetividad. De acuerdo con el diccionario de la Real Academia Española [66], en su primera acepción, la calidad es la "Propiedad o conjunto de propiedades 
inherentes a algo, que permiten juzgar su valor" y es en su tercera acepción, al referirse a la calidad de un producto, cuando establece que esta también corresponde con la "Adecuación de un producto o servicio a las características especificadas".

Resulta significativo que también en el mundo de la ingeniería del software se contemplen ambas acepciones, y que sea de igual forma la calidad percibida o en uso la que predomine como elemento de valoración de la satisfacción del usuario/cliente. Así se pueden encontrar en referencias fundamentales de la disciplina [25], que la calidad software se consigue cuando un sistema software resulta adecuado para su uso ("fit for purpose"), o dicho de otra forma, "los sistemas deberían satisfacer las necesidades de los usuarios, funcionando de manera eficiente y fiable, desarrollados a tiempo y ajustados al coste presupuestado".

El origen de la conceptualización y la gestión de la calidad tal y como se conoce actualmente se encuentra en la industria manufacturera [25]. Las principales influencias en el campo de la calidad tradicional occidental sería Philip B. Crosby (1926-2001), W. Edward Deming (19001993), Armand V. Feigenbaum (1922-2014) y Joseph M. Juran (1904-2008) [67].

Sus aproximaciones a la calidad y su gestión se pueden categorizar de acuerdo con el foco seguido: Crosby y Juran se centraron en la parte más estratégica, influyendo en los equipos de dirección, mientras que Deming y Feigenbaum trabajaron en la parte operativa, desarrollando las técnicas estadísticas y la mejora de procesos. En cualquier caso, en la industria manufacturera se asume que "las características del producto pueden ser completamente especificadas y que pueden establecerse procesos para comprobar que el producto elaborado se ajusta a los requisitos" [25].

La gestión de la calidad software tradicional hereda esta hipótesis, asumiendo que la calidad del software es resultado directo de la existencia de un proceso de producción, que cuenta con los mecanismos que aseguran su calidad. No obstante, la inherente naturaleza del software introduce desde el principio significativas diferencias que impiden la aplicación directa de las técnicas desarrolladas en el mundo de la industria manufacturera y convierten la calidad software y su evaluación en un proceso de elevada componente subjetiva, en particular a lo que se refiere a sus características no funcionales.

Esta divergencia se hará más patente al analizar los desarrollos de componentes web, realizados bajo el paradigma de software libre en repositorios abiertos, donde la ausencia de requisitos explícitos es habitual y las expectativas se construyen en base a elementos dispares. En este trabajo se muestra que dicha divergencia es solo parcial y aparente, pudiéndose educir un marco o modelo de calidad compatible, estableciendo la equivalencia de las valoraciones subjetivas de las características no funcionales con atributos medibles.

\subsection{Calidad Software}

En lo que se refiere a la calidad software, la sección del Guide to the Software Engineering Body of Knowledge de la IEEE Computer Society [27] correspondiente al área de conocimiento de la calidad software comienza con unos párrafos dedicados a la confusión reinante, la multitud de acepciones y lo difuso de las mismas debido a que las definiciones utilizadas incluyen el requisito de las especificaciones sin establecer su nivel de detalle o el tipo de requisito, que puede ser funcional, de eficiencia o eficacia por mencionar algunos. Por otra parte, existen características no funcionales que pueden medirse de manera directa, mientras que otras requieren un uso prolongado del software o su medida indirecta, haciendo necesarios atributos ad hoc.

Aún así se deja claro que la especificación de los requisitos es el elemento clave, determinando los mecanismos de medida y procesos de aceptación que permiten designar el nivel de calidad alcanzado. La revisión crítica de esta última sentencia permite sentar las bases del presente trabajo de investigación: debido a la disparidad entre los mecanismos de establecimiento de requisitos del desarrollo web en entornos de repositorios abiertos, los mecanismos de medida 
y procesos de aceptación difieren significativamente de los establecidos en el estándar ISO/ICE 25010; con este trabajo se explora la existencia de una equivalencia que dote de validez a unos frente a otros.

La industria valora la calidad como fundamental en el desarrollo de software y así lo demuestran los usuarios, que asocian las características comúnmente vinculadas con el concepto de calidad con altos grados de satisfacción. Los procesos de desarrollo de software supervisan el cumplimiento, coste y desempeño de los requerimientos de usuario, conectados todos ellos con la calidad software, ya sea la calidad funcional o la no funcional [68] [69].

La calidad funcional responde a las expectativas determinadas por los requisitos definidos por los usuarios; en cambio, la calidad no funcional corresponde a la calidad de los elementos software de apoyo necesarios para la implementación de los requisitos funcionales. En estos términos, la calidad software puede definirse como el atributo de un producto que cumple con el rendimiento y los requisitos funcionales, los criterios de desarrollo y la función inherente que todo producto software debe tener [68].

De acuerdo con la definición previa, la gestión de la calidad del software asegura que el software desarrollado alcanza su propósito, satisfaciendo las necesidades de los usuarios con el rendimiento y la fiabilidad esperadas, de acuerdo con los plazos y el presupuesto establecidos [25]. Con el fin de uniformar su aplicación y valoración, distintos organismos de estandarización han publicado estándares que determinan las diferentes dimensiones de la calidad software, así como los requerimientos para su mejora [68]:

- International Standard Organization (ISO) define la calidad software como una tabla de atributos que ilustran la calidad en productos software.

- La organización de estandarización de ANSI la define como la suma de todas las características de un producto software que representa su capacidad para satisfacer los requisitos de usuario.

- IEEE establece una lista de características que permiten al producto software satisfacer necesidades específicas.

Los diferentes aspectos que intervienen en la calidad software, su identificación, evaluación y mejora se agrupan en modelos de calidad. A lo largo de los últimos 40 años se han introducido varios, entre los que podríamos destacar Boehm [70], McCall [71], Dromey [72], FURPS [73], ISO/IEC 9126 [74] y su versión actualizada ISO/IEC 25010 [11]. De acuerdo con estos modelos, las tres definiciones más populares son:

1. La calidad software está determinada por un conjunto de factores de calidad.

2. La calidad software está determinada por la satisfacción de los usuarios.

3. La calidad software está determinada por errores o comportamientos no previstos.

Según el estándar ISO/IEC 25010, la calidad software se define como "la totalidad de aspectos y características de un producto o servicio que sustenta su capacidad de corresponder los requisitos establecidos, explícitos o implícitos". Para su especificación, el estándar se estructura en cuatro secciones: modelo de calidad, métricas extrínsecas, métricas intrínsecas y métricas de uso [11].

El reflejo de tales definiciones en los procesos de aseguramiento de la calidad se concreta en todas las etapas del ciclo de desarrollo software, incluyendo definición de requisitos, diseño del software, programación, control y revisión del código fuente, gestión del cambio, gestión de la configuración, pruebas, gestión de despliegue e integración de producto. De acuerdo con los estándares ISO 9001 [75] o IEEE CMM [76], la introducción de métricas permite el análisis y la comparación cuantitativa, necesarias para el aseguramiento de calidad. 
El estándar ISO/IEC 25010 distingue la calidad en uso y la calidad de producto. Para cada una de ellas se presenta un conjunto de características y sub-características, respectivamente cinco / doce para la calidad en uso, y ocho / treinta y uno para la calidad de producto. Existe un tercer modelo de calidad, aplicado a los datos, recogido en el estándar ISO/IEC 25012.

No obstante, el estándar no aborda el cómo han de medirse, estableciendo que "para obtener métricas de las características o sub-características, a menos que sean directamente medibles, se deberán identificar una colección de propiedades que cubran conjuntamente y que combinadas permitan la elaboración de las métricas correspondientes" [11]. Los detalles de la evaluación de la calidad software serán incluidos en la norma ISO/IEC 25040.

El modelo ISO/IEC 25010 de calidad en uso contempla cinco características: eficacia, eficiencia, satisfacción, ausencia de riesgo y cobertura de contexto. El modelo ISO/IEC 25010 de calidad de producto, interna y externa, contempla ocho características: adecuación funcional, rendimiento, compatibilidad, usabilidad, confiabilidad, seguridad, mantenibilidad y portabilidad.

En comparación con el estándar ISO/IEC 9126, el más reciente ISO/IEC 25010 reúne en el modelo de calidad de producto los antiguos modelos de calidad intrínsecos y extrínsecos. Las medidas externas requieren el producto final y la participación de los usuarios. En cambio, las medidas internas se realizan directamente sobre el código fuente mediante métricas software. Ambas perspectivas no son independientes, y así el mismo estándar establece que "las medidas internas de calidad pueden utilizarse para predecir medidas externas de calidad software."

\subsection{ISO/IEC 25010 Modelo de Calidad de Uso y de Producto}

El estándar ISO/ICE 25010 [11] define modelos de calidad en uso y de producto. La medida y evaluación de la calidad quedan recogidas en las series ISO/IEC 2502n y ISO/IEC 2504n respectivamente; todos ellos forman parte de los resultados del grupo de trabajo denominado Systems and Software Quality Requeriments and Evaluation (SQuaRE).

El estándar ISO/IEC 25010, que normaliza los Modelos de Calidad de Sistemas y Software, es la evolución del estándar de calidad de producto software ISO/IEC 9216:2001 [74], que excluye, comparado con el ISO/IEC 9216:1991 la norma correspondiente a la evaluación de producto software, que fue movida al estándar ISO/IEC 14598. Las principales mejoras de la norma ISO/IEC 25010, además de la redacción y las definiciones empleadas, han consistido en la introducción de nuevas características relevantes en la evaluación del contexto, la seguridad y la compatibilidad, así como la reunión de los modelos de calidad internos y externos combinados como modelo único de calidad software.

El estándar establece un modelo de calidad en uso caracterizado por cinco características fundamentales, así como un modelo de calidad de producto software, en el que se emplean ocho características. En ambos casos, la definición de sub-características permite precisar aún más la evaluación. Esta armazón proporciona una terminología consistente, tanto para producto software como para sistemas informáticos, permitiendo especificar y evaluar la calidad de ambos.

Es importante destacar que el estándar asume que el conjunto de características / subcaracterísticas seleccionadas no tiene por qué ser necesariamente exhaustivo. Es más, la obtención de medidas de dichas características, salvo para aquellas directamente observables, requerirá la identificación de propiedades que proporcionen cobertura, es decir, que permitan formular matemáticamente la relación entre las características no funcionales y dichas métricas. Este proceso responde a un elevado grado de subjetividad, requiriendo el consenso de facto entre los agentes reconocidos en el modelo y pudiendo variar por tanto en distintos escenarios.

El estándar incluye, con objeto de reducir la ambigüedad, un apéndice donde se establecen los elementos que definen las propiedades del software. Distinguiendo entre propiedades 
inherentes, como el número de líneas de código, y propiedades asignadas, como el precio; buscando un mayor grado de objetividad, se descartarán las últimas, las propiedades asignadas, en el proceso de evaluación.

Siguiendo un criterio similar, y con el fin de dotar a la norma de la máxima generalidad, se excluirán del proceso de evaluación de calidad a las propiedades inherentes funcionales, salvo la idoneidad (suitability), dejando únicamente las denominadas propiedades inherentes de calidad, que determinan lo bien que funciona el software (fit for use).

Una vez introducidos los conceptos de evaluación externa (black box), correspondiente al análisis del sistema/producto software durante su ejecución, y la evaluación interna (white box), que por fijar la atención en propiedades estáticas puede ser evaluada durante la fase de desarrollo, el estándar afirma que la calidad medida internamente impacta en la calidad del software medida externamente, que a su vez impacta en la calidad en uso. El estándar propone la evaluación de propiedades estáticas (ISO/IEC 25022 [77]) para medir las propiedades inherentes del producto software; de igual forma, las medidas externas de propiedades dinámicas (ISO/IEC 25023 [78]) permitirán evaluar la calidad inherente de sistemas informáticos.

Durante el proceso de validación del modelo empírico, manejaremos la definición precisa de las características de calidad de los modelos en uso y de producto. Las Tabla 2 y Tabla 3 recogen sus definiciones de acuerdo con el estándar ISO/IEC 25010:

\begin{tabular}{|c|}
\hline $\begin{array}{l}\text { Eficacia } \\
\text { Precisión y completitud con la que los usuarios alcanzan el objetivo especificado }\end{array}$ \\
\hline $\begin{array}{l}\text { Eficiencia } \\
\text { Relación de recursos empleados y la precisión y completitud con la que los usuarios alcanzan el objetivo especificado }\end{array}$ \\
\hline $\begin{array}{l}\text { Satisfacción } \\
\text { Grado de satisfacción de las necesidades del usuario cuando el producto se utiliza en el contexto de uso especificado. }\end{array}$ \\
\hline $\begin{array}{l}\text { Ausencia de riesgo } \\
\text { Grado en el que el producto reduce un potencial riesgo de carácter económico, humano o del medio ambiente. }\end{array}$ \\
\hline $\begin{array}{l}\text { Cobertura del contexto } \\
\text { Grado al cual un producto software puede utilizarse con eficacia, eficiencia, satisfacción y ausencia de riesgo tanto en contexto } \\
\text { de uso especificados, como más allá de las especificaciones iniciales. }\end{array}$ \\
\hline
\end{tabular}

\section{Adecuación Funcional}

Grado al cual un producto proporciona funcionalidad que cumple las necesidades implícitas o explícitas cuando se utiliza bajo unas condiciones especificadas.

Rendimiento

Rendimiento relativo a la cantidad de recursos consumidos bajo condiciones especificadas.

Compatibilidad

Grado con el que un producto puede intercambiar información con otros y/o realizar sus funciones mientras comparte el mismo entorno hardware/software.

Usabilidad

Grado con el que un producto puede ser utilizado por usuario específicos, alcanzando objetivos específicos con eficacia, eficiencia y satisfacción en el contexto especificado.

Fiabilidad

Grado con el que un producto realiza funciones especificadas bajo condiciones especificadas por un tiempo especificado. Seguridad

Grado con el que un producto protege la información y los datos de forma que usuarios u otros sistemas cuentan con el nivel de acceso adecuado a sus tipos y niveles de autorización.

Mantenibilidad

Grado de eficacia y eficiencia con el que un producto puede ser modificado por los agentes de mantenimiento especificados Portabilidad

Grado de eficacia y eficiencia con el que un producto puede ser transferido de un entorno hardware, software, de uso u otros, a un nuevo entorno.

Tabla 3: Definición de las Características del Modelo de Calidad de Producto.

El estándar no define el conjunto de agentes que intervienen en el proceso de evaluación y medida de la calidad, ya que estos dependen absolutamente del caso concreto que se esté analizando. Por el contrario, se presenta un ejemplo de identificación de dichos agentes mediante un proceso de análisis de los objetos (targets) del modelo de calidad. Estos se desglosan, partiendo del nivel correspondiente a los sistemas humano-computadora, para 
profundizar al nivel de sistemas de información, llegando finalmente al nivel del objeto de sistema IT (computer system). En este recorrido se identifican los distintos agentes del modelo, ejemplificando como habría de realizarse dicho proceso para un caso concreto. Adicionalmente, el estándar recoge un ejemplo detallado de las necesidades de usuario de acuerdo con algunas características de la calidad en uso y de producto, categorizadas de acuerdo con los roles de usuarios primarios (interactivos), secundarios (soporte) e indirectos (beneficiarios). En conjunto, estos ejemplos deberían servir para guiar la adaptación del modelo a otros escenarios.

El estándar incluye un apéndice donde se ilustra un ejemplo del proceso de adaptación del modelo, abstracto, a un caso concreto, utilizando una definición específica del atributo fiabilidad (dependability), correspondiente a la definición incluida en el estándar de medidas electrotécnicas IEC 60050-191. En este proceso, se selecciona el conjunto de características del estándar que pueden definirse de acuerdo con la acepción de fiabilidad introducida, excluyendo aquellas otras que no tienen sentido, y que solo podrían precisarse en un proceso de evaluación más general.

En la presente investigación se realizará el desarrollo de un modelo de calidad siguiendo una aproximación similar, donde las decisiones y las características a incluir, así como sus coberturas serán seleccionadas mediante el panel de expertos y las técnicas de consenso del método Delphi.

\subsection{ISO/IEC 25022 Medida de la Calidad en Uso}

La serie de estándares elaborados por el grupo System and Software Quality Requirements and Evaluation (SQauRE) incluye, junto con el modelo de calidad recogido en la ISO/IEC 25010, la norma ISO/IEC 25022 [77] que proporciona un conjunto de métricas para las características de calidad en uso. Dicho estándar proporciona las guías necesarias tanto para la especificación de requisitos relativos a la calidad en uso, como para su evaluación. Esta sección, resumiendo y adaptando el texto oficial, presenta sus detalles.

El estándar ISO/IEC 25022 incluye un conjunto de métricas que se aplican a todos aquellos sistemas en los que conviven computadoras y usuarios, así como también a los productos software que componen dichos sistemas. Como suele ocurrir en la mayoría de los estándares, pero más si cabe en este caso por su elevada dependencia del contexto de aplicación, las métricas no pretenden ser exhaustivas, ni tampoco finales, por lo que en la mayoría de las situaciones prácticas habrán de ser adaptadas siguiendo las recomendaciones para estos casos.

Esta dependencia del contexto de aplicación y las necesidades de los usuarios llevan al estándar a no recomendar rango de valores aceptables para las métricas presentadas; si bien se asume que en aquellos casos en los que se puedan establecer marcos de referencia absolutos determinados, por ejemplo, por características cognitivas propias del ser humano, será posible proponer valores recomendables.

Los ámbitos de aplicación se corresponden con los procesos de control de la calidad, así como con tareas de administración de sistemas y producto software dirigidas por el efecto que su uso produce en los usuarios. Esto determina los principales agentes que contemplan / se benefician de dichas métricas y que se corresponden con aquellos involucrados en la gestión técnica del desarrollo, adquisición y evaluación de sistemas y productos software, así como aquellos involucrados con su mantenimiento.

\subsubsection{Aplicación de las métricas de Calidad en Uso.}

La definición de la calidad en uso se presenta siguiendo el estándar ISO/IEC 25010 y así se establece que la calidad en uso se corresponde con el grado con el cual un producto o sistema puede ser utilizado por usuarios para satisfacer sus necesidades que les permitan lograr una 
serie de objetivos, de acuerdo con los requisitos especificados, con eficacia, eficiencia, satisfacción y ausencia de riesgo para los contextos de uso requeridos.

Resulta necesario aclarar que, en este ámbito, usabilidad hace referencia al subconjunto de características de calidad en uso formado por la eficacia, eficiencia, satisfacción y cobertura de contexto. La ausencia de riesgo se verá afectada tanto por la usabilidad (calidad en uso), así como por características de la calidad de producto.

Tal y como se ha mencionado, la evaluación de la calidad en uso es el resultado de la interacción de un usuario con un sistema o producto terminado, pero también puede ser utilizada durante las fases de diseño y desarrollo. En este último caso, (1) durante la fase de especificación de requisitos pueden introducirse los correspondientes a la calidad en uso para contemplar la experiencia de los usuarios y otros agentes; (2) durante la evaluación de prototipos en fase de definición, se pueden identificar carencias significativas de calidad en uso, mediante la experimentación con un número reducido de usuarios; (3) la evaluación de prototipos acabados permite obtener estimaciones de los valores finales de calidad en uso, esta vez con experimentaciones con grupos de usuarios mayor, pudiendo inferir el impacto en el control de riesgos.

Teniendo en cuenta que la calidad en uso depende no solo de la calidad de producto, si no también del contexto de uso específico, las dificultades para la estimación y análisis de la ausencia de riesgo son especialmente significativas. En este ámbito, el contexto de uso incluye aspectos relativos a los usuarios, las tareas a realizar, así como los entornos físicos y sociales que afectan a la calidad de uso. Esto da una idea de la dificultad de acotar el contexto o limitar el impacto que pudiese tener.

Con todo esto, algunas medidas de calidad en uso pueden ser especialmente difíciles de interpretar, requiriendo un marco interpretativo, que se puede establecer en términos de conformidad con ciertos casos de uso, en términos comparativos con productos similares de uso equivalente, observando su dinámica temporal, en relación con los resultados obtenidos por un experto del dominio de aplicación o de acuerdo con valores históricos recolectados de experiencias con versiones previas. Además, la obtención de valores fiables de medidas de eficacia, eficiencia o satisfacción exigirán un número de usuarios suficiente para alcanzar la confianza estadística deseada.

\subsubsection{Métricas de Calidad en Uso.}

La presentación de las métricas de calidad en uso se realiza siguiendo el orden establecido en estándar ISO/IEC 25010, e incluyen la especificación del contexto de uso, es decir, el tipo de usuario, las tareas y el entorno de medición, para las características de eficacia, eficiencia y satisfacción.

\subsubsection{Medidas de Eficacia.}

La eficacia corresponde con el grado de precisión y completitud con la que los usuarios alcanzan las metas especificadas en los requisitos, sin precisar cómo se logran, con el fin de resaltar los errores de diseño de los sistemas. Analíticamente viene determinada por cinco funciones:

- La proporción de tareas completadas correctamente sin requerir asistencia.

- La proporción de objetivos de una tarea que se logra correctamente sin requerir asistencia.

- El número de errores cometidos durante la realización de una tarea.

- La proporción de tareas en las que los usuarios cometieron errores.

- Proporción de usuarios que comenten errores para una tarea. 


\subsubsection{Medidas de Eficiencia.}

La eficiencia corresponde con la medida de los recursos consumidos en relación con la precisión y completitud con la que los usuarios alcanzan las metas especificadas, es decir, en relación con la eficacia.

En este contexto, el término recurso determina generalmente el tiempo que se requiere para completar una tarea, aunque podría también tratarse de esfuerzo requerido o recursos materiales del uso. Se trata de una medida que se suele comparar haciendo uso de un marco de referencia representado por una herramienta alternativa o el uso realizado por un experto. Analíticamente viene determinada por seis funciones:

- El tiempo necesario para completar con éxito una tarea.

- El numero de objetivos logrados por unidad de tiempo.

- El coste por objetivo logrado, donde coste podría ser tiempo de usuario, coste material de los recursos empleados, etc., frente al coste de no utilizar el sistema.

- La proporción del tiempo efectivo que emplea el usuario realizando la tarea frente al tiempo total, que incluye el tiempo empleado recibiendo ayuda, recuperándose de los errores o buscando soluciones.

- La proporción de acciones realizadas por el usuario no requeridas para completar la tarea.

- La reducción del rendimiento como consecuencia del uso prolongado del sistema.

\subsubsection{Medidas de Satisfacción.}

Las medidas de satisfacción corresponden con el grado al cual las necesidades de un usuario se satisfacen usando un producto o sistema dentro del contexto de uso especificado. Se evalúa de acuerdo con las siguientes dimensiones: utilidad, confianza, experiencia de usuario y ergonomía.

La utilidad corresponde con el grado con el que un usuario está satisfecho con su logro percibido de las metas prácticas, incluyendo los resultados y las consecuencias del uso del producto o sistema. Analíticamente se evalúa con cinco funciones:

- La satisfacción con las características del sistema.

- La proporción de usuarios potenciales que eligen usar el sistema o función.

- La proporción de usuarios, correspondientes al grupo de estudio, que hacen uso de una funcionalidad determinada.

- La proporción de usuarios que presentan quejas sobre el sistema o producto.

- La proporción de usuarios que presentan quejas sobre una funcionalidad determinada.

La confianza se corresponde con el grado con el que un usuario o agente, tienen confianza en que el sistema o producto se comportará como se pretende. Analíticamente se evalúa en función de la valoración psicométrica que hacen los usuarios mediante un cuestionario.

La experiencia de usuario o medida de agrado se corresponde con el grado con el que las necesidades de realización del usuario son alcanzadas. Las necesidades realización son de carácter difuso por naturaleza, pero se asimilan en numerosas ocasiones con el deseo de aprender nuevas capacidades o conocimientos, transmitir identidad o rememorar sentimientos agradables. Analíticamente se evalúa de nuevo en términos de encuestas de valoración psicométrica comparada con otros sistemas similares.

La ergonomía o medida de confort corresponde al grado con el que se satisface la necesidad de confort físico en el uso del sistema o producto. Analíticamente se evalúa mediante encuestas de valoración psicométrica.

Para todas aquellas dimensiones que se evalúan mediante cuestionarios psicométricos, el estándar incluye referencias con ejemplos de este tipo de cuestionarios. 


\subsubsection{Medidas de ausencia de riesgo.}

Las medidas de ausencia de riesgo corresponden con el grado con el que la calidad de un producto o sistema reduce o evita el riesgo potencial en términos económicos, de vidas humanas o salud y/o medioambientales. Como se ha comentado anteriormente, el origen de tales riesgos puede residir tanto en características de calidad de producto como en niveles inadecuados de eficacia, eficiencia, satisfacción o cobertura de contexto.

El alcance viene determinado por los agentes involucrados, afectando tanto al bienestar de usuarios, reputación empresarial o riesgo económico para la compañía que utiliza el sistema o incluso la sociedad, que podría verse afectada por desastres originados por el malfuncionamiento de los sistemas software. Las medidas de ausencia de riesgo se evalúan en función de las siguientes dimensiones: reducción de riesgo económico, reducción de riesgo sanitario y reducción de riesgo medioambiental.

La reducción del riesgo económico evalúa el impacto de la calidad en objetivos económicos, ya sean financieros, operativos, comerciales o de reputación. Analíticamente se evalúa con las siguientes funciones:

- Retorno de inversión.

- Tiempo necesario para alcanzar el retorno de inversión.

- Rendimiento empresarial.

- Beneficios derivados de la inversión en tecnología.

- Grado con el que se alcanzan los objetivos de satisfacción de cliente.

- Ratio de conversión de clientes.

- Valor total de cliente.

- Proporción de errores con consecuencias económicas.

La reducción del riesgo sanitario evalúa el impacto de la calidad en los objetivos de salud y seguridad sanitaria. Analíticamente se evalúa con las siguientes funciones:

- La proporción de usuario del sistema/producto que informan de problemas de salud tras comenzar a utilizar el sistema.

- La proporción correspondiente a la suma del tiempo que cada persona se ve afectada $\left(T_{i}\right)$, ponderada con una medida de impacto $\left(\mathrm{W}_{\mathrm{i}}\right)$, con respecto al tiempo total $(\mathrm{T})$ que el sistema lleva en uso $\left(\frac{1}{T} \sum_{i=1}^{n} T_{i} \times W_{i}\right)$.

- Proporción de usuarios con problemas de salud derivados del uso del sistema, con respecto al total de usuarios.

Por último, la reducción de riesgo medioambiental evalúa el impacto de la calidad en los objetivos medioambientales. Analíticamente se evalúa en relación con un objetivo, ya sea estándar, de mercado o especificado en los requisitos e incluiría no solo el uso, sino también la producción del sistema.

\subsubsection{Medidas de cobertura de contexto.}

La cobertura de contexto corresponde con el grado con el que un producto software o sistema puede ser utilizado con eficacia, eficiencia, satisfacción y ausencia de riesgo tanto en el contexto especificado como en un contexto que desborda los requisitos iniciales. Se evalúa bajo las dimensiones de completitud de contexto y flexibilidad.

La completitud de contexto corresponde al grado con el que el sistema puede ser utilizado con los niveles especificados de eficacia, eficiencia, satisfacción y libertad de riesgo en cada uno de los contextos determinados. Analíticamente se evalúa como la proporción de contextos especificados para los que el sistema o producto software cuenta con un nivel de usabilidad (eficacia, eficiencia y satisfacción) y riesgo. 
La flexibilidad corresponde con el grado con el que un sistema puede ser utilizado con niveles aceptables de eficacia, eficiencia, satisfacción y ausencia de riesgo en un contexto que se encuentra más allá de los contemplados inicialmente. Analíticamente se evalúa mediante las siguientes funciones:

- Proporción de contextos adicionales en los que el sistema o producto software puede ser utilizado de manera aceptable.

- Facilidad con la que un producto software puede modificarse para satisfacer requisitos adicionales.

- Proporción de usuarios potenciales que pueden utilizar el sistema sin conocimientos, capacidades o experiencias.

Antes de continuar, merece la pena detenerse unos instantes para, a la luz de la definiciones de características y atributos recogidos en el estándar, valorar la enormidad que separar los contextos de desarrollo de software contemplados y aquellos que se dan en los ecosistemas abiertos y de los que se hablará más adelante.

\subsection{ISO/IEC 25023 Medida de la Calidad de Sistemas y Productos Software.}

Complementando la norma ISO/IEC 25022, el conjunto de trabajos realizados por el grupo System and Software Quality Requirements and Evaluation (SQauRE) incluye un estándar, el ISO/IEC 25023 [78], que propone una colección de atributos, o medidas de calidad, de cobertura de las características propuestas por la norma ISO/IEC 25010 para la calidad de sistemas y producto software. Este apartado presenta los detalles de dicho estándar siguiendo el texto oficial [78].

Como ya ocurría en el caso del estándar ISO/IEC 25022, la selección de atributos se realiza de acuerdo con su aplicabilidad desde un punto de vista práctico, y organizados en niveles de fiabilidad. La colección de métricas incluidas no pretende ser exhaustiva y contempla solo medidas internas y externas, ya que las medidas de calidad en uso son objeto de otro estándar, presentado en la sección anterior.

A efectos del estándar, se consideran medidas externas aquellas que determinan el grado con el que un sistema o producto software habilita el comportamiento que responde a las necesidades del software, ya sean implícitas o explícitas, bajo condiciones de uso especificadas en los requisitos. En cambio, son medidas internas aquellas que determinan el grado con el que un conjunto de atributos estáticos de un producto software responden a las necesidades explícitas o implícitas para dicho producto usado bajo las condiciones especificadas por los requisitos.

El estándar no incluye rangos de valores aceptables para cada métrica, ya que estos dependerán de la naturaleza del producto o sistema software. No obstante, los atributos de calidad presentados son adecuados para asegurar la calidad y su mejora tanto durante el desarrollo como posteriormente, por lo que se convierte en herramienta imprescindible para desarrolladores y mantenedores del software, equipos de gestión de la calidad, así como a responsables de adquisición y proveedores.

Con el fin de facilitar su entendimiento, las métricas se presentan agrupadas por categoría de calidad. Cada una de las categorías podrá contar con una o más dimensiones de evaluación y cada dimensión un conjunto de funciones analíticas de medida. Estas últimas, por ser suficientemente sencillas, se recogen descritas y no formuladas en términos matemáticos. Dichas fórmulas, se pueden consultar directamente en el estándar.

\subsubsection{Uso de las métricas de Calidad de Producto.}

La calidad de un sistema o producto software representa el grado al cual se satisfacen las necesidades, implícitas o explícitas, del conjunto de agentes relacionados, proporcionando 
valor. De acuerdo con el estándar ISO/IEC 25010, el conjunto de necesidades contempladas se delimita por el conjunto de características y subcaracteristicas que define el modelo de calidad y que se recoge en la Tabla 3.

Como ya se habrá observado, el estándar tiene buen cuidado de aclarar la naturaleza implícita o explícita de las necesidades a satisfacer, reconociendo la dificultad de especificar de manera exhaustiva los requisitos de los sistemas y productos software, incluso en contextos de uso acotado, lo que supone el reconocimiento de cierto nivel de subjetividad en la definición de dicho conjunto de necesidades.

El conjunto de propiedades medibles relacionadas con la calidad de un sistema o producto software, se denominan propiedades a cuantificar y se asocian con medidas de calidad, que se determinan mediante métodos de medida. Estos métodos de medida constituyen una secuencia lógica de operaciones que cuantifican las propiedades de acuerdo con una escala especificada y que resultan en los denominados elementos de medida de calidad. Combinados algorítmicamente estos elementos de medida de calidad permitirán cuantificar las características de calidad. Las características de calidad, en general, vendrán representadas por mas de una medida de calidad.

Los elementos de medida de calidad utilizados para la definición de medidas de calidad contemplados por el estándar se recogen en la Tabla 4.

Número de Funciones

La cantidad de funciones que satisfacen un determinado criterio.

Número de Fallos

La cantidad de fallos sucedidos durante un periodo de tiempo.

Numero de defectos

La cantidad de defectos del producto software reales o estimados en un componente o producto software.

Tamaño de Producto

La cantidad de componentes de producto software. Pueden ser numero de líneas, puntos de función, módulos, etc.

Duración

Intervalo entre el comienzo y la finalización de un proceso.

Número de Pruebas

Cantidad de pruebas diferentes que satisfacen determinada condición.

Número de Entrada/Salida

Cantidad de operaciones de entrada salida que satisfacen determinada condición.

Número de Tareas

Cantidad de tareas necesarias para alcanzar un determinado objetivo.

Número de Intentos de Usuario

Cantidad de intentos realizando una misma operación.

Número de datos

Cantidad de diferentes estructuras, clases o formatos de datos.

Número de registros

Cantidad de registros de la misma estructura, clase o formato de datos.

Número de requisitos

Cantidad de requisitos.

Número de operaciones de usuario

Cantidad de operaciones realizadas por el usuario, donde una operación es una secuencia de pasos necesarios para realizar una tarea.

Número de operaciones de sistema

Cantidad de operaciones realizadas por el sistema.

Número de idiomas

Cantidad de idiomas distintos soportados por el sistema o producto software.

Número de Módulos de Software

Cantidad de componentes software que funcionan independientemente.

Número de interfaces

Cantidad de interfaces comunes entre dos componentes separados del sistema que intercambian información, ya sean hardware, software, usuarios, periféricos, etc.

Tabla 4: Elementos de Medida de Calidad 
Partiendo de las necesidades de usuario en un contexto de uso determinado que se recogen en los requisitos, se especifican las medidas internas y externas usando las características de calidad de producto. De esta forma, la calidad de producto software se puede evaluar midiendo la propiedades internas o externas. En el primer caso, las medias internas se suelen medir mediante la medida estática de productos intermedios, durante las fases de desarrollo, proporcionando por tanto una predicción de la calidad del producto final. Idealmente deberían utilizarse medidas internas con una fuerte conexión con las medidas externas, facilitando la estimación de dichas medidas.

En cambio, las medidas externas se obtienen mediante la medida del comportamiento cuando se ejecuta el código, realizadas las fases de prueba u operacionales. Esto se realiza ejecutando el software en un entorno, real o simulado, en el que tendrá que ser funcional. En este caso, el número de fallos sería una indicación del número de errores que contiene el software.

La gran mayoría de medidas de calidad contempladas por el estándar se definen en el rango de 0 a 1, correspondiendo los mejores resultados aquellos próximos a 1. En otros casos, las métricas se evaluarán de acuerdo con un valor objetivo establecido en los requisitos. Por último, aquellos valores no incluidos en las anteriores categorías se evaluarán de acuerdo con estándares del mercado, productos similares o la evolución temporal a lo largo de un periodo prolongado.

\subsubsection{Métricas de Calidad de Producto}

El estándar presenta de manera ordenada el conjunto de categorías de medidas para cada una de las características de calidad de producto. Cada categoría de medidas puede contener una o varias funciones, definidas haciendo uso de los denominados elementos de medida de calidad.

\subsubsection{Medidas de Adecuación Funcional}

La adecuación funcional corresponde al grado con el que un producto o sistema satisface las necesidades, explícitas o implícitas, cuando son utilizados bajo condiciones especificadas en los requisitos. Se evalúa bajo tres dimensiones: la completitud, la corrección y la conveniencia funcional.

La completitud funcional corresponde al grado con el que el conjunto de funcionalidades satisface las tareas especificadas y los objetivos del usuario. Analíticamente se determina como la proporción de funciones especificadas que han sido implementadas.

La corrección funcional corresponde al grado con el que un producto o sistema proporciona los resultados correctos con el grado requerido de precisión. Analíticamente se determina como la proporción de funciones que proporciona el valor correcto.

Por último, la conveniencia funcional que corresponde con el grado con el que las funciones facilitan la consecución de las tareas y objetivos especificados, viene determinada analíticamente por dos funciones:

- La conveniencia de los objetivos de uso se corresponde con la proporción de funciones requeridas por el usuario que proporcionan el resultado adecuado para alcanzar un objetivo concreto especificado.

- La conveniencia del sistema se corresponde la media de las conveniencias de los objetivos, obtenidas con la función anterior, y que permiten satisfacer los objetivos del sistema requeridos por el usuario.

\subsubsection{Medidas de Rendimiento.}

La eficiencia en el rendimiento se corresponde con el rendimiento relativo a la cantidad de recursos utilizados de acuerdo con las condiciones especificadas. Esta característica se ve dramáticamente afectada por las condiciones de uso, por lo que dichas medidas podrían incluir estimaciones y márgenes de error a comparar con los definidos por la especificación, que 
idealmente especificaría la tarea a realizar durante el proceso de medida. Se evalúa de acuerdo con las siguientes dimensiones: comportamiento temporal, uso de recursos y medidas de capacidad.

Las medidas de comportamiento temporal corresponden al grado al cual los tiempos de respuesta, proceso y ratio de rendimiento de un producto o sistema se corresponden con los requisitos. Analíticamente viene determinada por cinco funciones:

- El tiempo de respuesta medio corresponde con el tiempo medio que lleva al sistema a responder a la solicitud de una tarea de usuario o de sistema.

- La conveniencia del tiempo de respuesta compara dicho valor con el especificado por los requisitos.

- El tiempo de proceso medio refleja el tiempo medio que lleva al sistema completar una tarea o trabajo asíncrono.

- La conveniencia del tiempo de proceso medio compara dicho valor con el especificado por los requisitos.

- El rendimiento medio corresponde al número de trabajos completados por unidad de tiempo.

Las medidas de uso de recursos se corresponden con el grado con el cual la cantidad y tipo de recursos usados por un producto o sistema software cumple con las expectativas o requisitos, cuando realiza sus funciones. Analíticamente viene determinada por cuatro funciones:

- El uso de CPU medio se corresponde con el tiempo de CPU necesario para ejecutar un conjunto dado de tareas en relación con el total de tiempo empleado.

- El uso de memoria medio se corresponde con la memoria necesaria para ejecutar un conjunto dado de tareas en relación con la memoria disponible.

- El uso de I/O medio se corresponde con el tiempo de I/O requerido para ejecutar un conjunto dado de tareas comparado el tiempo de l/O del total de la operación.

- El uso de ancho de banda se corresponde con la proporción de ancho de banda utilizado para completar un conjunto dado de tareas comparado con el total disponible.

Las medidas de capacidad se corresponden con el grado al cual los límites máximos de un sistema o producto software satisfacen los requisitos. Analíticamente viene determinada por tres funciones:

- La capacidad de procesamiento de transacciones se corresponde con el número de transacciones que se pueden procesar por unidad de tiempo.

- La capacidad de acceso de usuarios se corresponde con el número de usuarios que pueden acceder simultáneamente en un momento determinado.

- La capacidad de incremento del número de usuarios se corresponde con la capacidad del sistema o producto software de incrementar el número de usuarios en un momento determinado.

\subsubsection{Medidas de Compatibilidad}

La compatibilidad se corresponde con el grado con el cual un producto, sistema o componente software puede intercambiar información con otros y/o realizar las funciones requeridas, compartiendo el mismo entorno hardware o software. Su evaluación se realiza de acuerdo con las siguientes dimensiones: coexistencia e interoperabilidad.

La medida de coexistencia se corresponde con el grado con el cual un producto puede realizar la funcionalidad especificada mientras comparte un entorno común y recursos con otros, sin que afecte a ninguno de ellos. Analíticamente se evalúa como la proporción de productos especificados que pueden compartir entorno con el software en evaluación, sin que sus características de calidad o funcionalidad se vean afectadas. 
La interoperabilidad se corresponde con el grado al cual dos o más sistemas, productos o componentes pueden intercambiar información, pudiendo hacer uso de ella de manera satisfactoria. Analíticamente viene determinada por tres funciones:

- La intercambiabilidad del formato de los datos se corresponde con la proporción de los formatos especificados de datos que son intercambiables con otros sistemas o productos software.

- La suficiencia de los protocolos de intercambio de datos se corresponde con la proporción de protocolos de intercambio de datos que son soportados.

- La adecuación de interfaces externos se corresponde con la proporción de interfaces externos especificados que son funcionales.

\subsubsection{Medidas de Usabilidad}

La usabilidad se corresponde con el grado al cual el producto o sistema puede ser utilizado por los usuarios contemplados por la especificación para alcanzar los objetivos con eficacia, eficiencia y satisfacción dentro del contexto de uso especificado por los requisitos.

Desde un punto de vista interno, las medidas de usabilidad permiten estimar hasta qué punto el software puede ser comprendido y manejado. Dichas medidas evaluarán los artefactos producidos como manuales, documentación y ayudas. Externamente, la usabilidad es evaluada por pruebas de usuario, agrupados poblacionalmente en casos estereotipados o personas. En general se trata de una medida de elevada componente subjetiva, que llevará en ocasiones al uso de escalas ordinales.

Su evaluación es de las más complejas e incluye las siguientes dimensiones: medidas de evaluación de conveniencia, medidas de comprensibilidad, medidas de manejabilidad, medidas de protección contra errores de usuario, medidas de estética de la interfaz de usuario y medidas de accesibilidad.

Las medidas de evaluación de conveniencia se corresponden con el grado con el cual un usuario puede evaluar si el producto o sistema es apropiado para sus necesidades. Analíticamente viene determinada por las siguientes funciones:

- La proporción de escenarios de uso descritos en la documentación de usuario o descripción del producto.

- La proporción de tareas que cuenta con características demostrativas que permiten evaluar su conveniencia.

- La proporción de páginas de la documentación online (landing page) que se encuentran adecuadamente explicadas.

Las medidas de comprensibilidad se corresponden con el grado con el cual un producto puede ser utilizado por lo usuarios contemplados en las especificaciones para lograr los objetivos de aprendizaje que permiten utilizarlo con eficacia, eficiencia, ausencia de riesgo y satisfacción, dentro del contexto de uso recogido en las especificaciones. Analíticamente se determina mediante las siguientes funciones:

- La proporción de funciones descritas con el nivel adecuado en la documentación, que permite a los usuarios utilizarlas.

- La proporción de valores de entrada que cuentan con valores asignados por defecto.

- La proporción de mensajes de error que incluyen la descripción de las razones que los producen y cómo remediarlas.

- La proporción de elementos de información y secuencia de pasos que permite a los usuarios nuevos realizar las tareas más frecuentes sin estudio previo, entrenamiento o asistencia. 
Las medidas de manejabilidad se corresponden con el grado al cual un producto tiene atributos que facilitan su manejo y control. Su evaluación se puede realizar dinámicamente mediante sesiones de prueba con operadores tipo, pero también estáticamente de manuales y documentación. Analíticamente se determina con las siguientes funciones:

- La proporción de tareas interactivas que no cuentan con una apariencia y comportamientos consistentes con el grupo de tareas similares.

- La proporción de mensajes que comunican el resultado o instrucciones correctas al usuario.

- La proporción de procedimientos operativos y funciones personalizables por el usuario.

- La proporción de elementos de la interfaz de usuario que pueden personalizar su apariencia.

- La proporción de funciones que pueden ser monitorizadas durante su ejecución.

- La proporción de tareas que, teniendo consecuencias significativas, cuentan con opciones que solicitan doble confirmación o permiten deshacer su ejecución.

- La proporción de elementos de información del sistema organizados en categorías que resultan familiares a los usuarios contemplados en la especificación y adecuadas para la realización de sus tareas.

- La proporción de interfaces de usuario que, contando con elementos similares, comparten apariencia similar.

- La proporción de tareas que pueden iniciarse con un conjunto adecuado de interfaces como teclados, comandos de voz, interfaces táctiles, etc.

Las medidas de protección contra errores de usuario se corresponden con el grado con el cual el sistema protege a los usuarios de los errores que puedan cometer. Su evaluación puede realizarse tanto dinámica como estáticamente. Analíticamente se evalúan con las siguientes funciones:

- Proporción de acciones o entradas de usuario que cuentan con mecanismos de protección que impiden acciones que pudiesen derivar en malfuncionamiento del sistema.

- Proporción de entradas de usuario que cuentan con sugerencias adecuadas de valores cuando se detectan errores.

- Proporción de errores de usuario que pueden corregirse o que permiten al sistema recuperarse.

Las medidas de estética de interfaz de usuario se corresponden con el grado al cual la interfaz de usuario proporciona una interacción satisfactoria y placentera. Estas medidas se ven afectadas de manera significativa por elementos de diseño y son especialmente importantes en productos de consumo. Elementos culturales, edad o incluso experiencias personales tienen un impacto importante. Analíticamente se determina como la proporción de interfaces de usuario que cuentan con una apariencia satisfactoria.

Por último, las medidas de accesibilidad se corresponden con el grado con el cual el producto puede ser utilizado por personas con un amplio grado de características y capacidades para lograr los objetivos especificados de acuerdo con el contexto de uso. Analíticamente se determina con las siguientes funciones:

- La proporción de funciones utilizables por personas en situación de discapacidad específica.

- Proporción de lenguajes que se soportan, en relación con los lenguajes nativos de la base de usuarios. 


\subsubsection{Medidas de Fiabilidad}

La fiabilidad se corresponde con el grado con el cual un sistema, producto o componente realiza funciones específicas de acuerdo con los requisitos, durante un periodo de tiempo especificado. Desde un punto de vista interno, la fiabilidad permite predecir si una vez completado, el sistema cumplirá las especificaciones de fiabilidad definidas durante el desarrollo. En cambio, externamente, las medidas de fiabilidad permiten evaluar los atributos que relacionan el comportamiento durante las pruebas con el que tendrá el sistema una vez puesto en producción. Su evaluación se realiza bajo cuatro dimensiones: madurez, disponibilidad, tolerancia a fallos y recuperación.

La madurez se corresponde con el grado al cual un sistema, producto o componente, satisface las necesidades de fiabilidad en condiciones normales de uso. Analíticamente se determina por las siguientes funciones:

- Proporción de fallos relacionados con la fiabilidad que, habiendo sido detectados durante las fases de diseño, programación y pruebas, han sido corregidos.

- Tiempo medio entre fallos en la ejecución.

- Número medio de fallos para un periodo de tiempo determinado de acuerdo con distintos escenarios de prueba.

- Porcentaje de las capacidades, escenarios operacionales o funciones que cuentan con pruebas.

La disponibilidad se corresponde con el grado con el cual un sistema, producto o componente está disponible, accesible y operacional, para su uso. Analíticamente se determina con las siguientes funciones:

- Proporción de tiempo planificado de ejecución en el que el sistema está realmente disponible para su uso.

- Tiempo medio de indisposición del sistema durante un fallo.

La tolerancia a fallos se corresponde con el grado con cual un sistema es capaz de continuar funcionado incluso en presencia de fallos. Analíticamente se determina con las siguientes funciones:

- Porcentaje de defectos corregidos o bajo control, que evitan fallos severos o críticos.

- Proporción de componentes que cuentan con sistema de respaldo para evitar fallos del sistema.

- Tiempo medio de notificación de fallos.

La recuperación se corresponde con el grado con el cual un sistema, ante la presencia de un fallo o interrupción, es capaz de recuperar los datos afectados y reestablecer el estado deseado del sistema.

\subsubsection{Medidas de Seguridad}

La seguridad se corresponde con el grado con el cual un sistema protege la información y los datos, de manera que personas u otros sistemas o productos cuentan con el acceso a los datos de acuerdo con su nivel y tipo de autorización. Se evalúa de acuerdo con las siguientes dimensiones: confidencialidad, integridad, autoría, responsabilidad y autenticidad.

La confidencialidad se corresponde con el grado con el cual un producto o sistema asegura que los datos son accesibles únicamente a aquellos que tienen permiso. Analíticamente se determina con las siguientes funciones:

- Proporción de datos confidenciales que se encuentran protegidos de accesos no autorizados. 
- Proporción de datos correctamente cifrados / descifrados, de acuerdo con las especificaciones.

- Proporción de algoritmos de cifrado de solidad validada o certificada.

La integridad se corresponde con el grado con el cual un sistema, producto o componente, previene el acceso o modificación no autorizados a programas o datos. Analíticamente se determina con las siguientes funciones:

- Proporción de datos que cuentan con mecanismos de prevención de la corrupción o modificación no autorizada.

- Proporción de métodos de prevención de corrupción de datos que se encuentran realmente implementados.

- Proporción de acceso a datos que se encuentran protegidos frente al desbordamiento de memoria.

La autoría es el grado con el cual las acciones o eventos pueden probarse en caso de suceder, imputándolos a usuarios o sistemas, sin que estos puedan renegar su atribución. Analíticamente se determina mediante el porcentaje de datos que cuentan con mecanismo de atribución.

La responsabilidad determina el grado al cual las acciones realizadas por una entidad del sistema pueden atribuirse de manera única a dicha entidad. Analíticamente se determina con las siguientes funciones:

- Proporción de datos sujetos a auditoría.

- Proporción del total del tiempo requerido en las especificaciones que los archivos de auditoría son realmente mantenidos por el sistema.

La autenticidad determina el grado con el cual la identidad de un sujeto o recurso se puede comprobar. Analíticamente se determina con las siguientes funciones:

- Proporción de métodos de autenticación facilitados con respecto a los especificados.

- Proporción de reglas de autenticación implementadas con respecto a las especificadas.

\subsubsection{Medidas de Mantenibilidad}

La mantenibilidad se corresponde con el grado de eficacia y eficiencia con el cual un producto o sistema puede ser modificado por miembros del equipo de mantenimiento, es decir, descontado conocimiento del sistema y contabilizando por tanto solo las dificultades intrínsecas al sistema. Se evalúa de acuerdo con las siguientes dimensiones: modularidad, reusabilidad, así como las categorías analizable, modificable y evaluable.

La modularidad se corresponde con el grado al cual un sistema o producto está compuesto de componentes discretos y de baja acoplamiento, de tal forma que el cambio en un componente tiene un impacto mínimo en el resto. Analíticamente se determina mediante las siguientes funciones:

- Proporción de componentes con bajo o nulo acoplamiento con el resto, comparados con el total de componentes.

- Proporción de módulos con complejidad Ciclomática por encima del baremo establecido, comparado con el total de módulos.

La reusabilidad se corresponde con el grado al cual un recurso puede ser utilizado en más de un sistema o en la definición de otros recursos. Analíticamente se determina mediante las siguientes funciones:

- Proporción de recursos diseñados e implementados para ser reutilizados.

- Proporción de recursos o módulos que siguen las guías de estilo de codificación. 
La valoración del carácter analizable se corresponde con el grado de facilidad y eficiencia con el cual es posible evaluar el impacto en el producto o sistema de un cambio intencionado en una o más de sus componentes, o conocer las deficiencias o causas de fallo introducidas, o identificar las partes a modificar. Analíticamente se determina mediante las siguientes funciones:

- Proporción de las tareas necesarias para realizar una operación que son registradas y trazadas.

- Proporción de las funciones de diagnóstico que son de utilidad para realizar un análisis causa efecto.

- Proporción de funciones de diagnóstico implementadas del conjunto de las especificadas.

La valoración del carácter modificable se corresponde con el grado al cual el producto o sistema puede ser modificado de forma efectiva y eficientemente, sin introducir defectos y sin degradar la calidad. Analíticamente se determina mediante las siguientes funciones:

- Eficiencia temporal media de las modificaciones realizadas.

- Proporción de modificaciones realizadas correctamente, evaluado dentro de un intervalo de tiempo definido y acotado.

- Proporción de modificaciones realizadas dentro de un periodo definido y acotado.

La valoración del carácter evaluable, es decir, verificable o probable, se corresponde con el grado de eficacia y eficiencia con el cual se pueden establecer criterios de verificación o prueba para un sistema, producto o componente y realizar las pruebas que determinan si dichos criterios se cumplen. Desde una perspectiva interna, las medidas internas identifican un conjunto de atributos que permiten predecir la cantidad de pruebas diseñadas e implementadas presentes en el sistema. Externamente, se validarían dichos atributos en términos del esfuerzo de los miembros del equipo de mantenimiento observando su comportamiento durante la realización de pruebas. Analíticamente se determina con las siguientes funciones:

- Proporción de funciones de prueba implementadas con respecto a las especificadas.

- Proporción de pruebas que, aún dependiendo de otros sistemas, pueden realizarse independientemente mediante simulación.

- Proporción de casos de prueba que pueden ser pausados y reiniciados en pruebas paso a paso.

\subsubsection{Medidas de Portabilidad}

La portabilidad se corresponde con el grado de eficacia y eficiencia con el que un sistema, producto o componente puede ser transferido de un entorno hardware, software u operacional a otro. Se evalúa según las siguientes dimensiones: adaptabilidad, facilidad instalación y de reemplazo.

La adaptabilidad se corresponde con el grado al cual un producto o sistema puede ser adaptado con eficacia y eficiencia a un entorno, hardware, software u operacional, diferente o cambiante. Analíticamente se determina con las siguientes funciones:

- Proporción de funciones que pueden ser adaptadas a un entorno hardware nuevo en relación con el número total de funciones evaluadas en el nuevo entorno.

- Proporción de funciones que pueden ser adaptadas a un entorno software nuevo en relación con el número total de funciones evaluadas en el nuevo entorno.

- Proporción de funciones que pueden ser adaptadas a un entorno operacional nuevo en relación con el número total de funciones evaluadas en el nuevo entorno.

La valoración de la facilidad de instalación se corresponde con el grado de eficacia y eficiencia con la que un producto o sistema puede ser instalado y/o desinstalado en un entorno específico. Analíticamente se determina con las siguientes funciones: 
- Eficiencia media del tiempo de instalación.

- Proporción de casos de uso correspondientes al proceso de instalación que permiten personalizarse.

La valoración de la facilidad de reemplazo se corresponde con el grado con el cual un producto puedo ser reemplazado por otro con el mismo propósito y dentro del mismo entorno. Analíticamente se determina con las siguientes funciones:

- Proporción de funciones que los usuarios pueden realizar con el producto reemplazado sin entrenamiento adicional o atajos.

- Proporción de requisitos de calidad que continúan cumpliéndose tras reemplazar el producto.

- Proporción de funciones que continúan produciendo resultados similares tras el reemplazo.

- Proporción de datos que continúan pudiéndose usar tras el reemplazo.

\subsubsection{ISO/IEC 25023: Implicaciones prácticas.}

La colección de métricas de calidad de producto incluidas en el apartado anterior refleja de manera fiel la naturaleza de los procesos de calidad necesarios para poner en práctica el modelo y las medidas contempladas por el estándar.

Si bien las dimensiones de evaluación pueden ser de aceptación universal, las evaluaciones analíticas contempladas introducen una visión limitada sobre los procesos de desarrollo. En particular es necesario señalar:

1. La evaluación estática requiere artefactos documentales que actúan a modo de contrato explícito, los requisitos, o implícito, diseños, manuales y documentos de proyecto.

2. La conexión existente entre la evaluación estática e interna y la evaluación externa y dinámica que permite que los atributos estáticos puedan predecir comportamientos dinámicos requiere una estrecha conexión entre ambas evaluaciones.

3. Las proporciones definidas en las funciones analíticas establecen siempre frente un número base (denominador) de casos reflejados en los requisitos explícitos si existe un documento formal o implícitos aceptados por los miembros del equipo de desarrollo.

Como veremos a continuación, el paradigma de desarrollo ágil que en distintas variantes predomina en el desarrollo de software en ecosistemas abiertos, no permite asumir dichas condiciones o solo de manera muy limitada.

\subsection{Desarrollo de Componentes en el mundo Web}

Los componentes web son un conjunto de tecnologías que permiten definir elementos HTML, encapsulando el código de visualización y la lógica del elemento, estableciendo una interfaz que permite su reutilización y portabilidad en aplicaciones web [7]. Facilitando la interoperabilidad y encapsulación del software, contribuye significativamente a mejorar la calidad del producto software, la calidad en uso de las aplicaciones web y de los procesos de desarrollo.

Partiendo de un conjunto aceptado de estándares [79] [80] [81] impulsados conjuntamente por la industria y los principales organismos de estandarización, actualmente existen numerosas propuesta e implementaciones de las tecnologías de componentes web [82] [49] [83] [84] [85]. En el presente trabajo nos centraremos en las tecnologías de componentes web que se han desarrollado por Google dentro del proyecto Polymer [49].

Incorporada desde hace mucho tiempo en lenguajes de programación y sistemas operativos móviles y de escritorio, el mundo web cuenta con la tecnología de componentes solo desde hace unos años, fechándose los primeros borradores del estándar W3C en 2014 [86]. Actualmente, con el respaldo significativo de la industria y los distintos organismos de estandarización, las 
tecnologías de componentes web se encuentran en su segunda generación, habiéndose integrado gran parte del soporte necesario en los navegadores [79] [80] [81] e introduciéndose componentes ligeros [49] que facilitan si cabe aún más su uso.

La definición de componentes web tiene tres pilares fundamentales, integrados actualmente en los navegadores web y que se materializan todos ellos en un conjunto de APIs en lenguaje JavaScript [7]:

- Los elementos HTML personalizados (custom elements [80]) permiten introducir nuevas etiquetas HTML (elementos), así como implementar el comportamiento deseado. De esta manera soportan el ciclo de vida de estos nuevos elementos y los hacen disponibles a las aplicaciones web.

- El árbol DOM privado (shadow DOM [79]) ofrece un modelo de representación de la estructura del documento HTML para cada elemento personalizado e implementa las APIs que permiten el acceso a sus atributos y métodos, sin efectos laterales y de manera independiente.

- Las plantillas HTML (HTML templates [81]) permiten incluir en los documentos HTML código de visualización para ser reutilizado discrecionalmente y está pensado para ser la estructura base de los elementos personalizados HTML.

Inicialmente dicha funcionalidad se ofrecía en forma de librerías externa, denominadas polyfills [87], pero actualmente la integración de esta funcionalidad en las máquinas virtuales de los navegadores ha permitido la simplificación de la definición de componentes web y así los componentes Polymer [49] han evolucionado para aligerar su estructura y reducir los elementos sintácticos necesarios.

Actualmente los componentes web cuentan únicamente con dos elementos nucleares definidos en JavaScript:

- La clase base LitElement [49], diseñada para facilitar al máximo la portabilidad, soportando cualquier entorno de programación y librerías. LitElement utiliza fundamentalmente la librería lit-html.

- La librería lit-html, que permite la gestión y manejo del DOM privado (shadow DOM) y proporciona el conjunto APIs necesario para gestionar atributos y propiedades del elemento. Actualmente soporta los principales navegadores y entornos de programación.

El ciclo de vida asociado al componente web depende significativamente de la tecnología utilizada. Si bien se han hecho esfuerzos para simplificar la dependencia de librerías moviendo gran parte de soporte necesario a la plataforma del navegador, no existe un criterio único sobre los elementos o azúcares sintácticos que han de proporcionar para una programación eficiente.

En términos próximos a una programación JavaScript pura o Vanilla JavaScript el ciclo de vida de un componente web puede establecerse en las siguientes etapas [7]:

1. Siguiendo la sintaxis establecida, la definición del estándar ECMAScript 2015 [88] se implementa una clase que especifica la funcionalidad el componente web.

2. El elemento personalizado se registra en el documento haciendo uso de la función CustomElementRegistry.define() según se establece en el estándar [80].

3. En caso necesario se añade un DOM privado utilizando el método Element.attachShadow(). Una vez hecho esto, se incluyen los elementos nodo, gestores de eventos haciendo uso de los métodos convencionales de gestión del árbol DOM.

4. Haciendo uso de las etiquetas del estándar [81] <template $>$ y $<$ slot $>$ se crea la plantilla HTML que permitirá reutilizar el componente. De nuevo, con los métodos de gestión del árbol DOM se incluye la plantilla en el DOM privado. 
5. Llegado a este punto, el componente está listo para su uso en todo el documento / aplicación web.

De esta manera, los componentes web resultan ser los elementos modulares que permiten la encapsulación de funcionalidad, convirtiendo la creación de aplicaciones web en un proceso de composición de componentes, facilitando la agregación de funcionalidad en forma de librerías de componentes, que a través de repositorios públicos permite la distribución a escala.

\subsection{Metodología Ágil y Desarrollos en Repositorios Abiertos}

El desarrollo de software en ecosistemas abiertos presenta una diversidad de escenarios difícilmente imaginable. Si bien, como se destacó en la introducción, existen logros destacados, sería ingenuo asumir que las historias de éxito corresponden con la norma. Haciendo de nuevo mención del denominado Cloud Native Interactive Landscape (Ilustración 2), en dicho documento se puede percibir la dimensión, complejidad, diversidad e impacto de lo que constituye una pieza entre muchas de software desarrollado en ecosistemas abiertos. Cualquier intento de definir, encorsetando, la forma en la que se desarrolla software en ecosistemas abiertos ha de tener presente esta situación.

Existen varios elementos que caracterizan los ecosistemas abiertos [89] y aunque los procesos de desarrollo forman parte en alguna medida de estos, lo cierto es que el elemento indispensable es el esquema de licenciamiento abierto que facilita la colaboración de los distintos agentes involucrados en el desarrollo de software. Y así, aunque no venga determina de manera inherente, lo cierto es que los métodos ágiles constituyen una constante presente, articulando también la colaboración de las entidades que contribuyen al desarrollo en estos ecosistemas abiertos.

El término "desarrollo de software ágil" reúne bajo un conjunto reducido de principios una variedad enorme de posibilidades, únicamente condicionadas por los resultados obtenidos, por el software funcionando. Este conjunto reducido de principios se denominan Manifiesto por el Desarrollo Ágil de Software [22] y sobre el mismo y sus implicaciones se han vertido ríos de tinta, realizado cientos de investigaciones y conferencias, y me atrevería a afirmar, que no siempre en un ambiente de cordial camaradería.

Fruto de una reunión en 2001 en la que participaron un reducido grupo de profesionales del desarrollo de software, los principios respondían a un sentir presente en la comunidad de expertos y que ya entonces se había plasmado en diversos movimientos como Extreme Programming [90] o Pragmatic Programming [21] entre otros.

Tal y como se anuncia en el sitio web que recoge los principios, incluso antes de mencionarlos, se deja claro que, fruto de la experiencia desarrollando software, se valoran:

- Individuos e interacciones sobre procesos y herramientas.

- Software funcionando sobre documentación extensiva.

- Colaboración con el cliente sobre negociación contractual.

- Respuesta ante el cambio sobre seguir un plan.

Resulta reseñable la forma en la que se establece esta predominancia ya que, si bien se entiende la importancia de procesos, herramientas, documentación, planes y contratos, se reconoce lo contraproducente que resulta supeditar individuos, software funcionando, colaboración o capacidad de reacción, si lo que se persigue es software funcionando.

Los doce principios del manifiesto ágil no hacen más que desarrollar estas cuatro ideas fundamentales, pero es conveniente incluirles a continuación, según se recogen en la traducción al castellano del sitio web del manifiesto [22]:

- Nuestra mayor prioridad es satisfacer al cliente mediante la entrega temprana y continua de software con valor. 
- Aceptamos que los requisitos cambien, incluso en etapas tardías del desarrollo. Los procesos Ágiles aprovechan el cambio para proporcionar ventaja competitiva al cliente.

- Entregamos software funcional frecuentemente, entre dos semanas y dos meses, con preferencia al periodo de tiempo más corto posible.

- Los responsables de negocio y los desarrolladores trabajamos juntos de forma cotidiana durante todo el proyecto.

- Los proyectos se desarrollan en torno a individuos motivados. Hay que darles el entorno y el apoyo que necesitan, y confiarles la ejecución del trabajo.

- El método más eficiente y efectivo de comunicar información al equipo de desarrollo y entre sus miembros es la conversación cara a cara.

- El software funcionando es la medida principal de progreso.

- Los procesos Ágiles promueven el desarrollo sostenible. Los promotores, desarrolladores y usuarios debemos ser capaces de mantener un ritmo constante de forma indefinida.

- La atención continua a la excelencia técnica y al buen diseño mejora la Agilidad.

- La simplicidad, o el arte de maximizar la cantidad de trabajo no realizado, es esencial.

- Las mejores arquitecturas, requisitos y diseños emergen de equipos auto-organizados.

- A intervalos regulares el equipo reflexiona sobre cómo ser más efectivo para a continuación ajustar y perfeccionar su comportamiento en consecuencia.

Así recogidos resaltan la distancia que separa estos principios de los requisitos que impone la aplicación de los estándares de calidad software y dan cuenta de la brecha que parece existir entre la industria de desarrollo de software y la producción en ecosistemas abiertos.

\subsection{Calidad de Componentes Web}

Hasta donde alcanza el conocimiento del autor de este trabajo, no existe actualmente ningún modelo de calidad formal de aplicación a los componentes web. Al contrario, como se verá en el desarrollo de esta investigación, los desarrolladores de componentes manejan una serie de criterios no recogidos ni siquiera informalmente. Las razones de esta situación se encuentran en la forma en la que se desarrollan tecnologías web hoy en día.

Actualmente gran parte de los desarrollos de aplicaciones web reutilizan librerías y componentes disponibles en repositorios públicos [91] [90] [92]. Este fenómeno está estrechamente relacionado con las dinámicas introducidas en los ecosistemas de desarrollo open source [25] [93] por los esquemas de licenciamiento abierto [94], ya que constituyen el fundamento que dirige la innovación en tanto que facilita el uso, aprendizaje, modificación y distribución del software por el ecosistema de desarrolladores web [95].

A pesar de los esfuerzos realizados para mejorar el conocimiento de los ecosistemas no existe en la actualidad un modelo de calidad del software producido bajo este paradigma. Como se ha venido repitiendo hasta ahora, el criterio manejado es el de software funcionando, el de responder con rapidez a la necesidad de cambio.

Aunque el número de repositorio es potencialmente alto, lo cierto es que son unas pocas compañías las que producen el grueso de los componentes generalmente utilizados. Debido a la ausencia de interoperabilidad de los procesos de desarrollo y la necesidad de contar con una comunidad de desarrolladores que proporcione a priori la valoración de los componentes, se limita el nivel de adopción de tecnología de proveedores más pequeños. Lejos de resultar una ley universal, si bien es cierto que las contribuciones tienen a aglutinarse en torno a proyectos existentes, desarrollando economías de escala en la producción de software, la aparición de una nueva tecnología disruptiva cuenta con enormes posibilidades de obtener el reconocimiento del ecosistema, pasando a ser adoptada de forma masiva. 
Estas características se podrían percibir como un factor limitante, pero lo cierto es que estos aspectos son fundamentales para la innovación de la tecnología web y constituyen la clave fundamental del éxito de las tecnologías web, por más que dificulten su adopción por parte de la industria. En definitiva, es la multitud de posibilidades de contribuir, de adaptar, de modificar y de usar las tecnologías de ecosistemas abiertos la razón simultánea de su éxito y su fracaso.

Para facilitar el desarrollo de un modelo de calidad ágil o de curación colectiva, la publicación de los componentes se realiza en plataformas que permiten la valoración y mejora continua. La valoración se realiza mediante una sencilla clasificación en base al número de votos recibidos, mientras que la mejora continua se logra mediante la definición de canales de retorno que permiten la comunicación entre los usuarios del componente y los desarrolladores de estos.

Estas plataformas permiten, cuando se dan los factores para la adopción de los componentes, crear un círculo virtuoso que no solo permite valorar la calidad de la tecnología producida, sino también su mejora continua. En conjunto estas características, si bien se han mostrado eficaces para abordar la complejidad creciente del desarrollo software, remueven los elementos sobre los que se fundamentan los modelos de calidad software tradicionales [25].

En el caso de aplicaciones con componentes web, el proceso de integración rompe la unidad organizativa del desarrollo de software, requiriendo evaluación externa de la calidad de los componentes integrados. La disparidad de procesos y criterios de evaluación de calidad dificultan los procesos informales, que resultan imposibles en los casos de distribución geográfica, o cuando el usuario final no es localizable para la evaluación.

Finalmente, los diferentes ciclos de vida software introducen alta variabilidad en los equipos y procesos, donde las técnicas ágiles de gestión de la configuración resultan completamente insuficientes. Su objetivo es el desarrollo del software, minimizando la documentación y los procesos que no estuviesen directamente relacionados con el código [25]. Este enfoque es tan radicalmente diferente a la estandarización propuesta por estándares como ISO/IEC 25010, que parecen irreconciliables. 


\section{Planteamiento del Problema.}

"Desafortunadamente lo que es poco reconocido es que los libros científicos más
valiosos son aquellos en los que el autor indica claramente lo que él no sabe."

Évariste Galois

\subsection{Motivación}

Esta investigación sitúa su objeto de estudio en el análisis empírico de la calidad de componentes web desarrollados en repositorios públicos. De acuerdo con la introducción y la revisión del estado del arte en apartados previos, el planteamiento del problema se realizará en términos de un conjunto de preguntas de investigación, incluidas en el siguiente apartado.

Su presentación se realiza siguiendo un razonamiento argumentativo que abarca de la aproximación metodológica que permita abordar el problema, hasta llegar a las preguntas en las que se valora la calidad de los componentes web.

Este enfoque, además de facilitar la comprensión del problema y la solución adoptada, habrá de ayudar a entender el estudio realizado, facilitando la aplicación del método seguido a otros estudios e investigaciones.

\subsection{Preguntas de Investigación}

Según se ha reflejado en los apartados anteriores, el desarrollo de software en ecosistemas abiertos involucra a diversas organizaciones, no existiendo una conexión explícita entre la especificación de requisitos y la validación de los mismo por parte de los usuarios, una vez el producto o sistema software esta finalizado.

El producto o sistema software resultan el collage en el que se integran componentes y librerías diversas para definir un conjunto final que responde a las necesidades del agente integrador y a los requisitos de los usuarios de este. El desarrollo de las distintas piezas no responde por tanto a las mismas motivaciones, el mismo momento tecnológico o los mismos agentes.

Resultado de esta situación, la metodología de desarrollo de software no es homogénea y claramente no explicita. Por tanto, muchos de los elementos de dicha metodología son implícitos, y se encuentran imbricados en elementos sociales, culturales incluso, de los ecosistemas abiertos. Por tanto, de manera más que evidente la primera pregunta de investigación será:

RQ1 ¿Contamos con metodología de investigación que permita investigar la calidad en ecosistemas de desarrollo de software abierto?

La anterior pregunta no responde únicamente a la necesidad de resolver el objeto de esta investigación, sino que considerando la complejidad creciente del desarrollo de software, así como el incremento en la relevancia de ecosistemas abiertos y la aparición de ecosistemas 
"cerrados" en empresas con grandes cantidades de ingenieros de software, el contar con herramientas de investigación que permitan el estudio de elementos sociales y culturales de la ingeniería del software resulta fundamental.

De ser posible abrir la puerta a la comprensión de estos ecosistemas abiertos de desarrollo de componentes web, la siguiente cuestión que surge tiene que ver con su idiosincrasia y como esta se plasma en elementos de ingeniería del software y en particular de la calidad software.

Aunque no existen estudios para ecosistema o tecnologías web, algunos estudios generales [96] apuntan a que cerca de un $30 \%$ de los desarrolladores no contaría con grado académico y de los que lo tiene solo un $60 \%$ sería en ciencias de la computación. Por tanto, de acuerdo con naturaleza heterogénea de los desarrolladores de los ecosistemas abiertos, la siguiente pregunta de investigación resulta completamente pertinente:

RQ2 ¿Existe un modelo de calidad de componentes web desarrollados en repositorios abiertos?

La gestión de la calidad, como actividad propia de la ingeniería del software, introduce un marco de definiciones y procesos que garantiza la adecuación del software a varios niveles: producto, calidad en uso, de proceso e incluso organizacional.

La enorme disparidad que presentan a todos los niveles los entornos industriales y los ecosistemas abiertos es incluso más pronunciada en la forma en la que se aborda la calidad software por ambos. Incluso aquellos entornos industriales que no siguen normas de calidad estandarizadas se integran en cadenas de desarrollo/integración con cierto nivel de homogeneidad; en cambio, la situación en ecosistemas abiertos dista de ser conocida, por lo que la siguiente pregunta de investigación es necesaria:

$R Q 3$ ¿Permite el modelo de calidad de componentes web educir sus características y evaluar la calidad de producto, de uso?

Considerando los estándares de calidad, al menos en parte, como resultado de un proceso deductivo que, tras analizar buenas prácticas y experiencias de la industria, homogeniza la aproximación de agentes reales a la calidad software para introducir una metodología aséptica que facilita su reusabilidad, resulta inmediato preguntarse el grado de coincidencia o alineación de los modelos de calidad empíricos presentes en el desarrollo de componentes web con los estándares definidos.

Así, tanto urgidos a explorar el nivel de contraste con respecto a los estándares reconocidos, como motivados por el deseo de facilitar la adopción de las tecnologías de componentes web por parte de la industria, que hace uso de las características de calidad que contempla para la calidad de producto y la calidad en uso los estándares ISO/IEC 25010, la siguiente pregunta de investigación sería:

RQ4 ¿Proporciona dicho modelo cobertura de las características de calidad en uso y calidad de producto recogidas en la formulación del estándar ISO/IEC 25010?

Una vez se llega a este punto, en el que los expertos en desarrollo web se han pronunciado, se ha establecido el nivel de alineación de la concepción empírica de calidad y la propuesta por los estándares de calidad, aún quedaría un agente para tener en cuenta, de hecho, el más importante: el usuario final.

Y así recuperando la acepción inicial de la que parte el concepto de calidad software y que concede al usuario la evaluación última de "la adecuación del producto o servicio a las características especificadas", es evidente plantear si el modelo de calidad identificado, sus 
características y atributos (métricas) establecidas permiten predecir el nivel de calidad que un usuario concedería. De forma concisa, la pregunta de investigación quedaría:

RQ5 ¿Es posible evaluar la calidad de los componentes web, de acuerdo con el modelo empírico, manera objetiva y automática?

La respuesta a esta última pregunta, dependiendo del grado en que fuese positiva, permitiría importantes mejoras, eliminando algunas de las grandes limitaciones que presenta la forma en la que se evalúa la calidad en los ecosistemas abiertos en la que se requiere

- Una comunidad de desarrollo, soporte y uso, y cuya ausencia penaliza aquellas tecnologías que carecen de tales ecosistemas a su alrededor.

- La curación de los componentes, que introduce un gap temporal entre el momento en el que esta disponible la tecnología y el momento en el que contamos con información sobre su calidad.

- Credibilidad y reputación como desarrollador, lo que de nuevo introduce un gap entre el momento en que está disponible la tecnología y el momento en el que se cuenta con el respaldo de la comunidad.

En conjunto el trabajo de investigación habrá de resolver algunas de las grandes limitaciones que existen para la adopción de la tecnología de componentes web, tanto en la industria como en ecosistemas abiertos. 


\section{Descripción de la Solución Propuesta}

"Todos mis seguidores, en efecto, parecen experimentar un refinado placer cuanto más exóticas son las cosas que contemplan."

Erasmo de Rotterdam

Esta sección de la tesis presenta la descripción de la solución. En ella se recogen el diseño de la investigación, las fases del estudio, así como los experimentos e instrumentos definidos para la obtención de los resultados y los análisis que habrán de aplicarse.

Presentado el diseño de la solución de esta manera, si bien se facilita enormemente la replicación del proceso de investigación, la narrativa puede parecer un poco fragmentada, al recogerse los resultados en la sección siguiente.

Así mismo, se diluye ligeramente la visión dinámica de la investigación, que habitualmente no presenta necesariamente la claridad y determinación recogidas en la documentación final. En el caso del presente estudio, este se ajusta a la categoría emergente de acuerdo con Creswell \& Plano Clark [12], y la aproximación, más que determinada desde el principio, emerge fruto del desarrollo y evolución de la investigación, de ahí lo significativo de la aportación de la tesis.

En conjunto, superando los beneficios a los inconvenientes, se ha optado por una presentación metodológica más formal y estructurada que resalte los logros de la aplicación de los métodos de investigación mixta a la ingeniería del software.

\subsection{Diseño de Investigación Mixta en Ingeniería del Software.}

La investigación recogida en esta tesis aborda el estudio de dos áreas de la ingeniería del software que pueden caracterizarse por su elevada componente cualitativa, es decir, relacionadas con el comportamiento humano y social del desarrollo de software. Estas dos áreas son los ecosistemas abiertos de desarrollo y la calidad software.

Los ecosistemas abiertos carecen de un marco formal que explicite procesos y criterios del desarrollo de software. Estos son inherentes a la cultura del ecosistema, constituyendo elementos sociales con lo que todo esto significa. No se perciben como una lacra, sino más bien como en elemento fundamental que posibilita la innovación rápida. La identificación y generalización de estos criterios dentro del ámbito de la calidad software es la intención de nuestro trabajo y su fundamento.

Respecto a la calidad software, incluso en contextos más convencionales para los que se han definido normas y estándares, tanto la caracterización de la calidad de producto y calidad de uso, como la cobertura de dichas características mediante un conjunto de atributos o métricas, incorporan una elevada dosis de dependencia del contexto, o si se quiere subjetividad, requiriéndose la adaptación a los distintos dominios, consenso de métricas e interpretación de resultados. Esta necesidad es tan importante, que se recoge explícitamente en el estándar ISO/IEC 25010, incluyendo ejemplos de adaptación. 
Además, debido a la creciente importancia del desarrollo de software en todo tipo de sectores y el éxito alcanzado por algunas compañías tecnológicas, los equipos de ingenieros de software y desarrolladores en la industria no han dejado de crecer, constituyendo, lo que se podría denominar con cautela, como ecosistemas cerrados. Estos presentan comportamiento y dinámicas similares a los ecosistemas abiertos, pero existen dentro del contexto delimitado de una misma empresa y sus colaboradores. Y así, los aspectos sociales y culturales, hasta ahora presentes principalmente en los ecosistemas abiertos, son cada vez más importantes también para el entendimiento de los ecosistemas cerrados.

Finalmente, es fundamental resaltar que lo importante de la aplicación de los métodos mixtos no es la caracterización e investigación de los elementos sociales de la ingeniería del software en ecosistemas abiertos y la calidad software. Lo verdaderamente importante es que, una vez caracterizados estos elementos cualitativos, el diseño exploratorio secuencial, en su fase cuantitativa, nos permite caracterizar e investigar cuál es el nivel de generalización de dichos resultados, cómo de objetivos y automatizables resultan, permitiendo su transferencia al corpus más formal de la ingeniería del software.

A continuación, se describen las distintas fases del diseño exploratorio secuencial del estudio de la tesis. Las siguientes secciones han de verse como una presentación sintética que permitirá entender la conexión entre las distintas actividades recogidas en el diseño de la solución.

\subsubsection{Diseño e implementación de la fase cualitativa}

Durante la fase de diseño e implementación cualitativa, se determinan la muestra cualitativa, los protocolos de recogida de datos en entrevistas abiertas y cerradas, así como los análisis cualitativos de los datos.

La muestra del estudio cualitativo está formada por un grupo de veinte desarrolladores web, seleccionados del programa Google Developer Experts [97], que serán objeto de categorización, para caracterizar la muestra según varias dimensiones relativas al dominio del estudio.

La recogida de datos se organiza en dos niveles relacionados: para comenzar, una serie inicial de entrevistas abiertas permiten caracterizar los elementos de valoración de la calidad de componentes web en ecosistemas abiertos; seguidamente, aplicando el método Delphi, una secuencia de entrevistas permitirá validar el modelo de calidad, con el respaldo de la evidencia que el consenso del grupo proporciona.

\subsubsection{Aplicación de las estrategias de diseño de fundamentos cualitativos.}

Resultado de la fase anterior, el modelo de calidad empírico concreta una colección de atributos que proporcionan cobertura (capacidad de evaluación) del conjunto de características de calidad de producto y calidad de uso establecidas por el estándar ISO/IEC 25010.

Seguidamente, en esta fase se diseña y desarrolla un instrumento digital, denominado plataforma de experimentación, que permite realizar el estudio cuantitativo exploratorio descriptivo que ha de determinar el grado de generalización posible de los resultados cualitativos obtenidos.

El diseño de la plataforma comienza definiendo un dominio de experimentación (dominio de la aplicación), un catalogo de componentes web dentro del dominio elegido y los atributos que habrán de caracterizar la calidad de componentes web durante la experimentación.

Respecto a la plataforma de experimentación, se trata de una aplicación web que integra todos los elementos necesarios para la realización experimental del estudio cuantitativo, estructurada en los siguientes tres módulos: el módulo de diseño experimental, el módulo aplicación web y el módulo de recogida y análisis de resultados. 
El módulo de diseño experimental realiza principalmente dos funciones: generación sintética de los atributos calidad en los componentes web del catálogo y configuración de escenarios de evaluación, composición funcional de componentes web, organizados en una muestra que permite la evaluación por parte de usuarios.

El módulo de aplicación web presenta los escenarios a los usuarios de la muestra de evaluación, integrados en un marco, una aplicación web, que permite además de la visualización en un navegador web, la identificación de usuarios, gestión de cuentas y elementos gráficos de interacción necesarios para recoger la evaluación de cada experimento.

Por último, el módulo de recogida y análisis de resultados agrega la información proveniente de cada una de las evaluaciones individuales, permitiendo determinar la evidencia de respaldo de la generalización de los resultados cualitativos.

La muestra elegida para la fase cuantitativa corresponde a un conjunto usuarios, principalmente alumnos de varias escuelas de Ingeniería Informática, que participaron desinteresadamente como voluntarios en la validación de la plataforma de experimentación.

\subsubsection{Diseño e implementación de la fase cuantitativa}

El alcance de la fase cuantitativa es exploratorio, como requiere la aproximación novedosa a la caracterización y evaluación de la calidad, y descriptivo-correlacional, con el objeto de detallar la calidad software en ecosistemas abiertos y su manifestación en los componentes web, explorando la correlación entre los atributos sintéticos y la calidad percibida por el usuario final.

En conjunto, esta aproximación ha de sentar las bases de futuros trabajos de un alcance correlacional-explicativo, que permita introducir técnicas predictivas de la calidad percibida y su generalización en términos de ecosistemas, tecnologías y dominios de aplicación.

Las variables independientes son de tipo sintético y corresponden con los atributos de la calidad implementados. La variable dependiente corresponde a la valoración de los componentes por parte de usuario final, obtenida a lo largo de varias dimensiones de evaluación recogidas en un formulario de satisfacción que se presenta tras la interacción con cada escenario.

Los escenarios se diseñan de manera que la evaluación de los componentes resulta independiente, resultando en una muestra de variables independientes de 120 registros en la experimentación. Por último, la muestra de participantes son quince alumnos voluntarios del grupo CONWET de la Escuela Técnica Superior de Ingenieros Informáticos.

Con estas muestras se realizará un análisis descriptivo-correlacional que complete la exploración cuantitativa previa al análisis de los resultados, última fase del diseño exploratoria secuencial seguida en este estudio. A modo de resumen, la llustración 3 muestra el proceso completo. 


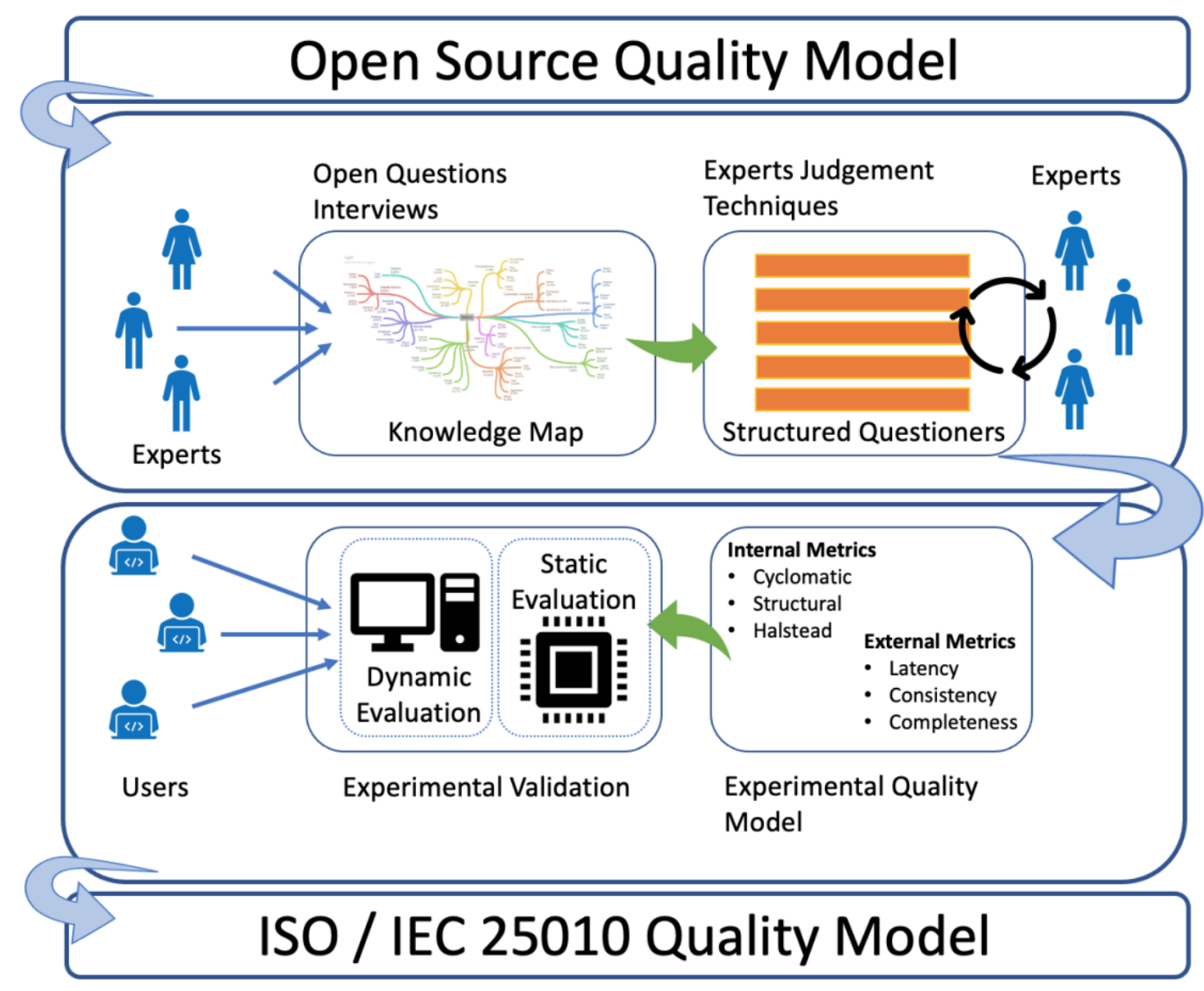

Ilustración 3: Diseño de Investigación Mixta en Ingeniería del Software

\subsection{Diseño de la fase Cualitativa: Caracterización de Calidad Software}

El conjunto de métricas incluidas los estandares ISO/IEC 25022 e ISO/IEC 25023 proporcionan una cobertura detallada de las características de calidad del modelo que presenta la ISO/IEC 25010. Esta cobertura si bien no pretende ser completa, sí resulta diversa. Como se observará durante el análisis con los expertos, si bien reconocen las características presentadas en el estándar, su acepción dista de encajar completamente con los aspectos que evalúan sus métricas e incluso, los expertos difieren ligeramente en lo que entienden por cada una de ellas.

\subsubsection{Conceptualización experimental del Modelo de Calidad.}

La aplicación del método Delphi contempla como alternativa válida al enfoque clásico la realización de una primera fase de entrevistas no estructuradas. Esta fase 0 facilita la definición de la materia de estudio, redacción de cuestionarios y técnicas de análisis o incluso, la selección y categorización del panel de expertos.

Esta será la aproximación seguida en nuestra investigación que, apoyándose en un conjunto de entrevistas grabadas con un subconjunto del grupo final de expertos, buscará la identificación de los elementos del modelo de calidad de componentes web, que serán objeto de validación durante la fase de entrevistas estructuradas.

En particular, los cuestionarios que guiarán las entrevistas no estructuradas persiguen conceptualizar empíricamente el modelo de calidad en función de los siguientes elementos (Tabla 5):

- Ámbito: qué productos o sistemas software contempla.

- Agentes: qué individuos y con qué roles intervienen en el modelo. 
- Identificación de las características no funcionales y sus atributos (métricas).

- Análisis de cobertura características / métricas.

El cuestionario sigue un guion en el que se introducen en forma de preguntas una serie de elementos para la valoración por parte de los expertos. Con el fin de facilitar la aportación de detalles por parte de los expertos, las entrevistas se graban en video, dirigidas por un mismo facilitador, sin limitación de tiempo y haciendo uso de un lenguaje que omiten términos excesivamente técnicos o extraídos de la norma ISO/IEC 25010.

\begin{tabular}{|l|l|}
\hline Elementos del Modelo de Calidad & Etapa del Método Delphi \\
\hline Ámbito (Scope) & Entrevista no estructurada (Primera cero) \\
\hline Agentes (Stakeholders) & Entrevista no estructurada (Primera cero) \\
\hline Identificación y Características y atributos & $\begin{array}{l}\text { Entrevista no estructurada (Primera cero) } \\
\text { Serie de Entrevistas Estructuradas }\end{array}$ \\
\hline Análisis de cobertura características / métricas. & $\begin{array}{l}\text { Entrevista no estructurada (Primera cero) } \\
\text { Serie de Entrevistas Estructuradas }\end{array}$ \\
\hline \\
\hline
\end{tabular}

El cuestionario se divide en tres categorías que permiten valorar la experiencia del experto, las tecnologías que conoce y el tipo de proyectos que desarrolla, la valoración de características de calidad de producto y métricas internas, así como las características de la calidad en uso y métricas dinámicas. Estas valoraciones se analizarán para conceptualizar el modelo de calidad de componentes web según los elementos del modelo de calidad ya mencionados. El conjunto de cuestiones planteadas, así como el razonamiento que hay tras ellas se encuentran recogidas en la Tabla 6.

\begin{tabular}{|c|c|}
\hline Pregunta & Descripción \\
\hline OQ1 ¿Qué tecnologías de componentes web conoces? & $\begin{array}{l}\text { El conocimiento de diversas tecnologías que } \\
\text { implementan componentes web y el uso de una u otra } \\
\text { determina distintos agentes y su grado de experiencia y } \\
\text { el ámbito de aplicación del modelo. }\end{array}$ \\
\hline $\begin{array}{l}\text { OQ } 2 \text { ¿Qué tipo de desarrollos realizas con } \\
\text { componentes web? }\end{array}$ & $\begin{array}{l}\text { El desarrollo de componentes web o su integración en } \\
\text { desarrollos de aplicaciones web, así como el carácter de } \\
\text { estos proyectos determina el tipo de agente y su grado } \\
\text { de experiencia y el ámbito de aplicación del modelo. }\end{array}$ \\
\hline $\begin{array}{l}\text { OQ } 3 \text { ¿Utilizas tecnología proveniente de repositorios } \\
\text { abiertos y por qué? }\end{array}$ & $\begin{array}{l}\text { El uso de tecnologías de repositorios abiertos responde } \\
\text { a criterios de calidad. Permite identificar características } \\
\text { y atributos del modelo. }\end{array}$ \\
\hline $\begin{array}{l}\text { OQ } 3 \text { Cuando utilizas componentes web de repositorios } \\
\text { públicos, ¿̇qué criterios de selección sigues? }\end{array}$ & $\begin{array}{l}\text { La selección de componentes web requiere identificar } \\
\text { los atributos que determinan idoneidad. Permite } \\
\text { identificar características y atributos del modelo. }\end{array}$ \\
\hline $\begin{array}{l}\text { OQ } 4 \text { En el proceso de selección de un componente } \\
\text { web, ¿consideras la reputación del desarrollador o la } \\
\text { comunidad? }\end{array}$ & $\begin{array}{l}\text { La reputación es un elemento de carácter exclusivo en } \\
\text { la selección de tecnología en repositorios abiertos. } \\
\text { Permite identificar características y atributos del } \\
\text { modelo. }\end{array}$ \\
\hline $\begin{array}{l}\text { OQ } 5 \text { Cuando compartes tus componentes en } \\
\text { repositorios abiertos, ¿Qué criterios consideras para } \\
\text { fomentar su uso? }\end{array}$ & $\begin{array}{l}\text { La promoción activa de tecnologías en repositorios } \\
\text { requiere conocer los atributos valorados por la } \\
\text { comunidad de desarrolladores. Permite identificar } \\
\text { características y atributos del modelo y sus coberturas. }\end{array}$ \\
\hline $\begin{array}{l}\text { OQ } 6 \text { ¿Qué elementos de un componente web } \\
\text { relacionas con calidad? }\end{array}$ & $\begin{array}{l}\text { Los atributos no funcionales son los que permiten } \\
\text { cualificar un componente de calidad. Permite } \\
\text { identificar características y atributos del modelo y sus } \\
\text { coberturas. }\end{array}$ \\
\hline $\begin{array}{l}\text { OQ } 7 \text { ¿Cómo verificas durante los procesos de prueba } \\
\text { que el componente cuenta con calidad? }\end{array}$ & $\begin{array}{l}\text { La verificación, en particular durante las pruebas, se } \\
\text { fundamenta en métricas que evalúan calidad de } \\
\text { producto. Permite identificar características y atributos } \\
\text { del modelo y sus coberturas. }\end{array}$ \\
\hline $\begin{array}{l}\text { OQ } 8 \text { ¿Cómo afecta la comunicación del componente } \\
\text { con el servidor a la calidad? }\end{array}$ & $\begin{array}{l}\text { Los atributos en dinámicos permiten evaluar la calidad } \\
\text { en uso. Permite identificar características y atributos } \\
\text { del modelo y sus coberturas. }\end{array}$ \\
\hline
\end{tabular}


OQ 9 ¿Cómo afecta la experiencia de usuario y el diseño a la calidad del componente?

OQ 10 ¿Puedes darnos algunos ejemplos?

OQ 11 ¿Cómo afecta la estructura del código del componente a la calidad?

OQ 12 ¿Cómo afectan las dependencias de módulos externos a la calidad del componente?

OQ 13 ¿Puedes darnos algunos ejemplos?

OQ 14 ¿Cómo afecta la seguridad a la calidad de los componentes?

Los atributos en dinámicos permiten evaluar la calidad en uso. Permite identificar características y atributos del modelo y sus coberturas.

Una vez ilustrada la calidad en uso y los atributos dinámicos, al preguntar por más ejemplos se exploran otros no contemplados. Permite identificar agentes y ámbito.

Los atributos en estáticos permiten evaluar la calidad de producto. Permite identificar características y atributos del modelo y sus coberturas.

Los atributos en estáticos permiten evaluar la calidad de producto. Permite identificar características y atributos del modelo y sus coberturas.

Una vez ilustrada la calidad de producto y los atributos estáticos, al preguntar por más ejemplos se exploran otros no contemplados. Permite identificar agentes y ámbito.

Dada la importancia de la seguridad, en particular en tecnologías web, se introduce una pregunta específica que combina elementos dinámicos y estáticos y por tanto permite valorar calidad en uso y de producto. Permite identificar agentes y ámbito. Permite identificar características y atributos del modelo y sus coberturas.

Tabla 6: Cuestionario de respuestas abiertas.

El análisis correspondiente a la fase cero consiste en la revisión de las entrevistas y la construcción de un mapa de términos que permitirá conceptualizar el modelo empírico de calidad de componentes web. Estos resultados alimentarán las fases sucesivas del método Delphi, donde se evaluarán siguiendo un proceso de validación estadística.

\subsubsection{Diseño del método Delphi}

\subsubsection{Definición de la materia de estudio}

Una vez conceptualizado el modelo de calidad, identificados agentes, ámbitos, características y atributos, se procede a construir los formularios que serán objeto de las entrevistas estructuradas realizadas al panel de expertos. La validación persigue determinar cuál es nivel de cobertura de los atributos (métricas) propuestos, de las características de calidad de producto y calidad en uso contempladas por el estándar ISO/IEC 25010.

Los resultados de la fase 0 (ver sección 4.2.1) conducen a la propuesta de tres métricas internas, de evaluación estática y tres métricas externas, de evaluación dinámica. Las tres métricas internas propuestas para la validación son:

- Complejidad de Halstead, que proporciona el orden de magnitud de tamaño del código en función del número de términos del vocabulario y las expresiones que definen.

- Complejidad Ciclomática, que evalúa la estructura del código analizando el grafo que definen las sentencias del código conectadas mediante sentencias de control de flujo (if, for, etc...) presentes en las funciones del componente web.

- Complejidad estructural, que proporciona el número de dependencias (fan out), ya sean módulos JavaScript, interfaces u otros componentes, que importa el componente web.

Las tres métricas externas propuestas son:

- Completitud, que representa el grado, de $0 \%$ a $100 \%$, de información disponible en el componente en tiempo de ejecución. Usando como ejemplo un componente visual, sería el porcentaje de información que el componente visualiza. 
- Latencia, que representa el retraso en la ejecución, medida milisegundos, del componente en la interacción con el usuario y comparado con el resto de los componentes de la aplicación web.

- Consistencia, que sería una variable bidimensional donde se combinan los efectos de latencia y completitud, para representar el retraso que se produce en la propagación de la información cuando existen varias instancias conectadas por un back-end común. EI ejemplo correspondería a la inconsistencia eventual presente entre instancias de una misma aplicación web conectada mediante bases de datos distribuidas.

Combinando la descripción formal de las características de calidad y la definición formal de las métricas mostradas en la lista anterior, se construyen los cuestionarios con la siguiente estructura:

- 45 preguntas en total.

- Tres secciones de 8 preguntas, una por cada característica de calidad en uso, que evalúan el nivel de cobertura que ofrecen las tres métricas estáticas propuestas.

- Tres secciones de 7 preguntas, una por cada característica de calidad en uso, a las que se le añaden 2 preguntas correspondientes a dos características de calidad de producto, que evalúan el nivel de cobertura que ofrecen las tres métricas dinámicas propuestas.

- La valoración del nivel de cobertura se realiza utilizando una escala ordinal de 5 niveles.

El elevado tono formal de la descripción de las características, dificultado por el posible desconocimiento de las normas de calidad, junto con el elevado número de preguntas incluidas nos lleva a introducir dos modificaciones significativas al método Delphi:

- Las entrevistas serán guiadas por un facilitador. En nuestro trabajo de investigación, y con el fin de evitar la introducción de sesgos, será siempre el mismo para todos los miembros del panel y las iteraciones, y seguirá un protocolo especificado acorde a un guion común.

- Si bien los expertos responden a formularios estándar, con el fin de facilitar los comentarios y el análisis posterior, las entrevistas serán grabadas.

Comenzando con las características de calidad de producto y las métricas internas, la lista de preguntas que evalúan el nivel de cobertura de las características de calidad de producto por parte de la complejidad Halstead son las siguientes:

Pregunta

QD1 El grado al cual un componente web proporciona funcionalidad que cumple las necesidades implícitas o explícitas cuando se utiliza bajo unas condiciones especificadas puede evaluarse con la medida del tamaño del código, en función del número de términos y las expresiones que definen

QD2 El rendimiento de un componente web relativo a la cantidad de recursos consumidos bajo condiciones especificadas puede evaluarse con la medida del tamaño del código, en función del número de términos y las expresiones que definen.

QD3 El grado con el que un componente web puede intercambiar información con otros y/o realizar sus funciones mientras comparte el mismo entorno hardware/software (browser) puede evaluarse con la medida del tamaño del código, en función del número de términos y las expresiones que definen.

QD4 El grado con el que un componente web puede ser utilizado por usuario específicos, alcanzando objetivos específicos con eficacia, eficiencia y satisfacción en el contexto especificado puede evaluarse con la medida del tamaño del código, en función del número de términos y las expresiones que definen

QD5 El grado con el que un componente web realiza funciones especificadas bajo condiciones especificadas por un tiempo especificado puede evaluarse con la medida del tamaño del código, en función del número de términos $y$ las expresiones que definen.

QD6 El grado con el que un componente web protege la información y los datos de forma que usuarios u otros sistemas cuentan con el nivel de acceso adecuado a sus tipos y niveles de autorización puede evaluarse con la medida del tamaño del código, en función del número de términos y las expresiones que definen.

QD7 El grado de eficacia y eficiencia con el que un componente web puede ser modificado por los agentes de mantenimiento especificado puede evaluarse con la medida del tamaño del código, en función del número de términos y las expresiones que definen. 
QD8 El grado de eficacia y eficiencia con el que un producto puede ser transferido de un entorno hardware, software, de uso u otros, a un nuevo entorno puede evaluarse con la medida del tamaño del código, en función del número de términos y las expresiones que definen.

Tabla 7: Cuestionario Dimensión Calidad de Producto / Métrica de Halstead.

La lista de preguntas que evalúan el nivel de cobertura de las características de calidad de producto por parte de la complejidad Ciclomática son las siguientes:

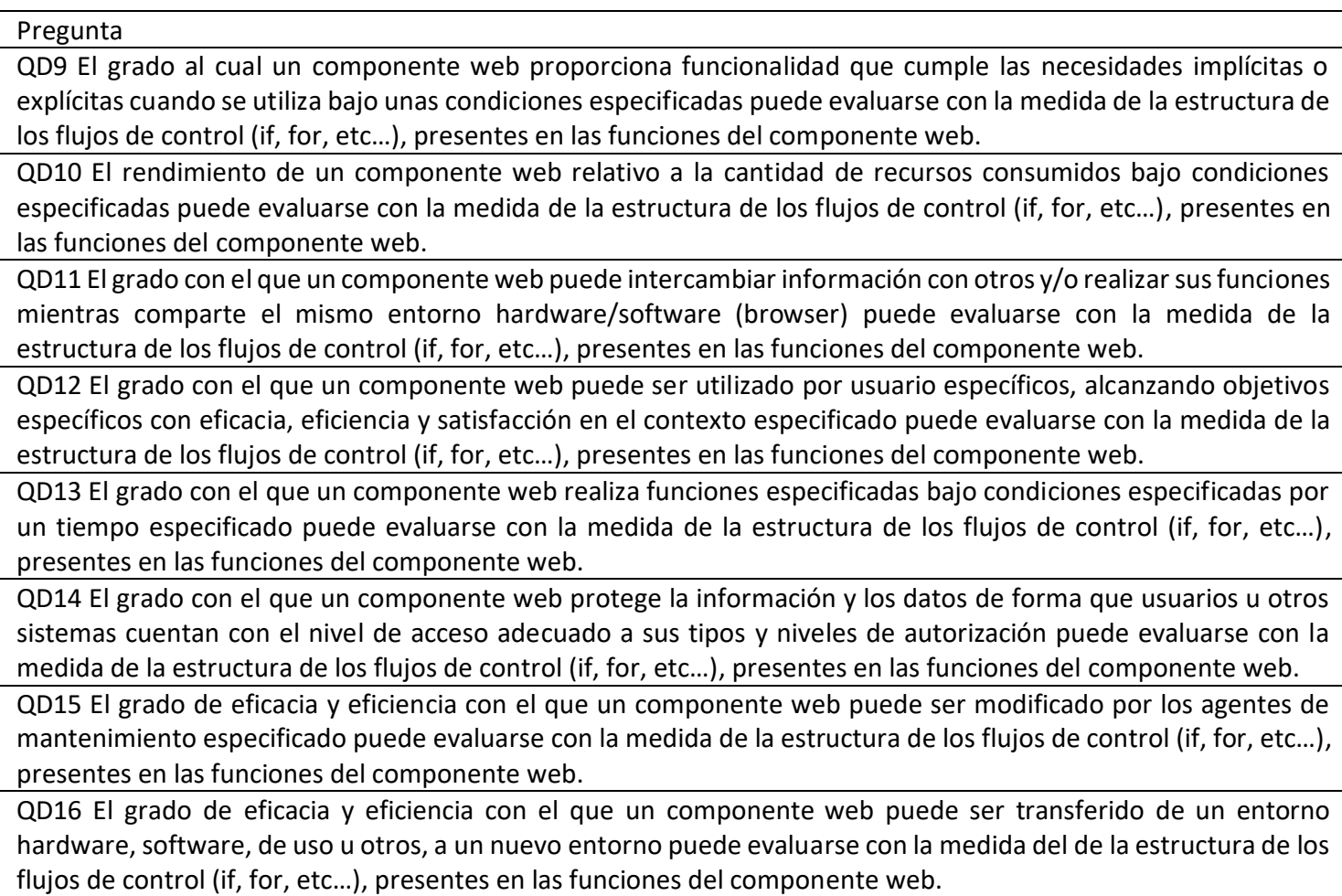

Tabla 8: Cuestionario Dimensión Calidad de Producto / Complejidad Ciclomática.

Por último, introducimos la colección de preguntas que permitirá evaluar la cobertura de las características de calidad de producto mediante la medida de complejidad estructural (fan-out).

\begin{tabular}{|c|}
\hline $\begin{array}{l}\text { Pregunta } \\
\text { QD17 El grado al cual un componente web proporciona funcionalidad, que cumple las necesidades implícitas o } \\
\text { explícitas cuando se utiliza bajo unas condiciones especificadas puede evaluarse con la medida del número de } \\
\text { módulos JavaScript u otros componentes que importan el componente web. }\end{array}$ \\
\hline $\begin{array}{l}\text { QD18 El rendimiento de un componente web relativo a la cantidad de recursos consumidos bajo condiciones } \\
\text { especificadas puede evaluarse con la medida del número de módulos JavaScript u otros componentes que } \\
\text { importan el componente web. }\end{array}$ \\
\hline $\begin{array}{l}\text { QD19 El grado con el que un componente web puede intercambiar información con otros y/o realizar sus funciones } \\
\text { mientras comparte el mismo entorno hardware/software (browser) puede evaluarse con la medida del número } \\
\text { de módulos JavaScript u otros componentes que importan el componente web. }\end{array}$ \\
\hline $\begin{array}{l}\text { QD20 El grado con el que un componente web puede ser utilizado por usuario específicos, alcanzando objetivos } \\
\text { específicos con eficacia, eficiencia y satisfacción en el contexto especificado puede evaluarse con la medida del } \\
\text { número de módulos JavaScript u otros componentes que importan el componente web. }\end{array}$ \\
\hline $\begin{array}{l}\text { QD21 El grado con el que un componente web realiza funciones especificadas bajo condiciones especificadas por } \\
\text { un tiempo especificado puede evaluarse con la medida del número de módulos JavaScript u otros componentes } \\
\text { que importan el componente web. }\end{array}$ \\
\hline $\begin{array}{l}\text { QD22 El grado con el que un componente web protege la información y los datos de forma que usuarios u otros } \\
\text { sistemas cuentan con el nivel de acceso adecuado a sus tipos y niveles de autorización puede evaluarse con la } \\
\text { medida del número de módulos JavaScript u otros componentes que importan el componente web. }\end{array}$ \\
\hline $\begin{array}{l}\text { QD23 El grado de eficacia y eficiencia con el que un componente web puede ser modificado por los agentes de } \\
\text { mantenimiento especificado puede evaluarse con la medida del número de módulos JavaScript u otros } \\
\text { componentes que importan el componente web. }\end{array}$ \\
\hline $\begin{array}{l}\text { QD24 El grado de eficacia y eficiencia con el que un componente web puede ser transferido de un entorno } \\
\text { hardware, software, de uso u otros, a un nuevo entorno puede evaluarse con la medida del número de módulos } \\
\text { JavaScript u otros componentes que importan el componente web. }\end{array}$ \\
\hline
\end{tabular}


Tabla 9: Cuestionario Dimensión Calidad de Producto / Complejidad Estructural (Fan-out).

A continuación, se incluyen los cuestionarios correspondientes a las características extrínsecas del modelo de calidad, y la correspondiente evaluación de la cobertura proporcionada por las métricas elegidas. Como ya se comentó anteriormente, tras las entrevistas abiertas, las características a evaluar durante este ciclo se han ampliado para incluir la adecuación funcional y el rendimiento, buscando una mayor cobertura de estas características de calidad de producto, pero que tienen también una dimensión de calidad de uso.

La lista de preguntas que permiten evaluar la cobertura de las características de calidad en uso mediante la métrica de completitud son las siguientes:

\begin{abstract}
Pregunta
QD25 El rendimiento de un componente web relativo a la cantidad de recursos consumidos bajo condiciones especificadas puede evaluarse midiendo la proporción de atributos utilizados y/o visualizados por el componente que cuenta con los valores necesarios.

QD26 El grado con el que un componente web puede ser utilizado por usuario específicos, alcanzando objetivos específicos con eficacia, eficiencia y satisfacción en el contexto especificado puede evaluarse midiendo la proporción de atributos utilizados y/o visualizados por el componente que cuenta con los valores necesarios.

QD27 La precisión y completitud con la que los usuarios alcanza el objetivo especificado cuando utiliza un componente web puede evaluarse midiendo la proporción de atributos utilizados y/o visualizados por el componente que cuenta con los valores necesarios.

QD28 La relación de recursos empleados por un componente web y la precisión y completitud con la que los usuarios alcanzan el objetivo especificado puede evaluarse midiendo la proporción de atributos utilizados y/o visualizados por el componente que cuenta con los valores necesarios.

QD29 El grado de satisfacción de las necesidades del usuario cuando el componente web se utiliza en el contexto de uso especificado puede evaluarse midiendo la proporción de atributos utilizados y/o visualizados por el componente que cuenta con los valores necesarios.

QD30 El grado en el que el componente web reduce un potencial riesgo de carácter económico, humano o del medio ambiente puede evaluarse midiendo la proporción de atributos utilizados $\mathrm{y} / \mathrm{o}$ visualizados por el componente que cuenta con los valores necesarios.

QD31 El grado al cual un componente web puede utilizarse con eficacia, eficiencia, satisfacción y ausencia de riesgo tanto en contexto de uso especificados, como más allá de las especificaciones iniciales puede evaluarse midiendo la proporción de atributos utilizados y/o visualizados por el componente que cuenta con los valores necesarios. Tabla 10: Cuestionario Dimensión Calidad en Uso / Completitud.
\end{abstract}

La lista de preguntas que permite evaluar la cobertura de las características de calidad en uso mediante la métrica de latencia son las siguientes:

Pregunta

QD32 El rendimiento de un componente web relativo a la cantidad de recursos consumidos bajo condiciones especificadas puede evaluarse midiendo la demora en la ejecución o visualización del componente web en relación con el resto de contenido de la aplicación web.

QD33 El grado con el que un componente web puede ser utilizado por usuario específicos, alcanzando objetivos específicos con eficacia, eficiencia y satisfacción en el contexto especificado puede evaluarse midiendo la demora en la ejecución o visualización del componente web en relación con el resto de contenido de la aplicación web.

QD34 La precisión y completitud con la que los usuarios alcanza el objetivo especificado cuando utiliza un componente web puede evaluarse midiendo la demora en la ejecución o visualización del componente web en relación con el resto de contenido de la aplicación web.

QD35 La relación de recursos empleados por un componente web y la precisión y completitud con la que los usuarios alcanzan el objetivo especificado puede evaluarse midiendo la demora en la ejecución o visualización del componente web en relación con el resto de contenido de la aplicación web.

QD36 El grado de satisfacción de las necesidades del usuario cuando el componente web se utiliza en el contexto de uso especificado puede evaluarse midiendo la demora en la ejecución o visualización del componente web en relación con el resto de contenido de la aplicación web.

QD37 El grado en el que el componente web reduce un potencial riesgo de carácter económico, humano o del medio ambiente puede evaluarse midiendo la demora en la ejecución o visualización del componente web en relación con el resto de contenido de la aplicación web.

QD38 El grado en el cual un componente web puede utilizarse con eficacia, eficiencia, satisfacción y ausencia de riesgo tanto en contexto de uso especificados, como más allá de las especificaciones iniciales puede evaluarse midiendo la demora en la ejecución o visualización del componente web en relación con el resto de contenido de la aplicación web. 
Por último, la lista de preguntas que permiten evaluar la cobertura de las características de calidad en uso mediante la métrica de completitud son las siguientes:

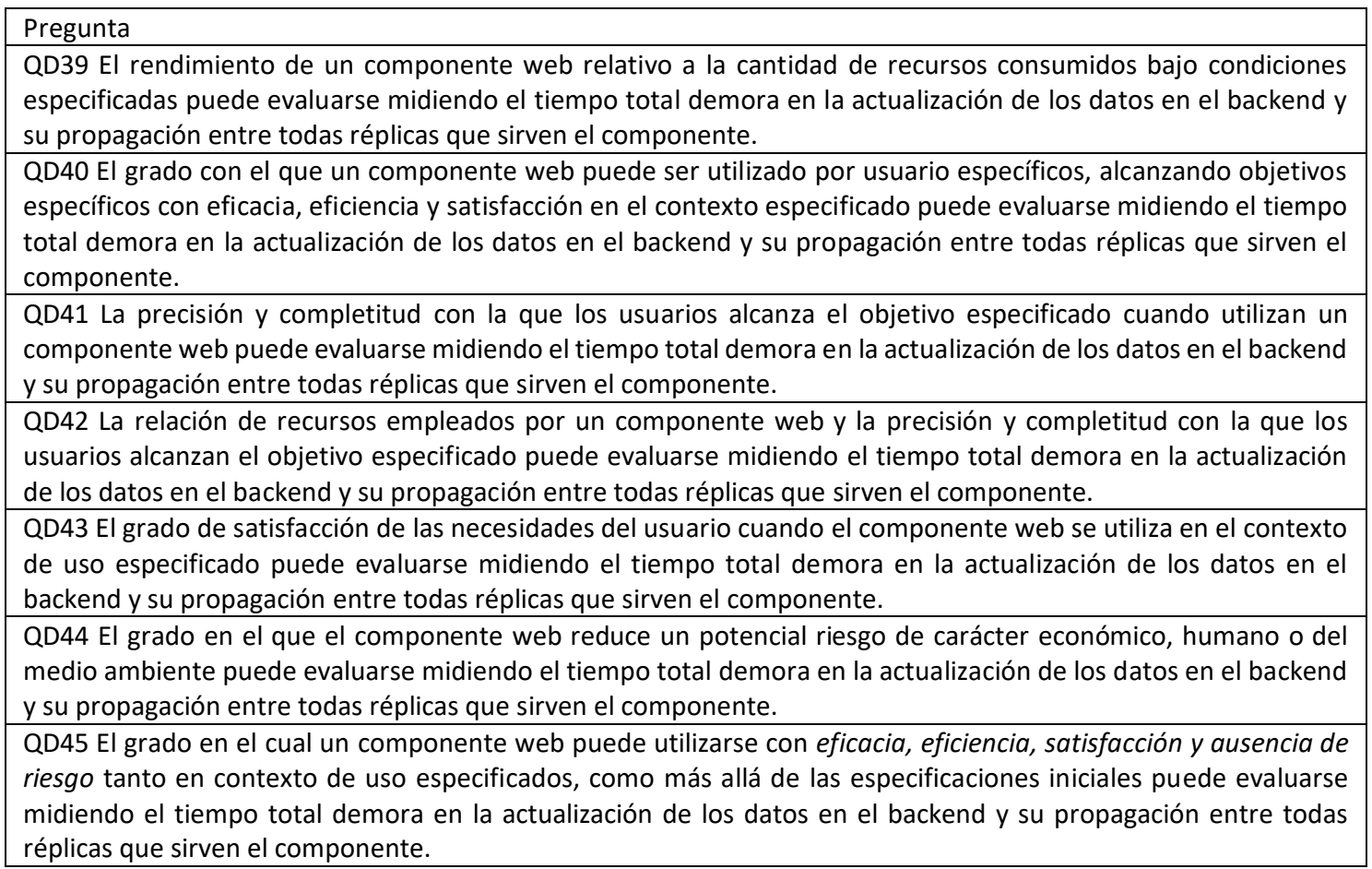
Tabla 12: Cuestionario Dimensión Calidad en Uso / Consistencia.

Algunos comentarios generales sobre la construcción de las preguntas del cuestionario:

- Los cuestionarios están redactados en inglés y las entrevistas se llevarán a cabo en castellano cuando este sea el idioma nativo del experto o en inglés en caso contrario.

- Cada pregunta se construye componiendo la definición de las características de calidad sacadas de la norma correspondiente y la definición del atributo propuesto tras la ronda 0 del Método Delphi.

- La parte correspondiente a la definición de las características de calidad se ajusta estrictamente a la formalidad del estándar.

- Por el contrario, la definición del atributo de calidad rehúye el formalismo y persigue un claro entendimiento por parte de los expertos.

- Los expertos pueden evaluar cada pregunta en una escala ordinal de cinco niveles que van desde el 1, que indica el total desacuerdo con la afirmación, hasta el 5 que indica una certeza absoluta de la cobertura.

- El nivel 3 indicaría la certeza de la cobertura no exclusiva y no determinante de la característica.

Por último una nota sobre las herramientas utilizadas: La infraestructura utilizada para esta fase de entrevistas estructuradas ha sido Google Workspace [98], incluyendo formularios, hojas de calculo, presentaciones y la herramienta de video conferencia Google Meet.

\subsubsection{Configuración del Panel de Expertos}

El método Delphi requiere la selección y caracterización de un panel de expertos que participarán en la investigación. No habiéndose encontrado en la bibliografía referencias previas sobre la constitución de un panel de expertos para este dominio, se ha configurado el panel seleccionando expertos pertenecientes al programa Google Developers Expert [97], dentro de la categoría de tecnologías web. 
El programa de Google Developer Experts es una iniciativa promovida por el equipo de Developer Relations de Google y constituye una red global de "expertos tecnológicos de elevada experiencia, referentes y líderes de opinión técnica que apoyan y promueven el desarrollo tecnológico de empresas y comunidades tecnológicas mediante la elaboración de contenido, desarrollo de software libre y presentación en conferencias y congresos tecnológicos." En la actualidad el programa cuenta con mas de 700 expertos de todo el mundo, de los cuales cerca del $40 \%$ corresponden a tecnologías web.

En la caracterización de los expertos participantes en el panel Delphi se introducen un conjunto de categorías que persiguen valorar el nivel de experiencia, el grado de conocimiento teórico y práctico en calidad software, así como el conocimiento las normas de calidad. Los expertos se autoevaluarán completando un cuestionario, que contiene las categorías que se recogen a continuación.

- ECOO Experiencia del experto, estableciéndose los siguientes niveles: (1) Desarrollador Web que no conoce ni utiliza Componentes Web, (2) Desarrollador Web que conoce, pero no utiliza componentes web, (3) Desarrollador Web que utiliza componentes web, (4) Desarrollador web que desarrolla ocasionalmente componentes y (5) Desarrollador Web de librerías de componentes. Este valor se utilizará en la denominación de los expertos, que consistirá en un código EXXY formado por la letra "E", dos dígitos XX que representa la secuencia de su participación, de 01 a 20, seguidos por un dígito $Y$ del nivel de experiencia auto asignado.

- EC01 Años de experiencia en tecnologías web, estableciéndose las siguientes categorías: (1) entre 1 y 3 años de experiencia, (2) entre 3 y 5 años de experiencia, (3) entre 5 y 7 años de experiencia y (4) más de 7 años de experiencia.

- EC02 Formación académica en Computer Science, estableciéndose las siguientes categorías: (1) PhD en Computer Science, (2) Máster en Computer Science, (3) Bachelor en Computer Science (4) y (5) otros. Para esta última categoría se piden más detalles en el campo de comentarios.

- EC03 Participación en proyectos de Open Source, con las categorías (1) si y (2) no.

- EC04 Sector Profesional, con las categorías (1) Servicios IT / Desarrollo de Software, (2) Non IT - Health, Financial, Retails, (3) Research / Academia y (4) otros.

- EC05 Tecnología de desarrollo de componentes web, estableciéndose las categorías (1) Angular Components, (2) Lit - Elements, (3) Hybrid y (4) otros.

- EC06 Existencia de un role o grupo de calidad software dentro del equipo de desarrollo del que forma parte el experto, con las categorías (1) si y (2) no.

- EC07 Existencia de pruebas de calidad en los procesos (análisis estático) de desarrollo software en los que participa el experto, con las categorías (1) si y (2) no.

- EC08 Existencia de pruebas con usuarios o clientes, como parte del proceso de desarrollo en los que participa el experto (análisis dinámico), con las categorías (1) si y (2) no.

- EC09 Uso de herramientas de análisis estático de código por parte del experto, con las categorías (1) si y (2) no.

- EC10 Conocimiento de las normas ISO / IEC 25000, con las categorías (1) si y (2) no.

El uso de estas categorías, además de la caracterización de los expertos, nos permitirá evaluar la existencia de asociación entre dichas categorías y el nivel de cobertura de características por parte de las diferentes métricas.

\subsubsection{Propuesta de Análisis}

El procesamiento de las entrevistas estructuradas se realiza analizando, para cada ronda y cada pregunta, los siguientes estadísticos [99]: 
- Estadísticas discretas de media, mediana y desviación estándar.

- Porcentaje de acuerdo, correspondiente al porcentaje de expertos que consideran que es posible evaluar la característica en función de la métrica con un nivel de acuerdo de 4 o 5.

- Porcentaje de desacuerdo, correspondiente al porcentaje de expertos que consideran que es posible evaluar la característica en función de la métrica con un nivel de acuerdo de 2 o 1.

De las definiciones anteriores se desprende la exclusión de aquellas opiniones que sitúan la cobertura en el nivel 3; si bien en la definición de la escala este valor corresponde con una certeza de la cobertura no exclusiva y no determinante, se ha preferido excluir para contar con una evidencia más fuerte.

La información correspondiente a las estadísticas se recoge en tabla numéricas, gráficos boxand-whisker y diagramas radiales que permiten comparar el nivel de cobertura por métrica. Finalmente, a modo de resumen se incluye una tabla que indica la cobertura o no de cada característica y cada métrica, en la que se asume que una característica cuenta con cobertura del atributo (métrica) correspondiente si el porcentaje de acuerdo supera al porcentaje de desacuerdo.

Para cada iteración se evalúan los siguientes estadísticos:

- Alfa de Chronbach, que determina la fiabilidad del cuestionario en la evaluación diseñada. Siguiendo las recomendaciones establecidas en la bibliografía, se consideran valores aceptables por encima de 0.7 , considerándose muy buenos a partir de 0.9 . El cálculo se realiza utilizando el paquete "psy" [100] de R.

- W de Kendall, que determina el nivel de consenso entre diversos evaluadores. En nuestra investigación lo utilizaremos para evaluar el nivel de acuerdo entre expertos de una misma ronda y, obtenidas las evaluaciones medias por ronda, para determinar el nivel de estabilidad entre rondas, es decir, si en la iteración los expertos alcanzaron un nivel de opinión estable. En este caso, valores de 0.5 se consideran consenso moderado, siendo 0.4 moderado débil y 0.6 moderado fuerte. Valores superiores a 0.7 se consideran consenso fuerte. El calculo se realiza utilizando el paquete "irr" [101] de R.

- Análisis de Correspondencia Simple [102], técnica visual y exploratoria que permite mediante la reducción de la dimensionalidad de los datos visualizar la homogeneidad de las preguntas y la valoración de los expertos. En nuestro caso valoramos no solo la información visual, sino también el grado de variabilidad que representa (inercia) y la representatividad de las dimensiones de proyección. El calculo se realiza utilizando el paquete "ca" [103] de R. La inercia, es una medida de dispersión, que se obtiene como la media ponderada de las distancias $\chi^{2}$ y el perfil medio. Valores pequeños, cercanos a cero, indican perfiles concentrados en pocas categorías [102].

Finalmente, se realiza un proceso diferencial entre rondas para analizar los cambios introducidos a nivel de pregunta y de experto. Con esto se persigue introduce una técnica que permita observar visualmente cómo varían las opiniones de los expertos entre rondas y qué preguntas son las que se ven afectadas por los cambios de opinión. Estos resultados pueden ayudar a determinar sesgos entre el grupo de expertos o preguntas controvertidas o poco claras que conducen a variaciones por la influencia de la opinión del grupo.

Con estas herramientas, el Método Delphi se implementa como un proceso iterativo en el que:

1. Se lleva a cabo el cuestionario mediante entrevistas con los expertos.

2. Se procesa los estadísticos y se incorporan las recomendaciones sobre el cuestionario si las hubiese. Si el consenso alcanzado entre rondas, expresado como valor del estadístico de Kendall, es suficiente $(>0.9)$, se acaba. 
3. En caso de que el consenso sea insuficiente, se presentan los resultados agregados al grupo de expertos para que puedan incorporar esta información extra a su valoración, volviendo al paso 1 de nuevo para realizar las entrevistas.

Los análisis realizados se han procesado utilizando hojas de calculo de Google Workspace, y scripts de código en Python y en R. Los datos obtenidos, así como los scripts de procesamiento se pueden consultar en nuestro repositorio online [104].

\subsubsection{Conglomerados de Consenso y su Categorización}

Como ya se ha mencionado en las secciones anteriores, de entre los estadísticos que validan el nivel de consenso durante las rondas de entrevistas del Método Delphi, la $W$ de Kendall o coeficiente de concordancia permite medir el nivel de acuerdo entre los miembros del panel de expertos.

En términos formales representa el nivel de acuerdo de $p$ expertos evaluando $n$ conceptos, preguntas o elementos a valorar y se calcula de acuerdo con la formula:

$$
W=\frac{12 S^{\prime}-3 p^{2} n(n+1)^{2}}{p^{2}\left(n^{3}-n\right)-p T}
$$

donde $T$ es un factor de corrección para los empates en las evaluaciones y $S^{\prime}$ es el estadístico de suma marginal a nivel de fila de los rangos. En este estudio contamos con $p=20$ expertos que evalúan $n=45$ preguntas y los cálculos se realizarán con el paquete de irr del software estadístico R [101]. En todo lo relativo a su uso como estadístico utilizado en el Método Delphi se siguieron las recomendaciones de algunas referencias actuales [105] [99].

Durante el estudio realizado en la secuencia de entrevistas se observó un interesante detalle derivado del proceso seguido para la actualización de los diferentes estadísticos utilizados en el método Delphi. En vez de esperar a tener completados los resultados de toda la ronda, los estadísticos se fueron actualizando tras cada entrevista, observándose un comportamiento dinámico que condujo a la siguiente pregunta: ¿qué subconjunto de expertos presenta mayor nivel de consenso? ¿presentan estos conglomerados alguna caracterización distintiva?

Para explorar esta idea, se ha introducido un análisis que se ha denominado "análisis y categorización de conglomerados de consenso". Este análisis consiste en la búsqueda combinatoria, para los distintos tamaños posibles de subgrupos, de aquellos conglomerados de expertos que presentan un mayor nivel de cohesión o consenso entre ellos, para analizar a posteriori, de acuerdo con la categorización introducida, las características que presentan.

Se han definido dieciocho espacios de búsqueda, comenzando con los conglomerados de veinte expertos tomados de dos en dos hasta llegar a los conglomerados de veinte expertos tomados de diecinueve en diecinueve. Para cada espacio de búsqueda se obtiene $W$ de Kendall de todas las combinaciones posibles, los valores máximos y mínimos, media y varianza.

Una vez recopilados dichos valores para todos los espacios de búsqueda, se analiza como evoluciona por un lado el nivel consenso de acuerdo con la $W$ de Kendall, y por otro la composición de los conglomerados de consenso máximo, de acuerdo con la categorización manejada.

En el presente estudio, el análisis de conglomerados de consenso es exploratorio-descriptivo, pero los resultados obtenidos apuntan a que esta podría ser una interesante manera de caracterizar resultados no concluyentes del método Delphi y en particular, dentro del objeto de esta tesis, dominios de calidad software. 


\subsection{Instrumentos experimentales de fundamentos cualitativos}

Los resultados obtenidos en la fase cualitativa son los fundamentos que dirigen el diseño de instrumentos cuantitativos. En este estudio, estos resultados son el modelo de calidad y el mapa de cobertura de sus atributos (métricas) de las características de calidad contempladas por el estándar ISO/IEC 25010.

Ante la ausencia de bibliografía o trabajos previos de investigación que aborden modelos de calidad en componentes web desarrollados en ecosistemas abiertos, el objeto del estudio cuantitativo de esta tesis es exploratorio y descriptivo-correlacional. Lo que significa que persigue examinar y caracterizar el nivel de generalización de los resultados cualitativos, y la posibilidad de automatizar la evaluación de la calidad de los componentes web.

Traducido en una estrategia de diseño de experimentación, esto significa que los instrumentos a definir habrán de posibilitar el examen del modelo de calidad desde una perspectiva real: explorando los elementos de calidad medibles en componentes web, la viabilidad práctica de implementar su medida y el impacto que tiene en la calidad percibida por los agentes seleccionados para la experimentación.

La caracterización se realizará en términos descriptivos-correlativos, mediante el uso del instrumento de experimentación, mostrando los aspectos de implementación de la evaluación y medida del modelo de calidad. Esta información se complementa con un análisis correlacional básico que haga emerger conexiones básicas entre los elementos del modelo y determine las bases de futuros trabajos de alcance correlacional-explicativo.

\subsubsection{Dominio de Experimentación y de Aplicación}

En el presente estudio se establece un dominio de experimentación y aplicación limitado. No tiene sentido hacerlo de otra manera dentro del alcance exploratorio.

El dominio de experimentación se acota a la evaluación agregada de componentes con atributos de calidad sintéticos, es decir simulados, y solo por parte de usuarios finales, sin considerar otros agentes, de una muestra seleccionada. La caracterización en ámbitos reales de componentes obtenidos de ecosistemas abiertos y su evaluación por parte de agentes como desarrolladores o integradores son sumamente interesantes, pero complejos, requiriendo una cantidad significativa de recursos, por lo que se dejan para trabajos futuros, que sin duda se beneficiarán del presente estudio.

La experimentación se llevará a cabo en un dominio, aplicación web, que hemos denominado PicBit y que presenta un concentrador (mashup) de componentes web que muestran información de distinta naturaleza a los participantes de la muestra seleccionada. Esta aplicación también incluye el interfaz necesario para la recogida de la valoración de la calidad por parte de los usuarios.

Los criterios que han conducido a la selección de este dominio de aplicación han sido sencillez de uso y familiaridad, buscando reducir el posible sesgo que introduciría una plataforma desconocida, con componentes ajenos a la experiencia cotidiana de la muestra de participantes.

Por un lado, la sencillez se consigue simplificando al máximo la interacción de los usuarios con la aplicación web, de tal forma que incluso incluyendo la recogida de valoración por parte de los usuarios la aplicación, tras la autenticación, solo cuenta con dos niveles de interacción. Además, los componentes únicamente visualizan información, por lo que más allá del refresco periódico, no requieren respuesta a entradas proporcionadas por los usuarios.

Respecto a la familiaridad, esta se consigue, por un lado, presentando una funcionalidad de clara necesidad, ya que la proliferación de servicios web ha popularizado la presentación agregada de los mismos en aplicaciones web denominadas mashups. Y, por otro lado, se han seleccionado 
componentes web que conectan con servicios web populares para los usuarios como pueden ser información del tráfico, Twitter o Facebook.

\subsubsection{Catalogo de Componentes Experimentales}

Los participantes en el estudio cuantitativo realizarán un conjunto de acciones de uso e interacción con los componentes contenidos en un catálogo definido para tal caso. Estos componentes permiten la consulta y visualización de datos relativos a un conjunto de servicios, seleccionados para garantizar la familiaridad de los usuarios con la aplicación.

El catalogo de componentes esta formado por un total de siete componentes, correspondiendo cuatro de ellos a la categoría de redes sociales y tres a la categoría lectores de fuentes RSS. Se incluye su descripción a continuación en la Tabla 13.

\begin{tabular}{|c|c|c|}
\hline Componente & Descripción & Detalles \\
\hline Google+ & $\begin{array}{l}\text { Componente web que encapsula el } \\
\text { histórico de publicaciones de usuario en } \\
\text { Google+. }\end{array}$ & $\begin{array}{l}\text { Refresco: automático } \\
\text { Periodo de refresco: } 60000 \mathrm{~ms} \text {. } \\
\text { Longitud de datos: } 20 \text { campos }\end{array}$ \\
\hline Twitter & $\begin{array}{l}\text { Componente web que encapsula el } \\
\text { histórico de publicaciones de usuario en } \\
\text { Twitter. }\end{array}$ & $\begin{array}{l}\text { Refresco: automático } \\
\text { Periodo de refresco: } 60000 \mathrm{~ms} \text {. } \\
\text { Longitud de datos: } 20 \text { campos }\end{array}$ \\
\hline Facebook & $\begin{array}{l}\text { Componente web que encapsula el } \\
\text { histórico de publicaciones de usuario en } \\
\text { Facebook. }\end{array}$ & $\begin{array}{l}\text { Refresco: automático } \\
\text { Periodo de refresco: } 60000 \mathrm{~ms} \text {. } \\
\text { Longitud de datos: } 20 \text { campos }\end{array}$ \\
\hline Pinterest & $\begin{array}{l}\text { Componente web que encapsula el } \\
\text { histórico de publicaciones de usuario en } \\
\text { Pinterest. }\end{array}$ & $\begin{array}{l}\text { Refresco: automático } \\
\text { Periodo de refresco: } 60000 \mathrm{~ms} \text {. } \\
\text { Longitud de datos: } 20 \text { campos }\end{array}$ \\
\hline Bolsa & $\begin{array}{l}\text { Componente web que encapsula la } \\
\text { fuente de datos RSS sobre valores y } \\
\text { mercados financieros. }\end{array}$ & $\begin{array}{l}\text { Refresco: automático } \\
\text { Periodo de refresco: } 60000 \mathrm{~ms} \text {. } \\
\text { Longitud de datos: } 20 \text { campos }\end{array}$ \\
\hline Tiempo & $\begin{array}{l}\text { Componente web que encapsula la } \\
\text { fuente de datos RSS sobre el tiempo } \\
\text { previsto en la ubicación del usuario. }\end{array}$ & $\begin{array}{l}\text { Refresco: automático } \\
\text { Periodo de refresco: } 60000 \mathrm{~ms} \text {. } \\
\text { Longitud de datos: } 20 \text { campos }\end{array}$ \\
\hline Tráfico & $\begin{array}{l}\text { Componente web que encapsula la } \\
\text { fuente de datos RSS sobre incidencias } \\
\text { de tráfico en las cercanías del usuario. }\end{array}$ & $\begin{array}{l}\text { Refresco: automático } \\
\text { Periodo de refresco: } 60000 \mathrm{~ms} \text {. } \\
\text { Longitud de datos: } 20 \text { campos }\end{array}$ \\
\hline
\end{tabular}

\subsubsection{Catálogo de Atributos de Calidad (Métricas) Experimentales}

Esta sección contiene la descripción del catálogo de atributos de calidad utilizados en la experimentación cuantitativa. Si bien esta colección está en estrecha conexión con los atributos obtenidos durante la investigación cualitativa (ver Tabla 23), durante la implementación se introducen algunas pequeñas modificaciones orientadas a facilitar la síntesis de dichos atributos y la evaluación mediante la plataforma de experimentación.

El resultado se resume la siguiente Tabla 14

\begin{tabular}{|c|c|c|c|c|c|}
\hline & Características & Métricas & Función & Rango & Interpretación \\
\hline 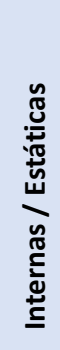 & Tamaño & $\begin{array}{l}\text { Complejidad } \\
\text { Halstead }\end{array}$ & $\begin{array}{l}\text { Longitud: } N=N_{1}+N_{2} \\
\text { Vocabulario: } \mu=\mu_{1+} \mu_{2} \\
\text { Volumen: } V=N \log _{2} \mu \\
\text { categorizados como } \\
\text { - } 1 \text { para } v<21 \\
\text { - } \quad 2 \text { para } 20>v<41 \\
\text { - } \quad 3 \text { para } 40>v<61 \\
\text { - } 4 \text { para } 50>v<81 \\
\text { - } 5 \text { para } 80>v\end{array}$ & [1..5] & $\begin{array}{l}\text { Orden de magnitud del } \\
\text { vocabulario y expresiones } \\
\text { del código. } \\
\text { Valores más pequeños } \\
\text { son mejores. }\end{array}$ \\
\hline
\end{tabular}




\begin{tabular}{|c|c|c|c|c|c|}
\hline & Estructura & $\begin{array}{l}\text { Complejidad } \\
\text { Ciclomática }\end{array}$ & $\begin{array}{l}v(G)=e-n+p+1 \\
\text { categorizados como } \\
\text { - } \quad 1 \text { para } v<11 \\
\text { - } \quad 2 \text { para } 10>v<21 \\
\text { - } \quad 3 \text { para } 20>v<36 \\
\text { - } \quad 4 \text { para } 35>v<51 \\
\text { - } \quad 5 \text { para } v>50\end{array}$ & [1..5] & $\begin{array}{l}\text { Número de caminos } \\
\text { independientes. } \\
\text { Valores más pequeños } \\
\text { son mejores: } \\
1 \text { fácil } \\
2 \text { aceptable } \\
3 \text { riesgo } \\
4 / 5 \text { inaceptable }\end{array}$ \\
\hline & Dependencias & Fan-out & Número de dependencias & [1..100] & $\begin{array}{l}\text { Análisis en profundidad } \\
\text { de todas las dependencias } \\
\text { del componente web. }\end{array}$ \\
\hline \multirow{3}{*}{ 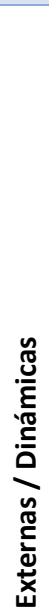 } & $\begin{array}{l}\text { Completitud } \\
\text { (Satisfacción) }\end{array}$ & Completitud & $\begin{array}{l}\text { Ratio de completitud de los } \\
\text { datos del componente web } \\
\text { categorizados como } \\
\text { - } 1 \text { hasta } 20 \% \\
\text { - } 2 \text { hasta } 40 \% \\
\text { - } 3 \text { hasta } 60 \% \\
\text { - } 4 \text { hasta } 80 \% \\
\text { - } 5 \text { hasta } 100 \%\end{array}$ & [1..5] & $\begin{array}{l}\text { Porcentaje del total de } \\
\text { información que se ofrece } \\
\text { al componente web. } \\
\text { Valores altos mejor. }\end{array}$ \\
\hline & $\begin{array}{l}\text { Latencia } \\
\text { (Usabilidad) }\end{array}$ & Latencia & $\begin{array}{l}\text { Tiempo de respuesta del } \\
\text { servidor en milisegundos. }\end{array}$ & $(0 . . \infty)$ & $\begin{array}{l}\text { Tiempo transcurrido } \\
\text { entre la petición y la } \\
\text { respuesta. Valores bajos } \\
\text { mejor. }\end{array}$ \\
\hline & $\begin{array}{l}\text { Consistencia } \\
\text { (Eficacia) }\end{array}$ & Refresco & $\begin{array}{l}\text { Tiempo de refresco en } \\
\text { milisegundos. }\end{array}$ & $(0 . . \infty)$ & $\begin{array}{l}\text { Tiempo de refresco de los } \\
\text { datos del componente } \\
\text { web. Valores bajos mejor. }\end{array}$ \\
\hline
\end{tabular}

\subsubsection{Diseño de la Plataforma de Experimentación}

Establecidos el dominio de experimentación, de aplicación, el catálogo de componentes y métricas experimentales, según se ha descrito en las secciones anteriores, en este apartado se describe el diseño de la plataforma de experimentación.

La plataforma de experimentación cuenta con tres módulos principales, el módulo de diseño de experimentos, el módulo de la aplicación web y el modulo de recogida y análisis de datos. Cada uno de ellos contiene una funcionalidad principal requerida para la experimentación cuantitativa y que se desprende fácilmente del nombre asignado. La estructura modular de la plataforma de experimentación, así como los elementos del diseño del experimento, se recoge en la llustración 4.

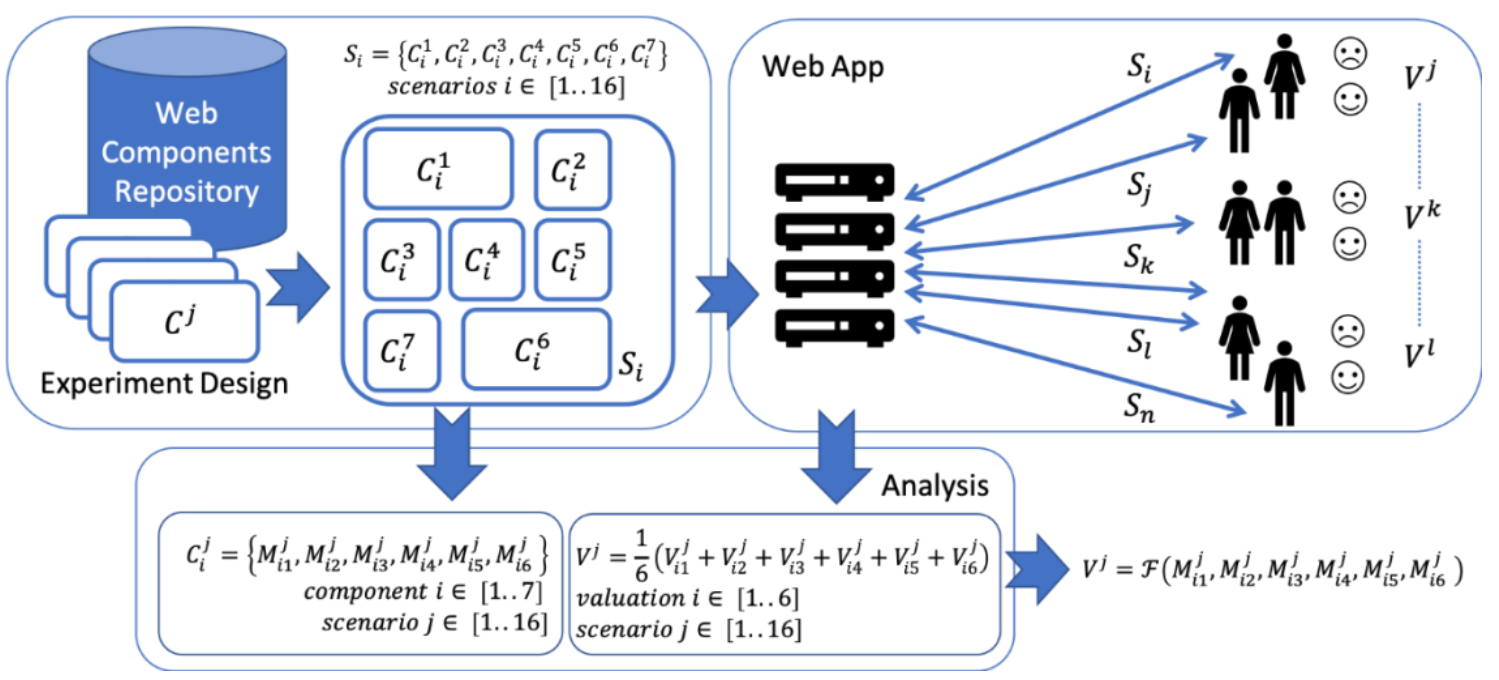

Ilustración 4: Plataforma de Diseño de Experimentación 
Las variables independientes o factores corresponden a el valor de cada uno de los seis atributos (métricas) de calidad $M_{i k}^{j}$ recogidos en el catálogo de métricas (ver sección 4.3.1.3). Estas variables caracterizan a cada uno de los siete componentes $C_{i}$ definidos en el catálogo componentes (ver sección 4.3.1.2), que a su vez se agrupan en dieciséis escenarios $S^{j}$ de experimentación. Expresadas matemáticamente estas relaciones quedan como sigue:

$C_{i}^{j}=\left\{M_{i 1}^{j}, M_{i 2}^{j}, M_{i 3}^{j}, M_{i 4}^{j}, M_{i 5}^{j}, M_{i 6}^{j}\right\} \quad$ escenario $j \in[1 . .16]$ componente $i \in[1 . .7]$,

$S_{i}=\left\{C_{i}^{1}, C_{i}^{2}, C_{i}^{3}, C_{i}^{4}, C_{i}^{5}, C_{i}^{6}, C_{i}^{7}\right\} \quad i \in[1.16]$

La variable dependiente del experimento corresponde con la valoración que hacen las unidades de experimentación, es decir, los participantes, de los componentes incluidos en el escenario de evaluación. Para cada uno de los componentes los usuarios valorarán haciendo uso de una escala ordinal de cinco niveles, correspondiendo 1 a la menor valoración y 5 a la mayor. El resumen se recoge en la Tabla 15:

\begin{tabular}{|c|l|r|}
\hline Variable & Descripción & \multicolumn{1}{|l|}{ Rango } \\
\hline$V_{i 1}^{j}$ & Valoración global & {$[1 . .5]$} \\
\hline$V_{i 2}^{j}$ & Recomendación probable & {$[1 . .5]$} \\
\hline$V_{i 3}^{j}$ & Uso probable & {$[1 . .5]$} \\
\hline$V_{i 4}^{j}$ & Dificultad (Usabilidad) & {$[1 . .5]$} \\
\hline$V_{i 5}^{j}$ & Atractivo (Usabilidad) & {$[1 . .5]$} \\
\hline$V_{i 6}^{j}$ & Legibilidad (Usabilidad) & {$[1 . .5]$} \\
\hline
\end{tabular}

Tabla 15: Variables y Rangos de Evaluación Experimental de Componentes Web

Siguiendo esta nomenclatura, el valor de la variable dependiente, o respuesta, quedaría expresado como sigue:

$V^{j}=\frac{1}{6}\left(V_{i 1}^{j}+V_{i 2}^{j}+V_{i 3}^{j}+V_{i 4}^{j}+V_{i 5}^{j}+V_{i 6}^{j}\right)$ escenario $j \in$ [1..16], componente $i \in[1 . .7]$

El objeto exploratorio y descriptivo del estudio se traduce en la recogida de resultados de la variables dependientes e independientes, permitiendo validar funcional y experimentalmente la plataforma. El objeto correlacional se traduce en el análisis estadístico de la relación que pueda existir entre factores y respuesta de la calidad de los componentes web.

Expresado analíticamente quedaría como sigue:

$V^{j}=\mathcal{F}\left(M_{i 1}^{j}, M_{i 2}^{j}, M_{i 3}^{j}, M_{i 4}^{j}, M_{i 5}^{j}, M_{i 6}^{j}\right)$ escenario $j \in[1 . .16]$, componente $i \in$ [1..7]

Una vez descrito el estudio que persigue la Plataforma de Diseño Experimental a continuación, se recogen algunos detalles particulares de los módulos.

\subsubsection{Módulo de Diseño de Experimentación}

Las principales funciones del módulo de Diseño de Experimentación son la síntesis de los atributos del modelo de calidad de componentes web y la configuración de escenarios que garanticen la evaluación aleatorizada de los componentes.

Tal y como se recogen en la Tabla 14, los atributos contemplados como variables independientes en la experimentación cuantitativa son la complejidad de Halstead, la complejidad Ciclomática y la medida de dependencias (fan-out), métricas internas de evaluación estáticas y la completitud, latencia y consistencia, métricas externas de evaluación dinámica.

Actualmente no existen valores de referencia para estos atributos en cuanto a componentes web se refiere. De hecho, esta es una de las líneas de investigación que se recogen en la sección 
7. Por lo tanto, siguiendo una aproximación exploratoria la síntesis de los atributos se realiza de manera que permite evaluar rangos y determinar la contribución en conjunto e individual de cada métrica.

Para cada uno de los atributos, se recogen los valores utilizados en cada uno de los atributos, incluyendo una tabla con las estadísticas descriptivas, así como una gráfica de representación. En primer lugar, se presenta el atributo correspondiente a la medida del tamaño del componente, calculado con la métrica de Halstead.

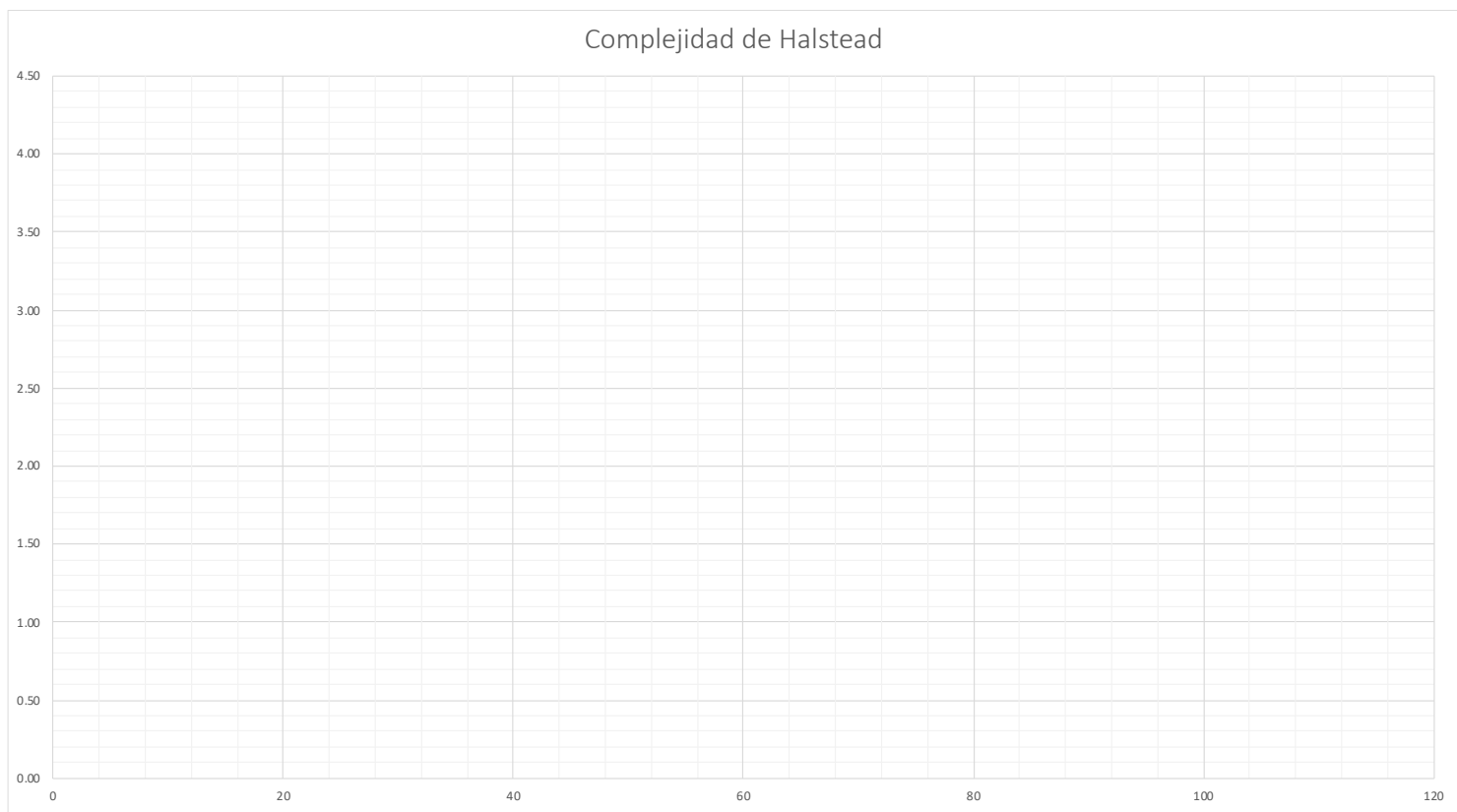

Ilustración 5: Gráfica de la Síntesis del Atributo de la Complejidad de Halstead

A continuación, la tabla de estadísticas descriptivas de la métrica de Halstead:

\begin{tabular}{|l|l|l|l|}
\hline Estadística & Valor & Estadística & Valor \\
\hline Número de valores & 112 & Mínimo & 2,350 \\
\hline Media & 3,402 & Máximo & 3,900 \\
\hline Varianza & 0,124 & Frecuencia Mínima & 2 \\
\hline Desviación Estándar & 0,354 & Frecuencia Máxima & 14 \\
\hline Mediana & 3,520 & Rango & 1,370 \\
\hline \multicolumn{2}{r}{ Tabla 16: Estadísticas Descriptivas del Atributo de la Síntesis de la Complejidad de Halstead }
\end{tabular}

Tras estos valores se recogen la gráfica y estadísticas descriptivas a la complejidad Ciclomática 


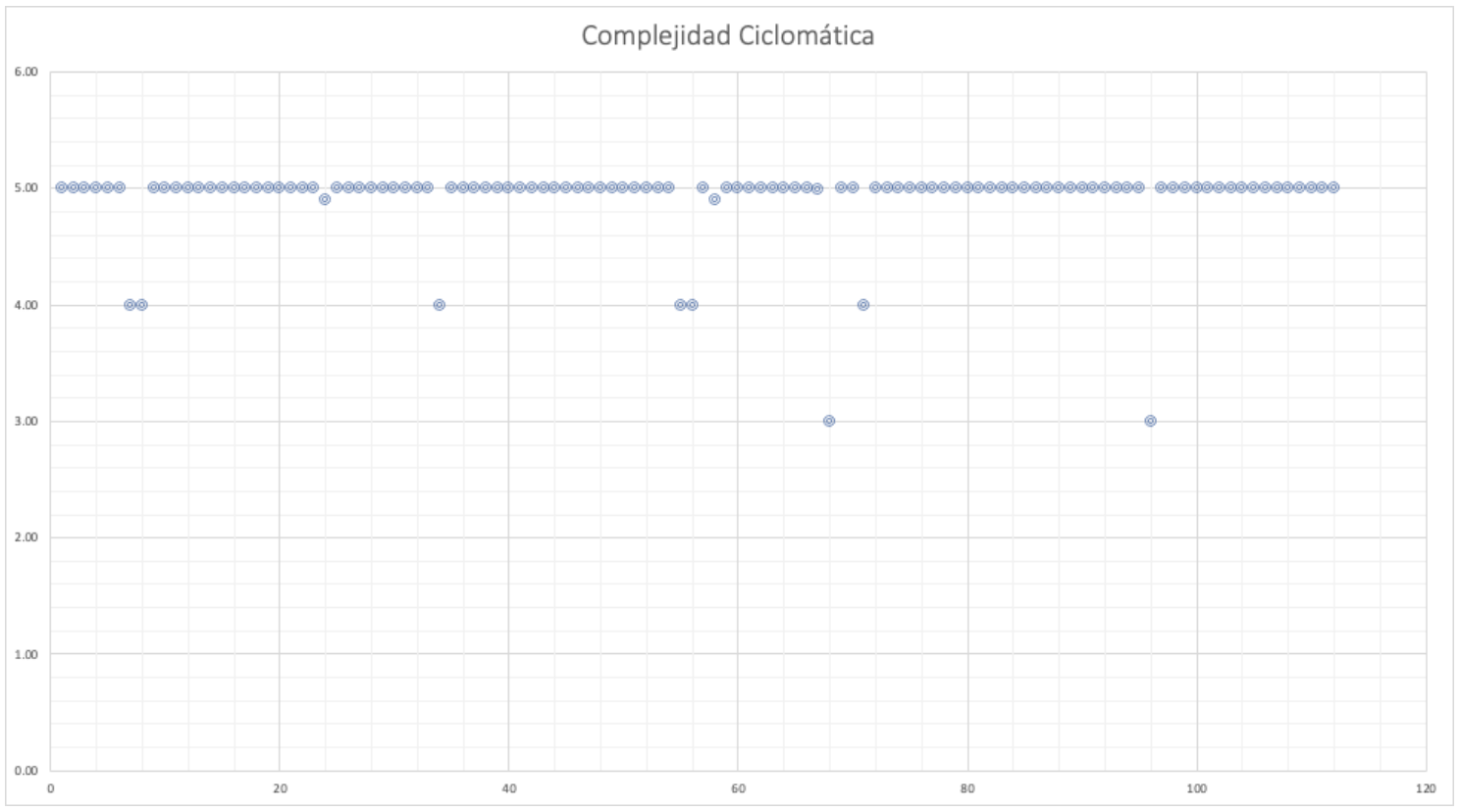

Ilustración 6: Gráfica de la Síntesis del Atributo de la Complejidad Ciclomática

\begin{tabular}{|l|l|l|l|}
\hline Estadística & Valor & Estadística & Valor \\
\hline Número de valores & 112 & Mínimo & 3,00 \\
\hline Media & 4,909 & Máximo & 5,00 \\
\hline Varianza & 0,118 & Frecuencia Mínima & 2 \\
\hline Desviación Estándar & 0,343 & Frecuencia Máxima & 101 \\
\hline Mediana & 5,0 & Rango & 2,00 \\
\hline
\end{tabular}

Tabla 17: Estadísticas Descriptivas del Atributo de la Síntesis de la Complejidad Ciclomática

Por último, se incluyen la representación gráfica y estadísticas descriptivas correspondientes al último de los atributos internos de evaluación estática, la medida de dependencias (fan-out).

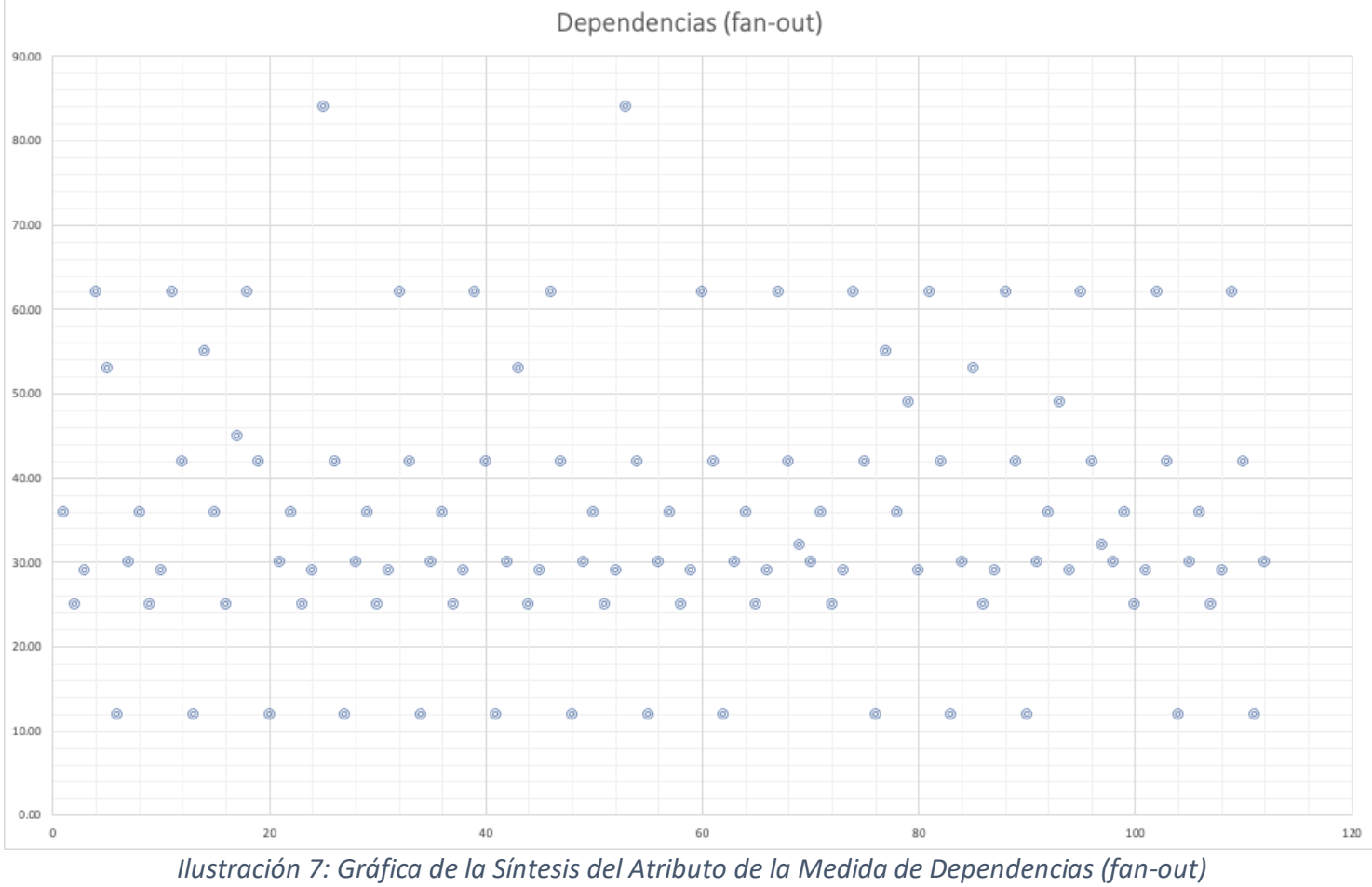




\begin{tabular}{|l|l|l|l|}
\hline Estadística & Valor & Estadística & Valor \\
\hline Número de valores & 112 & Mínimo & 12,00 \\
\hline Media & 35,884 & Máximo & 84,00 \\
\hline Varianza & 294,076 & Frecuencia Mínima & 14 \\
\hline Desviación Estándar & 15,782 & Frecuencia Máxima & 2 \\
\hline Mediana & 30,0 & Rango & 72,00 \\
\hline
\end{tabular}

Tabla 18: Estadísticas Descriptivas de la Síntesis del Atributo de la Medida de Dependencias (fan-out)

Seguidamente se presentan los detalles de la síntesis de los atributos externos de evaluación dinámica, comenzando con la completitud.

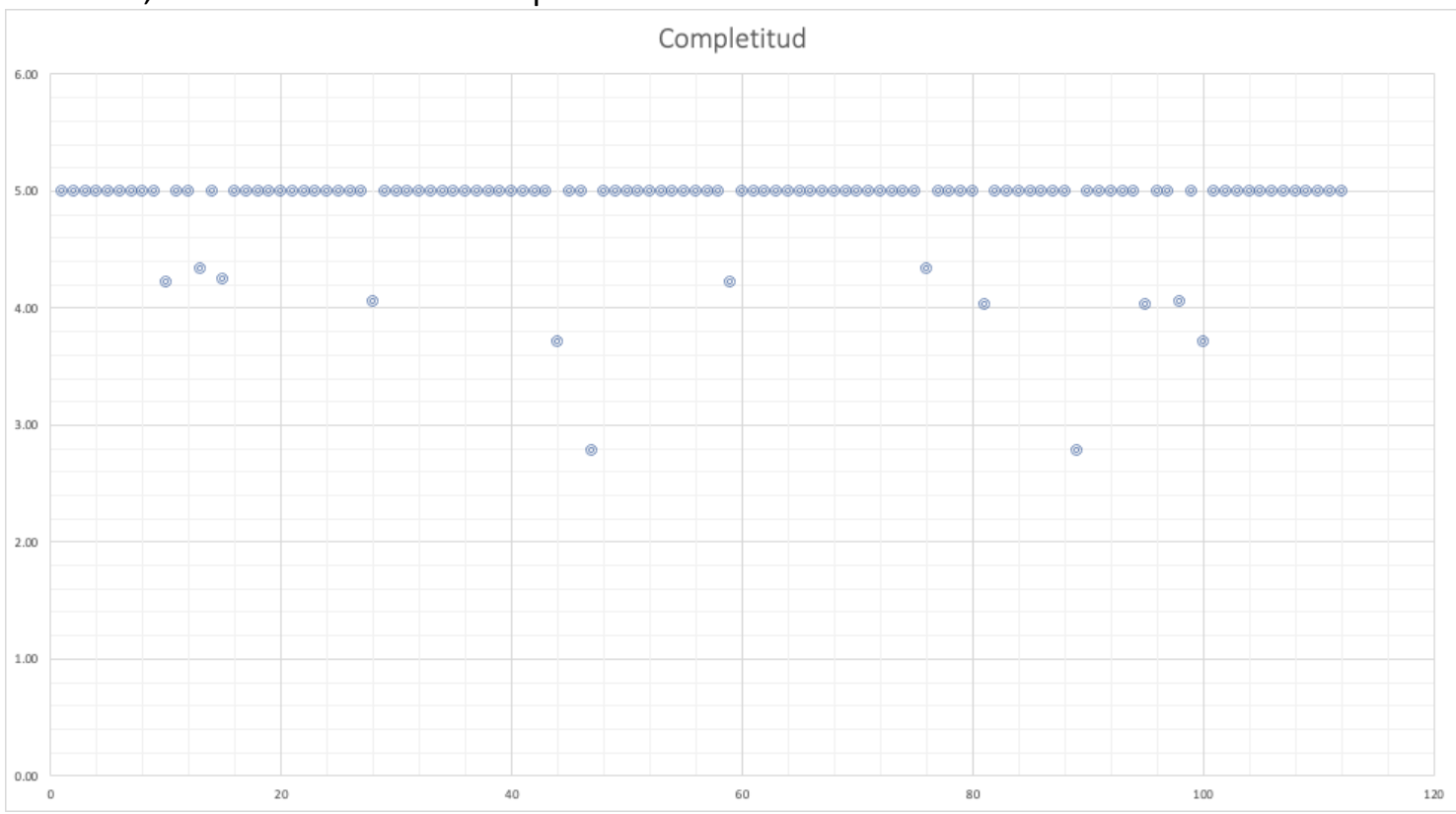

Ilustración 8: Gráfica de la Síntesis del Atributo de Completitud

\begin{tabular}{|l|l|l|l|}
\hline Estadística & Valor & Estadística & Valor \\
\hline Número de valores & 112 & Mínimo & 12,00 \\
\hline Media & 35,884 & Máximo & 84,00 \\
\hline Varianza & 294,076 & Frecuencia Mínima & 14 \\
\hline Desviación Estándar & 15,782 & Frecuencia Máxima & 2 \\
\hline Mediana & 30,0 & Rango & 72,00 \\
\hline
\end{tabular}

Tabla 19: Estadísticas Descriptivas de la Síntesis del Atributo de la Completitud

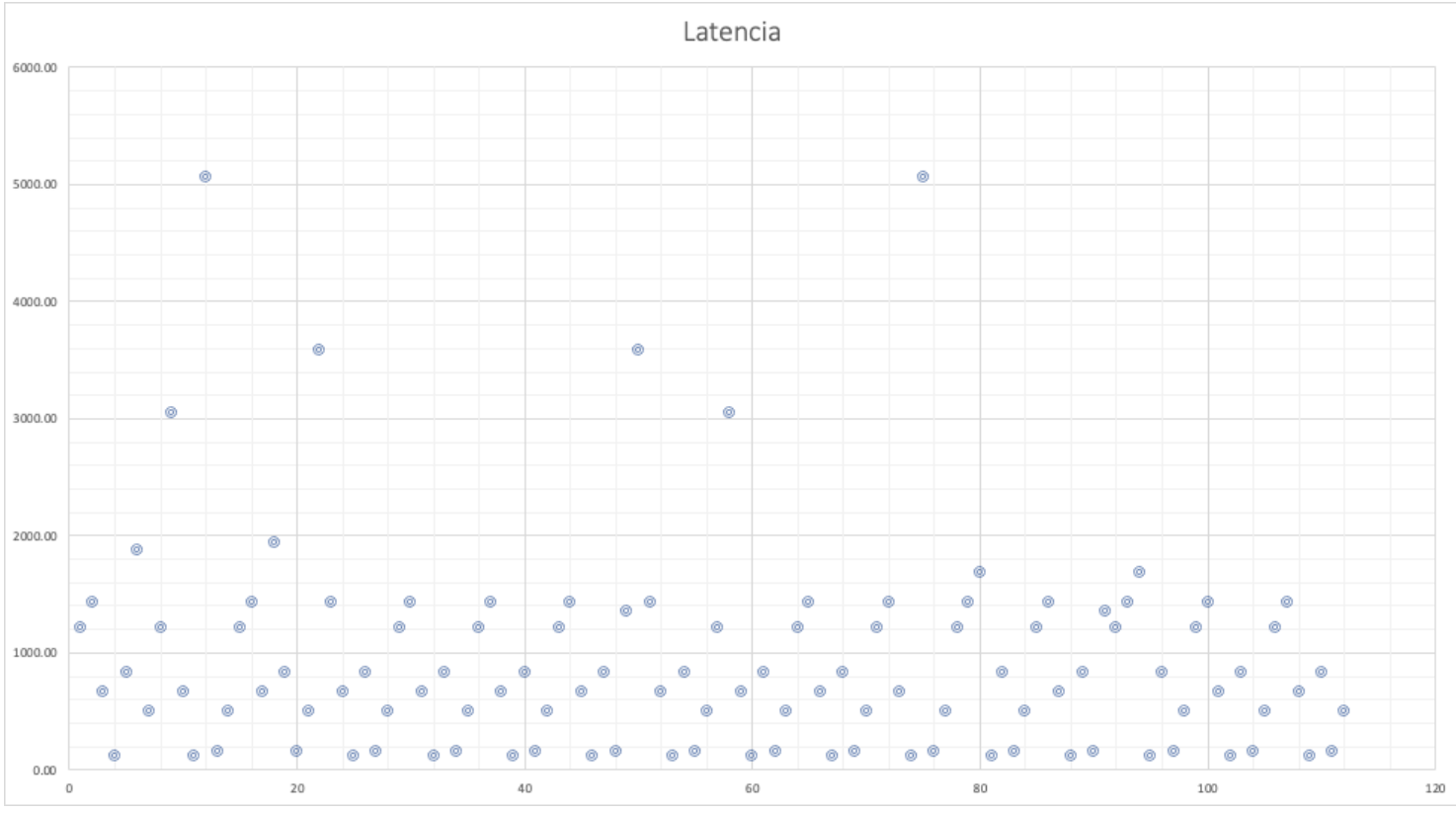


Ilustración 9: Gráfica de la Síntesis del Atributo de Latencia

\begin{tabular}{|l|l|l|l|}
\hline Estadística & Valor & Estadística & Valor \\
\hline Número de valores & 112 & Mínimo & 117,190 \\
\hline Media & 913,570 & Máximo & 5059,940 \\
\hline Varianza & 791985,30 & Frecuencia Mínima & 15 \\
\hline Desviación Estándar & 889,93 & Frecuencia Máxima & 2 \\
\hline Mediana & 665,950 & Rango & 4942,750 \\
\hline
\end{tabular}

Tabla 20: Estadísticas Descriptivas de la Síntesis del Atributo de Latencia

Por último, los detalles relativos a la síntesis del atributo de consistencia.

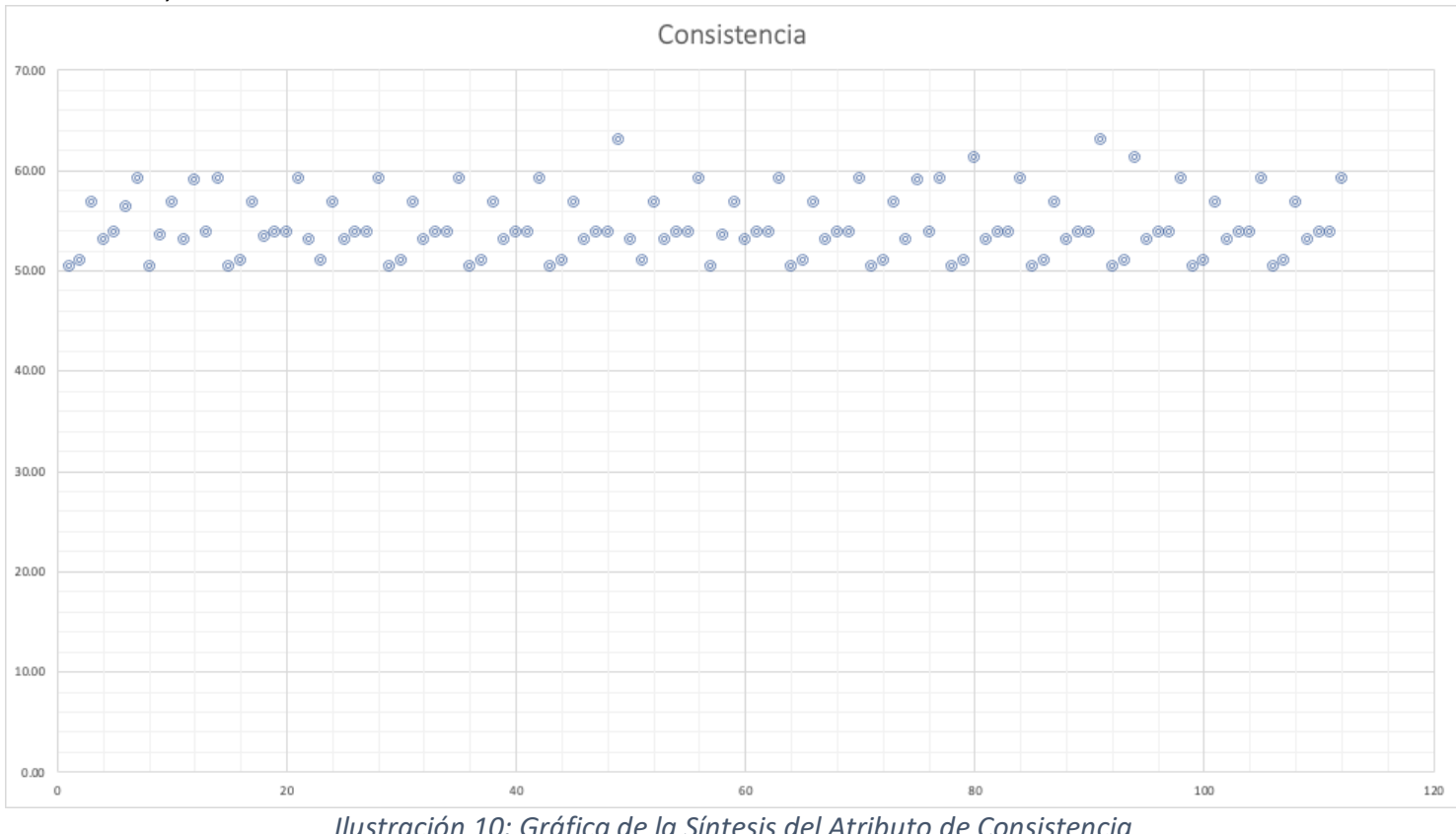

Ilustración 10: Gráfica de la Síntesis del Atributo de Consistencia

\begin{tabular}{|l|l|l|l|}
\hline Estadística & Valor & Estadística & Valor \\
\hline Número de valores & 112 & Mínimo & 50,410 \\
\hline Media & 54,412 & Máximo & 63,130 \\
\hline Varianza & 10,117 & Frecuencia Mínima & 14 \\
\hline Desviación Estándar & 3,181 & Frecuencia Máxima & 2 \\
\hline Mediana & 53,820 & Rango & 12,720 \\
\hline
\end{tabular}

Tabla 21: Estadísticas Descriptivas de la Síntesis del Atributo de Consistencia

\subsection{Diseño de la Fase Cuantitativa: Experimentación y Análisis.}

La Plataforma de Diseño de Experimentación posibilita la realización de experimentos que permiten el estudio de cómo los atributos del modelo empírico de calidad de componentes web influyen en la valoración por parte del usuario final.

En la preparación de la muestra, los participantes que harán de usuarios finales se seleccionan siguiendo una aproximación de muestreo de grupo: un grupo de dieciséis voluntarios seleccionados entre los estudiantes de ingeniería informática participarán en los experimentos que asignarán de manera aleatoria los escenarios de siete componentes caracterizados con seis atributos, resultando en una muestra total de ciento doce resultados.

La muestra corresponde a solo algunos de los agentes que intervienen en el modelo de calidad y a un número reducido de ellos ya que, por un lado, la fragmentación de procesos y relación entre agentes dificulta en primera instancia la extensión del análisis a desarrolladores e integradores, y por otro, la aproximación exploratoria secuencial no aconseja una experimentación masiva, hasta haber validado los instrumentos cuantitativos. La extensión a un 
mayor número de agentes del modelo de calidad y la experimentación masiva quedan por tanto para trabajos futuros.

Los participantes se categorizan de acuerdo con el cuestionario recogido en la Tabla 22 y que cada colaborador realiza al comienzo de cada experimento. El objeto no es tanto identificar categorías en la muestra, que como se ha mencionado pertenece a un grupo seleccionado, como el establecimiento de un perfil que permita la comparación entre muestra futuras.

\begin{tabular}{|c|c|}
\hline Pregunta & Descripción \\
\hline Edad & Edad del participante en años. \\
\hline Género & Género del participante. Opciones: Masculino / Femenino. \\
\hline Ocupado & Esta el participante trabajando. Opciones: Si / No \\
\hline Grado Académico & $\begin{array}{l}\text { Grado académico del participante. Opciones: Secundaria / } \\
\text { Grado / Máster / Doctorado }\end{array}$ \\
\hline Conocimiento de tecnologías & $\begin{array}{l}\text { Nivel de conocimiento de las tecnologías: } \\
\text { - HTML } \\
\text { - } \text { CSS } \\
\text { - } \text { JavaScript } \\
\text { - Appon } \\
\text { - Polymer } \\
\text { - Material Design } \\
\text { Opciones: Nada, Algo, Bastante }\end{array}$ \\
\hline Conocimiento de la norma ISO & Conocimiento de las normas ISO. Opciones: Si / No. \\
\hline Normas ISO conocidas & $\begin{array}{ll}\text { Descripción de las normas ISO conocidas por el participante: } \\
\text { - } & \text { Ninguna } \\
\text { - } & 27000 \\
\text { - } & 27001 \\
\text { - } & 9000 \\
\text { - } & 27000 \text { \& } 9000\end{array}$ \\
\hline
\end{tabular}

Tabla 22: Cuestionario de Categorización de la Muestra Cuantitativa

Siguiendo la aproximación exploratoria secuencial de nuestro diseño de investigación, las características del análisis cuantitativo son exploratorias, como corresponde con la novedad de nuestro estudio y la ausencia de resultados previos y persiguiendo tendencias, áreas o contextos de estudio, relaciones potenciales entre variables y la propia validación de la Plataforma de Diseño de Experimentación.

Adicionalmente, dentro del enfoque cuantitativo, se plantea también un análisis descriptivocorrelacional que, si bien puede resultar prematuro para alcanzar un incremento de la precisión de las relaciones descubiertas, sentarán las bases iniciales de estudios explicativos futuros.

Siguiendo el diseño de variables independientes y factores recogido en el apartado 4.3.2, los datos experimentales se organizan en tres niveles de detalle:

- A nivel de escenario, es decir, de contexto de evaluación en el que el usuario participante en la prueba evalúa individualmente los componentes, organizados en una composición o mashup. Si bien el presente estudio excluye la evaluación de calidad compuesta de contribuciones de componentes organizados en un mashup, objetivo de futuras líneas de investigación, este nivel de análisis permite probar la experimentación y recogida de datos dentro de un escenario de uso.

- A nivel de componente, es decir, las evaluaciones que de manera individual reciben cada uno de los componentes a lo largo de los dieciséis escenarios de evaluación. Es en este nivel de detalles donde se realizarán una primera exploración correlacional para determinar la existencia de modelos de regresión lineal que representen una relación entre los atributos de calidad y la valoración por parte de usuario final. 
- A nivel de estudio, aglutinados los datos en una única muestra, para investigar la evidencia que pudiese conectar los atributos de calidad con la valoración de usuario. El análisis a este nivel esta condicionado por la posibilidad de poder agregar los datos. $\mathrm{Si}$ las condiciones se satisfacen, se realizará un análisis de regresión en búsqueda de modelos que relacionen atributos con valoración.

Tanto a nivel de escenario, de componente, como de estudio, las valoraciones obtenidas se exploran en primer lugar realizando un análisis descriptivo que recoge valores máximos, mínimo, así como valores medios y desviación estándar.

Con objeto de identificar, si las hubiese, diferencias significativas a nivel de escenario o componente, se realizan las pruebas estadísticas que son requisito para un análisis de la varianza o ANOVA. Es decir, se realizan contrastes de hipótesis de normalidad, prueba Shapiro-Wilk con nivel de significación $\alpha=0.05$, e igualdad de la varianza, prueba Levene con un nivel de significación $\alpha=0.05$. Adicionalmente, con el fin de hacer más fácilmente entendible los datos se representarán las gráficas cuartil a cuartil o gráficos $Q-Q$.

A nivel de componente es interesante conocer la existencia de relaciones entre los atributos de cada componente, es decir, sus atributos de calidad y la valoración obtenida. Para aportar luz en este sentido se llevarán a cabo análisis de regresión lineal. Intencionadamente se excluyen modelos más complejos que, si bien pudiesen proporcionar una mayor efectividad analítica, resultan prematuros en un enfoque cuantitativo exploratorio descriptivo-correlacional.

Por último, tras realizar las pruebas pertinentes que garantizan el nivel de aleatoriedad de la muestra agregada, se realizará el análisis de regresión del conjunto resultante de combinar en una sola muestra los datos de evaluación de todos los componentes para todos los escenarios. 


\section{Discusión de los Resultados}

Que tu inteligencia siga atentamente todo lo que se dice y que penetre los hechos y

sus causas.

Marco Aurelio

Este capítulo incluye el producto de la labor de investigación diseñada en la solución propuesta, así como la discusión de los principales resultados del trabajo de investigación. La presentación persigue una secuencia lineal del trabajo realizado.

De esta forma, se comienza presentando las fases cualitativas, de entrevistas abiertas y método Delphi. La discusión del resultado de estas fases justifica la propuesta de un modelo de calidad de componentes web, que se presentará tras ellas.

Por último, se recoge el resultado de la validación cuantitativa obtenida con la puesta en práctica de la plataforma de evaluación empírica de calidad.

\subsection{Exploración Cualitativa de la Calidad de Componentes Web.}

\subsubsection{Caracterización del panel de expertos}

Los expertos seleccionados para el panel cuentan con significativo nivel de experiencia en desarrollo web: los menos experimentados (15\%) entre tres y cinco años de experiencia y un $65 \%$ de ellos tienen más de siete años de experiencia. Para poner en contexto el grado de experiencia, los componentes web comenzaron su estandarización en 2014 y contaban con implementaciones de referencia como Polymer [49] desde 2015.

En cuanto a su experiencia como desarrolladores de componentes web, un total de $89,5 \%$ desarrolla componentes web y un $26,3 \%$ trabaja específicamente desarrollando librerías de componentes.

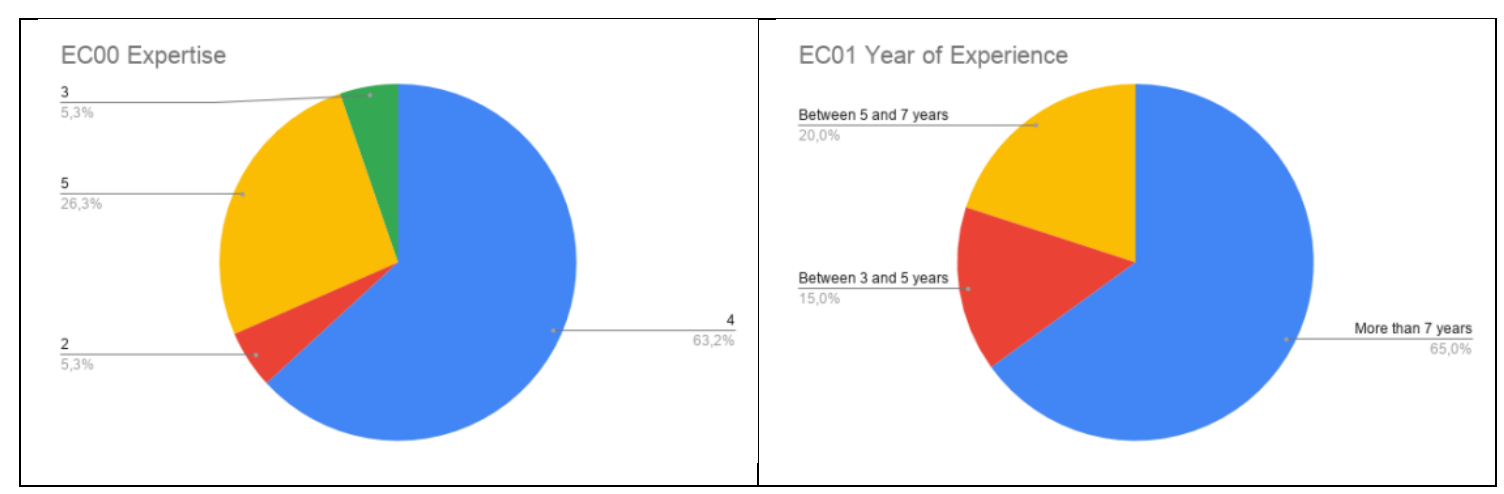

Ilustración 11: Experiencia del grupo de Expertos.

En relación con el conocimiento teórico de la calidad software, métricas y estándares, el $55 \%$ de los expertos cuentan con formación académica en ciencias de la computación y el $45 \%$ otro tipo 
de formación, incluyendo estos últimos un $10 \%$ de los expertos con máster en ingeniería. Significativamente un $10 \%$ de los expertos cuentan con PhD. No obstante, el desconocimiento de los estándares de calidad software es significativo: el 75\% de los expertos desconocen la norma ISO / IEC 25000. Estos porcentajes avalarían la hipótesis asumida al comienzo de esta investigación y una de sus principales motivaciones: los desarrolladores web, por expertos que puedan ser, no cuentan con conocimientos de los estándares de calidad software.

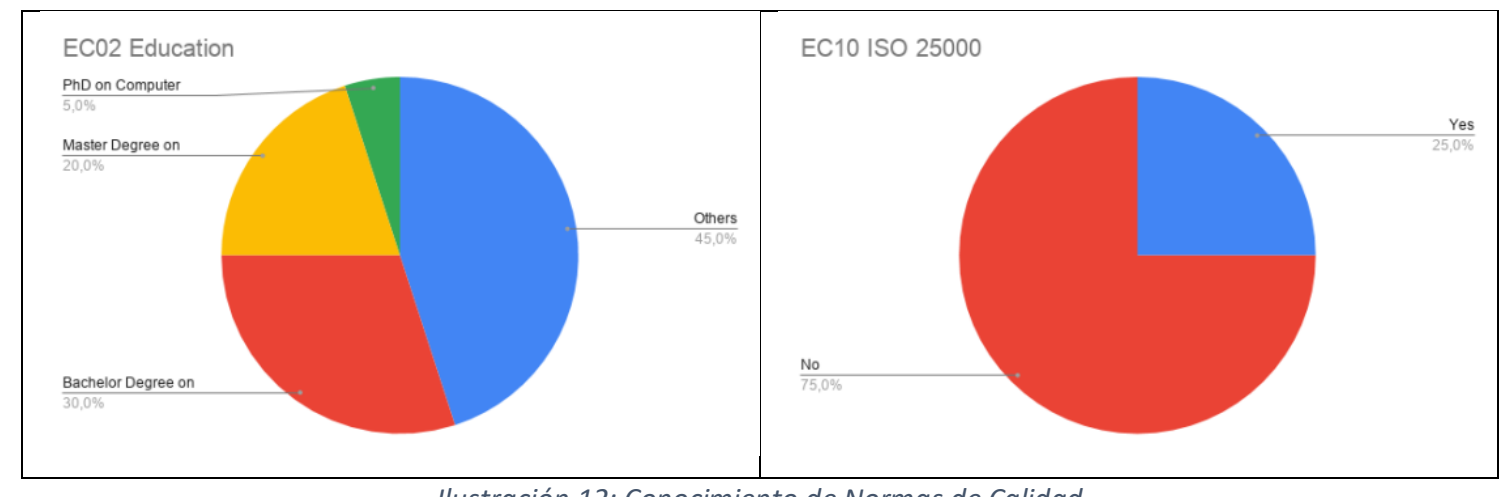

Ilustración 12: Conocimiento de Normas de Calidad

A la hora de categorizar la influencia del sector profesional en la opinión de los expertos, esta se contrapone con la participación en proyectos de en ecosistemas abiertos, de manera que puede evaluarse el conocimiento del desarrollo en este tipo de contextos. En este caso, los resultados muestran que los expertos trabajan en compañías que ofrecen servicios IT o desarrollan producto software en un porcentaje del $95 \%$; su participación en proyectos en ecosistemas abiertos alcanza un total del $80 \%$, lo que avala el elevado grado de experiencia en desarrollo de componentes web y en ecosistemas abiertos.

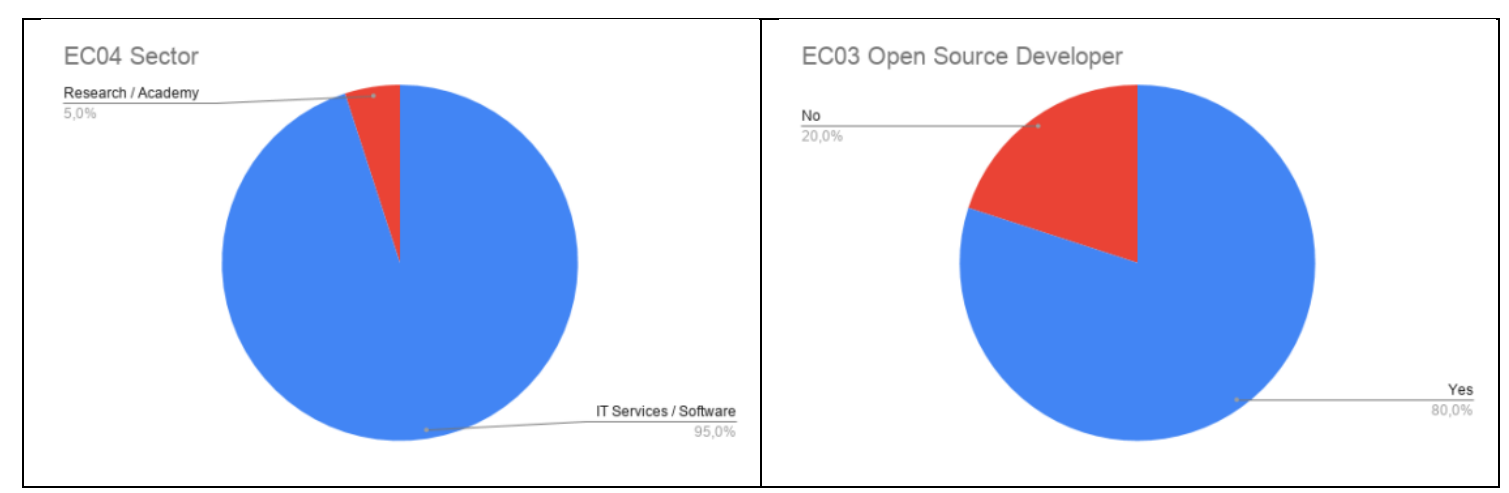

Ilustración 13: Participación en Proyectos de Open Source

En relación con la experiencia práctica en calidad, si bien solo el $50 \%$ de los expertos cuentan en sus equipos de desarrollo con roles o equipos de calidad software, el $85 \%$ de los expertos participa en proyectos que incluyen pruebas de calidad (análisis estático) y el $70 \%$ participa en proyectos que incluyen pruebas con usuarios, es decir, análisis dinámico de calidad en uso.

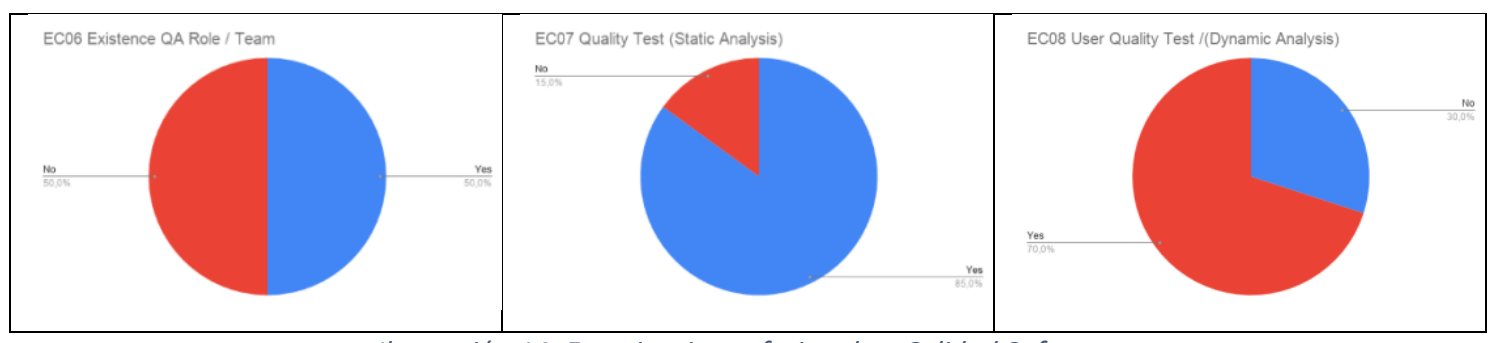

Ilustración 14: Experiencia profesional en Calidad Software

En relación con las tecnologías, teniendo en cuenta que el cuestionario solo permitía elegir una de las opciones, Lit Element es la tecnología más utilizada por los expertos, con un $45 \%$, seguida de Angular Components con un $25 \%$ y Hybrid con un $15 \%$. El resto de los expertos trabajan con 
una variedad diversa de tecnologías. En conexión con la tecnología utilizada, se ha incluido una pregunta sobre el uso de linters, herramientas de análisis estático habitualmente integradas con los editores y/o las pruebas unitarias. Y así: El 95\% de los expertos, utiliza linters como herramienta de análisis estático. Esto proporciona indicios sobre cuales podrían ser los mecanismos para introducir análisis de calidad más sofisticados en entornos de desarrollo correspondientes a ecosistemas abiertos.

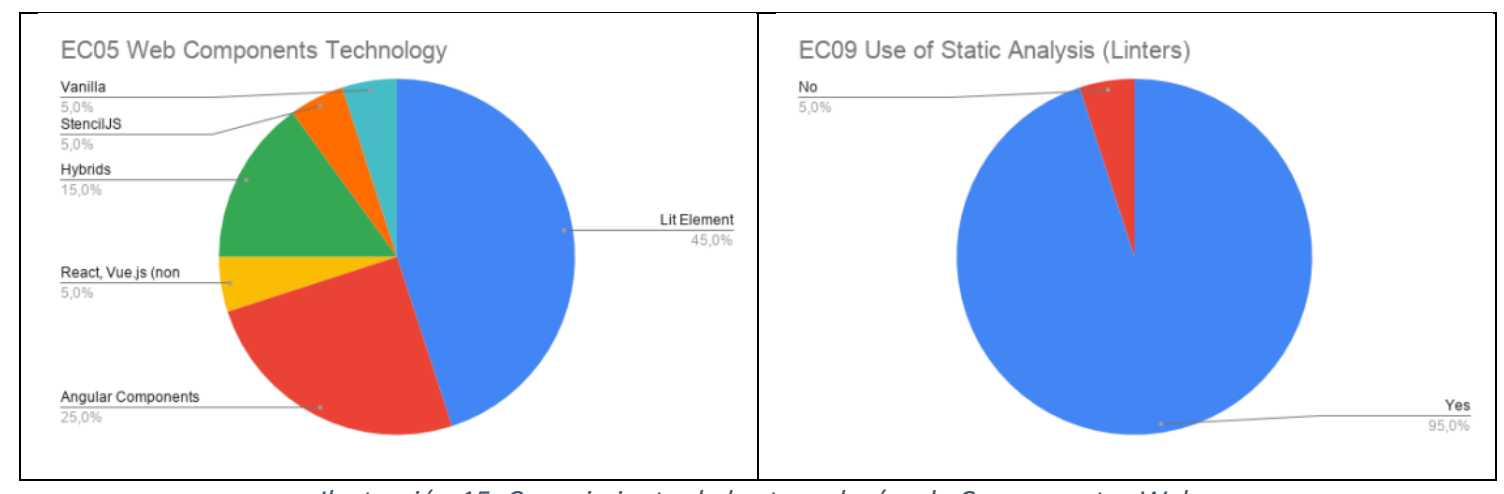

Ilustración 15: Conocimiento de las tecnologías de Componentes Web

Por último, hay que mencionar que los expertos pertenecen a un total de 8 nacionalidades distintas, de países de Latinoamérica, Europa y Estados Unidos y trabajan en compañías de ámbito internacional en dichos mercados.

\subsubsection{Conceptualización Experimental del Modelo de Calidad de Componentes Web}

El análisis de las entrevistas abiertas realizadas al primer grupo de expertos conduce a un modelo de calidad empírico que especificamos concretando su ámbito, los agentes que intervienen en su evaluación y medida, así como las características de calidad, categorizadas en intrínsecas/extrínsecas y en estáticas/dinámicas.

A partir de la transcripción de las entrevistas con los expertos, el equipo de investigación elabora un mapa de conocimiento que permite asignar relevancia a los términos utilizados, conectándolos en forma de grafo. El análisis de estos datos se realiza de manera manual, extrayendo los elementos destacados. El uso de técnicas de modelado de materias se descarta por lo reducido del conjunto de datos.

Los resultados pueden observarse en la llustración 16 y servirán como fundamento para la elaboración de una propuesta de modelo empírico, así como para la recomendación de métricas de las características no funcionales del modelo. Si bien este primer resultado es fruto de la experiencia y decisión del equipo de investigación, habrá de ser validado en la siguiente etapa por el panel de expertos. 


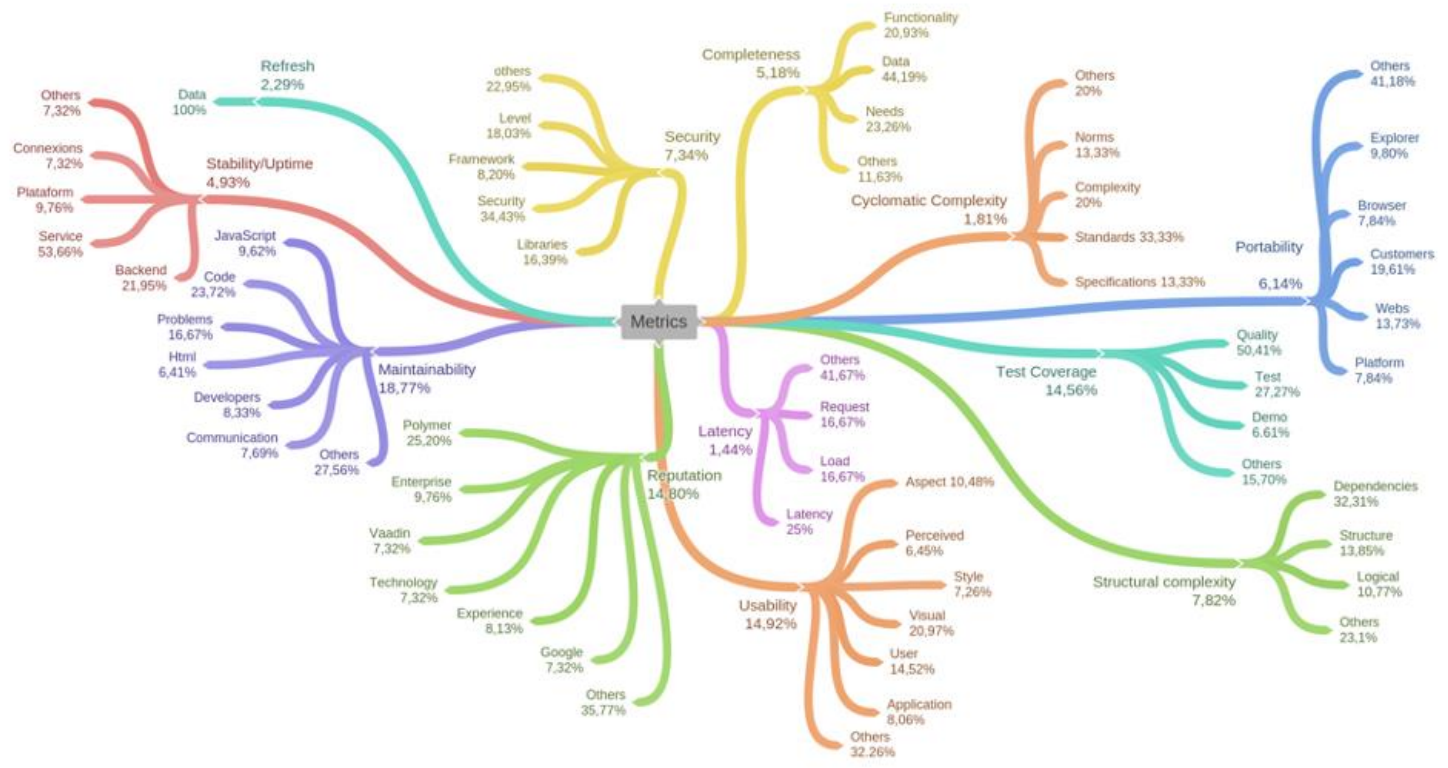

Ilustración 16: Mapa de conocimiento de Calidad de Componentes Web

El análisis de los términos utilizados por los expertos nos permite asignar una importancia subjetiva a cada uno de los conceptos, destacando especialmente los siguientes resultados:

- El concepto comúnmente asociado con la calidad se compone de variedad de atributos, de carácter intrínseco, extrínseco, organizacional e incluso de proceso.

- Atributos extrínsecos como la mantenibilidad (18,77\%), la usabilidad (14,92\%), seguridad $(7,34 \%)$ o la portabilidad $(6,14 \%)$ cuentan con una importancia agregada cercana al $50 \%$.

- El atributo organizacional como la reputación viene respaldado por $14,8 \%$.

- Los atributos intrínsecos más importantes son la complejidad estructural $(7,82 \%)$, relativa principalmente a las dependencias del componente, y la cobertura de pruebas $(14,56 \%)$, atributo este último que también podría caracterizar la calidad de proceso.

Estos resultados confirman como los procesos de desarrollo y distribución de componentes en repositorios abiertos condicionan la conceptualización de la calidad de los componentes web, así como los atributos que se utilizan para caracterizarla. Es necesario tener en cuenta estos resultados para la definición de un modelo adecuado y la validación de este.

En relación con el ámbito del modelo de calidad, los resultados de esta primera fase muestran que las características identificadas resultan relevantes para la evaluación y medida de la calidad de componentes web; si bien este resultado no sorprende en absoluto, si lo es el que estas mismas características pudiesen resultar también relevantes para evaluar la calidad de proceso y organizacional, que aunque no se considerarán en esta investigación pueden sentar las bases para investigaciones futuras. De igual forma, nuestra investigación excluye la evaluación y medida de sistemas que resulten de la agregación de componentes web (mashups), poniendo el foco exclusivamente en la calidad independiente de cada componente.

Siguiendo una aproximación similar, el modelo de calidad empírico determina tres categorías de agentes distintas: usuario final, integrador y desarrollador de componentes web. La primera categoría, la de usuario final, se corresponde al usuario último de la aplicación web y en ultima instancia el evaluador decisivo de la calidad de los componentes. No obstante, su evaluación corresponde a características extrínsecas y dinámicas, pues no cuenta con acceso al código.

El integrador es un usuario/desarrollador que integra, normalmente sin modificar, el componente web en su aplicación. En función del nivel de experiencia, puede considerarse un 
escenario de desarrollo por usuario final, o "end-user development", o simplemente un desarrollador que hace uso de los componentes en forma similar a la que utilizaría una librería. En este último caso, cuando el usuario integrador cuenta con conocimientos técnicos de desarrollo, está en condiciones de evaluar la calidad de una manera más amplia, observando el resultado final en forma de aplicación, es decir características extrínsecas y dinámicas, así como pudiendo revisar aspectos intrínsecos y estáticos de los componentes importados, ya que cuenta con acceso a las fuentes del código.

Finalmente, el desarrollador de componentes corresponde con aquel agente especializado en el desarrollo de componentes, agrupados habitualmente en colecciones o librerías y que, bajo el paradigma de desarrollo en repositorios de código abierto, persigue unas características de calidad que fomenten el uso de dichos componentes/librerías. Esta circunstancia le permite actuar de manera significativa en las características intrínsecas/estáticas, y debido a la potencial enorme cantidad de proyectos finales, solo parcialmente en las características extrínsecas/dinámicas.

Es necesario mencionar que el modelo de calidad empírico identifica una agente adicional: la comunidad u organización que lidera el ecosistema creado alrededor del componente. Aunque no será objeto de investigación en este estudio, es sin duda, un agente que será foco de estudio en líneas futuras de investigación.

En términos generales, la total desconexión entre los distintos agentes puede limitar la evaluación de ciertas características por parte de ciertos agentes: existe una elevada posibilidad de que el usuario final interactúe de alguna forma con el integrador, que a su vez puede interactuar con el desarrollador de componentes. La interacción entre el usuario final y el desarrollador de componentes será en términos generales nula.

El estándar de calidad recoge únicamente las características no funcionales, que en la mayoría de los casos no resultan medibles directamente. De hecho, según se observa en la Tabla 2 y la Tabla 3, las definiciones persiguen la generalidad más que la aplicación a un dominio concreto.

Esto exige completar el estándar con un conjunto de propiedades medibles o métricas de calidad software que, proporcionando la máxima cobertura posible, permita la medición directa. Dentro de la familia de estándares de calidad software, la serie ISO/IEC 2502n corresponde a la división de medidas de calidad. En particular los estándares ISO/IEC 25022 y ISO/IEC 25023 corresponden a la medida de calidad en uso y de producto. La aplicabilidad de estos estándares dista de ser directa y se han propuesto distintas ideas de mejora de estos [106].

Además, la elección de una golden metric carece de sentido para un significativo número de expertos [107], lo que refuerza aproximación empírica, hasta el punto de que a nivel industrial se ha realizado un esfuerzo importante en la recopilación de proyectos que guíen la elección del mejor conjunto de métricas, mediante un proceso de comparación con proyectos similares [108]. 


\begin{tabular}{|c|c|c|c|c|c|}
\hline & Características & Atributos & Función & Rango & Interpretación \\
\hline \multirow{3}{*}{ 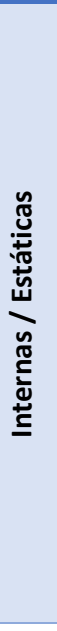 } & Tamaño & $\begin{array}{l}\text { Métrica de } \\
\text { Halstead }\end{array}$ & $\begin{array}{l}\text { Longitud: } N=N_{1}+N_{2} \\
\text { Vocabulario: } \mu=\mu_{1+} \mu_{2} \\
\text { Volumen: } V=N \log _{2} \mu\end{array}$ & {$[0 . . \infty)$} & $\begin{array}{l}\text { Orden de magnitud del } \\
\text { vocabulario y expresiones del } \\
\text { código. } \\
\text { Valores más pequeños son } \\
\text { mejores }^{1} \text {. }\end{array}$ \\
\hline & Estructura & $\begin{array}{l}\text { Complejidad } \\
\text { Ciclomática }\end{array}$ & $\begin{array}{l}\quad v(G)=e-n+p+1 \\
\text { Siendo } p \text { el número de } \\
\text { componentes conectados, } \\
\text { e el número de enlaces y } n \\
\text { el de nodos. }\end{array}$ & {$[0 . . \infty)$} & $\begin{array}{l}\text { Valores más pequeños son } \\
\text { mejores: } 0-7 \text { aceptable, 5-15 } \\
\text { riesgo, }>15 \text { rechazable }\end{array}$ \\
\hline & Dependencias & Fan-out & Numero de dependencias. & {$[0 . . \infty)$} & $\begin{array}{l}\text { Número de componentes } \\
\text { web, interfaces o librerías } \\
\text { JavaScript de las que depende } \\
\text { el componente (fan-out) } \\
\text { Valores pequeños son } \\
\text { mejores. }\end{array}$ \\
\hline \multirow{3}{*}{ 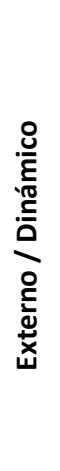 } & $\begin{array}{l}\text { Completitud } \\
\text { (Satisfacción) }\end{array}$ & Completitud & $\begin{array}{l}\text { Ratio de información } \\
\text { requerida que esta } \\
\text { efectivamente disponible. }\end{array}$ & {$[0 \ldots 1]$} & $\begin{array}{l}1 \text { o valores cercanos a } 1 \text { son } \\
\text { mejores. }\end{array}$ \\
\hline & $\begin{array}{l}\text { Latencia } \\
\left(\text { Usabilidad²) }^{2}\right.\end{array}$ & Latencia & $\begin{array}{l}\text { Retardo medio entre la } \\
\text { petición y la respuesta, } \\
\text { medida en milisegundos. }\end{array}$ & {$[0 . . \infty)$} & $\begin{array}{l}\text { Valores pequeños son } \\
\text { mejores. } \\
\text { Alcanzado un umbral, el } \\
\text { usuario desiste y se asume } \\
\text { valor infinito. }\end{array}$ \\
\hline & $\begin{array}{l}\text { Consistencia } \\
\text { (Eficacia) }\end{array}$ & Consistencia & $\begin{array}{l}(x, y) \text { donde la componente } \\
x \text { es latencia e y es } \\
\text { completitud }\end{array}$ & $\begin{array}{l}{[0 . . \infty)} \\
{[0 . .1]}\end{array}$ & $\begin{array}{l}\text { Las componentes se } \\
\text { interpretan de acuerdo con } \\
\text { las características de latencia } \\
\text { y completitud }\end{array}$ \\
\hline
\end{tabular}

Tabla 23: Atributos (Métricas) de Calidad Empírica

En los procesos de medida de atributos internos, la métrica más evidente es el tamaño del producto software, que se obtiene de forma estática, sin requerir su ejecución. Si bien, por si misma, esta métrica no permite evaluar esfuerzo o coste, será la base para la evaluación de distintas formas de complejidad. Es más, los conceptos de longitud, volumen o masa encuentran su correspondencia en la medida de dimensión del software de manera significativa en métricas como la Complejidad de Halstead [109].

En su versión más moderna, la Complejidad de Halstead define los siguientes elementos [110]:

- $\mu_{1}$ : número de operadores distintos

- $\mu_{2}$ : número de términos distintos.

- $\mathrm{N}_{1}$ : Número total de apariciones de los operadores.

- $\mathrm{N}_{2}$ : Número total de apariciones de los términos.

A partir de dichos elementos, se introducen siete métricas de producto, aunque en la actualidad se aceptan como plausibles solo las tres primeras, correspondientes a la medida de tamaño del software [111]. Estas se definen como siguen:

- Longitud: $\mathrm{N}=\mathrm{N}_{1}+\mathrm{N}_{2}$

- Vocabulario: $\mu=\mu_{1}+\mu_{2}$

\footnotetext{
${ }^{1}$ En realidad, el asunto es algo más complejo: De acuerdo S.H. Kan [113] existe un valor óptimo en torno a las 250 líneas de código que minimiza el número de defectos, incrementándose para valores menores y mayores a este punto.

${ }^{2}$ De acuerdo con el estándar ISO/IEC 25023, la usabilidad es una característica de la calidad de producto, donde se menciona explícitamente, y también de la calidad en uso, en la que sería una combinación de eficacia, eficiencia, satisfacción y ausencia de riesgo.
} 
- Volumen: $\mathrm{V}=\mathrm{N} \log _{2} \mu$

Con el fin de superar las limitaciones que impone las medidas básicas del tamaño software, en esta investigación consideraremos también como métricas intrínsecas y estáticas algunas métricas que reflejan la complejidad del software, así como su estructura, en términos de cohesión y acoplamiento.

La complejidad Ciclomática, definida por McCabe [112] evalúa la estructura de los flujos de control de funciones, procedimientos o métodos, correspondientes a lenguajes imperativos, modelizados como grafos dirigidos. En estos grafos, cada nodo $\boldsymbol{n}$ corresponde con una sentencia del código o bloque de código ejecutado secuencialmente, mientras que cada enlace $\boldsymbol{e}$ del grafo representa una sentencia de control de flujo, que altera la ejecución del código [111]. Ante la enorme variedad de medidas que pueden realizarse de un grafo de tales características, McCabe propone la siguiente fórmula $v(F)=e-n+2$ como medida de las secuencias de ejecución linealmente independientes.

Si bien la complejidad Ciclomática representa mejor que la métrica de Halstead la complejidad estructural, lo cierto es que solo resulta generalmente aceptada como medida de la dificultad de realizar pruebas o mantener una pieza de código [111]. Ambas métricas consideran cada módulo de programación como una entidad aislada e independiente. Evaluar elementos software modulares requiere métricas que contemplen la interdependencia entre módulos

Considerando como atributos estructurales la cohesión y el acoplamiento es posible evaluar la complejidad estructural del producto software analizando las dependencias (fan-in/fan-out) de llamada y uso [113]. Sin embargo, aplicadas a los componentes web desarrollados en ecosistemas abiertos, solo será posible aplicar una versión parcial de esta métrica, dada la imposibilidad de evaluar las llamadas que tendrá el componente; por esta razón solo se contemplarán las dependencias de uso (fan-out).

La evaluación de las características extrínsecas y dinámicas requiere de un conjunto diferente de métricas. Convencionalmente se les considera de más difícil evaluación, realizada durante una fase más tardía del desarrollo del producto software y con una elevada carga subjetiva. Estas características refuerzan más si cabe el carácter de conglomerado del concepto de calidad de software, requiriendo en muchos casos la definición ad hoc del modelo de calidad y su evaluación empírica.

En el caso de los componentes webs desarrollados y distribuidos en repositorios públicos, la evaluación de atributos extrínsecos y dinámicos se realiza de manera totalmente desacoplada en la mayoría de los casos, definiéndose como únicos canales de retorno la calificación del componente o el desarrollador, siguiendo los mecanismos de meritocracia de las comunidades o bien, mediante el reporte de errores, sugerencias de mejoras o nuevas características en el repositorio, si el desarrollo se realiza también de forma pública.

Con todas estas consideraciones, de las opciones posibles, en el presente trabajo solo contemplaremos las siguientes métricas de evaluación externa/dinámica: la completitud, la latencia y la consistencia.

La completitud en el contexto de los componentes web evalúa el impacto que tiene la ausencia parcial de información en la calidad percibida por el usuario, de tal forma que cuantifica, al menos parcialmente, la completitud del contexto y por tanto característica de calidad en uso. Más concretamente, esta métrica evaluará el nivel en el que los datos asociados con el componente cuentan con valores para todos los atributos necesarios para proporcionar la funcionalidad en un contexto definido. No contando con un nivel absoluto respecto al que medir la completitud, en este trabajo se cuantifica como un porcentaje, de $0 \%$ a $100 \%$, respecto al total de la información requerida. 
La métrica de latencia permite cuantificar el efecto de la dilación en la interacción con el componente, lo que en último extremo puede limitar la disponibilidad de la información requerida o afectar a la consistencia. El efecto de esta métrica en aplicaciones web ha sido ampliamente analizado por el impacto en la interacción, compras o multimedia en Internet [114]. En nuestro trabajo consideramos como valor de la latencia el retraso con el que la información del componente web se presenta con respecto al resto de componentes de la aplicación web, medido en milisegundos.

Finalmente, el carácter distribuido y sin estado de las aplicaciones web nos lleva a considerar como característica de calidad en uso la gestión que el backend hace de la información de estado en la que se apoya la ejecución de los componentes web y cómo la propagación adecuada influye en la misma. En el dominio de la gestión de bases de datos distribuidas, este concepto se conoce como la consistencia entre réplicas, y dadas las enormes similitudes, llamaremos así a nuestra métrica que permite evaluar el comportamiento de numerosas aplicaciones web.

En términos más formales la métrica de consistencia evaluará la inmutabilidad de los datos durante su procesamiento en operaciones de transmisión, almacenamiento o recuperación, garantizando que la información es consistente en todo momento. Asumiendo una inconsistencia solo eventual, la métrica de consistencia se calcula como el tiempo en milisegundos correspondiente al doble de la latencia más un tiempo constante necesario para actualizar la información entre réplicas.

\subsubsection{Validación del modelo empírico de calidad de componentes web.}

El objetivo de validación de un total de seis métricas, tres internas de evaluación estática y tres externas de evaluación dinámica, para el conjunto de características de calidad que contempla la norma ISO /IEC 25000 conduce a un cuestionario que presenta ciertos retos:

- La hipótesis de partida de toda la investigación, contrastada durante la categorización del panel de expertos, asume el desconocimiento de las normas de calidad. Esto significa que los expertos se enfrentan por primera vez a un lenguaje formal extraído de las normas.

- La elevada subjetividad de evaluación de las características de calidad, que responde de manera significativa al contexto de cada experto, dificulta la presentación de los casos del cuestionario.

- El cuestionario es de una extensión considerable, lo que aumenta significativamente la dificultad para los expertos de completarlo en un tiempo razonable, sin demasiados sesgos derivados del cansancio, y la facilidad con la que se permiten incluir consideraciones o comentarios.

Con el fin de resolver satisfactoriamente estas limitaciones, se adopta como decisión de investigación la implementación de una variante del método Delphi, en la que las entrevistas serán facilitadas, en nuestro caso, por un único facilitador y serán además grabadas, facilitando los comentarios y permitiendo la revisión completa a posteriori de todo el proceso.

\subsubsection{Análisis de Resultados del Método Delphi: primera ronda.}

Las entrevistas correspondientes a la primera ronda del método Delphi tuvieron lugar a lo largo 20 días. Con una duración media de 50 minutos, se estructuraron para incluir una presentación ${ }^{3}$ sobre el proyecto y la definición formal de las métricas a considerar, seguidas de la encuesta, en las que el facilitador leía cada una de las sentencias de valoración (ver de la Tabla 7) y pedía la

\footnotetext{
${ }^{3}$ La presentación no se adjunta al artículo para reducir su extensión, pero se puede facilitar bajo petición.
} 
valoración del experto. Excluyendo la presentación, el tiempo dedicado a responder se sitúa en torno a 45 segundos para responder cada pregunta.

Las estadísticas discretas correspondientes a los resultados de la primera ronda de entrevistas se encuentras recogidas en llustración 17, representadas mediante gráficos de tipo "box-andwhiskers". Algunos detalles resultan evidentes de la mera observación: existe una variación significativa, confirmada por un valor medio de la desviación estándar de 1,1 (22\%), si bien afecta más a la evaluación de métricas intrínsecas 1,2 (24\%). El hecho de que la variación de la valoración de la cobertura de las métricas extrínsecas sea 1 (20\%) resulta interesante, considerando que este tipo de métricas tiene una mayor componente subjetiva. En el apartado de conclusiones y futuros trabajos proporcionaremos algunas ideas que podrían explicar esta situación.

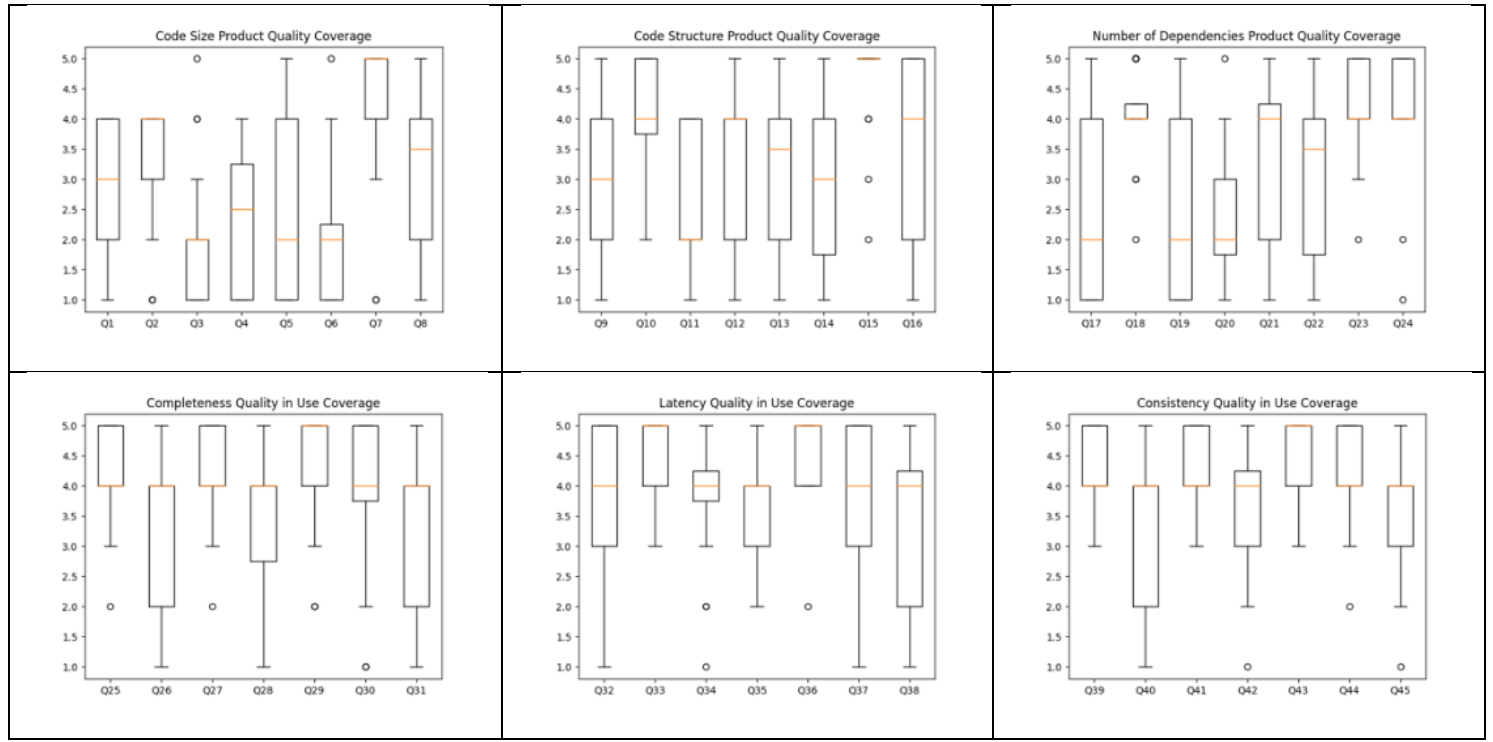

Ilustración 17: Resultados del Método Delphi, Estadísticas Descriptivas de la Ronda 1

La llustración 18 recoge los gráficos radiales que representan las medias de la evaluación de los expertos, permitiendo un primer análisis visual y pudiendo comparar las evaluaciones de cobertura a nivel de métrica.

\section{Cobertura de Atributos Internas/Estáticas $\quad$ Cobertura de Atributos Externos / Dinámicos}

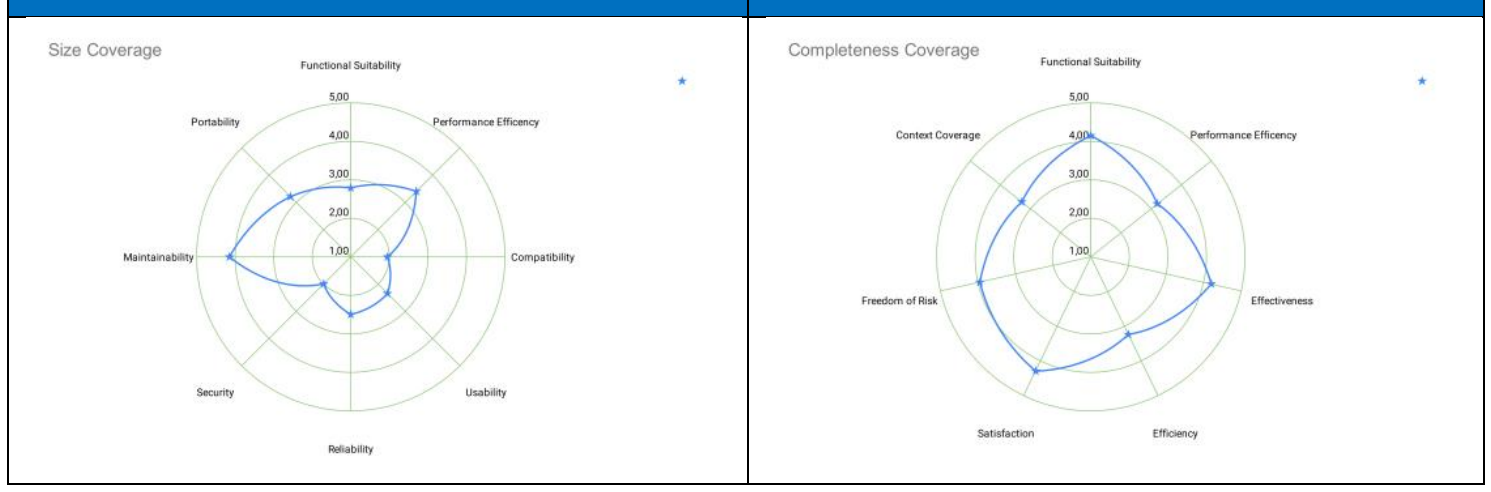




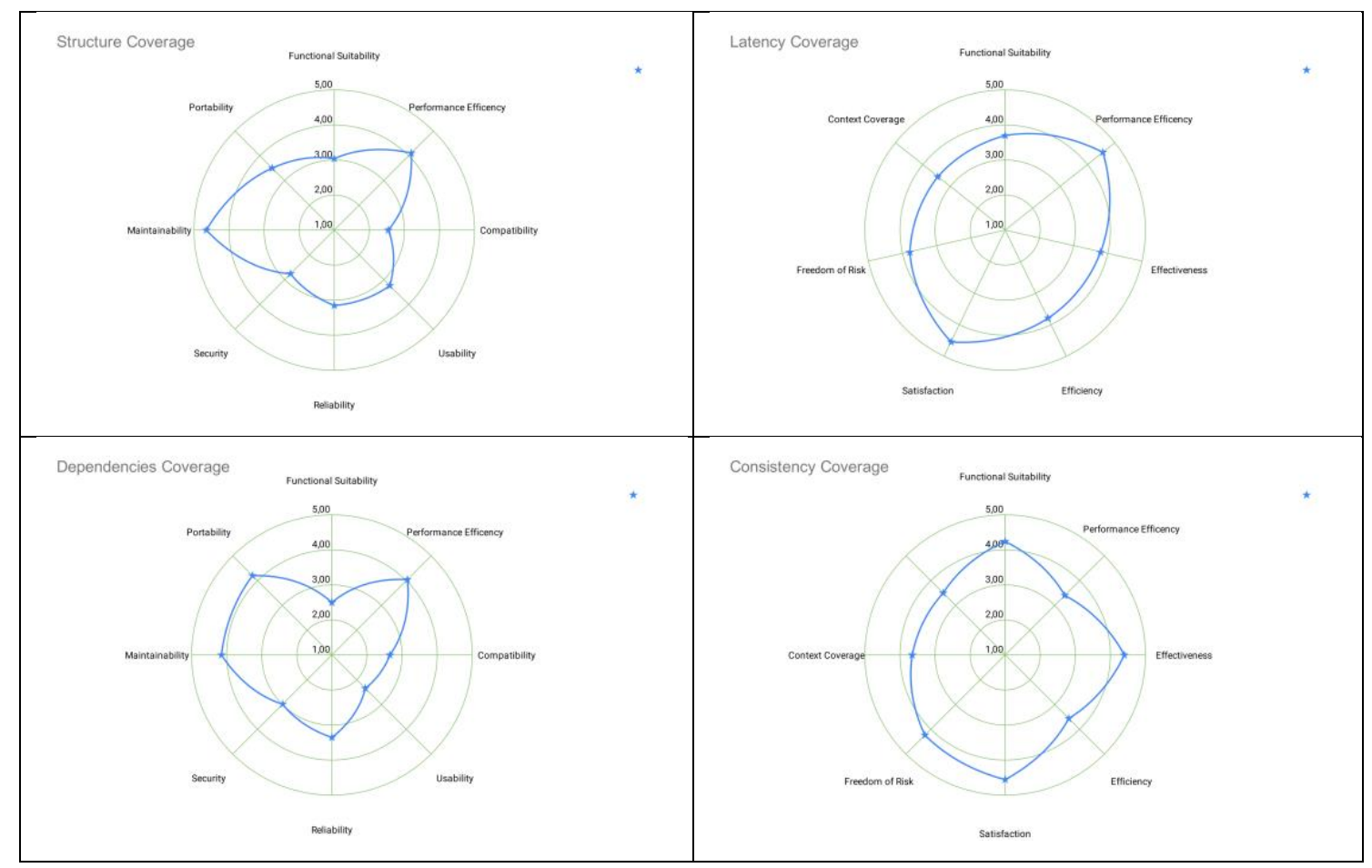

Ilustración 18: Resultados del Método Delphi, Cobertura de Calidad I en la Ronda 1

No obstante, en la presente investigación establecemos como criterio de cobertura un valor comparado entre el porcentaje de acuerdo y el de desacuerdo, asignado a la evaluación media (3) un carácter neutro, de cobertura no concluyente no determinante.

En términos formales definimos el porcentaje de acuerdo como el porcentaje de expertos que afirman que esta muy de acuerdo (4) o totalmente de acuerdo (5) con la capacidad de la métrica de evaluar la característica. De igual forma, definimos el porcentaje de desacuerdo como el porcentaje de expertos que afirman estar muy poco de acuerdo o totalmente en desacuerdo con la capacidad de la métrica de evaluar la característica.

Un importante aspecto que no puede pasar desapercibido es que la definición de cobertura que contemplamos en esta investigación es conservadora. Esto se debe a que nuestra definición excluye a los expertos que se mostraron de acuerdo (3), sin mostrar especial inclinación, con la capacidad de la métrica de evaluar la característica. Asumimos que esta decisión es arbitraria, lo que deja abierta la puerta a nuevas investigaciones considerando definiciones alternativas.

En función de los criterios anteriormente definidos, la llustración 19 incluye el nivel de cobertura para cada métrica y cada característica de calidad.

\begin{tabular}{|c|c|c|c|c|c|c|c|}
\hline & Size & Structure & Dependencies & & Completeness & Latency & Consistency \\
\hline Functional Suitability & Disagree & Agree & Disagree & Functional Suitability & Agree & Agree & Agree \\
\hline Performance Efficency & Agree & Agree & Agree & Performance Efficency & Agree & Agree & Agree \\
\hline Compatibility & Disagree & Disagree & Disagree & Effectiveness & Agree & Agree & Agree \\
\hline Usability & Disagree & Agree & Disagree & Efficiency & Agree & Agree & Agree \\
\hline Reliability & Disagree & Agree & Agree & Satisfaction & Agree & Agree & Agree \\
\hline Security & Disagree & Disagree & Agree & Freedom of Risk & Agree & Agree & Agree \\
\hline Maintainability & Agree & Agree & Agree & Context Coverage & Agree & Agree & Agree \\
\hline Portability & Agree & Agree & Agree & & & & \\
\hline Product Quality Coverage & 2,79 & 3,38 & 3,28 & Quality In Use Coverage & 3,76 & 3,95 & 4,4 \\
\hline
\end{tabular}

Ilustración 19: Resultados del Método Delphi, Cobertura de Calidad II en la Ronda 1 
De acuerdo con estos resultados, la primera ronda de entrevistas proporciona las siguientes evidencias:

- Las métricas externas de evaluación dinámica, según los expertos, dan cobertura completa a las características de calidad en uso, y también al rendimiento y adecuación funcional. Es decir, permiten evaluar dichas características.

- Las métricas internas de evaluación estática, según los expertos, dan cobertura completa a las características de calidad de producto correspondientes al rendimiento, la mantenibilidad y la portabilidad.

- Las métricas internas de evaluación estática, según los expertos, no permiten evaluar la característica de calidad de producto correspondiente a la compatibilidad, es decir, el grado con el que un componente web puede intercambiar información con otros y/o realizar funciones mientras comparte el mismo de entorno de ejecución software/hardware.

Para el resto de las características de producto, existe una cobertura parcial, y así, según los expertos:

- Solo la estructura del código permite evaluar la adecuación funcional y la usabilidad.

- La fiabilidad puede ser evaluada tanto por la complejidad del código como por el número de dependencias.

- Únicamente la métrica que cuenta el número de dependencias permite evaluar la seguridad.

Como nota al margen, se puede añadir que, si consideramos una definición débil de cobertura, incluyendo como respaldo a aquellos expertos que evaluaron la cobertura sin pronunciar especial acuerdo/desacuerdo (3), únicamente habría que añadir las coberturas de adecuación funcional con la métrica de tamaño y la de seguridad con la estructura.

La relación entre los niveles de acuerdo, desacuerdo y valoración neutra para la primera ronda se pueden observar en la llustración 20.

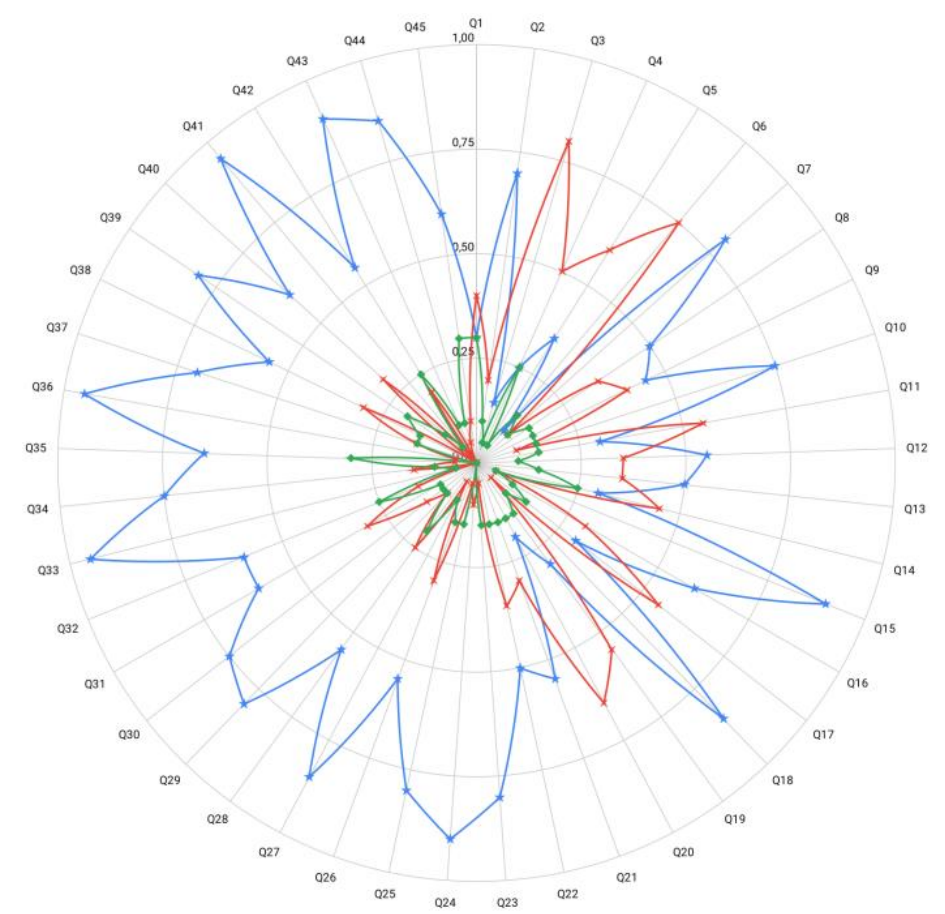

Ilustración 20: Resultados del Método Delphi, Distribución del Consenso en la Ronda 1 
Una vez completados el análisis de estadísticas discretas y las coberturas, se obtiene los estadísticos que permiten evaluar la consistencia del cuestionario, así como la consistencia estadística del consenso obtenido.

\begin{tabular}{|l|l|l|}
\hline Alfa de Chronbach & W de Kendall - Intra & W de Kendall - Inter \\
\hline$\alpha=0.846$ & W $=0.317$ & \\
\hline
\end{tabular}

De acuerdo con los datos obtenidos, recogidos en Tabla 24, la fiabilidad del cuestionario para esta primera ronda se encuentra por encima del nivel requerido para investigación aplicada. Respecto al estadístico W de Kendall correspondiente al nivel de consenso entre los expertos para esta primera ronda, el valor obtenido es débil. Estos resultados entran dentro de lo esperable para una primera ronda.

La pregunta sobre la existencia de mayor nivel de consenso para grupos más pequeños de expertos resulta evidente, y así mismo, la caracterización de dichos grupos según las categorías introducidas y la evolución del nivel de consenso según se avanza en el proceso. Este análisis se presenta en el siguiente apartado.

Por último, el análisis de la consistencia entre la opinión de los expertos se complementa con el análisis de correspondencia simple. Se trata de una técnica visual y exploratoria que permite, mediante una reducción de la dimensionalidad, determinar el nivel de consistencia respecto a los expertos y las preguntas del cuestionario.

Los resultados para esta primera ronda se encuentran en la llustración 21. Según se puede observar allí, si bien los dos ejes principales solo representan el $34.6 \%$ de la variación, la inercia total es 0.1 , lo que la sitúa próxima a cero, indicando una dispersión reducida del espacio de perfiles, que se concentra en pocas categorías.

De acuerdo con estos resultados, la representación gráfica presenta un nivel dispersión reducida, concentrando el intervalo $[-0.2,0.2],[-0.2,0.2]$ el $80 \%$ de la evaluación de los expertos. Únicamente las evaluaciones de los expertos E124, E034, E084 y E043 quedan fuera de este intervalo. Una situación similar presentan las categorías de preguntas, aunque en su agrupación se pueden observar dos grupos que aglutinan métricas de evaluación de características de calidad de producto y calidad en uso.

Esto grupos serían:

- Grupo \#1 en el que se concentran significativamente preguntas de la evaluación de calidad de producto ya sea usando métricas de tamaño (Q01, Q03, Q04, Q05, Q06), de estructura (Q09, Q11, Q12, Q13, Q14) o dependencias (Q17, Q19, Q20).

- Grupo \#2, que aglutina al resto, incluyendo significativamente a preguntas de evaluación de calidad en uso. 


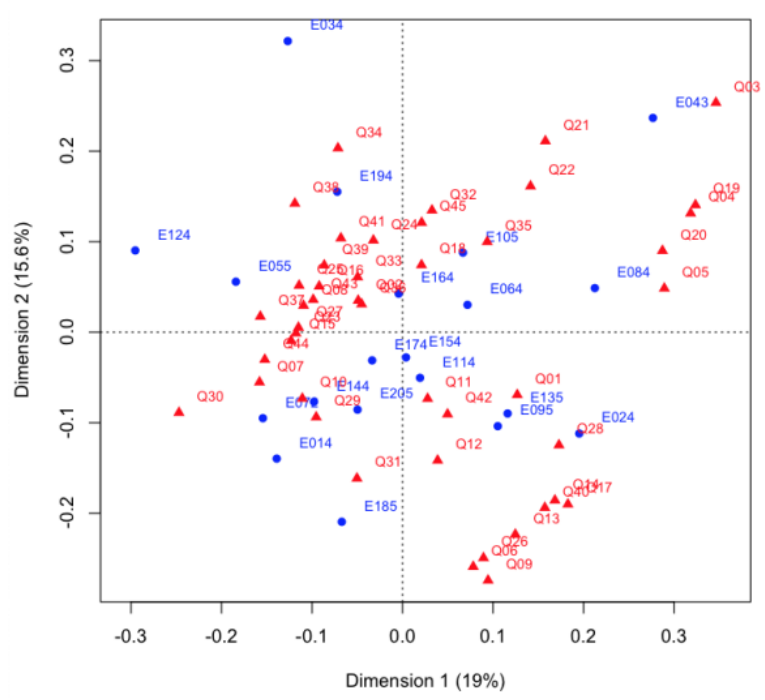

Ilustración 21: Resultados del Método Delphi, Análisis de Correspondencia Simple en la Ronda 1

Un último análisis persigue identificar la existencia de sesgos introducidos durante la fase de entrevistas. Esto es especialmente importante, dadas las particularidades que presenta nuestra aproximación al Método Delphi.

Para evaluar la existencia de sesgos se representan las desviaciones estándar por pregunta y por expertos y se evalúa la línea de tendencia. Las pendientes observadas, cogidas en la llustración 22 , para ambas rectas son negativas y prácticamente nulas, lo que indica que las opiniones no evolucionan significativamente según se avanza en la respuesta de preguntas, ni presenta diferencias significativas entre expertos.

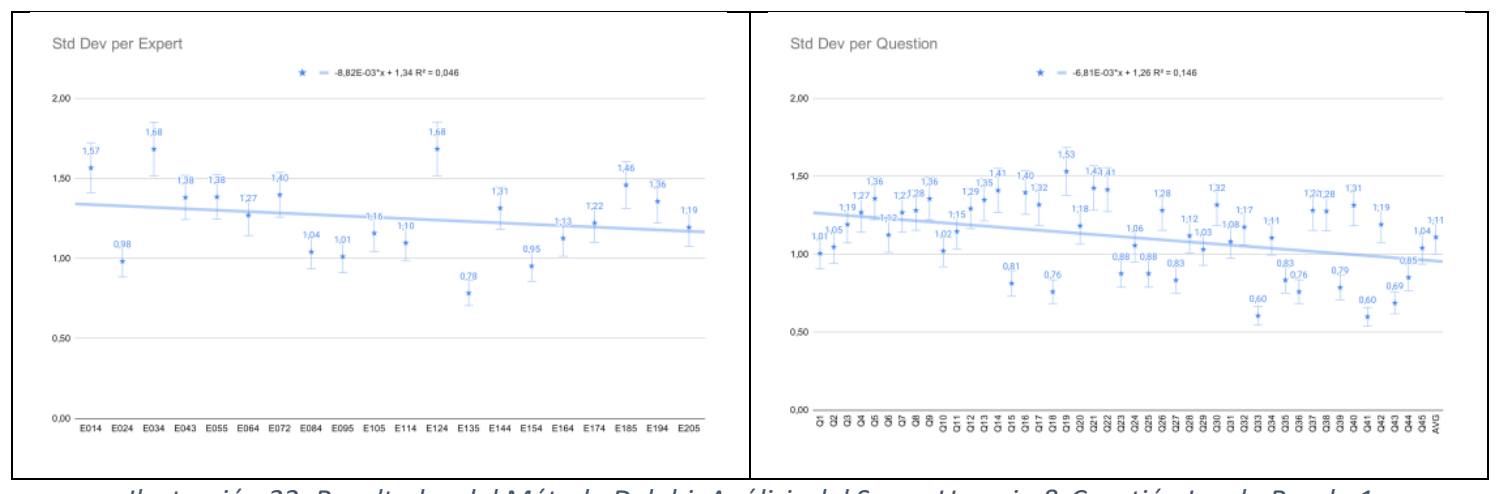

Ilustración 22: Resultados del Método Delphi, Análisis del Sesgo Usuario \& Cuestión I en la Ronda 1

\subsubsection{Análisis de Resultados del Método Delphi: segunda ronda.}

La ronda de segundas entrevistas tuvo lugar durante 20 días adicionales, tras un receso de una semana tras la primera ronda. Para esta segunda ronda de entrevistas se reservaron 50 minutos, que fue lo que en media duraron las entrevistas. Como en la primera ronda las entrevistas se grabaron para facilitar las observaciones y comentarios por parte de los expertos.

Siguiendo con las recomendaciones del método Delphi, previamente a la reunión, se compartió una presentación individualizada ${ }^{4}$ para cada experto con los resultados de la ronda inicial. En esta presentación se incluía para cada pregunta el mismo texto utilizado en el formulario, las estadísticas discretas de los resultados de grupo y correspondientes a la media, la mediana,

\footnotetext{
${ }^{4}$ La presentación no se adjunta al artículo para reducir su extensión, pero se puede facilitar bajo petición.
} 
desviación estándar, porcentaje de acuerdo y porcentaje de desacuerdo, así como la respuesta que dicho experto asignó en la ronda inicial.

Con esta información, el protocolo de la entrevista revisó todas y cada una de las preguntas, leyendo el texto, las estadísticas y pidiendo al experto que volviese a seleccionar una respuesta. Como resultado de todo el proceso, se obtuvo una nueva evaluación, con la participación de todos los expertos. La duración media se situó en esta segunda ronda en los 50 minutos, disponiéndose en media de algo más de un minuto para la lectura de cada una de las preguntas y la nueva evaluación por parte experto.

Las estadísticas discretas correspondientes a la segunda ronda de entrevistas se recogen en la llustración 23. En esta segunda iteración se observa una reducción clara en la diversidad de opiniones de los expertos, que lleva la desviación estándar media a 0.8 (16\%), y que también se distribuye de manera desigual entre evaluación de calidad de producto $(0.9 / 18 \%)$ y calidad en uso (0.7 / 14\%). De nuevo se observa una mayor coincidencia en la valoración de las características de calidad en uso.

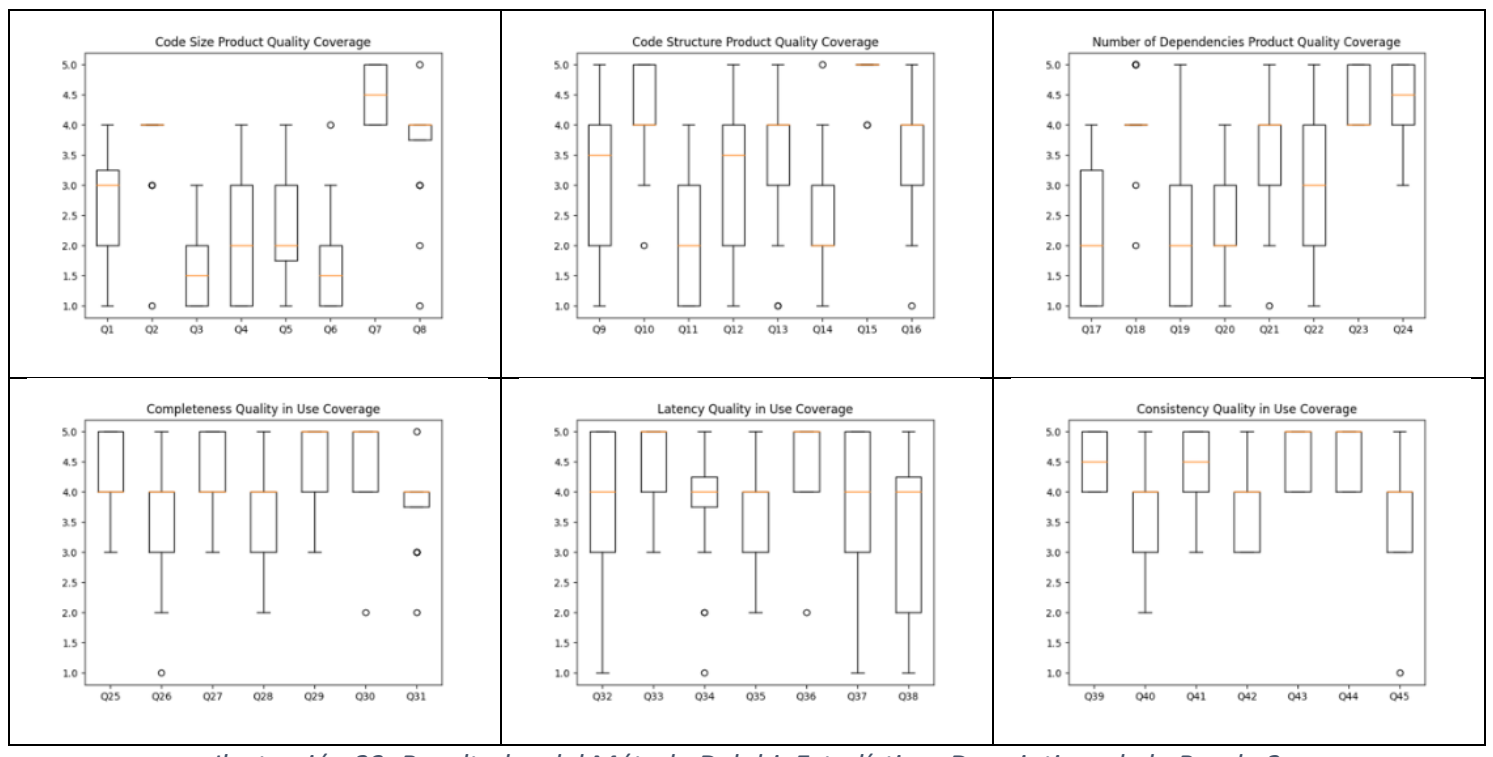

Ilustración 23: Resultados del Método Delphi, Estadísticas Descriptivas de la Ronda 2

Siguiendo con los análisis propuestos, en esta segunda ronda se continua analizando el nivel de cobertura que cada métrica ofrece de las características de calidad de producto y calidad en uso. Con el fin de facilitar la evolución entre rondas, la llustración 24 incluye en línea discontinua los resultados de la primera ronda. En la sección correspondiente al análisis diferencial se evaluará la diferencia entre las iteraciones.

Aplicando los criterios de cobertura introducidos en el análisis de la primera ronda, se incluyen las coberturas para esta segunda en la llustración 25 , sin que se produzca ningún cambio en las coberturas obtenidas. Únicamente considerando la definición débil de cobertura, donde las valoraciones neutras (3) se añaden al porcentaje de expertos que se pronunciaron de acuerdo (4) o muy de acuerdo (5), se obtiene como cobertura adicional la característica de seguridad por parte de la métrica de complejidad. 


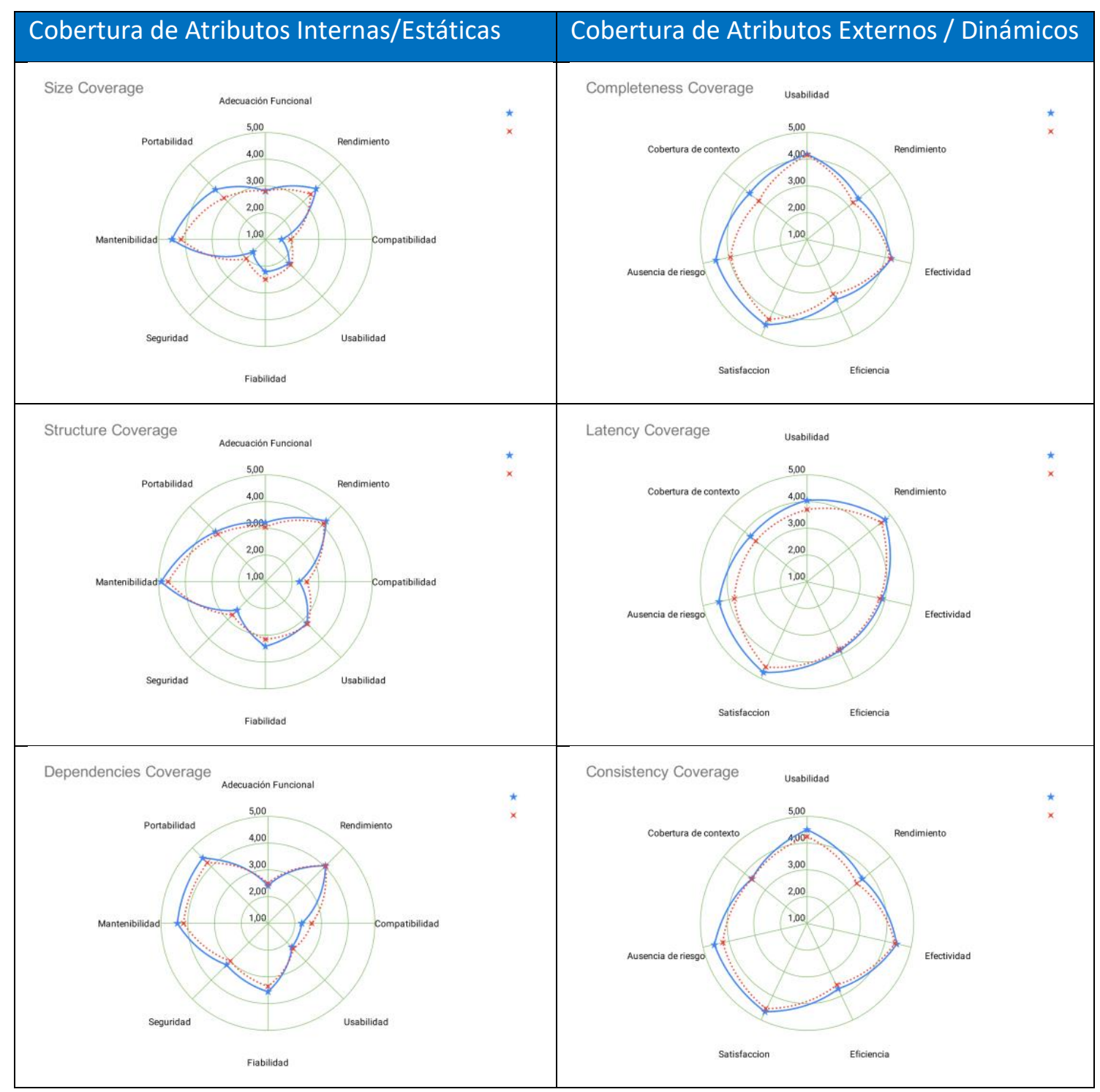

Ilustración 24: Resultados del Método Delphi, Cobertura de Calidad I en la Ronda 2

En esta segunda ronda es interesante destacar la evolución de los porcentajes de los expertos que se muestran de acuerdo, en desacuerdo y neutrales. Según se puede observar en la llustración 26, en comparación con la primera ronda se ha producido un incremento de la valoración neutra.

Expresado de otra manera, la iteración modula la opinión de los expertos, reforzando las tendencias y llevando los valores disonantes a posturas más en sintonía con el resto.

\begin{tabular}{|c|c|c|c|c|c|c|c|}
\hline & Halstead & Cyclomatic & Structural & & Completeness & Latency & Consistency \\
\hline Adecuación Funcional & Disagree & Agree & Disagree & Adecuación Funcional & | Agree & Agree & Agree \\
\hline Rendimiento & Agree & Agree & Agree & Rendimiento & Agree & Agree & Agree \\
\hline Compatibilidad & Disagree & Disagree & Disagree & Efectividad & Agree & Agree & Agree \\
\hline Usabilidad & Disagree & Agree & Disagree & Eficiencia & Agree & Agree & Agree \\
\hline Fiabilidad & Disagree & Agree & Agree & Satisfacción & Agree & Agree & Agree \\
\hline Seguridad & Disagree & Disagree & Agree & Ausencia de riesgo & Agree & Agree & Agree \\
\hline Mantenibilidad & Agree & Agree & Agree & Cobertura de contexto & Agree & Agree & Agree \\
\hline Portabilidad & Agree & Agree & Agree & & & & \\
\hline Product Quality Coverage & 2,79 & 3,41 & 3,32 & Quality In Use Coverage & 4,03 & 4,20 & 4,16 \\
\hline
\end{tabular}

Ilustración 25: Resultados del Método Delphi, Cobertura de Calidad II en la Ronda 2 


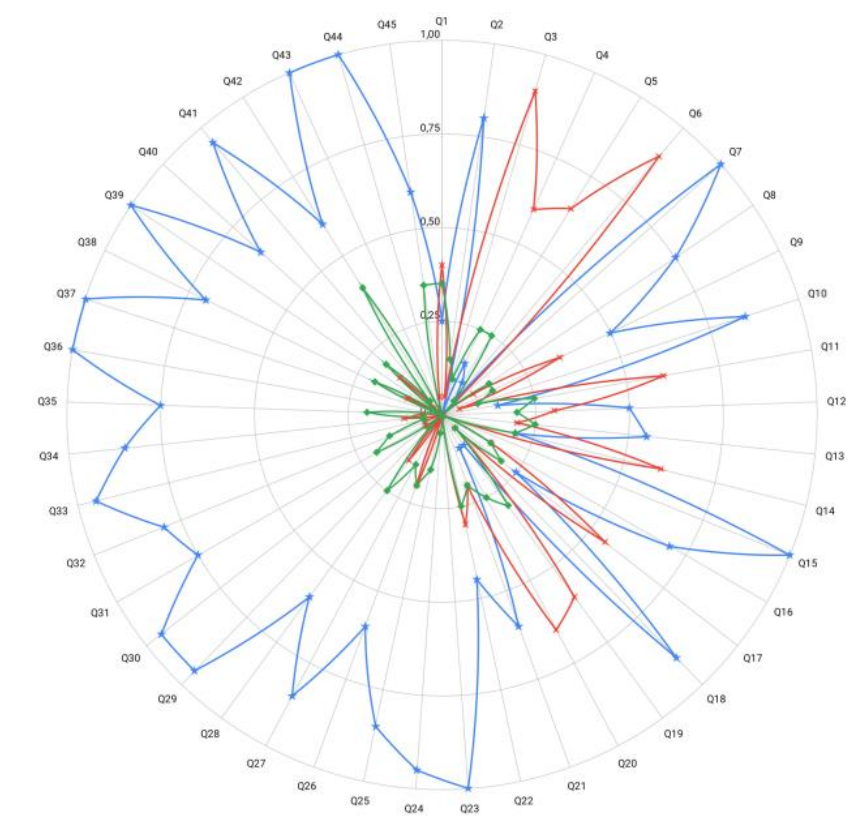

Ilustración 26: Resultados del Método Delphi, Distribución del Consenso en la Ronda 2

Una vez completado el análisis de las estadísticas discretas, se obtienen los estadísticos, recogidos Tabla 25, que permiten evaluar la consistencia del cuestionario, así como el nivel de consenso obtenido, tanto entre los valores medios de cada ronda, como entre la opinión de los expertos.

\begin{tabular}{|l|l|l|}
\hline Alfa de Chronbach & W de Kendall - Intra & W de Kendall - Inter \\
\hline$\alpha=0.861$ & W $=0.564$ & W $=0.987$ \\
\hline
\end{tabular}

Tabla 25: Resultados del Método Delphi, Estadísticos de Consistencia y Consenso en la Ronda 2

De acuerdo con los datos obtenidos, la fiabilidad del cuestionario para esta segunda ronda se encuentra por encima del nivel requerido para investigación aplicada, superando a la obtenida en la primera ronda $(\alpha=0.846)$. Respecto al estadístico $W$ de Kendall correspondiente al nivel de consenso entre los expertos para la segunda ronda, se obtiene un nivel de consenso moderado fuerte $(W=0.564)$, significativamente superior al obtenido en la primera ronda $(W=0.317)$ lo que indica la convergencia de criterios. Finalmente, el consenso existente entre los valores medios de ambas rondas $(W=0.987)$ indica que no es necesario realizar una tercera ronda, puesto que esto incrementaría marginalmente el consenso alcanzado. Este resultado determina el fin de la ronda de entrevistas.

Por último, el Análisis de Correspondencia Simple nos dará una visión adicional del consenso y la consistencia. Los resultados obtenidos para esta segunda ronda se pueden observar en la figura llustración 27.

En este caso, la representatividad de las dimensiones principales se reduce al $32 \%$; no obstante, la inercia total se reduce casi al $50 \%$ con un valor 0.054 , lo que muestra claramente la agrupación de opiniones. Los resultados indica de nuevo una dispersión reducida del espacio de perfiles, que se concentra más si cabe en pocas categorías. Si además se tiene en cuenta la reducción de la escala de la representación, podemos asumir la existencia de un único grupo, tanto de opiniones de expertos, como de preguntas. 


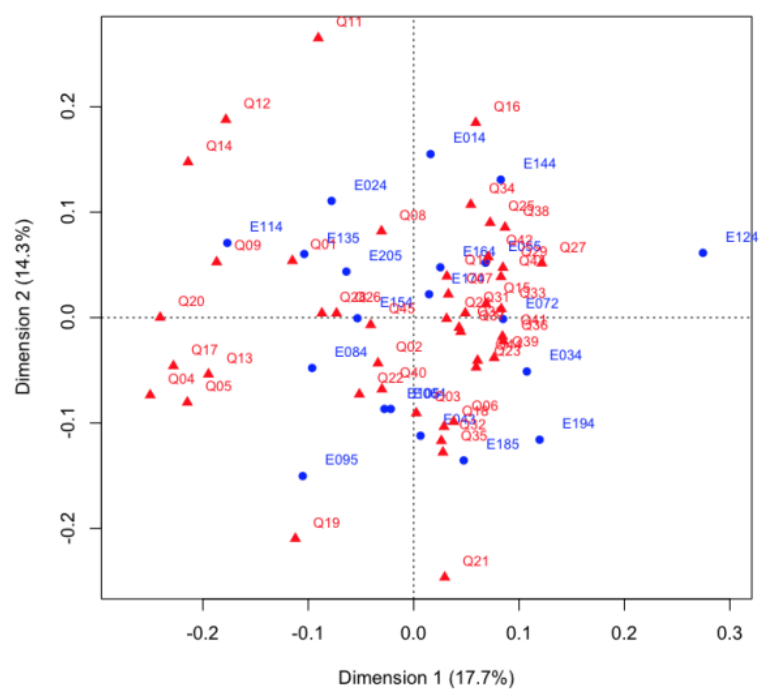

Ilustración 27: Resultados del Método Delphi, Análisis de Correspondencia Simple en la Ronda 2

Por último, se analizan la presencia de sesgos, haciendo uso de nuevo de las líneas de tendencia que presentan las desviaciones estándar de la evaluación a nivel de expertos y preguntas. Los datos obtenidos para esta segunda ronda, recogidos en la llustración 28 , muestran unas pendientes negativas y cercanas a cero, lo que interpretamos como ausencia de sesgos. No obstante, se observa un incremento de un orden de magnitud en la línea de tendencia de las desviaciones estándar de la valoración de los expertos.

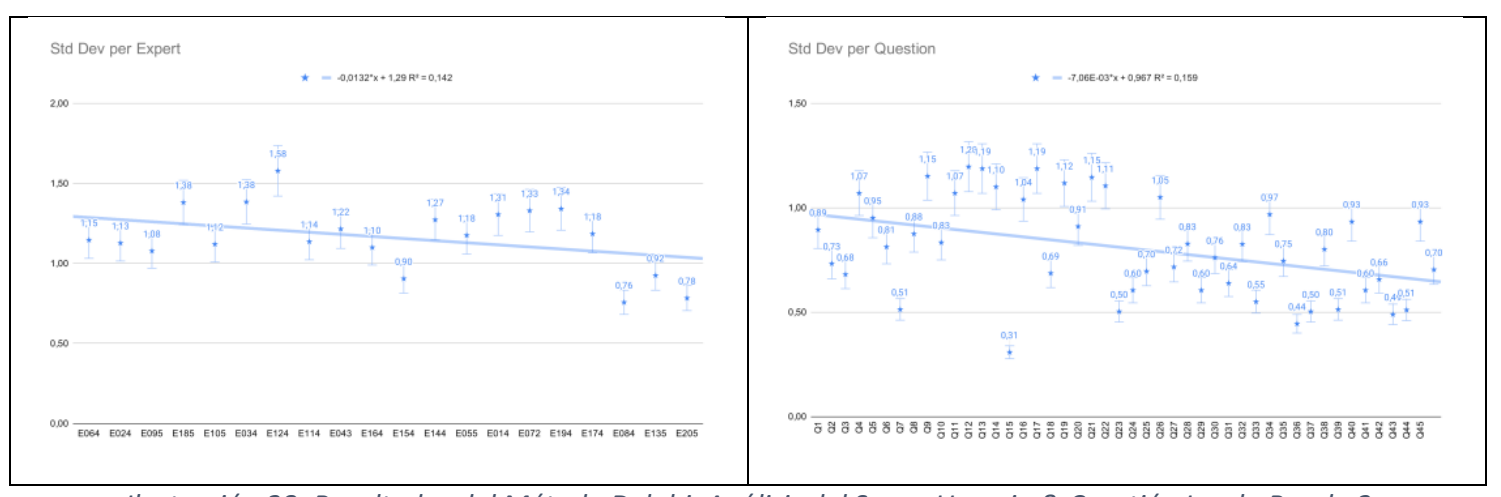

Ilustración 28: Resultados del Método Delphi, Análisis del Sesgo Usuario \& Cuestión I en la Ronda 2

\subsubsection{Análisis diferencial del Método Delphi}

Las características de nuestra investigación, tanto por las modificaciones introducidas en el método Delphi, como por su aplicación a la evaluación de características de calidad, resultan un tanto especiales. En particular:

- El lenguaje utilizado por la norma ISO / IEC 25000 introduce una barrera adicional de entendimiento, especialmente para aquellos expertos que desconocen la norma. Se trata de una hipótesis de partida, contrastada durante la categorización del panel de expertos.

- La longitud del cuestionario es un elemento diferencial, amenazando con introducir sesgos en los expertos derivados del cansancio o la perdida de interés.

Ambas características nos llevan a analizar con mayor detalle el proceso y la evolución del consenso. A este análisis es lo que hemos Ilamado "Análisis Diferencial del Método Delphi". Algunas cuestiones que deberíamos resolver con este análisis serían: 
- ¿A qué se debe el contraste entre la unanimidad de la cobertura de la calidad en uso frente a las claras matizaciones presentes en la cobertura de la calidad de producto?

- ¿Presentan aquellas características mas subjetivas un patrón de respuesta observable en las estadísticas discretas? ¿mayor variabilidad? ¿mayor matización tras la primera ronda? ¿es la unanimidad muestra de, una vez reconocido el impacto, la dificultad de establecer un grado?

- ¿ ¿Se observan sesgos en la variación de valoración según se avanza en la entrevista? ¿cansancio o falta de interés en las preguntas finales?

Con el fin de poder valoras estas cuestiones se introduce una representación que muestra combinadamente con información cuantitativa y cualitativa el grado de cambio introducido para cada una de las características. Para cada una de las preguntas se evalúa la diferencia entre la opinión registrada en la primera y la segunda ronda, recogiendo el valor numérico y resaltando dicho valor en una escala de colores de verde a rojo que varía entre 4 y -4 . Adicionalmente se obtendrá una valoración numérica que representa el cambio absoluto para la métrica y que se obtiene aplicando la formula siguiente para las evaluaciones de cada pregunta i por parte del experto $\mathrm{j}$ :

$$
\partial V_{21}=\sqrt{\sum_{i j}\left(E_{2 i j}-E_{1 i j}\right)^{2}}
$$

La valoración numérica anterior es un valor comprendido entre 0.0 y 50.6 para 20 expertos evaluando 8 preguntas (Calidad de Producto) y entre 0.0 y 47.33 evaluando 7 preguntas (Calidad en Uso).

A continuación, aplicando dicho criterio, se muestran en la Tabla 26 los resultados para evaluación de las características de calidad de producto por parte de las métricas estáticas.

\begin{tabular}{|c|c|c|c|c|c|c|c|c|c|c|c|c|c|c|c|c|c|c|c|c|c|c|c|}
\hline 0 & 3 & 0 & 0 & -2 & 0 & 0 & 2 & 0 & 0 & -1 & 0 & 1 & 0 & 0 & 0 & 1 & 1 & 0 & 0 & -1 & 0 & 0 & 1 \\
\hline-1 & 1 & -3 & -1 & -2 & -4 & 0 & 1 & 0 & 2 & 0 & 0 & -2 & -1 & 0 & 1 & 0 & 0 & 0 & 0 & -3 & 0 & 0 & 0 \\
\hline 0 & 1 & 0 & 0 & 0 & -1 & 0 & 0 & 0 & 0 & 0 & 0 & 0 & -2 & 1 & 0 & 0 & 0 & 0 & 0 & 0 & 0 & 0 & 1 \\
\hline 0 & 0 & 0 & 0 & 0 & 0 & 0 & 0 & -1 & -1 & 0 & 0 & 0 & 0 & 0 & 0 & 0 & 0 & 0 & 0 & 0 & 1 & 0 & 1 \\
\hline 0 & 0 & 0 & 0 & -1 & 0 & -1 & 1 & 3 & 0 & -1 & -2 & 0 & -2 & 0 & 0 & 0 & 0 & -1 & -1 & 0 & 0 & 0 & 1 \\
\hline 0 & 0 & 0 & 0 & 0 & 0 & 0 & 0 & 1 & 0 & 0 & 0 & 0 & 0 & 0 & 0 & 0 & 0 & 0 & 0 & 0 & 0 & 0 & 0 \\
\hline 0 & 0 & 0 & 0 & 0 & 0 & 0 & 0 & 0 & 0 & 0 & 0 & 0 & 0 & 0 & 0 & 0 & 0 & 0 & 0 & 0 & 0 & 0 & -1 \\
\hline 0 & 0 & 0 & 0 & 0 & -1 & 0 & 0 & 0 & 0 & 0 & 0 & 0 & 0 & 0 & -1 & 0 & 0 & 0 & 0 & 0 & 0 & 0 & 0 \\
\hline 0 & 0 & -3 & -1 & -1 & 0 & 3 & 2 & 0 & 0 & 0 & 1 & 2 & 0 & 3 & 1 & 0 & 0 & -2 & 0 & 0 & 0 & 2 & 0 \\
\hline-1 & 1 & -1 & -1 & 0 & 0 & 0 & 0 & 0 & 1 & -1 & 1 & 1 & -1 & 0 & 0 & -1 & 0 & 0 & 0 & 0 & 0 & 0 & 0 \\
\hline 0 & 0 & 0 & 0 & 1 & 0 & 0 & 0 & 0 & 0 & 0 & 0 & 0 & 0 & 0 & 0 & 0 & 0 & 0 & 0 & 0 & 0 & 0 & 0 \\
\hline 0 & 1 & 0 & 0 & 0 & -1 & 1 & 0 & 0 & 0 & -1 & 0 & 1 & 0 & 0 & 0 & 0 & 0 & 0 & 0 & 1 & 0 & 0 & 0 \\
\hline 2 & 0 & 0 & 1 & 0 & 0 & 0 & 0 & 0 & 0 & 0 & 0 & 0 & 1 & 1 & 0 & 0 & 0 & 0 & 0 & 1 & 0 & 0 & 0 \\
\hline 0 & 0 & 0 & 0 & -1 & -1 & 0 & 3 & 0 & 0 & 0 & 0 & 0 & 1 & 0 & 3 & 0 & 0 & 0 & 1 & 1 & 1 & 0 & 3 \\
\hline 0 & -1 & 0 & 0 & 0 & 0 & 1 & 0 & 0 & 0 & 0 & 0 & 1 & 0 & 0 & 1 & 0 & 0 & 1 & 0 & 3 & 0 & 1 & 0 \\
\hline 0 & 0 & 0 & 0 & 0 & 0 & 0 & 0 & 0 & 0 & 0 & 0 & 0 & 0 & 0 & 0 & 0 & 0 & 0 & 0 & 0 & 0 & 0 & 0 \\
\hline 0 & 0 & 0 & -1 & 0 & 0 & 0 & -1 & 0 & 0 & -1 & -1 & -1 & 0 & 0 & -1 & 0 & 0 & -2 & 0 & 0 & 1 & 0 & 0 \\
\hline 0 & 0 & 0 & 0 & 0 & 1 & 3 & 2 & 0 & 0 & -1 & 0 & 0 & 0 & 0 & 0 & -1 & 0 & -2 & -1 & 0 & 0 & 1 & 0 \\
\hline 0 & 0 & -1 & -1 & -1 & 0 & 0 & -1 & 0 & 0 & 0 & 0 & 1 & -1 & 0 & 0 & -1 & 0 & -2 & -1 & 0 & -1 & 0 & 0 \\
\hline 0 & 0 & 1 & 2 & 1 & 0 & 0 & 0 & 0 & 0 & 0 & 0 & 1 & 0 & 0 & -1 & 0 & -1 & 0 & 0 & 2 & 2 & 1 & -1 \\
\hline \multicolumn{9}{|c|}{$\partial V_{21}=9.38$} & \multicolumn{8}{|c|}{$\partial V_{21}=7.81$} & \multicolumn{7}{|c|}{$\partial V_{21}=5.48$} \\
\hline
\end{tabular}

Tabla 26: Análisis Diferencial de los resultados del Método Delphi para la calidad de Producto

Si bien las variaciones en términos absolutos resultan poco significativas, los resultados muestran en términos visuales unas diferencias claras en la variación en las opiniones expresadas por los expertos para la cobertura de las distintas métricas: Halstead (19\%), Ciclomática (15\%) o Dependencias (11\%). Los signos de la variación corresponden con correcciones a la baja para la métrica de Halstead, al alza para la métrica de Dependencias y una variación más diversa para la complejidad Ciclomática.

Realizando un análisis similar para las características de calidad en uso, los resultados se pueden observar en la Tabla 27. En este otro caso, las diferencias en términos comparativos en la variación en las opiniones expresadas por los expertos para la cobertura de las distintas métricas resultan menos significativas: Halstead (17\%), Ciclomática (15\%) o Dependencias (14\%). 
Analizados los resultados visualmente, queda claro que para calidad en uso las correcciones son claramente a la baja, aunque no muy grande en términos absolutos.

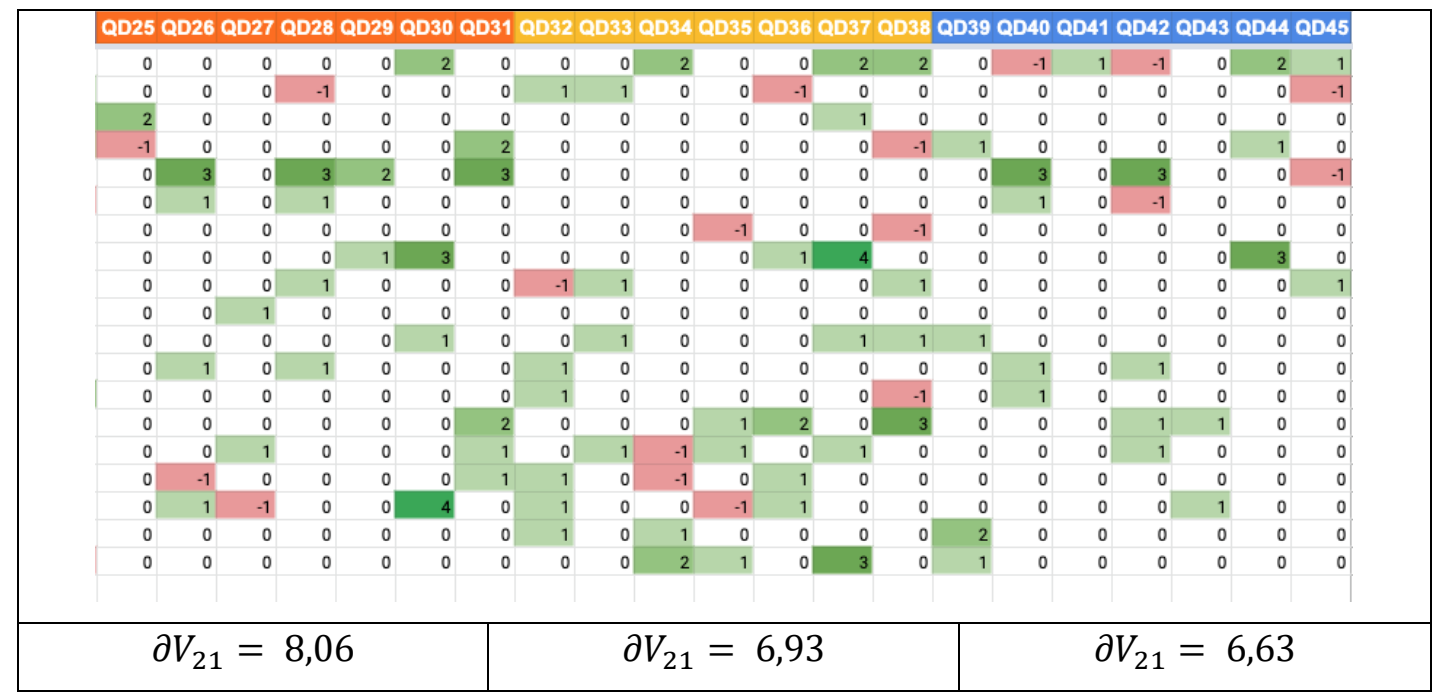

Tabla 27: Análisis Diferencial de los resultados del Método Delphi para la Calidad en Uso

Por último, también analizaremos el posible sesgo introducido entre rondas. Para ello analizamos las desviaciones estándar por experto y por pregunta, así como sus líneas de tendencia. Tal y como se puede observar en la llustración 29 ambas líneas de tendencia presentan pendientes negativas, prácticamente nulas, lo que interpretamos como la ausencia de sesgos significativos entre interacciones.

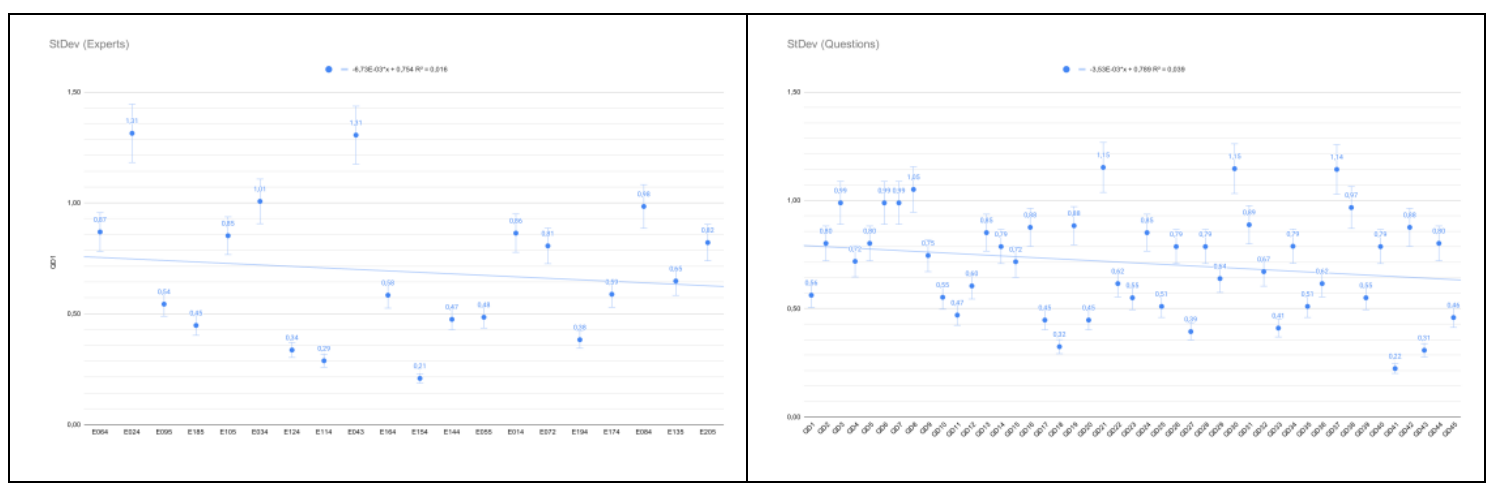

Ilustración 29: Análisis Diferencial: Sesgo Usuario \& Cuestión

\subsubsection{Conglomerados de Consenso y Calidad}

El estadístico W de Kendal se utiliza para determinar el grado de acuerdo entre opiniones de varios evaluadores. En nuestra aproximación inicial se utiliza para determina el grado de divergencia que existe entre rondas del método Delphi, estableciéndose como criterio de finalización del proceso. Es decir, si la opinión media entre dos rondas consecutivas es unánime $(W \sim 1.0)$ la realización de una nueva ronda no producirá cambios significativos entre los expertos, por lo que se detiene la ronda de entrevistas.

La aplicación del estadístico a la opinión entre los expertos, dentro de una misma ronda, por el contrario, permite evaluar la existencia de una opinión única, o lo que es más interesante, la coexistencia de varios criterios de cobertura de características mediante métricas. Este último aspecto es especialmente interesante en tanto en cuanto el proceso de asignación de métricas a un modelo de calidad específico es una actividad necesaria, sujeta a criterios no siempre objetivos y difícilmente sistematizable, dada la naturaleza variada de los procesos de desarrollo de software [11]. 


\subsubsection{Análisis de Conglomerados: primera ronda}

En la presente investigación se ha realizado para cada ronda el análisis combinatorio de agrupación de los expertos del panel, siguiendo como criterio el grado de acuerdo mostrado según el estadístico de la $\mathrm{W}$ de Kendall. Se trata de un proceso de agrupación donde la métrica utilizada corresponde a la definición del estadístico implementada en el módulo irr de R [101]. Como primer resultado se muestran los grupos de expertos con consenso máximo y mínimo, para tamaños de grupo que van de 2 hasta 19 expertos.

\begin{tabular}{|c|c|c|c|c|c|c|c|c|c|c|c|c|c|c|c|c|c|c|c|c|c|c|}
\hline \multirow{2}{*}{2} & Max & .854 & 总 & 志 & 蔗 & 竎 & 吕 & 志 & 㣽 & 嵒 & 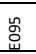 & 莕 & ت & $\underset{\tilde{u}}{\mathbb{Z}}$ & 惫 & 鉋 & 薦 & 志 & $\underset{\stackrel{J}{ \pm}}{\mathbb{Z}}$ & $\stackrel{\mathscr{ٌ}}{\underset{W}{~}}$ & 鹃 & 总 \\
\hline & Mix & .369 & 志 & 志 & 䍘 & $\stackrel{p}{\tilde{u}}$ & 㟔 & 惫 & 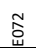 & 嘿 & 怘 & 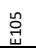 & 节 & $\underset{\tilde{Z}}{\mathbb{Z}}$ & 怘 & 蛋 & 节 & d & 声 & 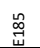 & 哥 & 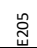 \\
\hline \multirow[t]{2}{*}{3} & Max & . 770 & 蕊 & 志 & 蒡 & $\stackrel{q}{\stackrel{q}{u}}$ & 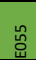 & 总 & 㣽 & 哾 & 总 & 总 & 䔍 & 胥 & 总 & 靑 & 志 & 志 & $\underset{ت}{ \pm}$ & 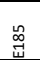 & 莺 & 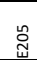 \\
\hline & Min & .260 & 吉 & 胥 & 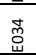 & 旁 & 总 & 惫 & 芯 & $\begin{array}{l}\text { 㩊 } \\
\end{array}$ & 吕 & 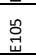 & J & 志 & 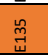 & 表 & 志 & 总 & 志 & 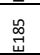 & $\begin{array}{l}d \\
g \\
\text { d }\end{array}$ & 岂 \\
\hline \multirow[b]{2}{*}{4} & Max & .700 & 志 & $\vec{d}$ & 总 & 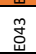 & 㟔 & 惫 & $\underline{\tilde{d}}$ & 总 & 岁 & 岂 & 胥 & 崩 & 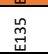 & 靑 & 岂 & 壳 & 声 & 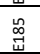 & 总 & 㟧 \\
\hline & Min & 200 & 志 & J & 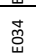 & 営 & 㟔 & 㟛 & 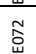 & 总 & 品 & 总 & $\overrightarrow{\vec{u}}$ & 岂 & $\stackrel{\tilde{m}}{\tilde{m}}$ & 急 & 岂 & 壱 & 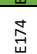 & 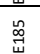 & 莺 & $\stackrel{\omega}{u}$ \\
\hline \multirow{2}{*}{5} & Max & .664 & $\begin{array}{l}\mathrm{w} \\
\overrightarrow{\mathrm{u}}\end{array}$ & 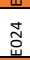 & 䍘 & 旁 & $\begin{array}{l}\text { w. } \\
\stackrel{u}{8} \\
\end{array}$ & 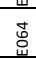 & $\begin{array}{l}\mathbf{w} \\
\tilde{\Xi} \\
\end{array}$ & 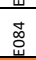 & 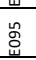 & 总 & 志 & $\begin{array}{l}\mathbf{W} \\
\stackrel{\Xi}{\mathbf{u}}\end{array}$ & $\begin{array}{l}w \\
\tilde{\tilde{w}} \\
\tilde{w}\end{array}$ & $\begin{array}{l}\mathrm{w} \\
\\
\end{array}$ & 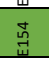 & 志 & $\underset{\mathrm{W}}{\mathbb{Z}}$ & 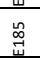 & 声 & w \\
\hline & Min & . 177. & 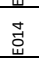 & 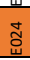 & 蔗 & 飬 & 㟔 & 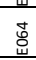 & 岕 & 嘿 & 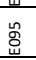 & 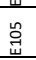 & ت & 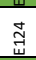 & $\begin{array}{l}\omega \\
\tilde{m} \\
\tilde{m}\end{array}$ & $\begin{array}{l} \\
\\
\end{array}$ & 志 & 壳 & 志 & 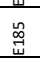 & 㟢 & : \\
\hline \multirow{2}{*}{6} & Max & .632 & 売 & 壳 & 总 & 总 & 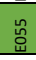 & 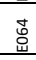 & 答 & 总 & 吕 & 总 & 壱 & $\underset{\mathbb{Z}}{\mathbb{Z}}$ & 惢 & 冞 & 壳 & 总 & $\begin{array}{c} \pm \\
\text { J } \\
\end{array}$ & 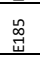 & 㞭 & 莡 \\
\hline & Min & . 177 & 吉 & 胥 & 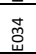 & 旁 & 总 & 胥 & 㣽 & 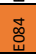 & 㤎 & 品 & $\vec{J}$ & $\begin{array}{l}\vec{Z} \\
\mathbb{Z}\end{array}$ & 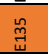 & 急 & 志 & 志 & 焉 & 总 & 总 & $\stackrel{u}{u}$ \\
\hline & Max & .610 & 吉 & $\vec{z}$ & 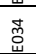 & 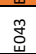 & 㟔 & 惫 & $\tilde{\tilde{S}}$ & 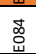 & 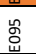 & 芑 & 声 & 胥 & 岁 & 表 & 莺 & 志 & 志 & 岕 & 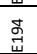 & $\stackrel{w}{u}$ \\
\hline & Min & .171 & 苟 & 岕 & 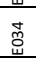 & 飬 & 总 & $\begin{array}{l}\mathbf{J} \\
\text { d् }\end{array}$ & 岕 & 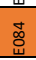 & 品 & 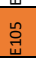 & 节 & $\underset{\tilde{Z}}{\mathbb{Z}}$ & $\stackrel{w}{\tilde{w}}$ & 永 & 志 & 壱 & 志 & $\underset{w}{\infty}$ & 总 & 苞 \\
\hline \multirow[b]{2}{*}{8} & Max & .585 & 志 & 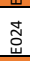 & 䓛 & 惫 & 㟔 & $\begin{array}{l}\vec{J} \\
\\
\end{array}$ & 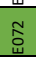 & 总 & 哭 & 总 & 离 & 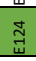 & 岕 & 声 & 志 & 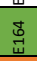 & 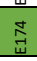 & 岕 & 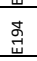 & 岂 \\
\hline & Min & .178 & 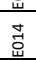 & 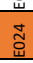 & 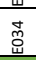 & 嵌 & 㟔 & 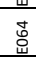 & 峜 & 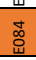 & 岂 & 峁 & 荘 & 岂 & $\underline{w}$ & $\underset{W}{J}$ & 壳 & 壳 & 壱 & 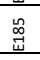 & 㟢 & : \\
\hline \multirow{2}{*}{9} & Max & .565 & 吉 & 志 & 芦 & 密 & 罳 & 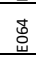 & 怤 & 总 & 总 & 总 & 志 & 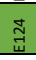 & 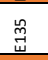 & 急 & 莺 & 志 & 志 & $\stackrel{\mathscr{\Delta}}{\underset{W}{*}}$ & ग् & 岂 \\
\hline & Min & .191 & 吉 & 胥 & 藻 & 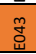 & 总 & 总 & 㤁 & 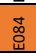 & 䓵 & 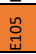 & 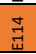 & 志 & 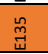 & 壱 & 嘻 & 壳 & 志 & $\underset{w}{\mathscr{B}}$ & 莺 & 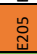 \\
\hline \multirow{2}{*}{10} & Max & .544 & 吉 & 胥 & 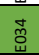 & 爰 & 苔 & $\begin{array}{l}\vec{t} \\
\vec{d}\end{array}$ & 芯 & 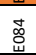 & 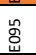 & 䓵 & 声 & $\begin{array}{l}\vec{J} \\
\overrightarrow{\tilde{u}}\end{array}$ & 晜 & 胥 & 䓌 & 志 & 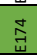 & 㟧 & 惫 & 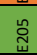 \\
\hline & Min & .204 & 苟 & İ & 溚 & 恖 & 吕 & 总 & 芯 & 善 & 足 & 䓵 & $\vec{J}$ & 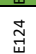 & $\underline{\ddot{m}}$ & $\underset{W}{\mathbb{Z}}$ & 志 & 壳 & 声 & $\stackrel{\leftrightarrow}{\mathscr{W}}$ & 总 & $\stackrel{u}{.}$ \\
\hline \multirow{2}{*}{11} & Max & .527 & 志 & IJ & 莟 & 誉 & 㟔 & 总 & $\tilde{\tilde{s}}$ & 㺼 & 吕 & 总 & 焉 & 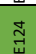 & 㟔 & 声 & 志 & 志 & 志 & $\stackrel{心}{\infty}$ & 志 & $\stackrel{u}{u}$ \\
\hline & Min & .213 & 萜 & 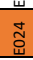 & $\begin{array}{l} \\
\tilde{d} \\
\\
\end{array}$ & 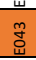 & 㟔 & $\begin{array}{l}\mathrm{w} \\
\\
\mathrm{d}\end{array}$ & 崩 & 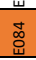 & 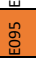 & 岂 & $\begin{array}{l}\mathrm{w} \\
\text { ज्ञ }\end{array}$ & $\begin{array}{l}w \\
\\
\tilde{U}\end{array}$ & 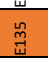 & 表 & 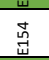 & $\begin{array}{l}w \\
\vec{w} \\
\end{array}$ & 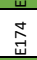 & 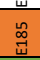 & 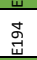 & 崫 \\
\hline \multirow{2}{*}{12} & Max & .506 & 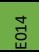 & 胥 & 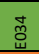 & 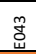 & 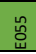 & 总 & $\begin{array}{l}\tilde{\tilde{s}} \\
\mathbf{u}\end{array}$ & 㺼 & 哭 & 总 & 胥 & 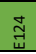 & 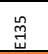 & 呇 & 窘 & $\begin{array}{l}\vec{d} \\
\end{array}$ & 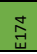 & 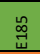 & 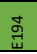 & 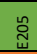 \\
\hline & Min & .224 & 莺 & $\overline{\text { dू }}$ & $\begin{array}{l}\text { 茄 } \\
\end{array}$ & 爰 & 总 & 惢 & $\tilde{s}$ & $\begin{array}{l}\text { 嵒 } \\
\end{array}$ & 䓵 & 萝 & 胥 & 烒 & 總 & 急 & 志 & $\begin{array}{l}d \\
\end{array}$ & 莺 & 总 & 哥 & 总 \\
\hline \multirow{2}{*}{13} & $\operatorname{Max}$ & .486 & 志 & $\underset{\tilde{Z}}{\tilde{W}}$ & 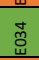 & 誉 & 㞻 & 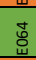 & 岕 & 崌 & 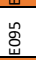 & 岂 & 离 & 岂 & $\begin{array}{l}w \\
\stackrel{m}{\tilde{u}} \\
\tilde{u}\end{array}$ & 声 & 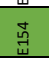 & 志 & 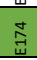 & 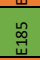 & 离 & 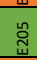 \\
\hline & Min & .234 & t & dٓ & 落 & के & 吕 & 总 & $\tilde{\sigma}$ & 釦 & 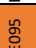 & 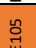 & $\vec{J}$ & $\mathbb{Z}$ & $\stackrel{\mathscr{m}}{\tilde{m}}$ & F & 孛 & t & I & $\stackrel{\infty}{\infty}$ & d & : \\
\hline \multirow{2}{*}{14} & Max & .467 & $\vec{J}$ & ذ్ & 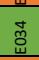 & 㥯 & 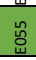 & 壳 & 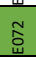 & 嵒 & 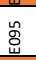 & 总 & 声 & 离 & $\stackrel{\mathscr{\tilde { Z }}}{\tilde{W}}$ & 売 & 栻 & 志 & \begin{tabular}{l}
$\mathrm{w}$ \\
\multirow{U}{*}{} \\
\end{tabular} & 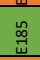 & 惢 & 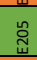 \\
\hline & Min & .243 & $\begin{array}{l}\vec{J} \\
\vec{J}\end{array}$ & 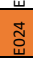 & 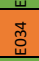 & 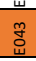 & 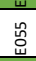 & 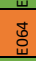 & 岕 & 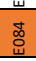 & 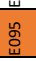 & $\underline{w}$ & $\begin{array}{l}\mathrm{w} \\
\vec{u} \\
\vec{u}\end{array}$ & 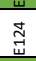 & $\begin{array}{l}w \\
\mathscr{m} \\
\tilde{u} \\
\end{array}$ & $\begin{array}{l} \\
\\
\vec{J}\end{array}$ & 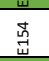 & $\begin{array}{l}\vec{d} \\
\vec{d} \\
\end{array}$ & 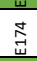 & 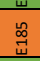 & \begin{tabular}{l} 
\\
\multirow{J}{J}{} \\
$\vec{J}$
\end{tabular} & 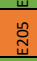 \\
\hline \multirow{2}{*}{15} & $\operatorname{Max}$ & .447 & 志 & 志 & 䍘 & $\stackrel{m}{\mathrm{~d}}$ & 罳 & 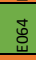 & 㣽 & 总 & 怘 & 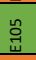 & 志 & Z & 嵒 & $\frac{g}{\vec{W}}$ & 鴶 & 志 & 志 & $\stackrel{\mathscr{D}}{\Psi}$ & 总 & 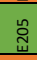 \\
\hline & Min & .254 & 志 & 胥 & 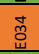 & 爰 & 啰 & 总 & $\tilde{\delta}$ & 嘿 & 然 & 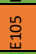 & 胥 & 胥 & 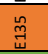 & 丞 & 苞 & $\begin{array}{l} \\
\end{array}$ & 志 & 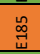 & 哥 & 嵓 \\
\hline \multirow{2}{*}{16} & Max & .420 & 峁 & $\underset{\tilde{~}}{\mathbb{Z}}$ & 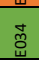 & 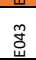 & 岂 & 壳 & 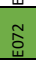 & 总 & 号 & 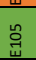 & 岂 & $\vec{U}$ & $\begin{array}{l}\omega \\
\tilde{u} \\
\tilde{u}\end{array}$ & 声 & 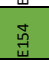 & 壱 & 志 & $\underset{\omega}{\infty}$ & 总 & 峁 \\
\hline & Min & .266 & 志 & J্ & 总 & 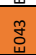 & 崌 & $\vec{d}$ & $\tilde{\Xi}$ & 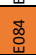 & 岁 & 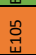 & $\vec{z}$ & $\vec{Z}$ & 岁 & 急 & 志 & 壳 & $\begin{array}{l}\vec{J} \\
\vec{U}\end{array}$ & 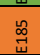 & 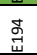 & 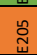 \\
\hline \multirow{2}{*}{17} & Max & .397 & 离 & 胥 & 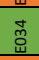 & 誉 & 嵓 & $\begin{array}{l}\vec{J} \\
\\
\end{array}$ & $\begin{array}{c}\tilde{w} \\
\tilde{w} \\
\end{array}$ & 嵒 & 怘 & 总 & 声 & 离 & 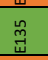 & 胥 & $\begin{array}{l} \\
\\
\vec{u} \\
\end{array}$ & 总 & 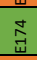 & 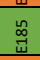 & 㟧 & 岂 \\
\hline & Min & .278 & $\begin{array}{l}\mathrm{w} \\
\overrightarrow{\mathrm{u}}\end{array}$ & 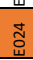 & 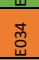 & $\begin{array}{l}\underline{m} \\
\\
\end{array}$ & $\begin{array}{l}\text { w } \\
\stackrel{u}{8} \\
\end{array}$ & 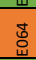 & $\begin{array}{l}\tilde{s} \\
\tilde{u}\end{array}$ & 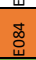 & $\begin{array}{l}\underline{u} \\
\stackrel{u}{\tilde{u}}\end{array}$ & 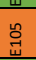 & 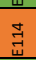 & 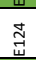 & $\begin{array}{l} \\
\tilde{m} \\
\tilde{u}\end{array}$ & 薯 & 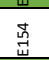 & 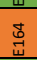 & 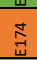 & 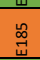 & $\begin{array}{l} \\
\\
\\
\end{array}$ & 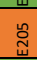 \\
\hline \multirow{2}{*}{18} & Max & .369 & 志 & 志 & 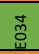 & 悉 & 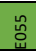 & 胥 & 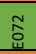 & 㘃 & 喽 & 总 & 声 & 离 & 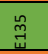 & 㞼 & 憙 & $\vec{d}$ & 志 & 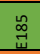 & 㖊 & 莡 \\
\hline & Min & .291 & 志 & J्ठ & 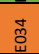 & 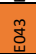 & 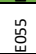 & 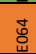 & : & 嘿 & 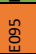 & 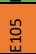 & 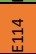 & 胥 & 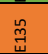 & 声 & 志 & 志 & $\underset{\mathrm{J}}{\Delta}$ & 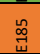 & 吢 & 䓀 \\
\hline \multirow{2}{*}{19} & $\operatorname{Max}$ & .342 & 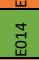 & 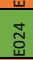 & $\begin{array}{l}\text { w } \\
\text { 䓵 }\end{array}$ & w & 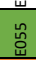 & $\begin{array}{l}\mathrm{w} \\
\overrightarrow{\mathrm{d}} \\
\mathrm{u}\end{array}$ & 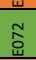 & 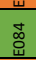 & 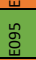 & w & 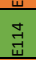 & $\begin{array}{l}\mathrm{w} \\
\\
\mathbb{Z}\end{array}$ & $\begin{array}{l}\omega \\
\stackrel{m}{\tilde{u}} \\
\stackrel{u}{*}\end{array}$ & 吾 & 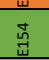 & $\begin{array}{l}w \\
\vec{w} \\
\end{array}$ & 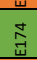 & $\begin{array}{l}\underset{\omega}{\infty} \\
\underset{\sim}{\Psi}\end{array}$ & 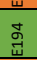 & 崫 \\
\hline & Min & .303 & 志 & dٓ & 咅 & o & 㟔 & 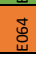 & 墕 & 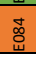 & 㟧 & 岂 & 胥 & 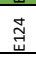 & 岕 & $\frac{w}{J}$ & 岕 & 壳 & $\begin{array}{l}\vec{J} \\
\vec{U}\end{array}$ & 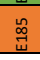 & 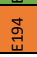 & 岂 \\
\hline
\end{tabular}

Ilustración 30: Análisis de Conglomerados de Consenso, Ronda 1

En la llustración 30 se han destacado tres elementos de la secuencia. El primero, correspondiente al análisis de grupos de cuatro expertos, destaca el tamaño máximo para el que se alcanza un consenso fuerte mínimo (>0.7), correspondiente al grupo de expertos E055, E124, E154 y E174. 
La Tabla 28 recoge la categorización de los expertos de este conglomerado.

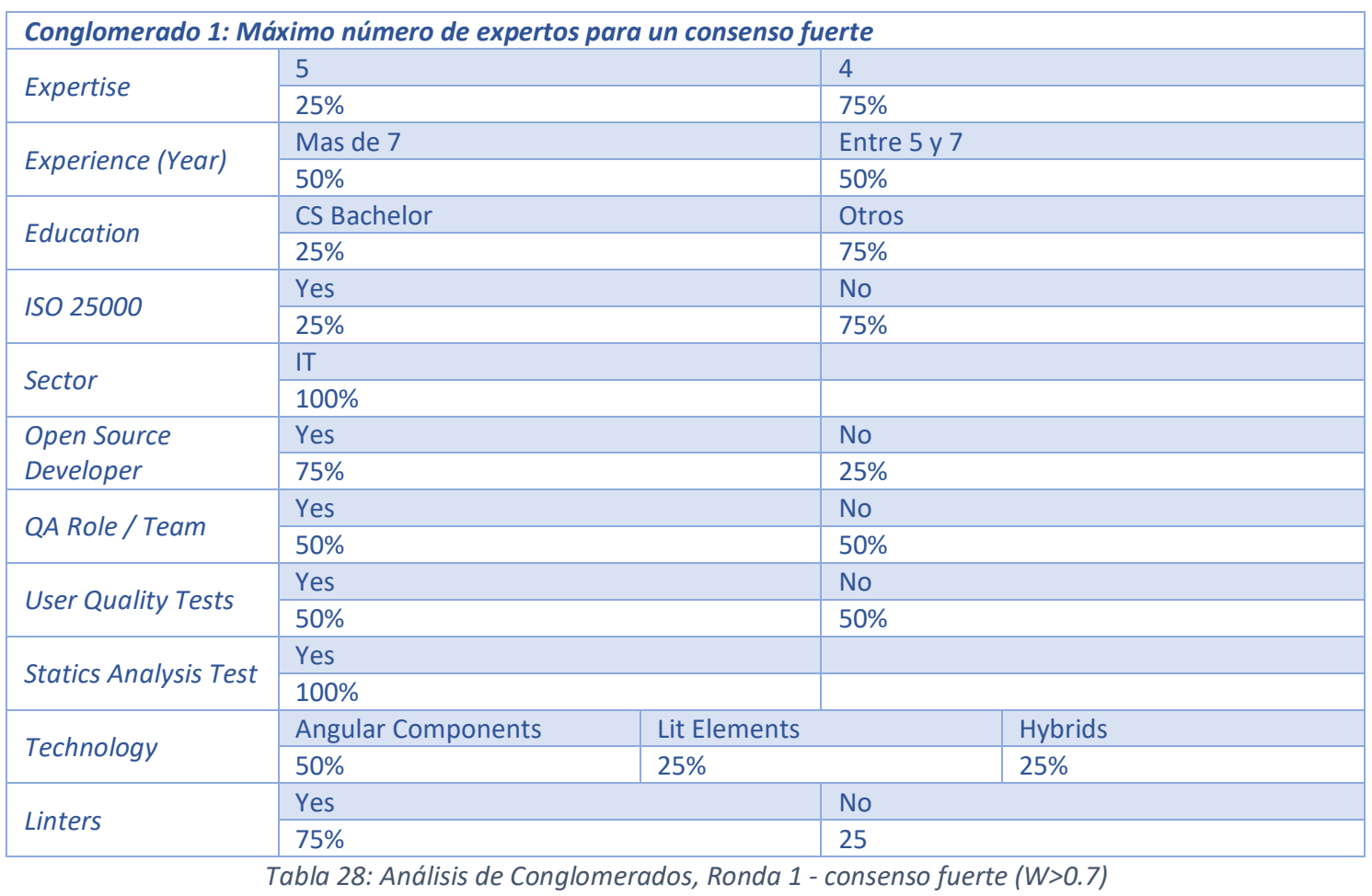

El siguiente elemento destacable, corresponde al análisis de grupos de siete expertos, corresponde al tamaño máximo para el que se alcanza un consenso moderado fuerte (>0.6), formado por grupo de expertos E055, E072, E124, E144, E154, E164 y E174. Es además el tamaño máximo de grupo para el que no se produce un solape entre los grupos de consenso máximo y mínimo. Es decir, las opiniones hasta este punto aún serían excluyentes. La Tabla 29 recoge la categorización de este grupo de expertos.

\begin{tabular}{|c|c|c|c|c|}
\hline \multicolumn{5}{|c|}{ Cluster 2: Maximum group of non-overlapping Max/Min consensus. } \\
\hline \multirow{2}{*}{ Expertise } & 5 & \multicolumn{2}{|c|}{4} & 2 \\
\hline & $25 \%$ & $50 \%$ & & 25 \\
\hline \multirow{2}{*}{ Experience (Year) } & \multicolumn{2}{|l|}{ Mas de 7} & \multicolumn{2}{|l|}{ Entre 5 y 7} \\
\hline & \multicolumn{2}{|l|}{$42.9 \%$} & \multicolumn{2}{|l|}{$57.1 \%$} \\
\hline \multirow{2}{*}{ Education } & \multicolumn{2}{|l|}{ CS Bachelor } & \multicolumn{2}{|l|}{ Otros } \\
\hline & \multicolumn{2}{|l|}{$28.6 \%$} & \multicolumn{2}{|l|}{$71.1 \%$} \\
\hline \multirow{2}{*}{ ISO 25000} & \multicolumn{2}{|l|}{ Yes } & \multicolumn{2}{|l|}{ No } \\
\hline & \multicolumn{2}{|l|}{$14.3 \%$} & \\
\hline \multirow{2}{*}{ Sector } & \multicolumn{2}{|l|}{ IT } & \multicolumn{2}{|l|}{$85.7 \%$} \\
\hline & \multicolumn{2}{|l|}{$100 \%$} & \\
\hline \multirow{2}{*}{$\begin{array}{ll}\text { Open } & \text { Source } \\
\text { Developer } & \end{array}$} & \multicolumn{2}{|l|}{ Yes } & \multicolumn{2}{|l|}{ No } \\
\hline & \multicolumn{2}{|l|}{$85.7 \%$} & \multicolumn{2}{|l|}{$14.3 \%$} \\
\hline \multirow{2}{*}{ QA Role / Team } & \multicolumn{2}{|l|}{ Yes } & \multicolumn{2}{|l|}{ No } \\
\hline & \multicolumn{2}{|l|}{$57.1 \%$} & \multicolumn{2}{|l|}{$42.9 \%$} \\
\hline \multirow{2}{*}{ User Quality Tests } & \multicolumn{2}{|l|}{ Yes } & No & \\
\hline & $57.1 \%$ & & $42.9 \%$ & \\
\hline & Yes & & No & \\
\hline Statics Analysis Test & $85.7 \%$ & & 14.3 & \\
\hline & Angular Components & Lit Elements & & Hybrids \\
\hline Technology & $42.9 \%$ & $42.9 \%$ & & $14.3 \%$ \\
\hline & Yes & & No & \\
\hline Linters & $85.7 \%$ & & 14.3 & \\
\hline
\end{tabular}

Tabla 29: Análisis de Conglomerados, Ronda 1 - consenso fuerte moderado(W>0.6)

Por último, el elemento correspondiente al análisis de grupo de doce expertos destaca el tamaño máximo para el que se alcanza un consenso moderado $(>0.5)$, correspondiente al grupo 
de expertos E014, E034, E055, E072, E124, E144, E154, E164, E174, E185, E194 y E205. La Tabla 30 recoge la categorización para este grupo de expertos.

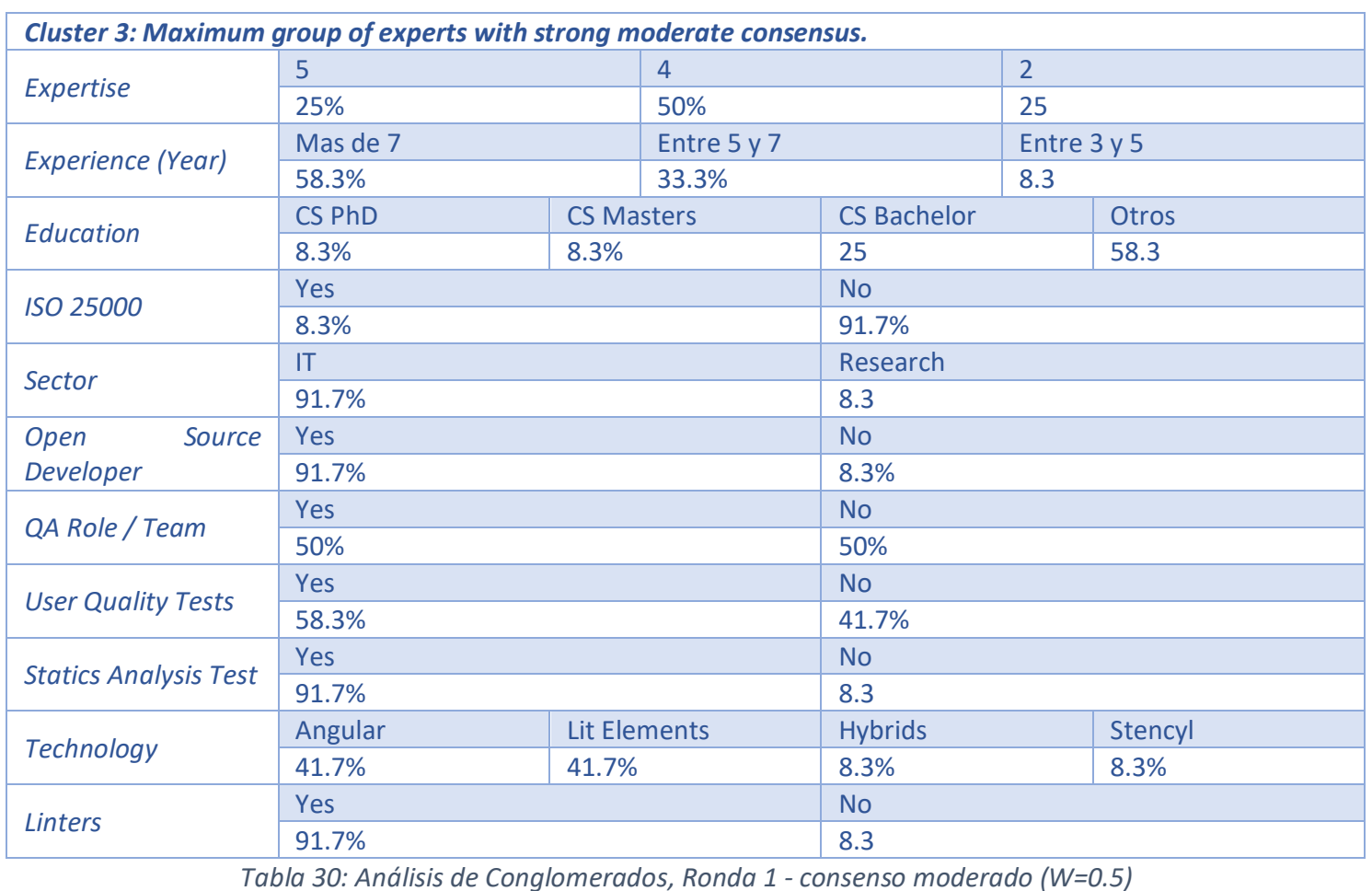

Finalmente, se recogen a continuación la representación de algunos datos sobre la evolución del estadístico $\mathrm{W}$ de Kendall según se procesa el consenso para grupos de expertos de distinto tamaño. Estos datos permiten observar la evolución del consenso máximo y mínimo, determinando la velocidad a la que convergen, dado que el valor máximo y mínimo coincide cuando consideramos el tamaño completo del grupo. La llustración 31 muestra como evoluciona el valor máximo, mínimo, medio y la varianza a lo largo del análisis combinatorio.

De igual forma, resulta interesante observar la evolución del consenso medio para cada tamaño de grupo, así como su varianza / desviación estándar, que apuntan a una distribución normal para los datos recogidos en esta investigación. Este dato permitiría evaluar el impacto de selección de subgrupos de discusión para abordar tareas específicas.

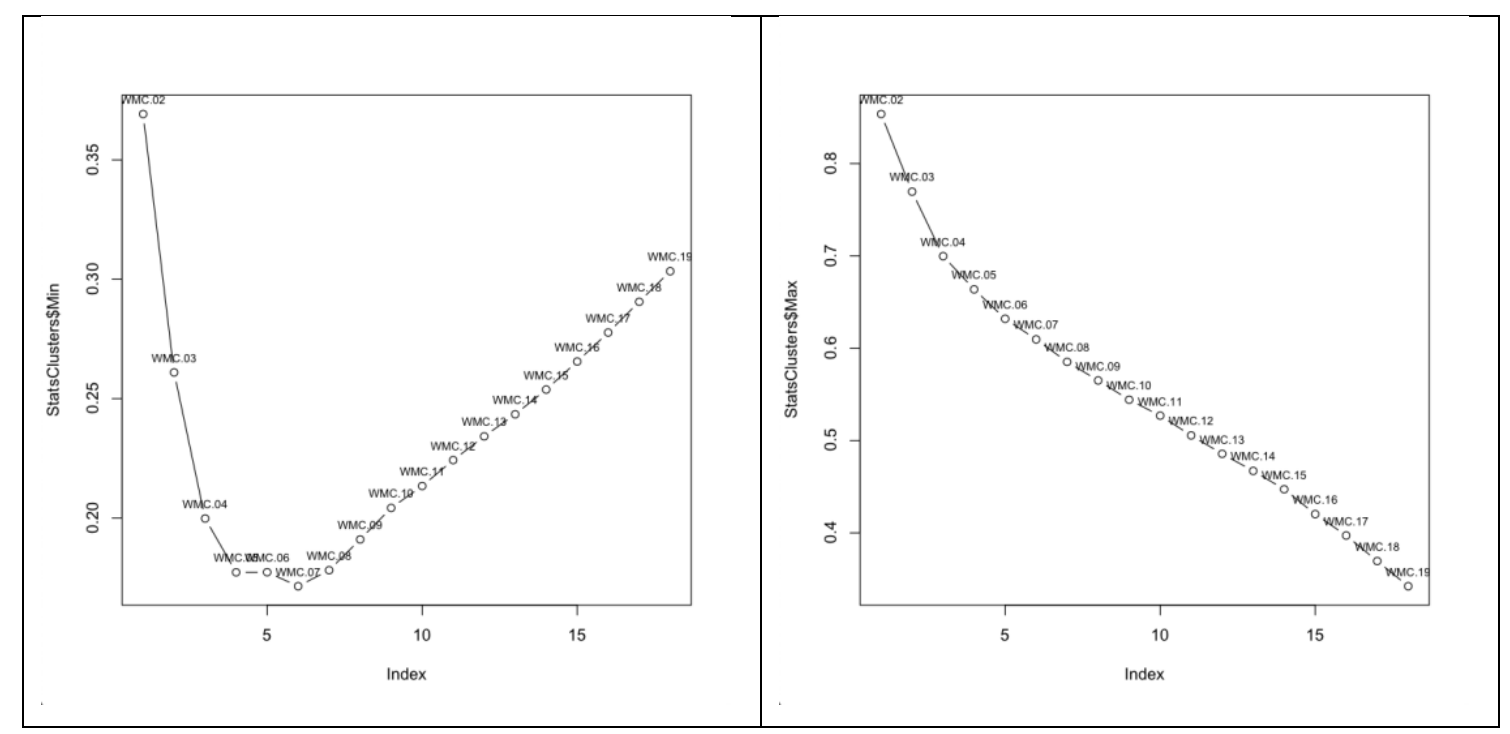




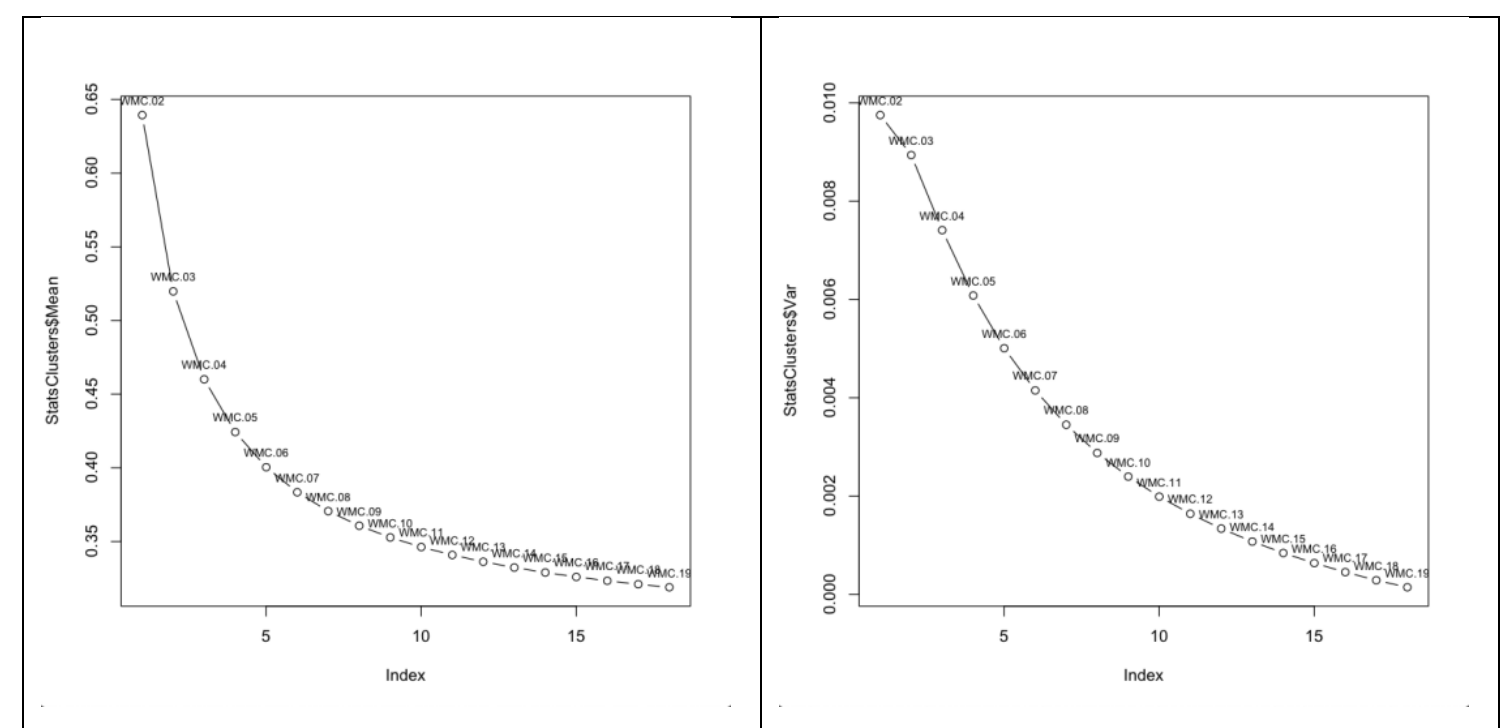

Ilustración 31: Análisis de la evolución dinámica del estadístico W de Kendal, Ronda 1.

El apéndice 9.2 incluye las distribuciones de consenso de cada iteración, permitiendo observar la posición relativa de los valores máximo, mínimo, medio en relación a la distribución completa. 


\subsubsection{Análisis de Conglomerados: segunda ronda}

Siguiendo la misma aproximación ya presentada para la primera iteración, en esta sección se presenta el proceso de análisis de conglomerados utilizando como medida la W de Kendall, en este caso correspondiente a los consensos de la segunda ronda.

\begin{tabular}{|c|c|c|c|c|c|c|c|c|c|c|c|c|c|c|c|c|c|c|c|c|c|c|}
\hline \multirow{2}{*}{2} & Max & .910 & 莕 & 志 & 䓛 & 胥 & 岂 & 志 & 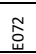 & 志 & 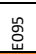 & 总 & ت & 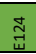 & 楚 & 㞼 & 鹃 & 䓌 & 志 & $\stackrel{\mathscr{D}}{\underset{\Psi}{\Psi}}$ & 駕 & 兽 \\
\hline & Mix & .569 & 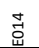 & 芯 & 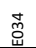 & 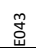 & 吕 & 惫 & 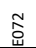 & 惌 & 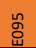 & 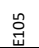 & 声 & $\underset{\mathbb{Z}}{\mathbb{W}}$ & $\stackrel{\mathscr{m}}{\tilde{m}}$ & $\underset{ت}{J}$ & 蔦 & t. & 莣 & $\stackrel{\leftrightarrow}{\mathrm{u}}$ & 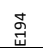 & 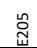 \\
\hline \multirow[t]{2}{*}{3} & Max & .853 & 胥 & ఫ్d & 蔰 & 誉 & 㟔 & 总 & 㣽 & 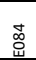 & 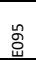 & 芑 & 志 & $\underset{\text { J }}{\mathbb{Z}}$ & $\stackrel{\mathscr{g}}{\tilde{u}}$ & 㞼 & 䓌 & 志 & 志 & 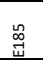 & 鹃 & $\underset{\underset{w}{W}}{\sim}$ \\
\hline & Min & . 453. & 节 & 岕 & 㑻 & 悉 & 㟔 & 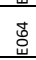 & 岕 & 总 & 岕 & $\underline{w}$ & $\vec{J}$ & 崩 & $\underline{\tilde{m}}$ & 表 & 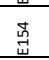 & $\vec{d}$ & 訔 & $\stackrel{w}{\mathscr{心}}$ & 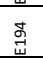 & 崩 \\
\hline \multirow{2}{*}{4} & Max & .826 & 峁 & 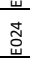 & 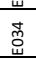 & 峛 & 㞻 & 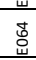 & $\begin{array}{l}\mathbf{w} \\
\tilde{u} \\
\end{array}$ & 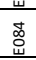 & 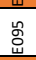 & 岂 & $\begin{array}{l}w \\
\vec{H}\end{array}$ & $\begin{array}{l}\mathbf{w} \\
\mathbb{Z} \\
\mathbb{u}\end{array}$ & 岕 & $\frac{W}{J}$ & 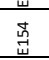 & 岌 & 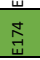 & 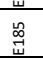 & 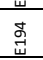 & w \\
\hline & Min & .426 & 志 & 志 & 莟 & 密 & 总 & 䓌 & 㣽 & 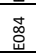 & 䓵 & 品 & 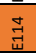 & 志 & 苞 & 䘽 & 嘻 & 壱 & 志 & $\underset{w}{\infty}$ & 㞭 & בֶّ \\
\hline \multirow[b]{2}{*}{5} & Max & .801 & 志 & 岕 & 总 & 旁 & 㟔 & 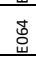 & 岕 & 总 & 怘 & 总 & ت्ञ & $\underset{\tilde{u}}{\mathbb{u}}$ & 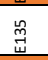 & 胥 & 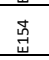 & d & 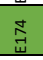 & $\stackrel{\mathscr{m}}{\mathscr{B}}$ & 吉 & 岂 \\
\hline & Min & .435 & 苔 & 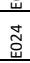 & 㟧 & 害 & 㟔 & $\begin{array}{l}\mathrm{w} \\
\overrightarrow{\mathrm{o}} \\
\mathrm{u}\end{array}$ & 岂 & $\begin{array}{l}\mathrm{w} \\
\mathrm{d} \\
\mathrm{u}\end{array}$ & w & w. & $\vec{w}$ & $\underset{\mathbb{Z}}{\mathbb{Z}}$ & $\begin{array}{l}\omega \\
\stackrel{m}{\tilde{m}} \\
\tilde{u}\end{array}$ & $\underset{\mathrm{J}}{\mathrm{J}}$ & 志 & 总 & 吉 & $\stackrel{\mathscr{\Delta}}{\Psi}$ & 㞭 & 通 \\
\hline \multirow[b]{2}{*}{6} & Max & .786 & 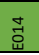 & 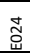 & 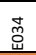 & 爰 & 嵓 & 总 & $\begin{array}{l}\tilde{\delta} \\
\end{array}$ & 喆 & 总 & 总 & 胥 & $\begin{array}{l}\vec{J} \\
\\
\end{array}$ & 嘿 & 丞 & $\begin{array}{l}\text { 罵 } \\
\end{array}$ & $\begin{array}{l}d \\
\end{array}$ & 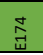 & 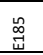 & 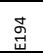 & 总 \\
\hline & Min & .450 & 吉 & 胥 & 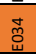 & 誉 & 崌 & 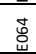 & $\tilde{\delta}$ & 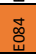 & 哭 & 然 & 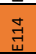 & 䓽 & 岕 & 急 & 志 & 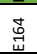 & 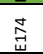 & 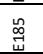 & 总 & 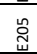 \\
\hline \multirow[b]{2}{*}{7} & Max & .763 & 咅 & 崩 & 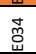 & 旁 & 㟔 & 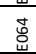 & 岕 & 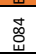 & 㟔 & 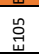 & 声 & $\begin{array}{l}\vec{D} \\
\vec{Z}\end{array}$ & 岕 & 声 & 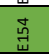 & $\begin{array}{l} \\
\\
\end{array}$ & 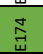 & 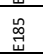 & $\begin{array}{l} \\
g \\
\end{array}$ & $\stackrel{w}{u}$ \\
\hline & Min & .461 & 营 & 㟧 & 峁 & 密 & 㟔 & 壳 & 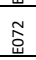 & 总 & 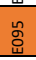 & 总 & 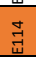 & $\underset{\underset{్}{ \pm}}{\mathbb{Z}}$ & 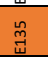 & 毒 & 总 & 志 & $\underset{ت}{ \pm}$ & $\stackrel{\leftrightarrow}{\underset{u}{\prime}}$ & 惢 & 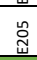 \\
\hline \multirow[b]{2}{*}{8} & Max & .741 & 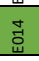 & 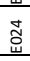 & 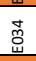 & 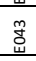 & 㟢 & $\begin{array}{l} \\
\\
\end{array}$ & 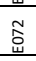 & 袁 & 总 & 总 & 离 & 胥 & $\begin{array}{l}\stackrel{w}{\tilde{m}} \\
\tilde{w}\end{array}$ & $\begin{array}{l} \\
\\
\end{array}$ & 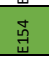 & $\begin{array}{l}\vec{d} \\
\vec{u}\end{array}$ & 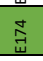 & 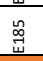 & $\begin{array}{l} \\
g \\
\vec{Z}\end{array}$ & 㟧 \\
\hline & Min & .470 & 壳 & 㟧 & 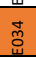 & 誉 & 㟔 & 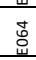 & 岕 & 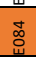 & 崩 & $\underline{\omega}$ & 荘 & $\begin{array}{l}\vec{W} \\
\mathbb{Z} \\
\mathbb{W}\end{array}$ & $\underline{w}$ & $\begin{array}{l} \\
\\
\end{array}$ & 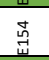 & 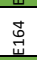 & 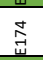 & 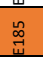 & \begin{tabular}{l} 
\\
\multirow{g}{J}{} \\
\end{tabular} & 岂 \\
\hline \multirow{2}{*}{9} & $\operatorname{Max}$ & .723 & 志 & 胥 & 蔰 & 釆 & 搃 & 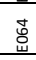 & 跑 & 志 & 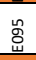 & 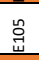 & 胥 & 志 & 嵒 & 胥 & 莺 & 䓌 & 吉 & $\stackrel{\mathscr{D}}{\Psi}$ & 吉 & : \\
\hline & Min & .474 & 志 & 胥 & 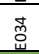 & 旁 & 虽 & 惫 & $\tilde{\tilde{s}}$ & 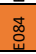 & 总 & 总 & 胥 & 志 & 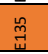 & 壱 & 䓌 & 志 & 咅 & 悤 & J & 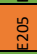 \\
\hline \multirow[b]{2}{*}{10} & Max & .707 & $\overrightarrow{\tilde{u}}$ & 㟧 & 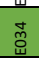 & 誉 & 怠 & 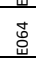 & 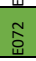 & 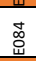 & w & $\begin{array}{l}\omega \\
\end{array}$ & 离 & $\begin{array}{l}\vec{w} \\
\tilde{u} \\
\tilde{u}\end{array}$ & $\begin{array}{l}\omega \\
\tilde{m} \\
\tilde{u} \\
\tilde{u}\end{array}$ & 竎 & 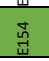 & 壱 & 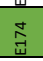 & 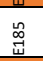 & 㟢 & 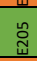 \\
\hline & Min & .481 & 总 & 峁 & 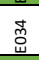 & 峛 & 虽 & 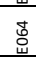 & 岕 & 崖 & 㟔 & 岂 & 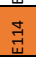 & 离 & $\stackrel{w}{\mathscr{m}}$ & $\begin{array}{l} \\
\end{array}$ & 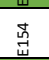 & 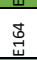 & 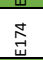 & 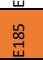 & 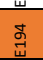 & 觊 \\
\hline \multirow{2}{*}{11} & Max & .693 & 壳 & 志 & 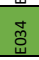 & 咅 & 㟔 & $\begin{array}{l}\text { 总 } \\
\end{array}$ & 墕 & 总 & 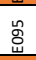 & 总 & $\overrightarrow{\vec{u}}$ & 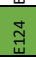 & 嵓 & $\underset{J}{\mathbb{Z}}$ & 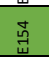 & 䓌 & 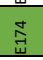 & 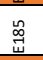 & 尌 & 通 \\
\hline & Min & .488 & 离 & 志 & 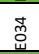 & 爰 & 总 & 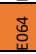 & $\tilde{\tilde{s}}$ & $\begin{array}{l}\text { 嘿 } \\
\end{array}$ & 嘧 & 总 & 胥 & 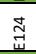 & $\underline{\tilde{B}}$ & 壳 & 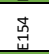 & 志 & 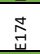 & 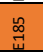 & 离 & $\stackrel{\ddot{z}}{\tilde{u}}$ \\
\hline \multirow{2}{*}{12} & Max & .677 & 岂 & 胥 & 惫 & 惫 & 罳 & $\begin{array}{l}\text { 总 } \\
\end{array}$ & 总 & 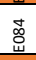 & 吕 & 哭 & 声 & 志 & 惢 & 売 & 莺 & 志 & 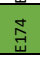 & 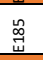 & 㞭 & : \\
\hline & Min & .494 & 莺 & 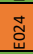 & 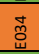 & 爰 & 总 & 志 & $\tilde{s}$ & $\begin{array}{l}\text { 嵒 } \\
\end{array}$ & 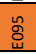 & 品 & 胥 & 志 & 㩊 & 急 & 志 & 䓌 & $\begin{array}{l} \\
\text { 节 }\end{array}$ & 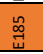 & 奇 & 总 \\
\hline \multirow{2}{*}{13} & Max & .665 & $\overrightarrow{\tilde{u}}$ & 岕 & 嶽 & 离 & 㟔 & 总 & 岕 & 总 & 亗 & 㞻 & $\underset{\vec{w}}{\vec{W}}$ & $\overrightarrow{\tilde{Z}}$ & 嵓 & 胥 & 壹 & 岂 & 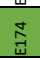 & 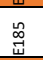 & 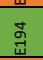 & 岂 \\
\hline & Min & & 志 & 范 & 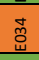 & 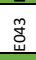 & 哭 & 㕝 & 管 & 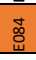 & 哭 & 品 & $\vec{J}$ & 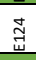 & $\stackrel{\mathscr{m}}{\tilde{U}}$ & 急 & 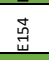 & 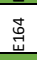 & 趸 & 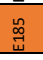 & 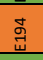 & 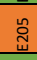 \\
\hline \multirow{2}{*}{14} & Max & .655 & 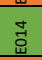 & $\underset{\tilde{d}}{\mathbf{W}}$ & 蔰 & 㟧 & 㟔 & 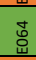 & 峜 & 总 & 总 & 总 & 节 & ב্ & 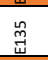 & $\underset{W}{\mathbb{J}}$ & 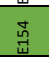 & 总 & 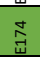 & 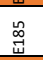 & 㞭 & 岂 \\
\hline & Min & .507 & 节 & 胥 & $\begin{array}{l}\text { 䓵 } \\
\end{array}$ & 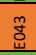 & 总 & 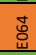 & 㣽 & 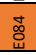 & 然 & 哭 & 胥 & 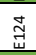 & 惢 & 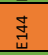 & 志 & 壳 & 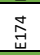 & 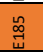 & 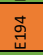 & 总 \\
\hline \multirow{2}{*}{15} & Max & .644 & $\stackrel{\vec{J}}{\mathrm{~d}}$ & 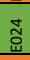 & 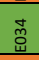 & 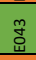 & 吕 & 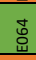 & 芯 & 总 & 吕 & 号 & 壵 & ב্ & 鹈 & 売 & 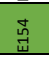 & 志 & 志 & $\stackrel{\mathscr{\Delta}}{\sim}$ & 总 & : \\
\hline & Min & .518 & 志 & 志 & 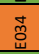 & 吕 & 㟔 & 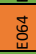 & $\begin{array}{l}\tilde{\delta} \\
\tilde{\delta} \\
\tilde{u}\end{array}$ & 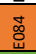 & 哭 & 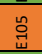 & 胥 & 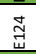 & 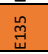 & 壱 & 烏 & 壳 & 䒾 & 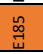 & 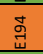 & 总 \\
\hline \multirow{2}{*}{16} & Max & .634 & 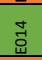 & 胥 & 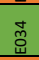 & 密 & 㟔 & 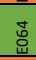 & 洁 & 嵒 & 总 & 总 & $\underset{\vec{H}}{\vec{H}}$ & $\underset{\tilde{Z}}{\mathbb{Z}}$ & 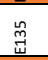 & $\underset{W}{\mathbb{Z}}$ & 嘉 & 志 & 志 & 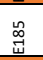 & 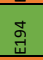 & : \\
\hline & Min & .527 & $\underset{\tilde{u}}{\vec{J}}$ & 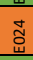 & 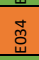 & 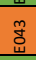 & 㟔 & $\begin{array}{l}\vec{J} \\
\end{array}$ & $\tilde{\tilde{w}}$ & 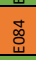 & 㟧 & $\stackrel{\omega}{\stackrel{m}{u}}$ & 売 & 离 & 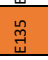 & 売 & 莺 & 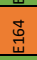 & 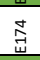 & $\stackrel{\omega}{\mathscr{\Delta}}$ & $\begin{array}{l} \\
g \\
\mathcal{Z}\end{array}$ & 峜 \\
\hline \multirow{2}{*}{17} & $\operatorname{Max}$ & .628 & 志 & 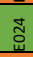 & 惫 & 密 & 㟔 & $\begin{array}{l}\text { 惫 } \\
\end{array}$ & $\underset{\tilde{W}}{\tilde{S}}$ & $\begin{array}{l}\text { 总 } \\
\end{array}$ & 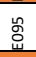 & 岂 & 声 & 胥 & 惢 & 壱 & 悫 & 壳 & $\begin{array}{l}\text { I } \\
\vec{W}\end{array}$ & 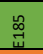 & $\begin{array}{l}d \\
\\
\end{array}$ & 总 \\
\hline & Min & .536 & 吉 & 芯 & 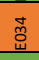 & 旁 & 愬 & 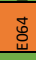 & 古 & 嘿 & 怘 & 兽 & 胥 & $\underset{\mathbb{Z}}{\mathbb{Z}}$ & $\stackrel{\mathscr{m}}{\tilde{u}}$ & 売 & 志 & 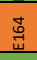 & 売 & 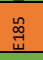 & 咅 & 莡 \\
\hline \multirow{2}{*}{18} & Max & .608 & 志 & 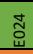 & 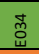 & 爰 & 㟔 & $\begin{array}{l}t \\
\\
\end{array}$ & $\tilde{\tilde{S}}$ & $\begin{array}{l}\text { 嘿 } \\
\end{array}$ & 哭 & 愙 & 声 & 苂 & 惢 & 急 & 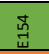 & $\begin{array}{l}t \\
\end{array}$ & 壳 & 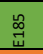 & 莺 & 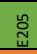 \\
\hline & Min & .545 & J & $\underset{\tilde{~}}{\tilde{u}}$ & 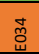 & $\stackrel{m}{\tilde{u}}$ & 崌 & 壱 & $\tilde{\Xi}$ & 嘿 & 怘 & 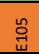 & $\vec{J}$ & 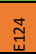 & 恖 & $\underset{⿱ 乛 龰}{*}$ & 鴶 & 壱 & 莣 & 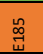 & 莺 & 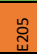 \\
\hline \multirow{2}{*}{19} & $\operatorname{Max}$ & .589 & $\underline{\underline{u}}$ & 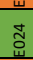 & 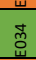 & w & 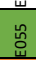 & $\begin{array}{l}\mathrm{w} \\
\\
\\
\end{array}$ & 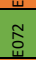 & 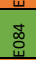 & 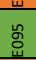 & 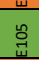 & 㟛 & $\begin{array}{l}w \\
\\
\mathbb{Z}\end{array}$ & $\begin{array}{l}w \\
\ddot{m} \\
\ddot{u} \\
\end{array}$ & $\underset{w}{J}$ & 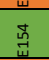 & $\begin{array}{l}w \\
\vec{w} \\
\end{array}$ & 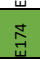 & $\begin{array}{l}\omega \\
\stackrel{\leftrightarrow}{\Psi} \\
\mathbb{W}\end{array}$ & \begin{tabular}{l} 
\\
\multirow{g}{J}{} \\
\\
\end{tabular} & 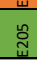 \\
\hline & Min & .553 & 志 & $\overline{\tilde{z}}$ & 惫 & 峦 & 岂 & 焉 & 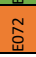 & 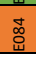 & 峞 & 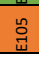 & $\vec{J}$ & $\bar{Z}$ & 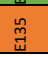 & 声 & 志 & 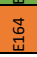 & 吉 & 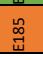 & 声 & 㟧 \\
\hline
\end{tabular}

Tabla 31: Análisis de Conglomerados de Consenso, Ronda 2

De los resultados de la segunda ronda de entrevista se desprenden algunas interesantes conclusiones, desde el punto de vista de la evolución del consenso. En primer lugar, la técnica de Delphi ha facilitado en este caso la homogeneización del grupo, que en conjunto alcanza un consenso entre los miembros de grupo de expertos de $W=0.564$, considerado moderado.

Analizando el consenso de subgrupos, se observa también una homogenización y así, comparado con los resultados de la primera ronda, el tamaño máximo de grupo para el que se alcanza un consenso fuerte $(>0.7)$ pasa de 4 a 10 expertos $(W=0.707)$. 
En cambio, el tamaño de grupo para el que el consenso máximo y mínimo conduce a grupos disjuntos pasa de 7 a 6 expertos, en este caso para un consenso fuerte $(W=0.786)$. La categorización correspondiente a este grupo de expertos se recoge en la Tabla 32.

\begin{tabular}{|c|c|c|}
\hline \multicolumn{3}{|c|}{ Conglomerado 1: Non overlapping Max/Min Consensus groups. } \\
\hline \multirow{2}{*}{ Expertise } & 5 & 4 \\
\hline & $16.7 \%$ & $83.3 \%$ \\
\hline \multirow{2}{*}{ Experience (Year) } & Mas de 7 & Entre 5 y 7 \\
\hline & $50 \%$ & $50 \%$ \\
\hline \multirow{2}{*}{ Education } & CS Bachelor & Otros \\
\hline & $16.7 \%$ & $83.3 \%$ \\
\hline \multirow{2}{*}{ ISO 25000} & Yes & No \\
\hline & $16.7 \%$ & $83.3 \%$ \\
\hline \multirow{2}{*}{ Sector } & IT & \\
\hline & $100 \%$ & \\
\hline \multirow{2}{*}{$\begin{array}{ll}\text { Open } & \text { Source } \\
\text { Developer } & \end{array}$} & Yes & No \\
\hline & $83.3 \%$ & $16.7 \%$ \\
\hline \multirow{2}{*}{ QA Role / Team } & Yes & No \\
\hline & $66.7 \%$ & $33.3 \%$ \\
\hline \multirow{2}{*}{ User Quality Tests } & Yes & No \\
\hline & $50 \%$ & $50 \%$ \\
\hline \multirow{2}{*}{ Statics Analysis Test } & Yes & No \\
\hline & $83.3 \%$ & $16.7 \%$ \\
\hline \multirow{2}{*}{ Technology } & Angular Components & Lit Elements \\
\hline & $33.3 \%$ & $66.7 \%$ \\
\hline \multirow{2}{*}{ Linters } & Yes & No \\
\hline & $83.3 \%$ & $16.7 \%$ \\
\hline
\end{tabular}

Tabla 32: Análisis de Conglomerados, Ronda 2 - consenso fuerte ( $W>0.7)$, sin solapes

Por otra parte, la categorización del grupo máximo, no solapante, para un consenso fuerte ( $W=$ 0.707) se incluye en la Tabla 34.

\begin{tabular}{|c|c|c|c|c|}
\hline \multicolumn{5}{|c|}{ Conglomerado 2: Strong consensus Max cluster. } \\
\hline \multirow{2}{*}{ Expertise } & 5 & \multicolumn{2}{|l|}{4} & 2 \\
\hline & $20 \%$ & $70 \%$ & & $10 \%$ \\
\hline \multirow{2}{*}{ Experience (Year) } & \multicolumn{2}{|l|}{ Mas de 7} & \multicolumn{2}{|l|}{ Entre 5 y 7} \\
\hline & \multicolumn{2}{|l|}{$60 \%$} & \multicolumn{2}{|l|}{$40 \%$} \\
\hline \multirow{2}{*}{ Education } & CS Master & \multicolumn{2}{|l|}{ CS Bachelor } & Otros \\
\hline & $10 \%$ & $20 \%$ & & $70 \%$ \\
\hline \multirow{2}{*}{ ISO 25000} & \multicolumn{2}{|l|}{ Yes } & \multicolumn{2}{|l|}{ No } \\
\hline & \multicolumn{2}{|l|}{$10 \%$} & \\
\hline \multirow{2}{*}{ Sector } & \multicolumn{2}{|l|}{ IT } & \multicolumn{2}{|l|}{$90 \%$} \\
\hline & \multicolumn{2}{|l|}{$100 \%$} & \\
\hline \multirow{2}{*}{$\begin{array}{ll}\text { Open } & \text { Source } \\
\text { Developer } & \end{array}$} & \multicolumn{2}{|l|}{ Yes } & \multicolumn{2}{|l|}{ No } \\
\hline & \multicolumn{2}{|l|}{$90 \%$} & \multicolumn{2}{|l|}{$10 \%$} \\
\hline \multirow{2}{*}{ QA Role / Team } & \multicolumn{2}{|l|}{ Yes } & \multicolumn{2}{|l|}{ No } \\
\hline & \multicolumn{2}{|l|}{$50 \%$} & \multicolumn{2}{|l|}{$50 \%$} \\
\hline \multirow{2}{*}{ User Quality Tests } & \multicolumn{2}{|l|}{ Yes } & \multicolumn{2}{|l|}{ No } \\
\hline & \multicolumn{2}{|l|}{$50 \%$} & \multicolumn{2}{|l|}{$50 \%$} \\
\hline & Yes & & No & \\
\hline Statics Analysis Test & $90 \%$ & & $10 \%$ & \\
\hline & Angular Components & Lit Elements & & Hybrids \\
\hline Technology & $40 \%$ & $50 \%$ & & $10 \%$ \\
\hline linters & Yes & & No & \\
\hline Linters & $90 \%$ & & $10 \%$ & \\
\hline
\end{tabular}

Finalmente, como ya se hizo en el análisis de conglomerados de la primera ronda, la llustración 32 recoge la evolución dinámica de las estadísticas discretas de los niveles de consenso. 


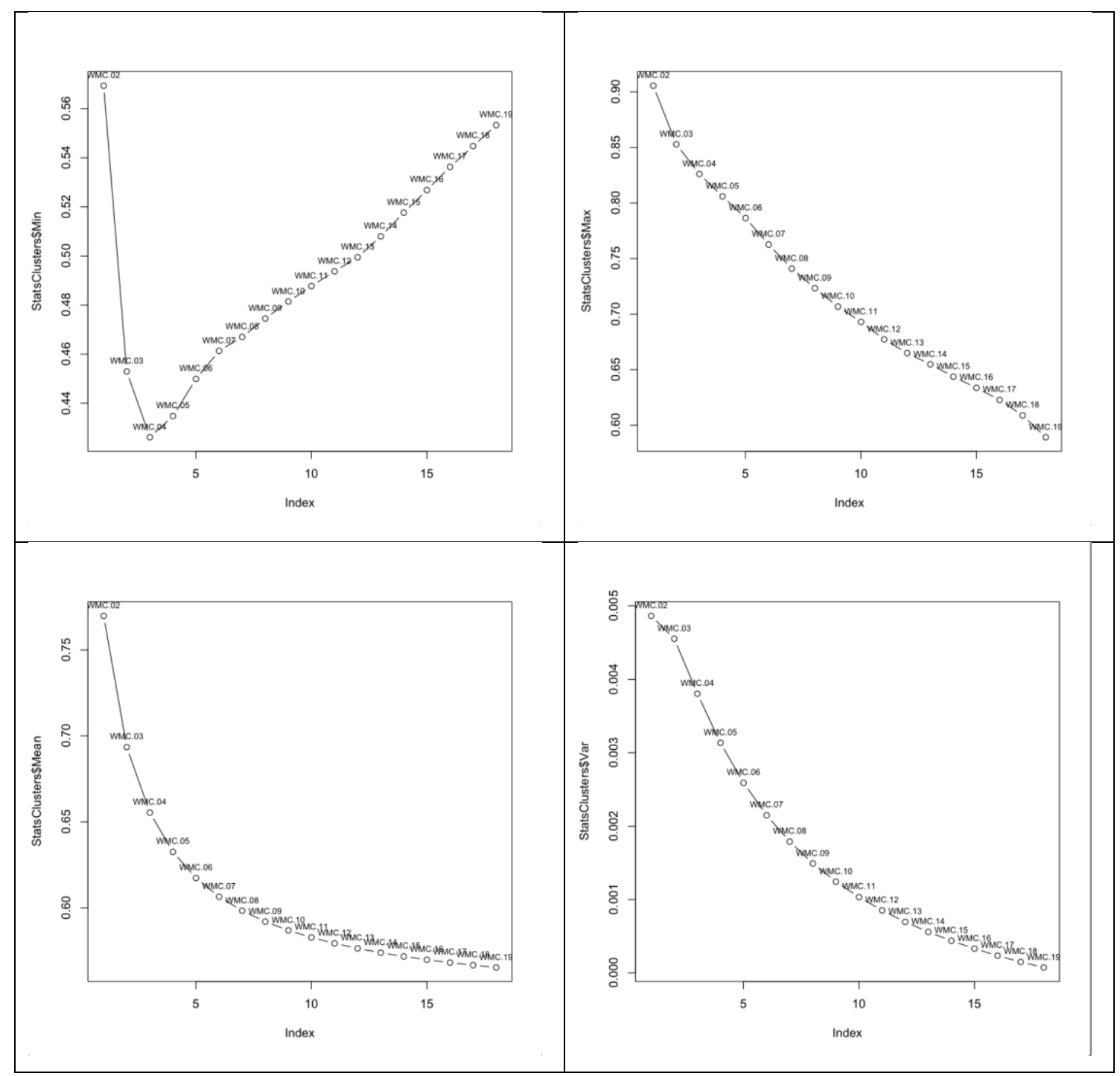

Ilustración 32: Análisis de la evolución dinámica del estadístico W de Kendal, Ronda 2.

Para esta segunda ronda, una vez alcanzado el consenso, se procede al análisis de los conglomerados de expertos de segundo nivel, es decir, aquellos que no alcanzan un consenso fuerte $(W>0.7)$, buscando entender si entre los discrepantes existe cierto nivel de acuerdo. De nuevo, lo interesante de esta aproximación es la identificación de categorías que respondan a contextos específicos.

Para ello, partiendo de la información recogida en la Tabla 31, se procede como sigue:

1. Se establece un valor de consenso de corte. En este caso seleccionamos el valor de W que se obtiene para el grupo de seis expertos de máximo consenso, es decir, $W=$ 0.786 , que corresponde con un consenso fuerte.

2. Se elimina de grupo inicial los expertos que forman parte del grupo de consenso máximo y se vuelve a realizar el proceso de análisis de conglomerados de Kendall.

Para cada iteración de este proceso se analizará el nivel de consenso de cada uno de los conglomerados, tanto entre los expertos restantes, como entre rondas. De esta forma, eliminando el conglomerado no solapante para el que se obtiene un valor máximo, el consenso entre los expertos restantes es de $W=0.527$ y $W=0.987$ para el consenso del grupo restante con la iteración anterior. 
Una vez eliminados los expertos del primer grupo, se realiza el análisis de todas las combinaciones de expertos restantes, calculando los valores máximos, mínimos, medios y la desviación estándar de valor del estadístico $\mathrm{W}$ de Kendall. Los resultados son los siguientes, donde se indica un conglomerado con consenso fuerte $W=0.708$.

\begin{tabular}{|c|c|c|c|c|c|c|c|c|c|c|c|c|c|c|c|c|}
\hline & & & 柆 & & & & & & & & & & & & & \\
\hline \multirow{2}{*}{2} & Max & .880 & 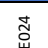 & 䓵 & $\frac{m}{\tilde{u}}$ & 总 & 惢 & 嵒 & 总 & 总 & 声 & 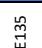 & 志 & 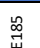 & 总 & 嵌 \\
\hline & Min & .569 & d̃ & 蔰 & fै & 惫 & 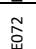 & 患 & 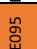 & 总 & $\exists$ & 恖 & 志 & 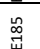 & 总 & 疋 \\
\hline \multirow{2}{*}{3} & Max & .793 & & 䀫 & 飬 & 总 & 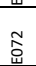 & 总 & 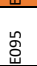 & 总 & $\underset{\tilde{H}}{\vec{H}}$ & 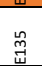 & 吉 & $\stackrel{\mathscr{\Xi}}{\underset{\sim}{*}}$ & J & 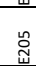 \\
\hline & Min & .453 & త్ర & 总 & f & 总 & 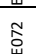 & 总 & 嘿 & 总 & $\stackrel{ \pm}{\vec{u}}$ & 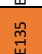 & 志 & 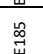 & 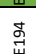 & :ٌ \\
\hline \multirow[b]{2}{*}{4} & Max & .739 & 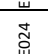 & 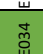 & $\frac{m}{s}$ & 㕝 & 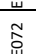 & 惌 & 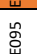 & $\stackrel{\text { g }}{g}$ & $\exists$ & 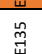 & 志 & $\stackrel{\mathscr{\Xi}}{\sharp}$ & g & 先 \\
\hline & Min & .426 & $\frac{\omega}{\tilde{Z}}$ & 总 & $\frac{w}{\tilde{g}}$ & 总 & 㷛 & 丞 & 怘 & $\underline{w}$ & 荘 & 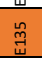 & 苟 & 怘 & 苟 & 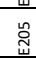 \\
\hline \multirow{2}{*}{5} & Max & .708 & 岂 & 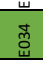 & $\frac{w}{\tilde{m}}$ & $\frac{w}{d}$ & 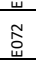 & 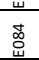 & 总 & $\stackrel{w}{u}$ & 岂 & w & $\frac{w}{\tilde{u}}$ & 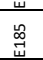 & 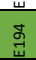 & 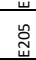 \\
\hline & Min & .437 & 壳 & 蔏 & $\stackrel{m}{\stackrel{m}{W}}$ & d্ & 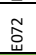 & 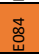 & 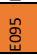 & 苛 & 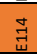 & 总 & 苟 & $\stackrel{\mathscr{\Xi}}{\underset{\Psi}{\Psi}}$ & 奇 & 莡 \\
\hline \multirow[b]{2}{*}{6} & Max & .681 & 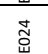 & 嗯 & gै & d & 总 & 总 & 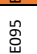 & 总 & $\underset{ت}{ \pm}$ & 駡 & 䔍 & 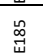 & 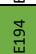 & 岂 \\
\hline & Min & .450 & w & 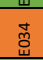 & $\frac{w}{q}$ & 惫 & 㣽 & 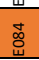 & 总 & 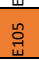 & $\vec{J}$ & 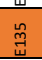 & 志 & 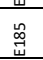 & 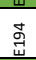 & : \\
\hline \multirow[b]{2}{*}{7} & Max & .663 & 范 & 惢 & $\frac{w}{\tilde{m}}$ & 岁 & 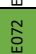 & 䓌 & 怘 & 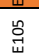 & 岂 & 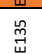 & 岕 & 岕 & 嶽 & 㟧 \\
\hline & Min & .461 & W & 总 & 息 & 总 & 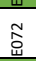 & 总 & 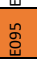 & $\stackrel{w}{u}$ & $\vec{W}$ & 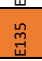 & 鹃 & $\stackrel{\mathscr{\Xi}}{\underset{\sim}{*}}$ & 悫 & 忌 \\
\hline \multirow{2}{*}{8} & Max & .647 & $\frac{\tilde{u}}{\tilde{J}}$ & 产 & $\begin{array}{l} \\
\end{array}$ & d্ & 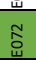 & 总 & 哭 & 总 & ت્ & $\stackrel{\stackrel{m}{\exists}}{\underline{u}}$ & ড్ & $\stackrel{\leftrightarrow}{్}$ & 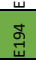 & $\tilde{w}$ \\
\hline & Min & .468 & 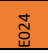 & 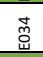 & 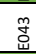 & 总 & 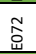 & 嵒 & 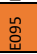 & 莒 & $\vec{I}$ & 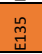 & 䔍 & 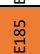 & 嵒 & 岂 \\
\hline \multirow[b]{2}{*}{9} & Max & .634 & J̃ & 总 & $\frac{m}{\tilde{u}}$ & 离 & $\tilde{s}$ & 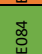 & 骂 & 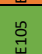 & 苐 & 岕 & 志 & 怘 & 吉 & 㟧 \\
\hline & Min & .475 & 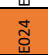 & 嗯 & m & 惫 & 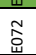 & 嵒 & 总 & $\underline{m}$ & 荘 & $\stackrel{\underline{m}}{\underline{m}}$ & 苦 & 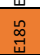 & J & $\stackrel{w}{\stackrel{u}{u}}$ \\
\hline \multirow{2}{*}{10} & Max & .617 & త్ & 产 & m & 总 & $\underset{\mathrm{d}}{\tilde{S}}$ & 志 & 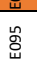 & 总 & $\underset{ت}{ \pm}$ & $\stackrel{\mathscr{m}}{\tilde{U}}$ & 䓌 & $\underset{\underset{\sim}{\infty}}{\llcorner}$ & ذ్ & 疋 \\
\hline & Min & .483 & 范 & 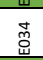 & 吕 & 总 & 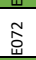 & 嘿 & ณू & 总 & $\vec{I}$ & 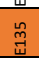 & 志 & $\stackrel{\mathscr{J}}{్}$ & J & 己ٌ \\
\hline \multirow{2}{*}{11} & Max & .603 & 范 & 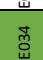 & 誉 & 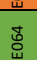 & $\tilde{\delta}$ & 嵒 & 总 & 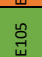 & 志 & $\stackrel{\mathscr{m}}{\tilde{U}}$ & 䔍 & $\stackrel{\mathscr{\Xi}}{\underset{\Psi}{\Psi}}$ & ذ్ & 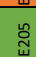 \\
\hline & Min & .490 & 㟧 & 总 & 学 & 总 & 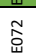 & 嵒 & 吕 & 总 & $\underline{\underline{u}}$ & 怘 & 莺 & 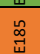 & 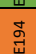 & 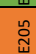 \\
\hline \multirow{2}{*}{12} & Max & .585 & త్ర్జ & 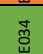 & 多 & d্d & 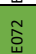 & 总 & 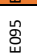 & $\stackrel{n}{\stackrel{u}{u}}$ & $\underset{ت}{ \pm}$ & 兽 & 岂 & 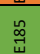 & 志 & జٌ \\
\hline & Min & .504 & 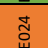 & 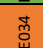 & 学 & 惫 & s్ & 嘿 & 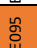 & 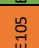 & $\vec{\exists}$ & 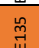 & 志 & 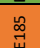 & J & ฉั \\
\hline \multirow[b]{2}{*}{13} & Max & .564 & 志 & 悥 & 孞 & 志 & 墕 & 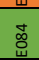 & 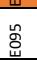 & $\stackrel{\text { }}{\stackrel{u}{u}}$ & 䔍 & 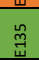 & 駕 & $\stackrel{\mathscr{\infty}}{\underset{\Psi}{\Psi}}$ & 胥 & 莡 \\
\hline & Min & .515 & $\frac{w}{\tilde{J}}$ & 骨 & \% & $\stackrel{d}{8}$ & $\tilde{\delta}$ & 志 & ณू & $\stackrel{n}{g}$ & $\Xi$ & $\stackrel{m}{\dddot{m}}$ & 声 & $\stackrel{\Xi}{\approx}$ & gू & $\frac{w}{\breve{a}}$ \\
\hline
\end{tabular}

Tras eliminar los expertos pertenecientes a este nuevo conglomerado, se vuelven a obtener las medidas de consenso entre rondas $W=0.944$ y correspondiente a los expertos restantes $W=$ 0.506 .

\begin{tabular}{|c|c|c|c|c|c|c|c|c|c|c|c|}
\hline & & & $A(01) E 064$ & |E095 & E114 & E084 & & & & & \\
\hline \multirow{2}{*}{2} & Max & 8.843 & 志 & 总 & 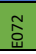 & 总 & 总 & $\underset{\exists}{ \pm}$ & 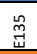 & $\stackrel{\leftrightarrow}{\underset{్}{్}}$ & : \\
\hline & Min & .569 & 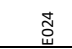 & 妾 & 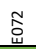 & 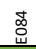 & 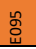 & 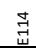 & $\stackrel{\mathscr{m}}{\tilde{H}}$ & 总 & 莡 \\
\hline \multirow{2}{*}{3} & Max & .753 & 芯 & 志 & 舒 & 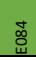 & 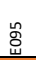 & $\vec{Z}$ & $\stackrel{\mathscr{m}}{\tilde{W}}$ & 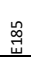 & 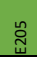 \\
\hline & Min & .452 & 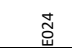 & 志 & 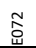 & 总 & 怘 & $\vec{W}$ & 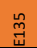 & 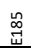 & $\underset{\sim}{\sim}$ \\
\hline \multirow{2}{*}{4} & Max & $\begin{array}{l}.689 \\
\end{array}$ & 芯 & ¿্口 & s్ & 参 & 号 & 胥 & 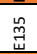 & 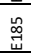 & 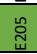 \\
\hline & Min & .446 & 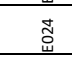 & 总 & 㣽 & 总 & 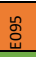 & $\underset{\exists}{ \pm}$ & 鴾 & 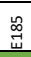 & 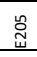 \\
\hline \multirow[b]{2}{*}{5} & Max & $\begin{array}{l}.647 \\
\end{array}$ & 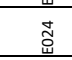 & 志 & 㣽 & 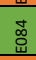 & 忠 & $\vec{z}$ & $\stackrel{\mathscr{m}}{\tilde{W}}$ & $\stackrel{\leftrightarrow}{్}$ & 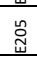 \\
\hline & Min & .457 & 志 & 志 & 芯 & 惢 & 吕 & I & $\stackrel{\mathscr{m}}{\tilde{u}}$ & 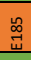 & $\stackrel{\sim}{\tilde{W}}$ \\
\hline \multirow{2}{*}{6} & Max & 2.615 & 芯 & d. & 芯 & 惢 & 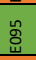 & 志 & 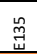 & $\stackrel{\infty}{\breve{్}}$ & : \\
\hline & Min & .463 & 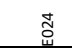 & 总 & 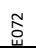 & 总 & 吕 & J्य & 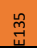 & $\stackrel{\mathscr{B}}{\underset{W}{4}}$ & 䓵 \\
\hline \multirow[b]{2}{*}{7} & Max & .586 & 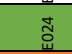 & 离 & 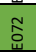 & 志 & 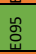 & 壱 & 总 & $\stackrel{\mathscr{B}}{\breve{u}}$ & 雚 \\
\hline & Min & $\begin{array}{l}.467 \\
\end{array}$ & d̃ & 总 & 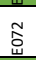 & 嵒 & 怘 & ت्चี & $\stackrel{\mathscr{m}}{\tilde{u}}$ & $\underset{్}{\stackrel{్}{్}}$ & 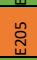 \\
\hline \multirow[b]{2}{*}{8} & Max & .556 & 胥 & ఫ্ & స్ & 嵒 & 总 & $\vec{J}$ & $\stackrel{m}{\tilde{u}}$ & $\underset{్ త ్}{\infty}$ & : \\
\hline & Min & .481 & dू & 总 & 今̃ & 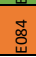 & 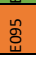 & ज्ञ & $\stackrel{m}{g}$ & $\stackrel{\infty}{\infty}$ & ֻٌ జِ \\
\hline
\end{tabular}


La Tabla 36 y la Tabla 37 recogen los conglomerados finales para las dos últimas iteraciones y donde se pueden observar niveles de consensos altos, $W=0.797$ y $W=0.757$ respectivamente. Teniendo en cuenta que el consenso entre los expertos del conglomerado es en el primer caso $W=0.494$ y $W=0.534$, estos resultados muestran un elevado nivel de aglomeración si se seleccionan los expertos adecuados. Por último señalar que le consenso entre estas iteraciones y las anteriores son en ambos casos $W=0.92$, es decir, estas opiniones no cambiarían significativamente si se realizase una tercera ronda de entrevistas del Método Delphi.

\begin{tabular}{|c|c|c|c|c|c|c|c|c|}
\hline & & & (01) $E 0$ & ( $(04) E 18$ & & & & \\
\hline \multirow[b]{2}{*}{2} & Max & .797 & E024 & E064 & E095 & E114 & E135 & E185 \\
\hline & Min & .569 & E024 & E064 & E095 & E114 & E135 & E185 \\
\hline \multirow{2}{*}{3} & Max & $\begin{array}{l}.691 \\
\end{array}$ & E024 & E064 & E095 & E114 & E135 & E185 \\
\hline & Min & .453 & E024 & E064 & E095 & E114 & E135 & E185 \\
\hline \multirow{2}{*}{4} & Max & 2.625 & E024 & E064 & E095 & E114 & E135 & E185 \\
\hline & Min & .469 & E024 & E064 & E095 & E114 & E135 & E185 \\
\hline \multirow{2}{*}{5} & Max & .564 & E024 & E064 & E095 & E114 & E135 & E185 \\
\hline & Min & .048 & E024 & E064 & E095 & E114 & E135 & E185 \\
\hline
\end{tabular}

\begin{tabular}{|l|l|l|l|l|l|l|}
\hline & & & \multicolumn{1}{|l|}{ (01)E024 (02)E185 (03)E114 (04)E135 } & E185 \\
\hline \multirow{2}{*}{2} & Max & .757 & E024 & E114 & E135 & E185 \\
\cline { 2 - 7 } & Min & .605 & E024 & E114 & E135 & E185 \\
\hline \multirow{3}{*}{3} & Max & .0643 & E024 & E114 & E135 & E185 \\
\cline { 2 - 7 } & Min & .537 & E024 & E114 & E135 & \\
\hline
\end{tabular}

Tabla 37: Análisis de Conglomerados, Ronda 2 - Conglomerados de Quinto Nivel

\subsection{Modelo de Calidad de Componentes Web}

El modelo de calidad obtenido en este trabajo de investigación se resume en la llustración 33 que muestra la cobertura de las características de calidad que el estándar ISO/IEC 25010 propone para la calidad de producto y la calidad en uso. Se trata de una forma alternativa de representación de los datos mostrados en la llustración 25.

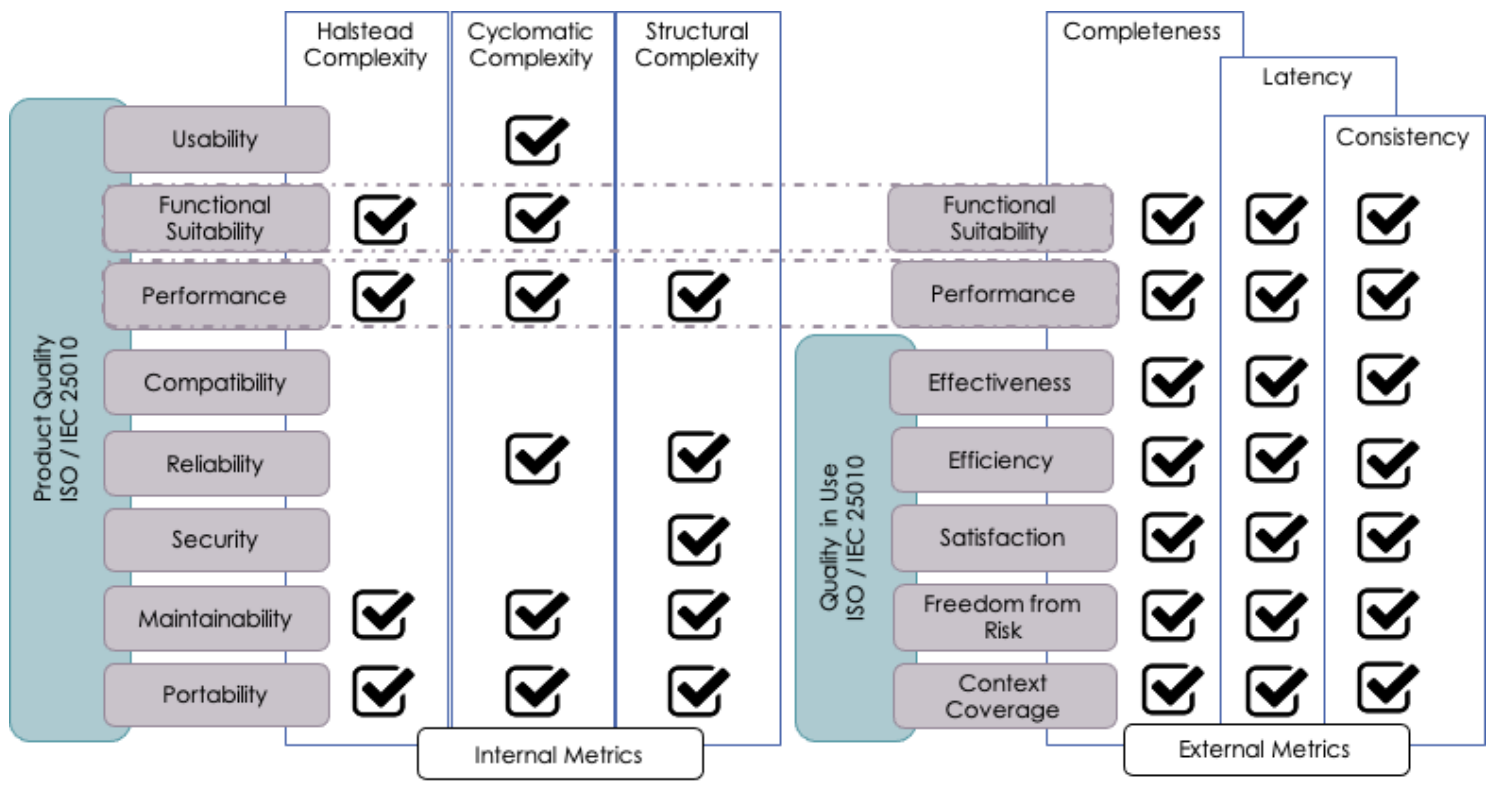


Tal y como se ha explicado en la sección 5.1.3, la cobertura se establece siguiendo una condición fuerte, exigiendo que el nivel de acuerdo, que corresponde con valoraciones mayores de tres, supere al desacuerdo, que corresponde con valores de evaluación menores de tres. Aunque el valor intermedio, que corresponde con el valor de tres, se interpreta como un acuerdo no determinante con la cobertura propuesta, con el fin eliminar posibles sesgos o malentendidos por parte de los entrevistados, se ha decidido aplicar esta condición fuerte, excluyendo completamente aquellas valoraciones intermedias.

Aunque se realizará una valoración de los resultados en la sección 6.4, vale la pena añadir algunos comentarios aquí. Por un lado, la cobertura de las características de calidad de producto y de calidad en uso son significativas: la calidad en uso se encuentra completamente cubierta, de acuerdo con el consenso alcanzado por los expertos, mientras que las características de la calidad de producto cuentan con una cobertura parcial.

A la hora de diseñar los atributos de calidad, se ha primado la sencillez y familiaridad, con el fin de reducir la ambigüedad potencial en el lado de la comprensión de las características de calidad. El proceso de entrevistas y las conversaciones con los expertos así lo han confirmado, lo que permite aventurar cierto análisis de las razones que subyacen detrás de estos resultados.

En particular, respecto al nivel de cobertura de las características de calidad de producto, esto permite pensar que la cobertura completa de las características de rendimiento, portabilidad y mantenimiento responden al hecho de que estas características son más fácilmente entendibles en general y por los expertos en desarrollo web en particular.

En el extremo opuesto estarían las características de usabilidad y seguridad que, si bien resultan presentes de manera constante en el desarrollo web, cuentan con elementos de mayor nivel de subjetivad en el primer caso o resultan difícilmente evaluables con métricas tan sencillas en el segunda.

En cuanto a los resultados de la cobertura de las características de calidad en uso, la unanimidad apunta a una valoración de grano grueso, que reconoce la conexión, pero impide precisar con suficiente nivel de detalle como para alumbrar diferencias significativas entre características.

En cualquier caso, una revisión de estos aspectos se completará con más detalles en la sección correspondiente al análisis de los resultados del trabajo de investigación.

\subsection{Resultados del Análisis y Experimentación Cuantitativa.}

Los resultados obtenidos de la experimentación, de acuerdo con el diseño de la investigación, se organiza bajo una triple perspectiva: de escenario, de componente y de estudio.

La perspectiva de escenario muestra la valoración de cada componente, caracterizados con los correspondientes atributos sintéticos, por parte de los usuarios a nivel de escenario. Los resultados organizados en forma tabular tienen el aspecto que se recoge en la llustración 34 . El conjunto completo de datos se encuentra incluido en el apéndice 9.3.

\begin{tabular}{|c|c|c|c|c|c|c|c|c|}
\hline \multirow{9}{*}{ 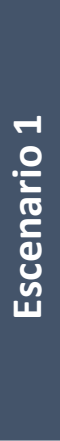 } & & \multicolumn{3}{|c|}{ Atributos Internos / Estáticos } & \multicolumn{3}{|c|}{ Atributos Externos / Dinámicos } & \multirow{2}{*}{ Valoración } \\
\hline & & Tamaño & C. Interna & C. Externa & Completitud & Latencia & Refresco & \\
\hline & \multirow{5}{*}{$\begin{array}{l}\text { Google+ } \\
\text { Twitter } \\
\text { Facebook } \\
\text { Pinterest } \\
\text { Bolsa }\end{array}$} & 2.76 & 5.00 & 36.00 & $\begin{array}{r}5.00 \\
\end{array}$ & 1210.42 & 50.41 & 4.33 \\
\hline & & 3.53 & 5.00 & 25.00 & 5.00 & 1433.48 & 51.10 & 3.83 \\
\hline & & 3.40 & 5.00 & 29.00 & 5.00 & 665.95 & 56.81 & 2.83 \\
\hline & & 3.52 & 5.00 & 62.00 & 5.00 & 117.19 & 53.10 & 3.17 \\
\hline & & 3.90 & 5.00 & 53.00 & 5.00 & 833.45 & 53.82 & 2.50 \\
\hline & \multirow{2}{*}{$\begin{array}{l}\text { Tiempo } \\
\text { Tráfico }\end{array}$} & 3.03 & 5.00 & 12.00 & 5.00 & 1876.99 & 56.34 & 2.33 \\
\hline & & 3.79 & 4.00 & 30.00 & 5.00 & 499.60 & 59.26 & 2.33 \\
\hline
\end{tabular}


La perspectiva de componente muestra la valoración de los usuarios de cada uno de los componentes, de nuevo caracterizados con atributos sintéticos, a lo largo de todos los escenarios. Los resultados organizados en forma tabular tienen el aspecto que presenta la llustración 35. El conjunto completo de los datos se encuentra incluido en el apéndice 9.4.

\begin{tabular}{|c|c|c|c|c|c|c|c|c|}
\hline & & \multicolumn{3}{|c|}{ Atributos Internos / Estáticos } & \multicolumn{3}{|c|}{ Atributos Externos / Dinámicos } & \multirow{3}{*}{$\begin{array}{c}\text { Valoración } \\
\text { V }\end{array}$} \\
\hline & & Tamaño & C. Interna & C. Externa & Completitud & Latencia & Refresco & \\
\hline & & 11 & 12 & 13 & E1 & E2 & E3 & \\
\hline \multirow{16}{*}{ 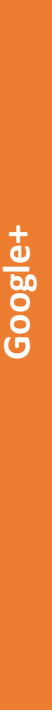 } & Escenario 1 & 2.76 & 5.00 & 36.00 & 5.00 & 1210.42 & 50.41 & 4.33 \\
\hline & Escenario 2 & 3.10 & 4.00 & 36.00 & 5.00 & 1210.42 & 50.41 & 3.33 \\
\hline & Escenario 3 & 3.10 & 5.00 & 36.00 & 4.25 & 1210.42 & 50.41 & 2.50 \\
\hline & Escenario 4 & 3.10 & 5.00 & 36.00 & 5.00 & 3579.17 & 53.14 & 4.67 \\
\hline & Escenario 5 & 3.10 & 5.00 & 36.00 & 5.00 & 1210.42 & 50.41 & 2.67 \\
\hline & Escenario 6 & 3.10 & 5.00 & 36.00 & 5.00 & 1210.42 & 50.41 & 2.83 \\
\hline & Escenario 7 & 3.10 & 5.00 & 53.00 & 5.00 & 1210.42 & 50.41 & 2.17 \\
\hline & Escenario 8 & 3.10 & 5.00 & 36.00 & 5.00 & 3579.17 & 53.14 & 4.00 \\
\hline & Escenario 9 & 3.10 & 5.00 & 36.00 & 5.00 & 1210.42 & 50.41 & 3.50 \\
\hline & Escenario 10 & 3.10 & 5.00 & 36.00 & 5.00 & 1210.42 & 50.41 & 3.83 \\
\hline & Escenario 11 & 3.10 & 4.00 & 36.00 & 5.00 & 1210.42 & 50.41 & 3.83 \\
\hline & Escenario 12 & 3.10 & 5.00 & 36.00 & 5.00 & 1210.42 & 50.41 & 5.00 \\
\hline & Escenario 13 & 3.10 & 5.00 & 53.00 & 5.00 & 1210.42 & 50.41 & 3.83 \\
\hline & Escenario 14 & 2.76 & 5.00 & 36.00 & 5.00 & 1210.42 & 50.41 & 2.83 \\
\hline & Escenario 15 & 3.10 & 5.00 & 36.00 & 5.00 & 1210.42 & 50.41 & 4.33 \\
\hline & Escenario 16 & 3.10 & 5.00 & 36.00 & 5.00 & 1210.42 & 50.41 & 5.00 \\
\hline
\end{tabular}

Ilustración 35: Organización tabular de los Resultados Experimentales de un Componente

Por último, la perspectiva de estudio ofrece la valoración de los usuarios de los componentes a lo largo de todos los escenarios del estudio. Su organización tabular, resultado de la agregación de los resultados correspondientes a cada componente, se puede consultar en el apéndice 9.5.

\subsubsection{Categorización de participantes del estudio cuantitativo.}

La muestra de participantes esta definida por un grupo de estudiantes de Ingeniería de Informática, a los que se presentaran un conjunto de escenarios aleatorios. Caracterizados de acuerdo con el cuestionario diseñado, los resultados se recogen en la Tabla 38.

\begin{tabular}{|c|c|c|}
\hline Categoría & Media & Var. \\
\hline Edad & 25.00 & 4.63 \\
\hline Categoría & Rangos & Distribución \\
\hline \multicolumn{3}{|l|}{ General } \\
\hline Género & Femenino | Masculino & $2 \mid 14$ \\
\hline Trabajando & SI | No & $11 \mid 5$ \\
\hline Estudios & Secundaria | Grado | Máster | Doctorado & $1|7| 7 \mid 1$ \\
\hline \multicolumn{3}{|l|}{ Tecnologías } \\
\hline HTML & Nada | Algo | Bastante & $1|6| 9$ \\
\hline CSS & Nada | Algo | Bastante & $4|4| 8$ \\
\hline JavaScript & Nada | Algo | Bastante & $2|4| 10$ \\
\hline Python & Nada | Algo | Bastante & $2|6| 8$ \\
\hline App Engine & Nada | Algo | Bastante & $10|6| 0$ \\
\hline Polymer & Nada | Algo | Bastante & $13|2| 1$ \\
\hline Material Design & Nada | Algo | Bastante & $8|6| 2$ \\
\hline AngularJS & Nada | Algo | Bastante & $7|5| 4$ \\
\hline \multicolumn{3}{|l|}{ Estándares } \\
\hline Norma ISO & Yes | No & $7 \mid 9$ \\
\hline Normas de Calidad & None $|25000| 25010|9000| 25000 \& 9000$ & $9|1| 4|1| 1$ \\
\hline
\end{tabular}


Según estos resultados, se trata de una muestra de estudiantes con edades en torno a los veinticinco años, de baja diversidad de género y que trabajan a tiempo parcial mientras completan sus estudios de grado o máster. Cuentan con conocimientos de tecnologías Web a nivel básico, pero desconocen tecnologías de componentes web como Polymer (Lit-Elements); si bien cuentan con conocimiento de tecnologías web como AngularJS (Angular), que permiten el desarrollo de componentes, se trata de un conocimiento básico lo que no permite asegurar que conozcan el desarrollo de componentes usando Angular. Por último, si bien conocen la organización ISO, mayoritariamente desconocen las normas de calidad de esta.

\subsubsection{Exploración Cuantitativa a nivel de Escenario}

La exploración cuantitativa corresponde a la evaluación de dieciséis participantes de la muestra definida, a los que se presenta un escenario aleatorio, compuesto de siete componentes caracterizados cada uno de ellos por seis atributos sintéticos. En primer lugar, se recogen las gráficas que muestran las valoraciones de los usuarios a nivel de escenario.

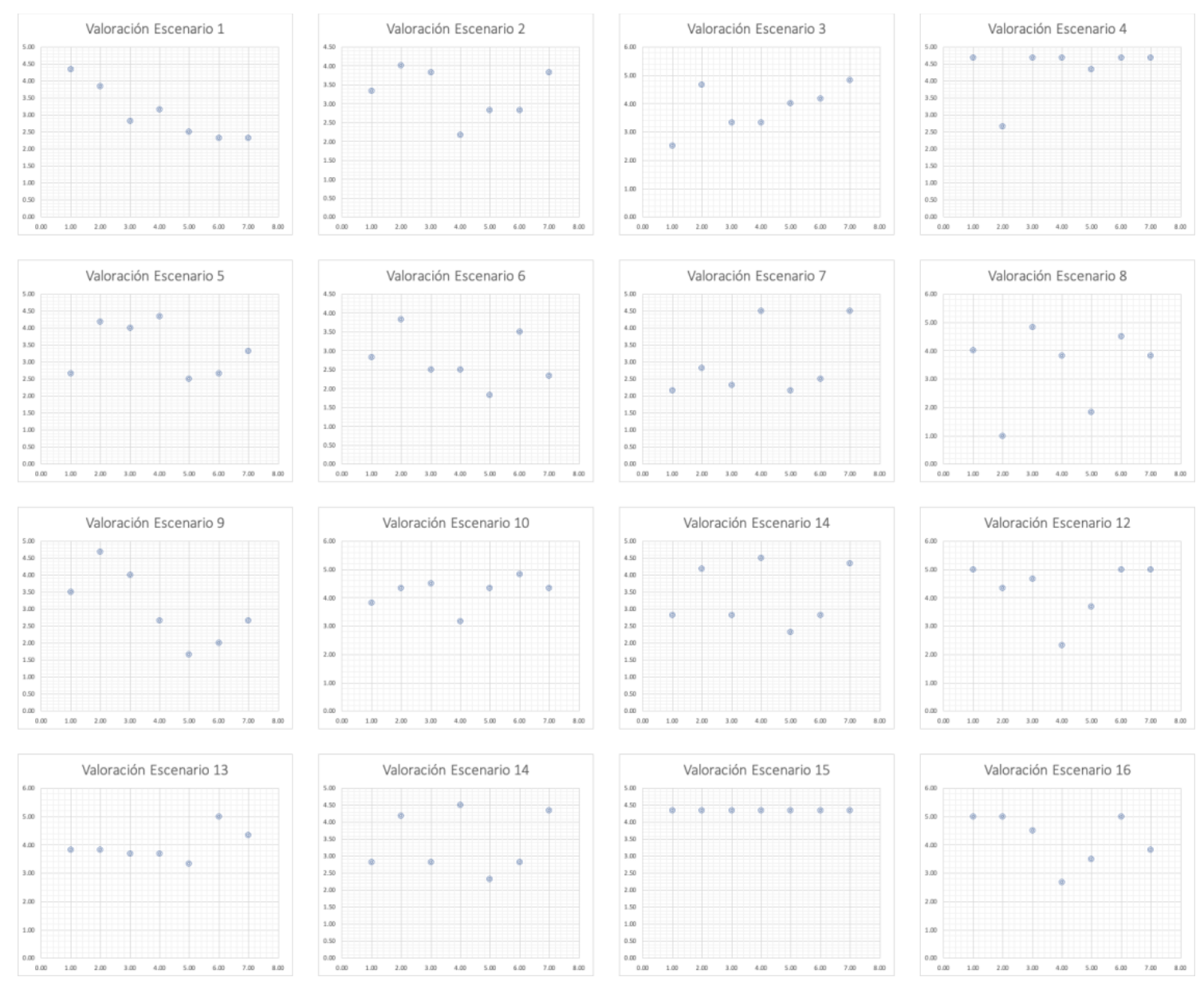

Ilustración 36: Valoración Escenarios 1-16

Las estadísticas descriptivas se recogen en la Tabla 39, donde se destacan en amarillo aquellos escenarios para los que la hipótesis nula de la prueba de normalidad puede rechazarse.

\begin{tabular}{|c|c|c|c|c|}
\hline Variable & Mínimo & Máximo & Media & Std. Dev. \\
\hline Escenario 01 & 2.330 & 4.330 & 3.046 & 0.780 \\
\hline Escenario 02 & 2.170 & 4.000 & 3.260 & 0.678 \\
\hline Escenario 03 & 2.500 & 4.830 & 3.833 & 0.829 \\
\hline
\end{tabular}




\begin{tabular}{|l|l|l|l|l|}
\hline Escenario 04 & 2.670 & 4.670 & 4.336 & 0.745 \\
\hline Escenario 05 & 2.500 & 4.330 & 3.381 & 0.785 \\
\hline Escenario 06 & 1.830 & 3.830 & 2.760 & 0.693 \\
\hline Escenario 07 & 2.170 & 4.500 & 3.000 & 1.049 \\
\hline Escenario 08 & 1.000 & 4.830 & 3.403 & 1.427 \\
\hline Escenario 09 & 1.670 & 4.670 & 3.026 & 1.082 \\
\hline Escenario 10 & 3.170 & 4.830 & 4.189 & 0.538 \\
\hline Escenario 11 & 2.170 & 4.670 & 3.784 & 0.836 \\
\hline Escenario 12 & 2.330 & 5.000 & 4.286 & 0.990 \\
\hline Escenario 13 & 3.330 & 5.000 & 3.951 & 0.550 \\
\hline Escenario 14 & 2.330 & 4.500 & 3.403 & 0.893 \\
\hline Escenario 15 & 4.33 & 4.33 & 4.33 & 0.911 \\
\hline Escenario 16 & 2.670 & 5.000 & 4.214 & 0 \\
\hline
\end{tabular}

Tabla 39: Estadísticas Descriptivas de la Exploración Cuantitativa a nivel de Escenario

Con el fin de evaluar la existencia de diferencias significativas entre los resultados de valoración a nivel de escenario, realizaremos un análisis de la varianza ANOVA de un factor. Para poder llevar a cabo este análisis se han de cumplir:

- Las valoraciones de cada escenario han de ser independientes, lo que sucede en este caso, ya que cada escenario es valorado por un participante distinto.

- Las valoraciones son valores numéricos y distribuidos normalmente. Esto ultimo se confirmará realizando las pruebas de normalidad.

- Las varianzas de la población coinciden, lo que se comprobará con una prueba específica.

Se comienza con la prueba de normalidad realizando la prueba de Shapiro-Wilk al conjunto de los datos, salvo a los correspondientes al escenario quince que, por contar con todas sus valoraciones iguales, de manera clara no se distribuye normalmente.

Los resultados, recogidos en la Tabla 40, muestran que, con una significación de $\alpha=0.05$, sólo se cuenta con evidencia estadística para rechazar la hipótesis nula de la prueba, es decir, la distribución normal de los resultados, en el caso de los escenarios cuatro, siete y doce.

\begin{tabular}{|c|c|c|c|c|}
\hline Escenario 1 & Escenario 2 & Escenario 3 & Escenario 4 & Escenario 5 \\
\hline 0.2417 & 0.3925 & 0.7148 & 0.0001 & 0.1503 \\
\hline Escenario 6 & Escenario 7 & Escenario 8 & Escenario 9 & Escenario 10 \\
\hline 0.6519 & 0.0132 & 0.1203 & 0.7951 & 0.2389 \\
\hline Escenario 11 & Escenario 12 & Escenario 13 & Escenario 14 & Escenario 16 \\
\hline 0.2687 & 0.0356 & 0.2185 & 0.0836 & 0.1587 \\
\hline
\end{tabular}

Como siguiente paso, se eliminan de la muestra de resultados, todos aquellos escenarios para los que existe evidencia estadística que permite rechazar la hipótesis nula en la prueba de normalidad.

La Tabla 41 incluye los diagramas Q-Q de los escenarios para los que no existe evidencia estadística para rechazar la hipótesis nula. En estos diagramas los datos se comparan con una distribución normal $\mathrm{N}(4.21,0.84)$. 

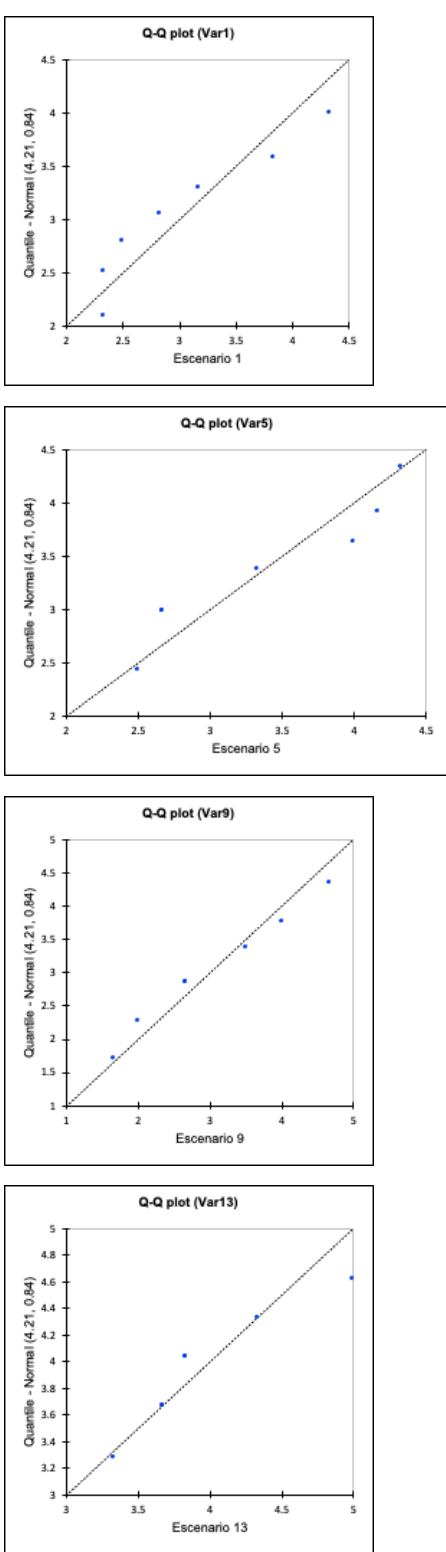
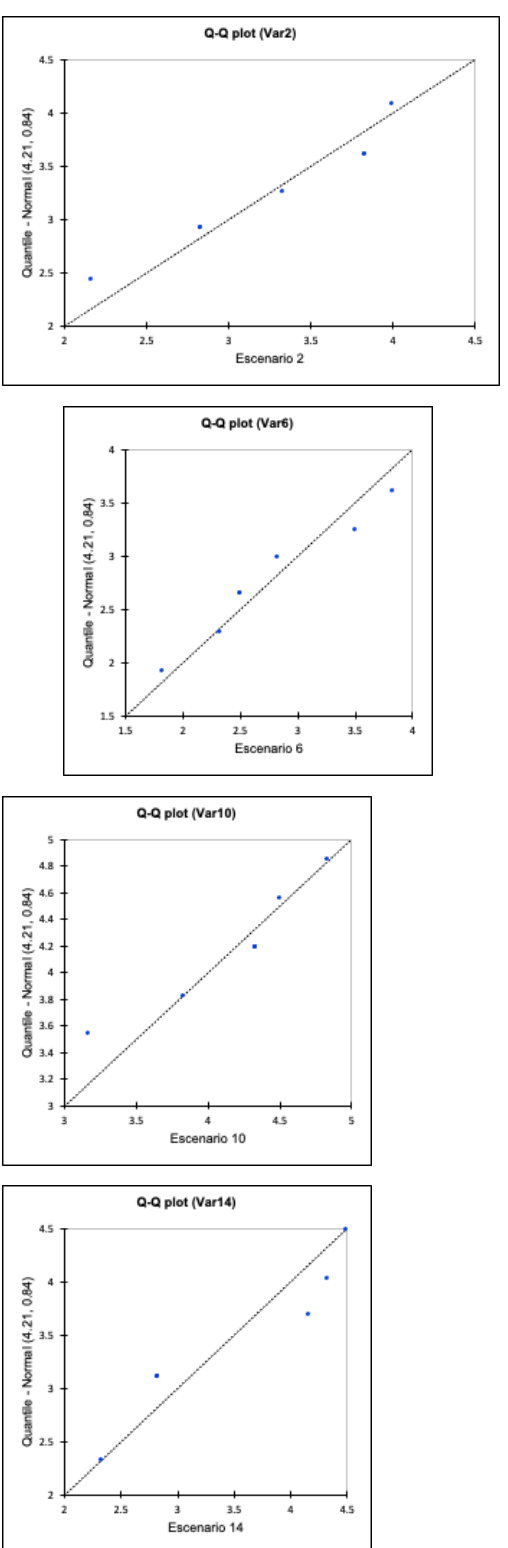
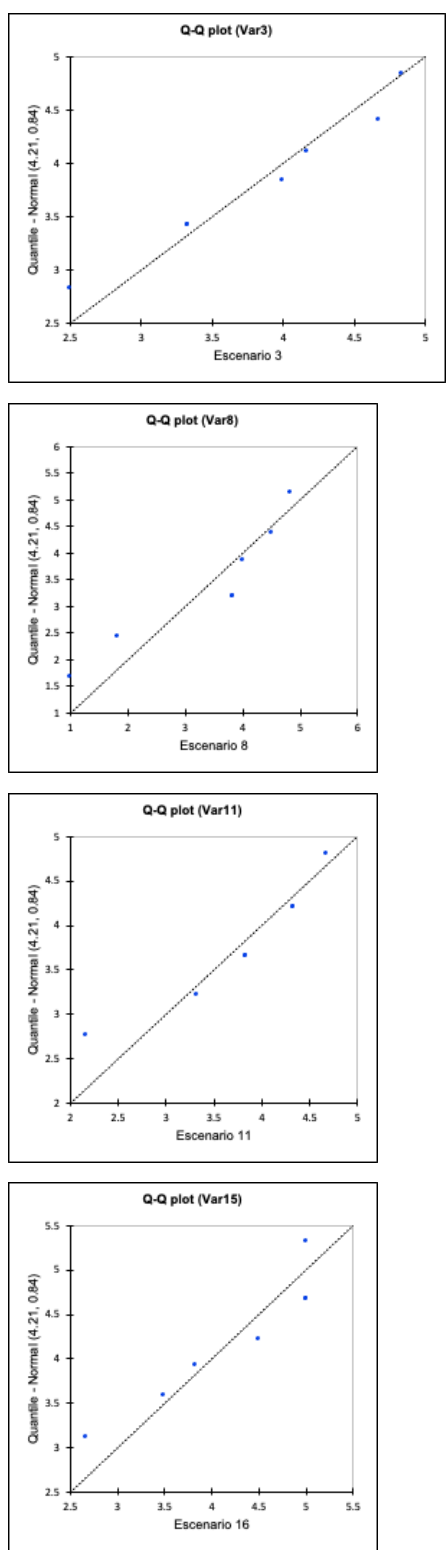

Tabla 41: Diagramas Q-Q de la Exploración Cuantitativa a nivel de Escenario

A continuación, y con el fin de determinar si las valoraciones correspondientes a los distintos escenarios tienen la misma varianza, se lleva a cabo una prueba de Levene, con un nivel de significación $\alpha=0.05$. El valor $p=0.101$ resultante de la prueba confirma la ausencia de evidencia estadística que permita rechazar la hipótesis nula de igualdad de las varianzas.

En estas circunstancias, se realiza un análisis ANOVA de un factor, con un nivel de significación $\alpha=0.05$, a los escenarios uno, dos, tres, cinco, seis, ocho, nueve, diez, once, trece, catorce y dieciséis.

\begin{tabular}{|c|c|c|c|c|c|}
\hline Fuente & DF & $\begin{array}{l}\text { Suma de } \\
\text { Cuadrados }\end{array}$ & $\begin{array}{l}\text { Media de } \\
\text { cuadrados }\end{array}$ & $F$ & $\operatorname{Pr}(>F)$ \\
\hline Factor & 11 & 17.108 & 1.555 & 2.080 & 0.033 \\
\hline Error & 72 & 53.849 & 0.748 & & \\
\hline Total & 83 & 70.956 & & & \\
\hline \multicolumn{3}{|c|}{ Calculado con el modelo $Y=$ Media $(Y)$} & & & \\
\hline
\end{tabular}

Tabla 42: Análisis ANOVA de un Factor Exploración Cuantitativa a nivel de Escenario 
Como se observa en los resultados, la probabilidad $\operatorname{Pr}(>F)$ es 0.033 , menor que el nivel de significación de la prueba $\alpha=0.05$, y por lo tanto existe evidencia estadística para poder rechazar la hipótesis nula de igualdad de las medias de cada población. Esto sumado con el un valor del coeficiente de determinación ajustado de $R^{2}=0.125$, nos permite aceptar que la variación de la muestra es suficientemente alta o lo que es lo mismo, la aleatoriedad de la muestra es suficiente y el modelo resultante no presenta sesgo a los escenarios respecto.

\subsubsection{Exploración Cuantitativa a nivel de Componente}

La exploración cuantitativa corresponde a la evaluación de siete componentes, realizada por los participantes en el estudio en dieciséis escenarios aleatorios. En primer lugar, se incluyen las gráficas correspondientes a la valoración de cada componente en cada uno de los escenarios.

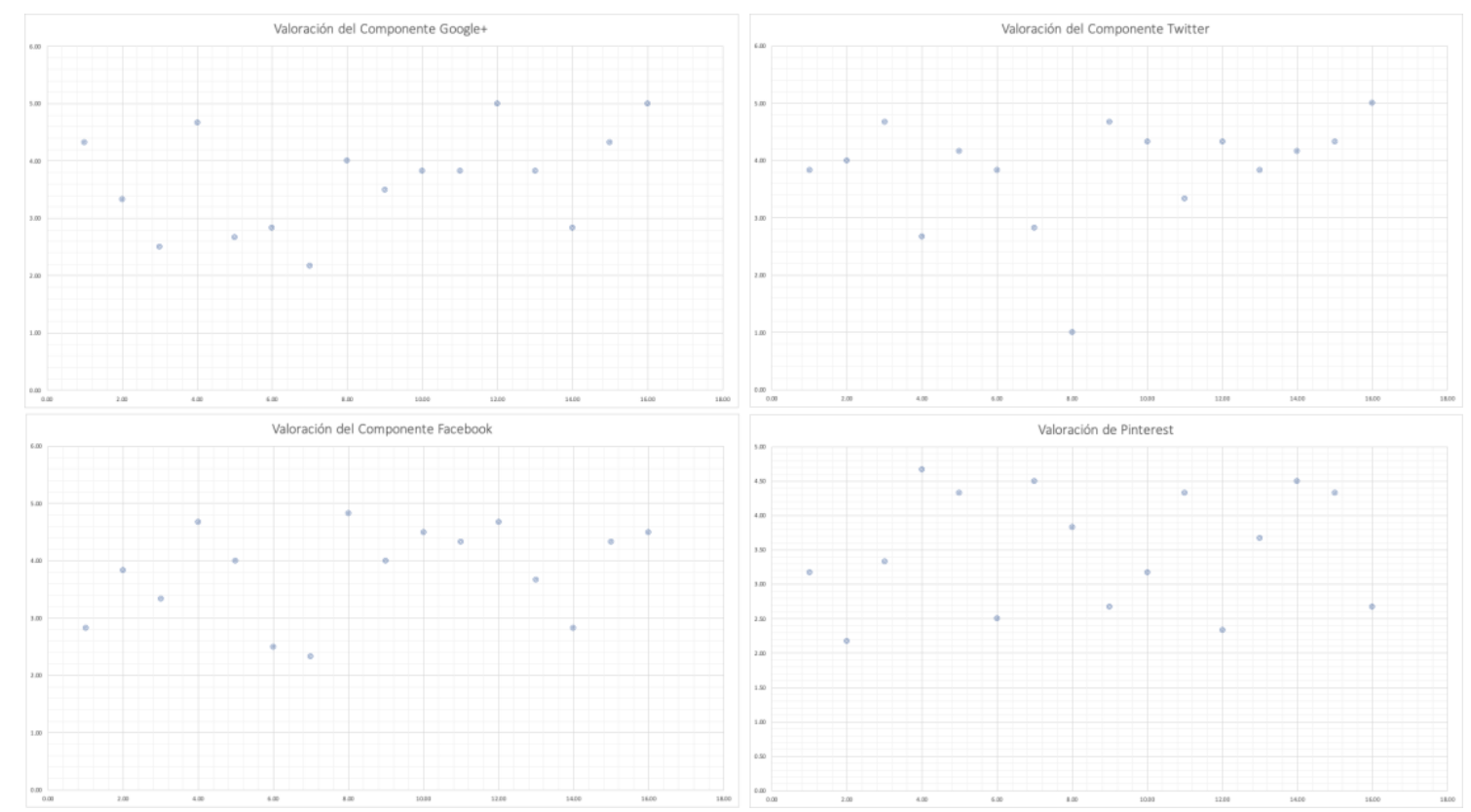

Ilustración 37: Valoración de los Componentes Google+, Twitter, Facebook y Pinterest.

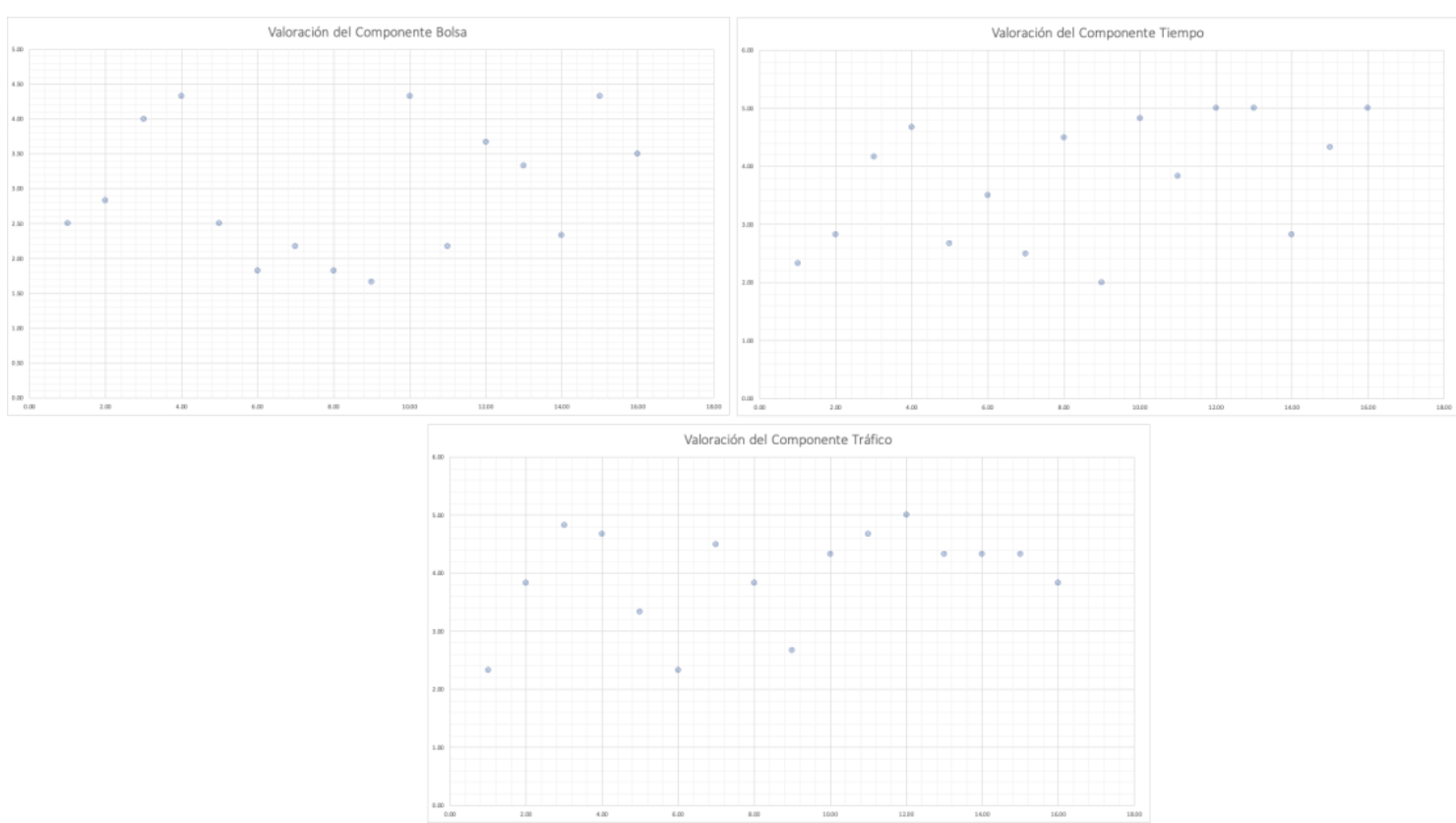

Ilustración 38: Valoración de los Componentes Bolsa, Tiempo y Tráfico 
Las estadísticas descriptivas se recogen en la Tabla 43, donde se destacan aquellos escenarios para los que la hipótesis nula de la prueba de normalidad puede rechazarse.

\begin{tabular}{|l|l|l|l|l|}
\hline & Mínimo & Máximo & Media & \multicolumn{1}{c|}{ Std. Dev } \\
\hline Google+ & 2.170 & 5.000 & 3.666 & 0.886 \\
\hline Twitter & 1.000 & 5.000 & 3.812 & 0.979 \\
\hline Facebook & 2.330 & 4.830 & 3.822 & 0.823 \\
\hline Pinterest & 2.170 & 4.670 & 3.511 & 0.869 \\
\hline Bolsa & 1.670 & 4.330 & 2.958 & 0.964 \\
\hline Tiempo & 2.000 & 5.000 & 3.749 & 1.075 \\
\hline Tráfico & 2.330 & 5.000 & 3.946 & 0.861 \\
\hline
\end{tabular}

Tabla 43: Estadísticas Descriptivas de la Exploración Cuantitativa a nivel de Componente

A continuación, se realizan una serie de comprobaciones adicionales, necesarias para los análisis estadísticos posteriores. Se comienza con la prueba de normalidad realizando la prueba de Shapiro-Wilk al conjunto de los datos.

Los datos muestran que, con una significación de $\alpha=0.05$, sólo se cuenta con evidencia estadística para rechazar la hipótesis nula de la prueba, es decir, la distribución normal de los resultados, en el caso de los componentes segundo y séptimo.

\begin{tabular}{|l|l|l|l|}
\hline \multicolumn{4}{|l|}{ Prueba de Normalidad Shapiro-Wilk, significación $\alpha=0.05$} \\
\hline Google+ & Twitter & Facebook & Pinterest \\
\hline 0.572 & $\mathbf{0 . 0 1 1}$ & 0.094 & 0.105 \\
Bolsa & Tiempo & Tráfico & \\
\hline 0.080 & 0.061 & $\mathbf{0 . 0 3 0}$ & \\
\hline
\end{tabular}

La Tabla 45 incluye los diagramas $Q-Q$ de los escenarios para los que no existe evidencia estadística para rechazar la hipótesis nula. En estos diagramas los datos se comparan con una distribución normal $\mathrm{N}(3.95,0.83)$.
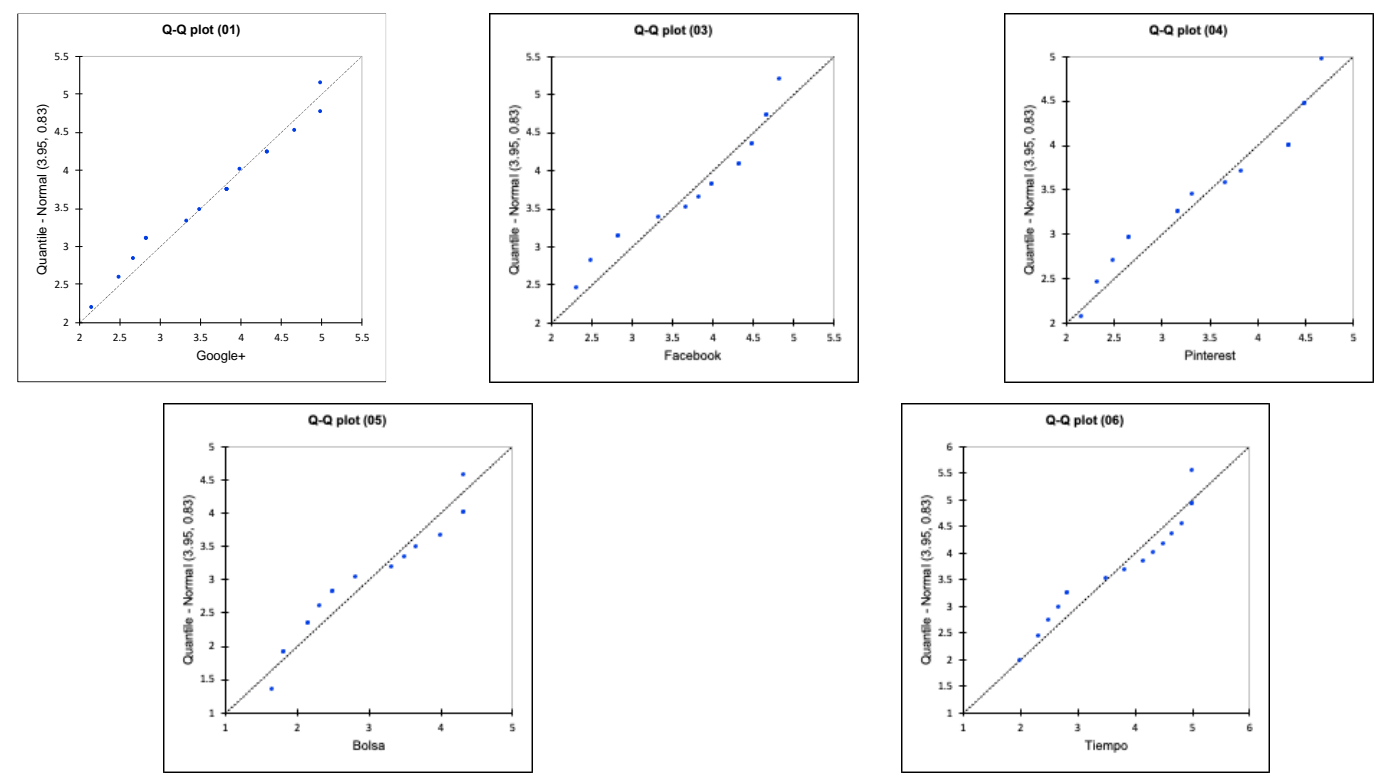

Tabla 45: Diagramas $Q-Q$ de la Exploración Cuantitativa a nivel de Componente

A continuación, y con el fin de determinar si las valoraciones correspondientes a los distintos componentes tienen la misma varianza, se lleva a cabo una prueba de Levene, con un nivel de 
significación $\alpha=0.05$. El valor $p=0.412$ resultante de la prueba confirma la ausencia de evidencia estadística que permita rechazar la hipótesis nula de igualdad de las varianzas.

Hechas las comprobaciones, podemos afirmar que se cumplen los requisitos para realizar el análisis de varianza ANOVA de un factor sobre las valoraciones de los usuarios para cada uno de los componentes, excluidos aquellos sobre los que existe evidencia estadística que permite rechazar la hipótesis nula de la prueba de normalidad. Los resultados, para un nivel de significación $\alpha=0.05$. son recogidos en la Tabla 46 .

\begin{tabular}{|l|l|l|l|l|l|}
\hline Fuente & DF & $\begin{array}{l}\text { Suma de } \\
\text { Cuadrados }\end{array}$ & $\begin{array}{l}\text { Media de F } \\
\text { cuadrados }\end{array}$ & Pr (> F) \\
\hline Factor & 4 & 7.668 & 1.917 & 2.227 & 0.074 \\
\hline Error & 75 & 64.556 & 0.861 & & \\
\hline Total & 79 & 72.224 & & & \\
\hline Calculado con el modelo Y=Media $(Y)$ & & & \\
\hline
\end{tabular}

Tabla 46: ANOVA de un Factor de la Exploración Cuantitativa a nivel de Componente

Como se observa, la probabilidad $\operatorname{Pr}(>F)$ es 0.074 lo que determina que a nivel de componente las variables independientes no proporcionan explicación de la variación del factor dependiente. Esto se confirma con los resultados de la regresión que se muestran a continuación.

A continuación, se exploran modelos de regresión para la valoración (factor) por los usuarios de los componentes, considerando como variables independientes los atributos de calidad establecidos en el modelo empírico.

Los resultados se recogen como sigue:

- Tabla 47: Exploración Cuantitativa a nivel de Componente: Regresión lineal Componente Google+

- Tabla 48: Exploración Cuantitativa a nivel de Componente: Regresión lineal Componente Twitter

- Tabla 49: Exploración Cuantitativa a nivel de Componente: Regresión lineal Componente Facebook

- Tabla 50: Exploración Cuantitativa a nivel de Componente: Regresión lineal Componente Pinterest

- Tabla 51: Exploración Cuantitativa a nivel de Componente: Regresión lineal Componente Bolsa

- Tabla 52: Exploración Cuantitativa a nivel de Componente: Regresión lineal Componente Tiempo

- Tabla 53: Exploración Cuantitativa a nivel de Componente: Regresión lineal Componente Tráfico 
Componente: Google+

Coeficiente de determinación: 0.297

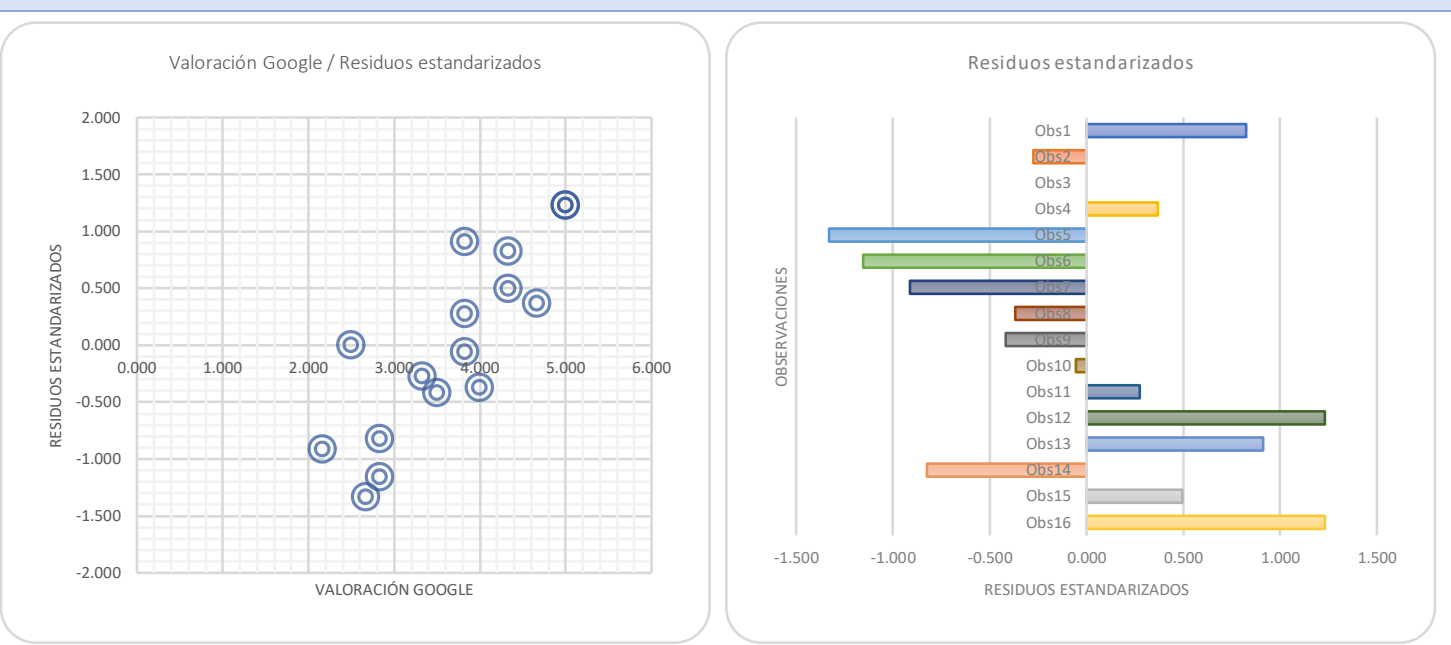

Tabla 47: Exploración Cuantitativa a nivel de Componente: Regresión lineal Componente Google+

\section{Componente: Twitter}

\section{Coeficiente de determinación: 0.179}

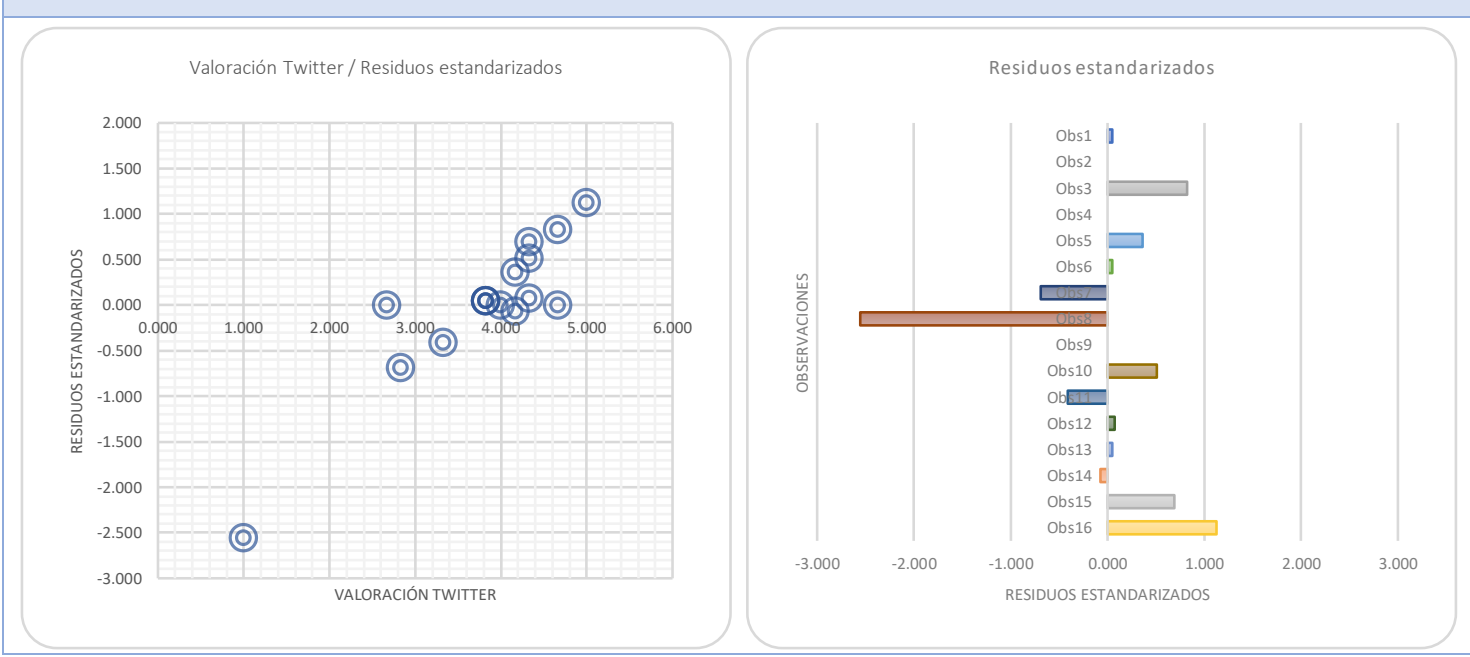

Tabla 48: Exploración Cuantitativa a nivel de Componente: Regresión lineal Componente Twitter

\section{Componente: Facebook}

\section{Coeficiente de determinación: 0.249}

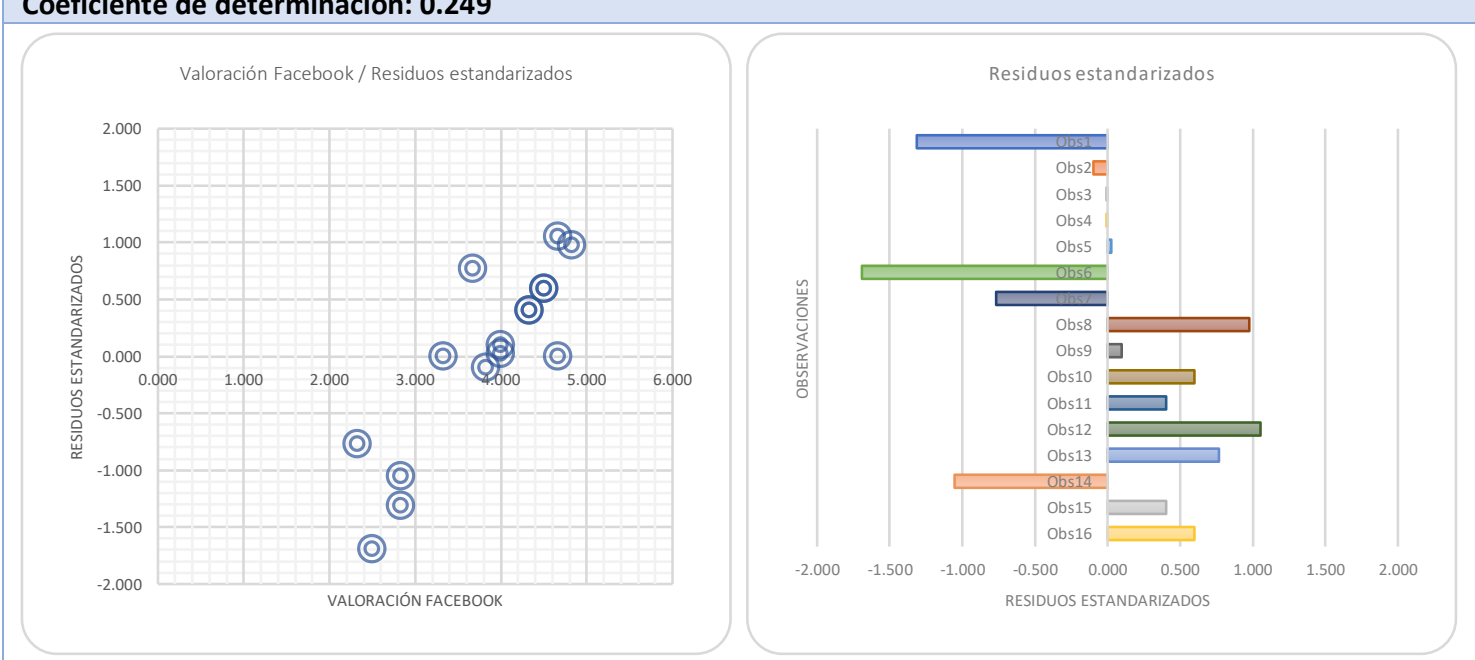

Tabla 49: Exploración Cuantitativa a nivel de Componente: Regresión lineal Componente Facebook 


\section{Componente: Pinterest}

\section{Coeficiente de determinación: 0.124}

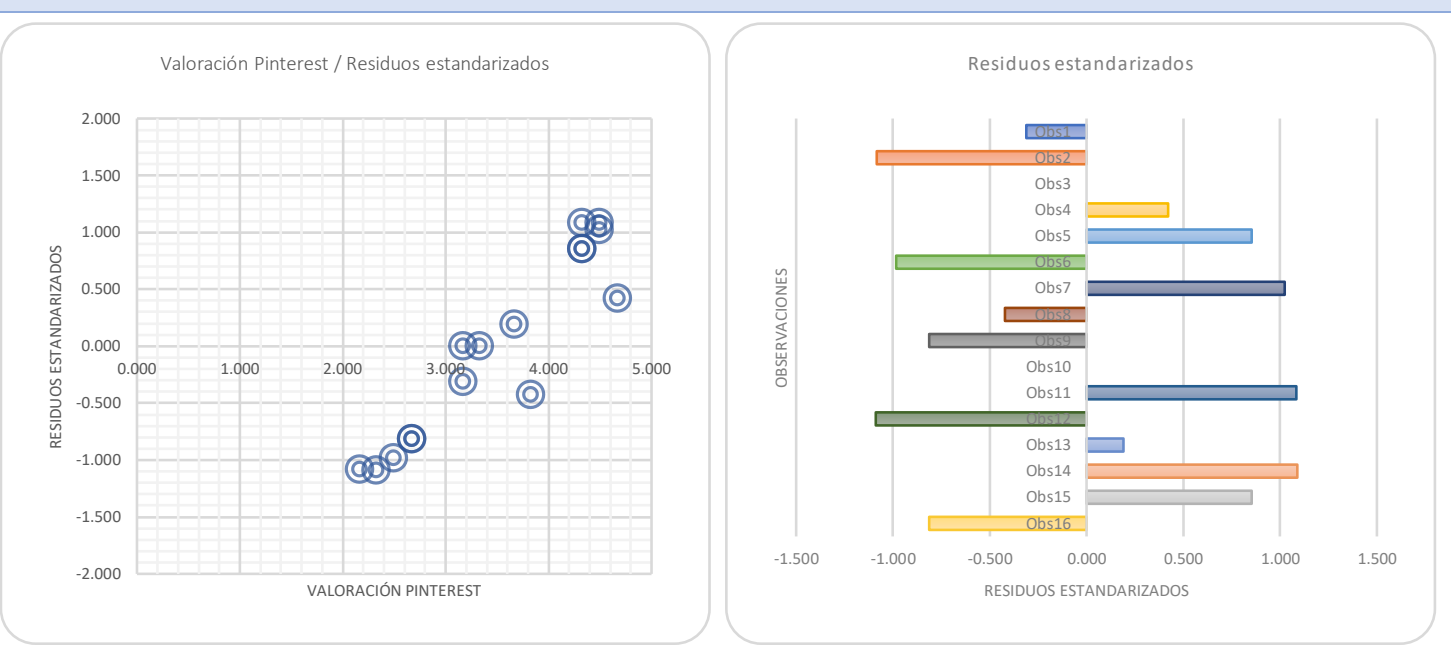

Tabla 50: Exploración Cuantitativa a nivel de Componente: Regresión lineal Componente Pinterest

\section{Componente: Bolsa \\ Coeficiente de determinación: $\mathbf{0 . 2 3 2}$}

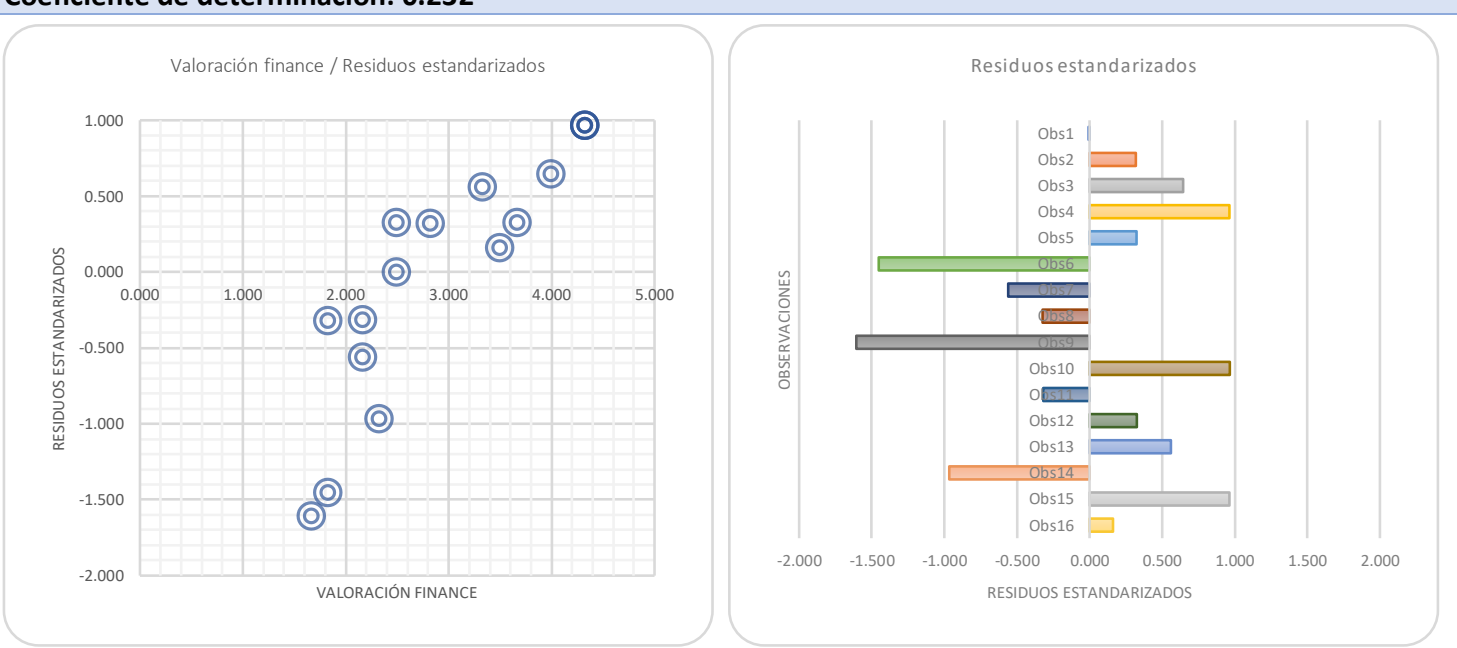

Tabla 51: Exploración Cuantitativa a nivel de Componente: Regresión lineal Componente Bolsa

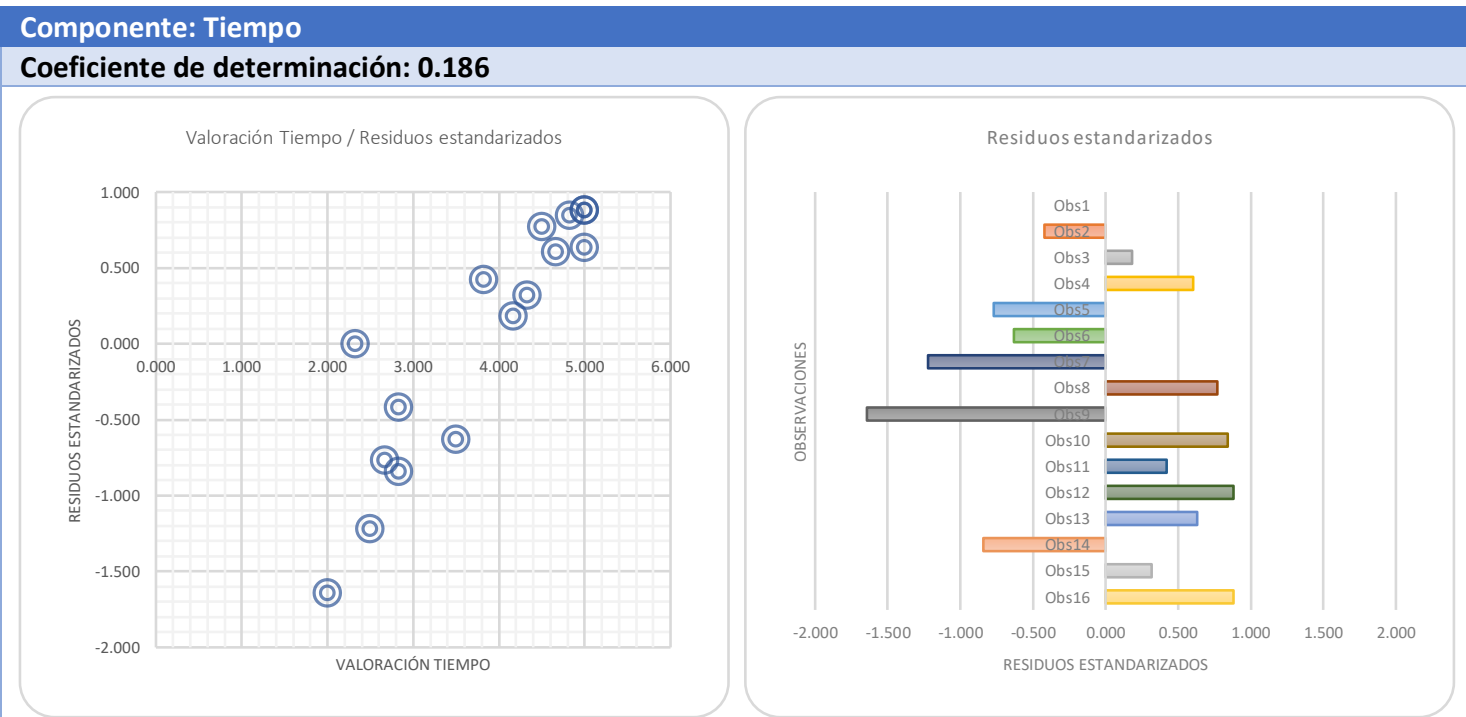

Tabla 52: Exploración Cuantitativa a nivel de Componente: Regresión lineal Componente Tiempo 


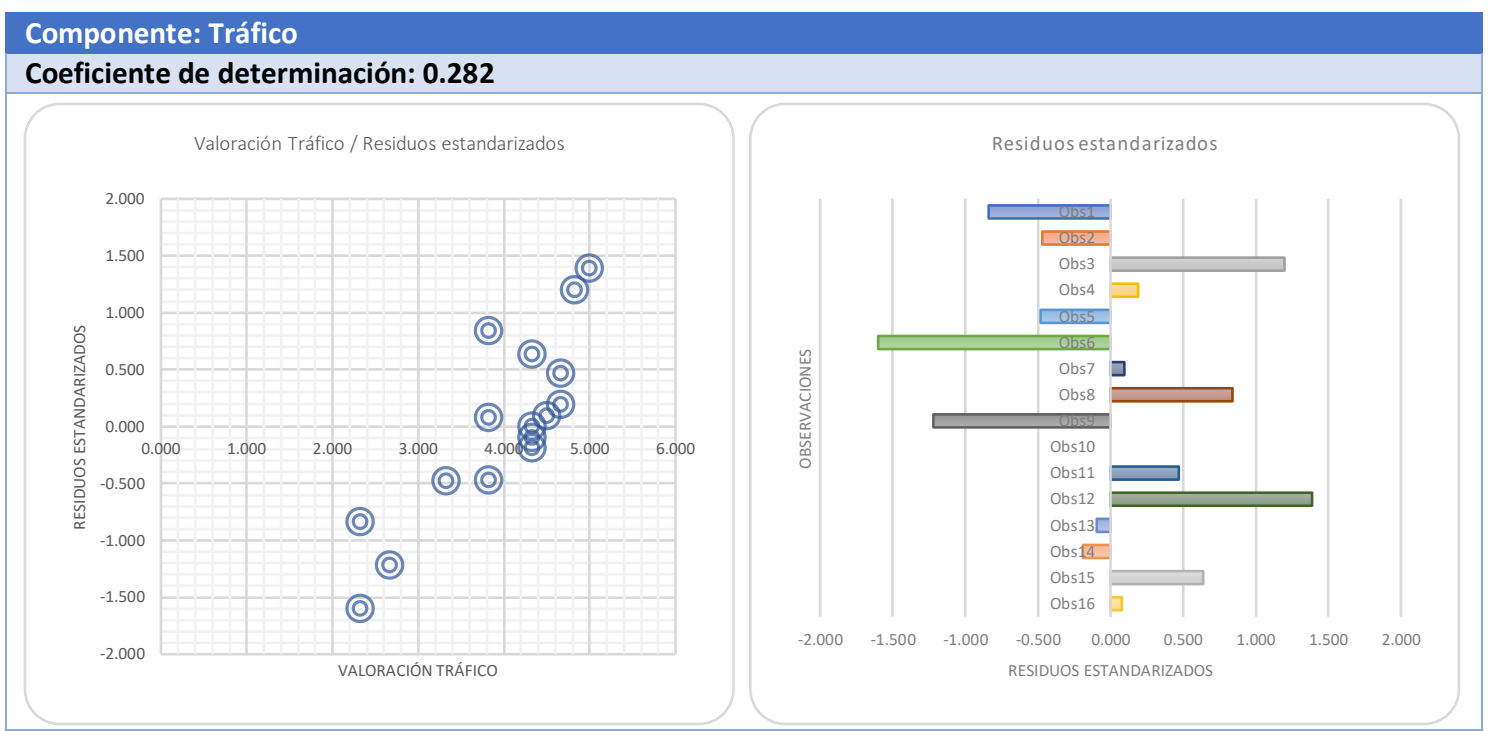

Tabla 53: Exploración Cuantitativa a nivel de Componente: Regresión lineal Componente Tráfico

Este análisis de regresión se amplia mediante una ANCOVA para cada escenario, estableciendo como variable dependiente la valoración de los usuarios y como variables independientes el valor de cada métrica del componente.

\begin{tabular}{l|lllllll}
\multicolumn{1}{c|}{} & Google & Facebook & Twitter & Pinterest & Bolsa & Tiempo & Tráfico \\
\hline$R$ & 0.545 & 0.499 & 0.423 & 0.352 & 0.482 & 0.431 & 0.531 \\
$R^{2}$ & 0.297 & 0.249 & 0.179 & 0.124 & 0.232 & 0.186 & 0.282 \\
& $\operatorname{Pr}>\mathrm{F}$ & & & & & & \\
Latencia & 0.292 & 0.903 & 0.483 & 0.855 & 0.519 & 0.246 & 0.446 \\
Completitud & 0.250 & 0.888 & 0.830 & 0.873 & 0.696 & 0.526 & 0.313 \\
Ciclomática & 0.905 & 0.332 & 0.672 & 0.708 & 0.704 & 0.671 & 0.255 \\
Estructural & 0.279 & 0.632 & 0.504 & 0.315 & 0.611 & 0.843 & 0.566 \\
Halstead & 0.690 & 0.187 & 0.357 & 0.776 & 0.190 & 0.762 & 0.564
\end{tabular}

Los resultados del primer análisis aparecen recogidos en la Tabla 54. Como puede comprobarse allí los coeficientes de regresión obtenidos $\left(R / R^{2}\right)$ se encuentran dentro de los rangos $[0.352 \ldots$ $0.545]$ y [0.297 ... 0.124], en ambos casos lejos de valores que permitan conjeturar alguna evidencia estadística y así, de acuerdo con los datos experimentales analizados, se puede afirmar que no existe evidencia a nivel de componente de la relación lineal entre los atributos internos y la valoración de los usuarios.

Sin embargo, analizando la contribución individual de cada una de las métricas, es posible identificar algunas componentes explicativas. En particular, en base a los resultados obtenidos puede afirmarse que existe evidencia estadística que permite afirmar:

- La complejidad Ciclomática (0.905) y de Halstead (0.690) son las principales contribuciones a la valoración que el usuario hace de Google Plus.

- La latencia (0.903 / 0.855) y la completitud $(0.888$ / 0.873) son las componentes más significativas que explican la valoración del componente web de Facebook y de Pinterest.

- La completitud (0.830 / 0.696) y la complejidad Ciclomática (0.672 / 0.704) son las principales variables explicativas de la valoración del componente de Twitter y el lector RSS de la información financiera.

- Por último, la complejidad estructural (0.843 / 0.566) y de Halstead (0.762 / 0.564) permiten explicar la valoración del usuario correspondiente a los lectores RSS de la información del tiempo y el tráfico. 
Esta aproximación proporciona como resultado colateral, la posibilidad de utilizar la plataforma experimental para la identificación de cómo nuevas métricas puede ayudar a valorar la experiencia de usuario.

La introducción de este proceso constructivo puede ser de especial utilidad para abordar la cuantificación de calidad en nuevas categorías de componentes. Estas son consideraciones que se abordarán en trabajos futuros.

\subsubsection{Exploración Cuantitativa a nivel de Estudio}

En primer lugar, se presenta la gráfica que muestra las evaluaciones de los usuarios, para a continuación presentar también las estadísticas descriptivas.

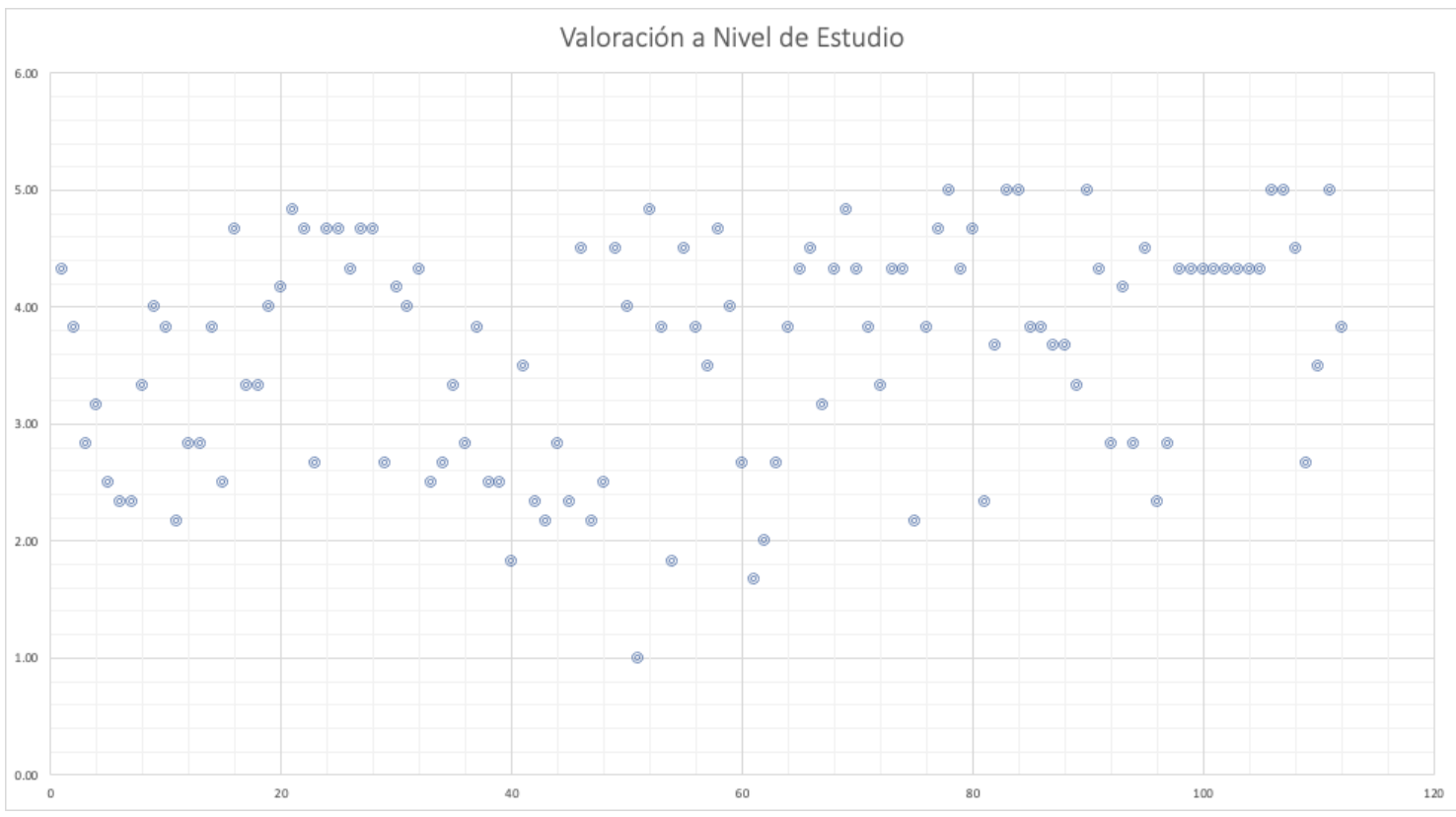

Ilustración 39: Valoraciones de Usuarios a Nivel de Estudio

\begin{tabular}{|l|l|l|l|}
\hline Estadística & Valor & Estadística & Valor \\
\hline Número de valores & 112 & Mínimo & 1,0 \\
\hline Media & 3,638 & Máximo & 5,0 \\
\hline Varianza & 0,905 & Frecuencia Mínima & 1 \\
\hline Desviación Estándar & 0,951 & Frecuencia Máxima & 7 \\
\hline Mediana & 3,830 & Rango & 4,0 \\
\hline
\end{tabular}

Tabla 55: Estadísticas Descriptivas de la Valoración de Usuario a Nivel de Estudio

Si bien los resultados de la llustración 39 presentan una razonable aleatoriedad, se observan también algunos patrones que pudieran responder a coordinación en las respuestas y que pudiesen deberse a la realización de los experimentos en grupo dentro del mismo espacio físico, permitiendo la coordinación de algunos participantes en el estudio. Las estadísticas descriptivas se recogen Tabla 55.

Seguidamente, se analizan las diferentes componentes y las diferentes versiones para comprobar si resultan estadísticamente significativas e independientes para utilizar en el análisis de los modelos de regresión y correlación. Siguiendo las pautas estándares de análisis realizamos una prueba ANOVA sobre la valoración subjetiva de los usuarios y la métrica objetiva para cada una de las distintas versiones de cada componente, comparando los grupos entre ellos.

\begin{tabular}{l|lll} 
Componente & Suma & Media & Varianza \\
\hline Google & 4.16 & 4.06 & 0.140408 \\
Facebook & 4.23 & 4.40 & 0.804489 \\
Twitter & 4.21 & 4.45 & 0.758962 \\
Pinterest & 4.01 & 4.32 & 0.058210
\end{tabular}




\begin{tabular}{l|lll|} 
Bolsa & 4.35 & 3.89 & 0.034679 \\
Tiempo & 4 & 4 & 0.467258 \\
Tráfico & 4.5 & 4.28 & 0.137962 \\
F & P-value & F critical \\
O.833074 & 0.004465 & 3.938110 \\
\multicolumn{2}{r}{ Tabla } & 56: ANOVA de un factor $\alpha=0.05$
\end{tabular}

Los resultados recogidos en la Tabla 56 muestran que $F(0.833)$ es mucho mas pequeño que el valor crítico (3.938). Como consecuencia, es posible afirmar que la variación de la valoración de los usuarios y las métricas objetivas son similares y estadísticamente equivalentes con un nivel de significancia de $\alpha=0.05$. Como consecuencia de esto, es posible agregar todas las valoraciones de los usuarios, permitiendo esto analizar la correlación entre dichas valoraciones y las métricas definidas.

En esta situación se evalúan varios modelos lineales, no lineales y de regresión paramétrica para identificar una relación funcional que conecte la valoración del usuario con las métricas establecidos.

Como resultado de dicho análisis se ha obtenido el siguiente modelo:

\begin{tabular}{l|llll}
\multicolumn{2}{c}{ Descripción } & Media & Des. Est. & Pr $>F$ \\
\hline X1 & Latencia & 913.570 & 889.936 & 0.806 \\
X2 & Completitud & 4.871 & 0.399 & 0.286 \\
X3 & Complejidad Ciclomática & 4.909 & 0.343 & 0.371 \\
X4 & Dependencias (fan-out) & 35.884 & 15.782 & 0.153 \\
X5 & Consistencia & 54.412 & 3.181 & 0.702 \\
X6 & Complejidad Halstead & 3.402 & 0.354 & 0.562
\end{tabular}

Tabla 57: Modelo de Regresión Paramétrica

Dicho modelo permite representar la valoración para cada escenario en función de las métricas de este. La representación funcional se encuentra recogida en la ecuación:

$$
V^{j}=w_{0}+\sum_{i} X_{i}\left(w_{i}+u_{i} X_{i}\right) \quad \text { componente } i \in[1 . .7] \text {, escenario } j \in[1 . .16]
$$

Los parámetros de modelo son los siguientes

\begin{tabular}{|l|l|l|l|l|l|l|l|}
\hline $\mathrm{w}_{0}$ & $\mathrm{w}_{1}$ & $\mathrm{w}_{2}$ & $\mathrm{w}_{3}$ & $\mathrm{w}_{4}$ & $\mathrm{w}_{5}$ & $\mathrm{w}_{6}$ & $\mathrm{w}_{7}$ \\
\hline 16.220 & 0.000 & 0.681 & -2.551 & -0.031 & -0.880 & 8.624 & 0.000 \\
\hline & $\mathrm{u}_{1}$ & $\mathrm{u}_{2}$ & $\mathrm{u}_{3}$ & $\mathrm{u}_{4}$ & $\mathrm{u}_{5}$ & $\mathrm{u}_{6}$ & $\mathrm{u}_{7}$ \\
\hline & 0.000 & -0.056 & 0.317 & 0.000 & 0.008 & -1.267 & 0.000 \\
\hline
\end{tabular}

La validación de dicho modelo funcional se realiza ejecutando una ANCOVA de tipo I y de tipo II SS cuyos resultados se muestran en la Tabla 59. De acuerdo con estos, los datos confirman la hipótesis nula $\mathrm{HO}$, lo que significa que, para el nivel de significación determinado, $\alpha=0.05$, existe una correlación entre la valoración obtenida y las métricas correspondientes. De acuerdo con el valor de R obtenido, el modelo explica el $96 \%$ de las valoraciones de usuario.

\begin{tabular}{|c|c|c|c|c|c|}
\hline$R$ & & & 0.584 & & \\
\hline$R^{2}$ & & & 0.931 & & \\
\hline$R^{2}$ adj. & & & 0.960 & & \\
\hline$S C R$ & & & 66,262 & & \\
\hline Source & GDL & SS & MS & $\mathrm{F}$ & $\mathrm{Pr}>\mathrm{F}$ \\
\hline Model & 21 & 34.217 & 1.629 & 2.213 & 0.005 \\
\hline Residues & 90 & 66.262 & 0.736 & & \\
\hline
\end{tabular}




\section{Total $\quad 111 \quad 100.478$ \\ Evaluación del valor del factor producido por las variables independientes. \\ $H O=Y=\operatorname{Moy}(y)$ \\ Tabla 59: ANCOVA a nivel de estudio}

Por lo tanto, si bien no se cuenta con evidencia para establecer una relación a nivel de componente, los resultados agregados de los 16 escenarios permiten identificar un modelo polinómico que conecta la valoración de lo usuarios con los atributos de calidad de los componentes.

Si bien el estudio cuantitativo es de carácter exploratorio y descriptivo correlacional, los resultados permiten validar el instrumento digital diseñado, la plataforma de experimentación, sustentando el desarrollo de líneas futuras que incrementen la muestra de experimentación e introduzcan nuevos atributos, marcos de referencia de valoración de los atributos e incluso características alternativas del modelo empírico. 


\section{Conclusiones}

"Creímos que para quien tuviese la voluntad del león, conocer sería su mayor

alegría."

Friedrich Nietzsche

A la luz de los resultados obtenidos, las conclusiones del presente trabajo de investigación corresponden a distintas áreas de interés que, yendo de lo particular a lo general, de lo deductivo a lo inductivo, responden a las preguntas que sustentaron la formulación del problema.

Siguiendo un esquema similar al que nos permitió establecer el planteamiento del problema en forma de preguntas de investigación, las conclusiones se presentan como respuesta a esas mismas preguntas. Producto inmediato de los estudios realizados surgen también nuevas áreas de investigación, nuevas preguntas e hipótesis a contrastar que se recogen en la sección 7 Futuras Líneas de Investigación.

\subsection{Métodos mixtos de investigación en Ingeniería del Software}

RQ1 ¿Contamos con metodología de investigación que permita investigar la calidad en ecosistemas de desarrollo de software abierto?

Los resultados de la tesis permiten concluir la existencia aspectos de la ingeniería del software que no solo presentan carácter cualitativos o cuantitativos, lo que podría decantar el paradigma de investigación en uno $u$ otro sentido, sino que combinan indisolublemente la naturaleza cualitativa y cuantitativa, requiriendo una aproximación adecuada a la esencia de estos problemas.

El trabajo de investigación ha conducido a los métodos mixtos de investigación y su adaptación a la investigación dentro del campo de la ingeniería del software. En el dominio especifico del estudio, de entre las técnicas existentes, el diseño secuencial exploratorio ha resultado ser el más idóneo para la identificación del modelo empírico de calidad de componentes web, así como para el desarrollo de la plataforma de evaluación cuantitativa del mismo.

La situación actual, de la que se derivan importantes limitaciones a la innovación en el desarrollo del software, es fruto en gran medida de los silos de conocimiento producto de la aplicación limitante de uno y otro enfoque. La creciente complejidad del desarrollo de software, la evolución de ecosistemas abiertos y la aparición de ecosistemas de desarrollo en empresas y su 
interdependencia creciente apuntan a que la necesidad de técnicas mixtas de investigación no solo no desaparecerá en el medio y largo plazo, sino que aumentará su ámbito.

Esto lleva a considerar este primer resultado como una contribución fundamental en el área de investigación de la ingeniería del software en general y en el área de la calidad de software en particular. Además del diseño de investigación aplicado en este estudio, es de esperar que los diseños convergentes y explicativo secuencial se muestre también de utilidad.

\subsection{Calidad en ecosistemas abiertos}

RQ2 ¿Existe un modelo de calidad de componentes web desarrollados en repositorios abiertos?

Como primera aproximación, los resultados de la serie de entrevistas abiertas constatan un conjunto de elementos de valoración utilizados por los expertos en desarrollo web como criterio o representación de la calidad.

De acuerdo con los expertos, la calidad de los componentes web está conformada por una serie de componentes: comunidad de desarrollo, uso y soporte $(18,77 \%)$, usabilidad técnica o de aplicación y visual $(14,92 \%)$, experiencia y reputación técnica y corporativa $(14,80 \%)$, cobertura de pruebas y demostradores (14,56\%), complejidad estructural y dependencias $(7,82 \%)$, seguridad $(7,34 \%)$ y portabilidad $(6,14 \%)$.

Las componentes señaladas caracterizan en un $85 \%$ la calidad de los componentes web. Su conexión con las características de calidad estándares en la ingeniería del software dista de ser evidente, especialmente para aquellas componentes de mayor peso. El restante 15\% corresponde a una amalgama de componentes como estabilidad, latencia, refresco, completitud o complejidad Ciclomática, y que cuentan con una mayor conexión con las características de calidad de producto y calidad en uso.

Es importante señalar que, si bien algunas de estas componentes cuentan con atributos medibles (métricas) otras, bien son conglomerados de conceptos de mayor o menor complejidad o son de elevado carácter subjetivo e impreciso, y que por tanto no cuentan de manera directa con funciones medibles para su evaluación. De ahí que intencionadamente hayamos evitado utilizar el término "característica" para definirlos, reservando esta denominación para la caracterización medible de la calidad.

Los resultados de la primera exploración cualitativa, obtenidos de las entrevistas abiertas, conducen a la propuesta de un modelo de calidad de base empírica, hipótesis de trabajo intermedia, cuyas características de calidad y atributos medibles (métricas) aparecen recogidos en la Tabla 23, y que se resumen a continuación: los atributos internos de evaluación estática son métrica de Halstead (tamaño), complejidad Ciclomática (complejidad estructural interna), dependencias fan-out (complejidad estructural externa); los atributos externos de evaluación dinámica son completitud (eficacia), latencia (usabilidad ${ }^{5}$ ), consistencia (satisfacción).

El modelo asume, al igual que el estándar ISO/IEC 25010, sin precisar las dependencias funcionales, que los atributos internos de evaluación estática, propios de la calidad de producto, intervienen en la percepción y valuación de los atributos externos de evaluación dinámica, propios de la calidad en uso. Siguiendo este principio, el modelo propuesto considera que ambos atributos estáticos y dinámicos ofrecen cobertura de las componentes de calidad relativos a la existencia de comunidad de desarrollo, uso y soporte, así como de las componentes de experiencia y reputación tecnológica y corporativa.

\footnotetext{
${ }^{5}$ Ver nota a pie de pagina 2
} 


\subsection{Calidad de Componentes Web}

$R Q 3$ ¿Permite el modelo de calidad de componentes web educir sus características y evaluar la calidad de producto, de calidad en uso?

De acuerdo con los resultados del presente estudio, es posible validar la caracterización del modelo empírico de calidad de componentes web mediante un panel de expertos orquestados con técnicas de consenso, el método Delphi, adaptadas al caso.

La técnica es modificada para introducir un facilitador y la grabación de las entrevistas, que reducen el sesgo derivado de la fatiga presente en entrevistas extensas, 45 preguntas nuestro estudio, y que requieren la presentación de contexto y recogida de comentarios de elevada complejidad.

La validación se realiza evaluando el nivel de cobertura de las características de calidad del estándar ISO/IEC 25010 por parte de los atributos (métricas) del modelo empírico:

- El nivel de cobertura de las seis características de calidad de producto por parte de los tres atributos internos / estáticos.

- El nivel de cobertura de las cinco características de calidad en uso, junto con dos de las características de calidad de producto (adecuación funcional y rendimiento) por parte de los tres atributos externos / dinámicos.

Los estadísticos utilizados en la validación muestran un elevado nivel de fiabilidad del cuestionario (Alfa de Chronbach $\alpha=0.861$ ), alcanzándose en la validación del modelo un consenso moderado fuerte (W de Kendall intra-ronda $\omega=0,564$ ) y estabilidad (W de Kendall inter-ronda $\omega=0,987)$. El análisis complementario de Correspondencia Simple refuerza los resultados analíticos.

El análisis de la formación de consensos conduce al concepto de conglomerado de consenso: agrupaciones de expertos que maximizan el valor del estadístico de Kendal, utilizado como función de medida en el espacio de opiniones. La caracterización de dichos conglomerados haciendo uso de la categorización de expertos permite identificar modelos de calidad por dominio y/o categorías.

\subsection{Cobertura Empírica del Estándar ISO/IEC 25010}

$R Q 4$ ¿Proporciona dicho modelo cobertura de las características de calidad en uso y calidad de producto recogidas en la formulación del estándar ISO/IEC 25010?

La introducción de escalas ordinales, escalas Likert de 5 niveles, permiten la valoración de las coberturas de las características de calidad de producto y calidad en uso por parte de los atributos internos de evaluación estática y externos de evaluación dinámica:

- Escasa evidencia (desacuerdo): valoraciones de 1 o 2 en la escala.

- Evidencia no concluyente (neutro): valoración de 3 en la escala.

- Evidencia fuerte (acuerdo): valoración 4 o 5 en la escala.

Estableciendo como criterio de cobertura la existencia de un consenso entre los miembros del panel en el que el porcentaje de expertos que apoyan la evidencia fuerte es mayor al porcentaje de aquellos que apoyan una escasa evidencia, el modelo empírico de calidad de componentes web proporciona una cobertura de las características de estándar ISO/IEC mostrado en la siguiente figura: 


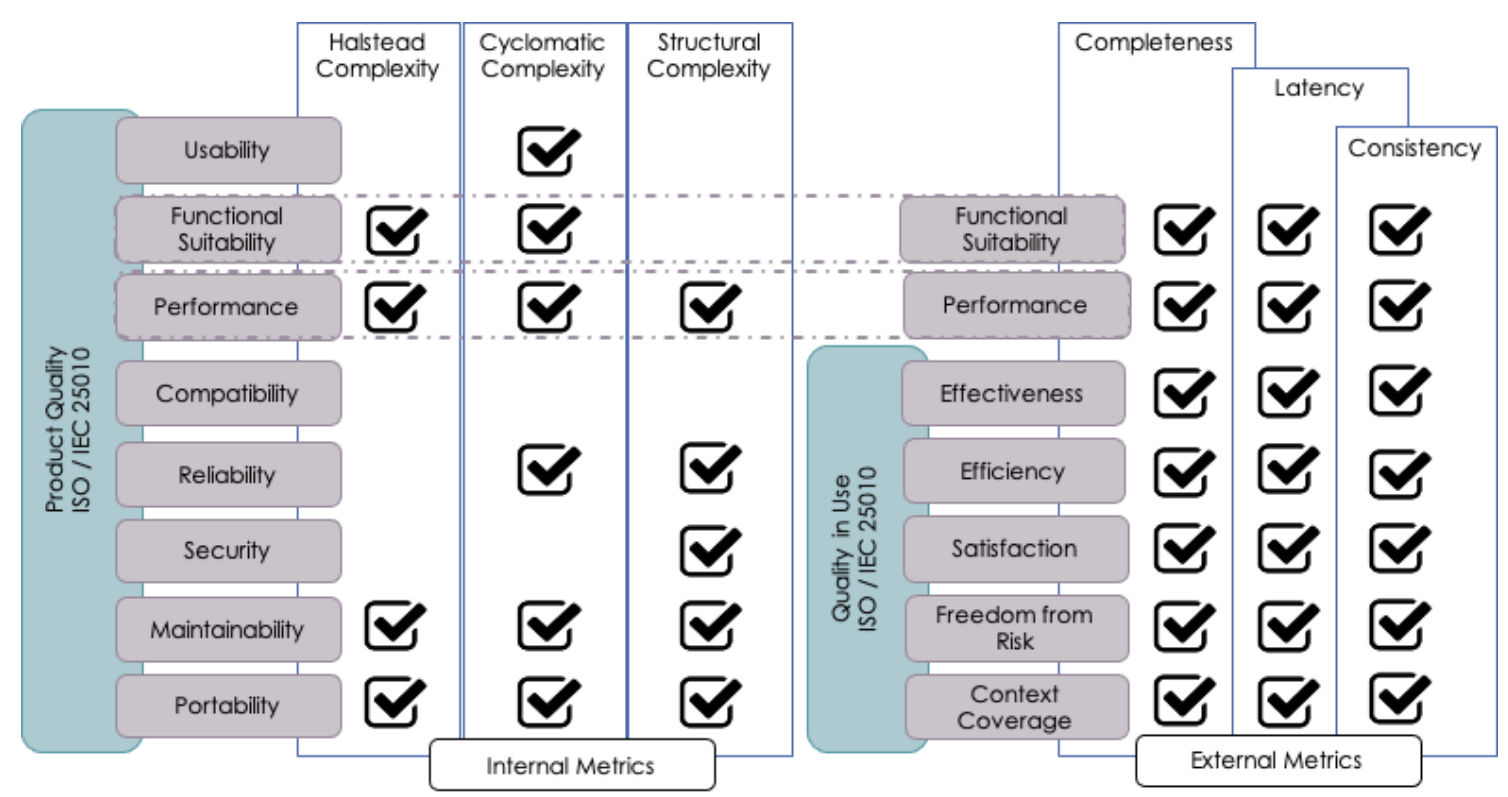

El modelo proporciona una cobertura parcial de las características de la calidad de producto. Este resultado es consistente con la facilidad de comprensión y evaluación de los atributos internos / estáticos, que permiten una mayor precisión en las opiniones de los expertos.

En un extremo, los resultados muestran la escasa evidencia sobre la posibilidad de de evaluar el grado con el que un componente web puede intercambiar información con otros y/o realizar sus funciones mientras comparte el mismo entorno hardware/software (Compatibilidad) haciendo uso de atributos internos.

Algunas otras características de calidad de producto cuentan con cobertura parcial existiendo consenso sobre la evidencia fuerte de evaluación por parte de uno o dos de los atributos internos de evaluación estática del modelo empírico.

Así, los resultados muestran una evidencia fuerte de que el grado con el que un componente web puede ser utilizado por usuario específicos, alcanzando objetivos específicos con eficacia, eficiencia y satisfacción en el contexto especificado (Usabilidad) puede evaluarse haciendo uso de la complejidad Ciclomática.

De igual forma, de acuerdo con el consenso alcanzado, existe una evidencia fuerte de que el grado con el que un componente web protege la información y los datos de forma que usuarios u otros sistemas cuenten con el nivel de acceso adecuado a sus tipos y niveles de autorización puede evaluarse en función de la complejidad estructural externa o número de dependencias (fan-out).

Como caso intermedio, la evaluación por parte de los atributos que miden el tamaño (complejidad de Halstead) y la complejidad estructural interna (Complejidad Ciclomática) del grado al cual un componente web proporciona funcionalidad que cumple las necesidades implícitas o explícitas cuando se utiliza bajo unas condiciones especificadas (Adecuación Funcional) cuenta con evidencia fuerte.

Y de manera similar, ejemplo de caso intermedio, la evaluación por parte de los atributos que miden la complejidad estructural interna (Complejidad Ciclomática) y la complejidad estructural externa (fan-out) del grado con el que un componente web realiza funciones especificadas bajo condiciones especificadas por un tiempo especificado (Fiabilidad) también cuenta con evidencia fuerte.

Por ultimo, la evaluación mediante los atributos que miden el tamaño (complejidad de Halstead), la complejidad estructural interna (Complejidad Ciclomática) y la complejidad estructural externa (fan-out) del rendimiento de un componente web relativo a la cantidad de 
recursos consumidos bajo condiciones especificadas (Rendimiento), del grado de eficacia y eficiencia con el que un componente web puede ser modificado por los agentes de mantenimiento especificado (Mantenibilidad), y del grado de eficacia y eficiencia con el que un producto puede ser transferido de un entorno hardware, software, de uso u otros, a un nuevo entorno (Portabilidad) cuenta con evidencia fuerte.

Los resultados relativos a la cobertura de las características de la calidad en uso por parte de los atributos (métricas) externos de evaluación dinámica presentan una mayor uniformidad.

Siguiendo los mismos criterios establecidos para determinar la cobertura de las características de calidad de producto, se cuenta con evidencia fuerte de la cobertura de todas las características de calidad en uso y las dos características extra de calidad de producto, adecuación funcional y rendimiento.

Si bien el estudio no permite valorar detalles de grano fino sobre la cobertura, la uniformidad en la evidencia puede responder a la mayor dificultad de evaluar la bondad de los atributos externos, que dificultaría la presencia de discrepancia. Dilucidar este corresponderá a líneas futuras de investigación.

\subsection{Generalización de Modelos Empíricos de Calidad}

RQ5 ¿Es posible evaluar la calidad de los componentes web, de acuerdo con el modelo empírico, manera objetiva y automática?

El enfoque exploratorio, descriptivo-correlativo, que se ha seguido en la experimentación cuantitativa confirma de manera parcial la eficacia de los instrumentos cuantitativos definidos.

Si bien a nivel de escenario y componente la plataforma ha permitido la definición de escenarios, experimentación y análisis de los resultados, estos no han logrado evidenciar modelos de regresión a nivel de escenario y componente. La inexistencia de valores de referencia en los atributos seleccionados, la falta de precisión proporcionada por la plataforma de experimentación o la existencia de relaciones más sutiles, pueden requerir planeamientos alternativos.

En cambio, la agregación de resultados correspondiente a escenario distintos, así como la aglutinación de las contribuciones de las variables independientes, atributos de calidad, en la valoración por parte del usuario, han sustanciado un modelo de regresión polinómico que evidencia ( $R 2$ adj. $=0,960)$ la conexión entre factor y variables explicativas.

La ampliación de la plataforma de experimentación con una síntesis de atributos guiada por valores de referencia obtenidos del análisis de repositorios, así como el diseño de nuevos experimentos que permita aislar contribuciones individuales a nivel de componente o escenario, corresponde a líneas futuras de investigación. 


\section{Futuras Líneas de Investigación}

"I've seen the future, brother"

Leonard Cohen

Llegados a este punto, sólo queda presentar las líneas de trabajo futuro que se abren como resultado de la investigación recogida en esta tesis. Tal y como ha venido ocurriendo hasta este momento, y para entender la conexión con el presente estudio, la presentación de las líneas futuras se encuadrará dentro de la organización utilizada para presentar las preguntas de investigación y las correspondientes conclusiones.

\subsection{El Futuro de los Métodos mixtos en Ingeniería del Software.}

En la presente investigación se ha utilizado un diseño exploratorio secuencial, especialmente conveniente en situaciones de significada incertidumbre en dominio no explorados. No obstante, este es sólo uno de los diseños posibles, lo que abre la posibilidad de planteamientos alternativos.

En particular el estudio de la aplicación de diseños convergentes, que permiten la comparación del análisis de datos resultado de la investigación cuantitativa y cualitativa, o explicativo secuencial, que enriquece los resultados cuantitativos con interpretación cualitativa, son líneas potencialmente fructíferas para mejorar el conocimiento de la ingeniería del software.

Adicionalmente, la aplicación del diseño exploratorio secuencial habrá de aportar interesantes resultados en dominios de innovación disruptiva, donde los métodos, aplicaciones o valoraciones éticas aun no se han consolidado lo suficiente como para reflejarse en procesos de transferencia, metodologías o estándares. Ejemplo de estos dominios podrían ser la inteligencia artificial, en especial las consideraciones éticas o de valoración de sesgos, o la computación cuántica, en especial en los aspectos relacionados con procesos de formación en la tecnología, desarrollo de aplicaciones o valoración de la calidad del producto software.

\subsection{El Futuro de la investigación de la Calidad Software de Ecosistemas Abiertos.}

Si bien la investigación realizada en esta tesis se ha circunscrito a la calidad de producto y calidad en uso, lo cierto es que la producción de software que integra tecnologías o se realiza completamente en ecosistemas abiertos presenta una enorme riqueza de posibilidades desde el punto de vista de proceso u organización.

La fragmentación en formas y metodologías, la ausencia de interoperabilidad y la opacidad de las distintas organizaciones que contribuyen al desarrollo, o las tecnologías integradas, si bien pueden resultar inasumibles de abordar a nivel cuantitativo, la aproximación cualitativa puede resultar más sencilla de unificar, permitiendo a posteriori el desarrollo de instrumentos cuantitativos una vez identificadas las líneas viables a ese nivel. Esto sentaría las bases de un modelo de calidad de software de ecosistemas abiertos a nivel de proceso $u$ organizacional. 


\subsection{El Futuro de la Evaluación de Calidad de Componentes Web.}

Frente a la exploración cuantitativa por usuario final seguida en esta tesis, se abren como enfoques futuros:

1. La categorización mediante la evaluación de atributos estáticos a nivel de componente primero y luego a nivel de repositorio, por agregación, de los distintos conjuntos de componentes desarrollados en ecosistemas abiertos y el estudio de como esta información permitiría establecer una escala por comparación para nuevos componentes o componentes desarrollados en ecosistemas cerrados.

2. La categorización mediante la evaluación de atributos dinámicos en términos similares al análisis planteado en el punto anterior. Teniendo en cuenta que con frecuencia existe una desconexión total entre los desarrolladores de los componentes y sus integradores y usuarios, la evaluación de la calidad en uso de repositorios arbitrarios introduce interesantes líneas de investigación.

Alternativamente, la evaluación de escenarios considerados como la composición de componentes, si bien cuenta con algunos resultados previos relacionados con la calidad de mashups web, sin duda con el enfoque seguido en esta investigación que caracteriza la calidad en función de atributos internos/estáticos y externos/dinámicos, posibilita una revisión de tales planteamientos iniciales, con una mayor riqueza de análisis.

\subsection{El Futuro de la Evaluación Empírica del Estándar ISO/IEC 25010.}

A tenor de los resultados obtenidos, existen al menos dos líneas de investigación futura sobre la evaluación empírica del estándar ISO/IEC 25010.

Por un lado, desde el punto de vista de la calidad de producto las características de seguridad y usabilidad cuentan con una cobertura mínima y la característica de compatibilidad no cuenta con cobertura por ninguno de los atributos propuestos. Esto introduce la pregunta de si existen conjuntos alternativos de atributos que mejoren la cobertura de estas características.

Además, en el caso de la característica de seguridad, por ser este un tema de especial importancia en el mundo de las tecnologías web, habría que aumentar de manera significativa la cobertura proporcionada por el modelo, de manera que pudiesen levantarse, al menos de manera parcial, las restricciones al uso de componentes web de ecosistemas abiertos que existen actualmente en numerosas empresas de la industria.

Por otra parte, tal y como se presentó en las conclusiones de esta investigación, la cobertura de las características de calidad en uso cuenta con una unanimidad y uniformidad que, si bien corresponde a la evidencia observada, parece difuminar la valoración, aportando únicamente información de grano grueso. Son necesarios posiblemente conjuntos nuevos de atributos que aporten un grano más fino en el análisis de cobertura, así como la exploración de procesos de evaluación y validación más especializados, que, sin llegar a dificultar el entendimiento e implementación del modelo, permitan un mejor análisis.

\subsection{El Futuro de la Generalización de Modelos Empíricos de Calidad.}

El enfoque aplicado en la investigación cuantitativa ha sido exploratorio, descriptivo-correlativo, ya que si bien la aplicación de los métodos mixtos ha permitido la definición de instrumentos cuantitativos lo inexplorado del dominio ha requerido esta aproximación. Partiendo de estos resultados, el enfoque cuantitativo correlativo-predictivo resulta una línea futura inmediata

Por otra parte, si bien los resultados obtenidos proporcionan un modelo de regresión del factor valoración a partir de las variables independientes atributos de calidad, la ampliación del dominio y la generalización poblacional son investigaciones que permitirían ahondar en la identificación de conexiones a nivel de componente o escenario, idealmente facilitando la 
predicción. Adicionalmente el análisis masivo de componente alojados en repositorios públicos podría ayudar a reemplazar los atributos sintéticos utilizados en la evaluación por otros acordes con este análisis empírico.

Por último, los valores referenciales obtenidos del análisis obtenidas de la categorización de repositorios públicos y la evaluación de poblaciones mayores abrirían la investigación de modelos estadísticos y neuronales.

En conjunto, también en términos de líneas futuras de investigación los resultados de esta tesis son alentadores y espero que sean la inspiración de nuevos trabajos en el campo de los métodos mixtos de investigación en la ingeniería del software en general y la calidad software en particular.

De confirmarse los resultados positivos de algunas de estas líneas de investigación, estoy convencido que en el futuro se incrementará el uso de tecnologías provenientes de ecosistemas abiertos, contribuyendo a resolver muchos de los retos tecnológicos a los que nos enfrentamos.

We chased our pleasures here

Dug our treasures there

But can you still recall

The time we cried

Break on through to the other side.

Break on through to the other side.

The Doors. 


\section{Bibliografía}

[1] Internet Engineering Task Force, «Hypertext Transfer Protocol Version 2,» Internet Engineering Task Force, [En línea]. Available: https://bit.ly/32m NzGz. [Último acceso: 12 July 2020].

[2] World Wide Web Consortium (W3C), «Hypertext Markup Language 5.2,» World Wide Web Consortium (W3C), 2017. [En línea]. Available: https://bit.ly/2DuTZIZ. [Último acceso: 12 July 2020].

[3] World Wide Web Consurtium (W3C), «World Wide Web Consurtium,» [En línea]. Available: https://bit.ly/2W5Lv1p. [Último acceso: 10 July 2020].

[4] Mozilla Foundation, "Mozilla Foundation," [Online]. Available: https://mzl.la/2Co6CVG. [Accessed 10 July 2020].

[5] ECMA International, "ECMAScript 2020 Language Specification," 2020. [Online]. Available: https://bit.ly/2DwqSoZ. [Accessed 10 July 2020].

[6] «TypeScript Language Organization,» Microsoft Inc, [En línea]. Available: https://bit.ly/2Duiczl. [Último acceso: 10 July 2020].

[7] Mozilla Developer Network, "Web Components.," [Online]. Available: https://mzl.la/2svVka0. [Accessed January 2019].

[8] GitHub, Inc, «GitHub,» GitHub, [En línea]. Available: https://bit.ly/3gRBywN. [Último acceso: 2020 July 2020].

[9] Twitter, Inc, «Bower,» Twitter, [En línea]. Available: http://bit.ly/2Mz1770. [Último acceso: 10 July 2020].

[10] NPM, Inc., «NPM,» npm, Inc., [En línea]. Available: https://bit.ly/3iJWtnb. [Último acceso: 10 July 2020].

[11] ISO/IEC, «System and Software Engineering. System and Software Quality Requirement and Evaluation. System and Software Quality Model ISO/IEC 25010,» 2011.

[12] J. W. Creswell and V. L. Plano Clark, Designing and Conducting Mixed Methods Research, 3rd ed., SAGE, 2018.

[13] N. Dalkey and O. Helmer, "An Experimental Application of the Delphi Method to the use of experts," Management Science, vol. 9, no. 3, pp. 458-467, 1963.

[14] G. Dyson, La catedral de Turing: Los orígenes del universo digital, Barcelona: Debate, 2015.

[15] F. P. Brooks Jr., The Mythical Man-Month: Essays on Software Engineering, AddisonWesley Longman , 1995.

[16] S. Levy, Hackers, Sebastopol CA: O'Reilly Media Inc, 2010.

[17] E. S. Raymond, he Cathedral and the Bazaar: Musings on Linux and Open Source by an Accidental Revolutionary, Sebastopol, CA: O'Reilly Media Inc, 1999.

[18] H. W. Chesbrough, Open Innovation: The New Imperative for Creating and Profiting from Technology, Brighton, Massachusetts: Harvard Business Review Press, 2006. 
[19] S. Jansen, M. Cusumano y K. M. (. Popp, «Managing Software Platforms and Ecosystems, » IEEE Software, vol. 36, no 3, pp. 17-60, May / June 2019.

[20] G. Robles, P. Adams, I. Steinmacher y C. (. Treude, «Twenty Years of Open Source: from Skepticism to Mainstream, » IEEE Software, vol. 36, no 6, pp. 12-32, 2019.

[21] A. Hunt and D. Thomas, The Pragmatic Programmer: From Journeyman to Master, Boston, Massachusetts: Addison Wesley, 1999.

[22] K. Beck, M. Fowler, W. Cunningham, A. Cockburn, A. v. Bennekum and M. Beedle, "Principles behind the Agile Manifesto," February 2001. [Online]. Available: https://agilemanifesto.org/principles.html. [Accessed 10 April 2020].

[23] A. Barr, The Problem With Software: Why Smart Engineers Write Bad Code, Boston, MA: The MIT Press, 2018.

[24] "When bits bite. Why companies struggle with recalcitrant IT," The Economist, p. 56, 18 th July 2020.

[25] I. Sommerville, Software Engineering, 10th ed., London: Pearson Education, 2016.

[26] ISO/IEC/IEEE, «Systems and software engineering -- Vocabulary,» 24765, pp. 1-541, 28 Aug. 2017.

[27] P. Bourque y R. E. Fairley, Edits., Guide to the Software Engineering Body of Knowledge, version 3.0 ed., IEEE Computer Society, 2014.

[28] Association for Computing Machinery, "Association for Computing Machinery," ACM, [En línea]. Available: https://bit.ly/2ZHGILm. [Último acceso: 20 July 2020].

[29] Institute of Electrical and Electronics Engineers, «Institute of Electrical and Electronics Engineers,» IEEE, [En línea]. Available: https://bit.ly/2OA7OIC. [Último acceso: 20 July 2020].

[30] IEEE Computer Society, «IEEE Computer Society, » IEEE Computer Society, [En línea]. Available: https://bit.ly/3he5Qcz. [Último acceso: 20 July 2020].

[31] IEEE-CS/ACM Joint Task Force on Software Engineering Ethics and Professional Practices, "IEEE Computer Society - Code of Ethics," Computer Society, [Online]. Available: https://bit.ly/3jke6Kr. [Accessed 20 July 2020].

[32] Association for Computing Machinery's Committee on Professional Ethics, "ACM Code of Ethics and Professional Conduct,» Association for Computing Machinery, [En línea]. Available: https://bit.ly/2Cl6A1s. [Último acceso: 20 July 2020].

[33] E. W. Dijkstra, "Letters to the editor: Go to statement considered harmful," Communications of the ACM, vol. 11, no 3, pp. 147-148, 1968.

[34] B. Boehm, C. Abts, A. W. Brown, S. Chulani, B. K. Clark, E. Howoritz, R. Madachy, D. Reifer y B. Steece, Software Cost Estimation with COCOMO II, Englewood Cliffs, NJ: Prentice Hall, 2000.

[35] CMMI Institute, «Introducing $\mathrm{CMMI}^{\circledR}$ V2.0,» $\mathrm{CMMI}$ Institute, [En línea]. Available: https://bit.ly/2ZHGj6c. [Último acceso: 20 July 2020].

[36] ISO, «International Organization for Standardization, » International Organization for Standardization, [En línea]. Available: https://bit.ly/2Be9B2Q. [Último acceso: 20 July 2020].

[37] K. Xu and J. Schneider, "The Future of American Industry Depends on Open Source Tech," Wired, 26082020.

[38] Free Software Foundation, "What is free software? The Free Software Definition,» Free Software Foundation, [En línea]. Available: http://bit.ly/2Rbaprj. [Último acceso: 20 July 2020]. 
[39] Wikipedia, «Emergence,» Wikipedia, [En línea]. Available: https://bit.ly/3juaztg. [Último acceso: 20 July 2020].

[40] Vision Mobile, «Developer Economics: State of the Nation Q3 2014,» Slash Data Inc, London, 2014.

[41] Google Inc, «The Chromium Projects, " Google Inc, [En línea]. Available: https://bit.ly/3jjlZjl. [Último acceso: 20 July 2020].

[42] Apache Foundation, "Apache Foundation,» [En línea]. Available: https://bit.ly/2ZJ8Bx8. [Último acceso: 20 July 2020].

[43] CNCF, «Cloud Native Computing Foundation,» CNCF, [En línea]. Available: https://bit.ly/3jipjeD. [Último acceso: 20 July 2020].

[44] Software in the Public Interest, Inc., "The Debian Project,» [En línea]. Available: https://bit.ly/32ANmj8. [Último acceso: 20 July 2020].

[45] "PostgreSQL: The World's Most Advanced Open Source Relational Database," The PostgreSQL Global Development Group, [En línea]. Available: https://bit.ly/3hkv75z. [Último acceso: 20 July 2020].

[46] "Python programming language,» The Python Software Foundation, [En línea]. Available: https://bit.ly/398RiJ2. [Último acceso: 20 July 2020].

[47] "What is R?,» The R Foundation, [En línea]. Available: https://bit.ly/3fMEb2O. [Último acceso: 20 July 2020].

[48] «TensorFlow,» Google Inc, [En línea]. Available: https://bit.ly/2WD10y6. [Último acceso: 20 July 2020].

[49] Google, «Polymer Project - LitElement,» [En línea]. Available: http://bit.ly/2DmwmA5. [Último acceso: January 2019].

[50] The Linux Foundation, «The Linux Foundation,» [En línea]. Available: https://bit.ly/3hsfd9p. [Último acceso: 20 July 2020].

[51] CNCF , "Cloud Native Interactive Landscape," Cloud Native Computing Foundation, [En línea]. Available: https://bit.ly/3fPyTU4. [Último acceso: 20 July 2020].

[52] C. Christensen, The Innovator's Dilemma, Harvard Business Review Press, 1997.

[53] D. Campbell y D. Fiske, «Convergent and discriminat validation by the multitraitmultimethod matrx,» Psychological Bulletin, vol. 56, pp. 81-105, 1959.

[54] N. Denzin, The research act: A theoretical introduction to sociological methods., New York: McGraw-Hill, 1978.

[55] D. Campbell , "Quantitative knowing in action research.," de Annual Meeting of the American Psychological Association, New Orleans, 1974.

[56] L. J. Cronbach, «Beyond the two disciplines of scientific psychology.," American Psychologist, vol. 30, pp. 116-127, 1975.

[57] J. Brewer y A. Hunter, Multimethod research: A synthesis of Styles, Newbury Park: Sage, 1989.

[58] A. Bryman, Quantity and quality in social research, London: Routledge, 1988.

[59] J. Creswell, Research design: quantitative and qualitative approaches, Thousand Oaks: Sage, 1994.

[60] R. Hernández Sampieri, C. Fernández-Collado y P. Baptista Lucio, Metodología de la Investigación, México: McGrau-Hill, 2006.

[61] E. Zerbe, "A Mixed Methods Approach to Understanding Engineering Identity in Students from Varied Academic Environments," in IEEE Frontiers in Education Conference (FIE), Covington, KY, USA, USA, 2019. 
[62] R. D'souza, M. Bhayana, M. Ahmadzadeh and B. Harrington, "A Mixed-Methods Study of Novice Programmer Interaction with Python Error Messages," in WCCCE '19: Proceedings of the Western Canadian Conference on Computing Education, Calgary, 2019.

[63] A. Meyer, E. Barr, C. Bird and T. Zimmermann, "Today was a Good Day: The Daily Life of Software Developers," IEEE Transactions on Software Engineering, 2019.

[64] P. Chandar, J. Garcia-Gathright, C. Hosey and B. St. Thomas, "Developing Evaluation Metrics for Instant Search Using Mixed Methods Methods," in SIGIR'19: Proceedings of the 42nd International ACM SIGIR Conference on Research and Development in Information Retrieval, Paris, 2019.

[65] R. Tinati, S. Halford, L. Carr and C. Pope, "Mixing methods and theory to explore web activity," in WebSci '12: Proceedings of the 4th Annual ACM Web Science Conference, Evanston, Illinois, USA., 2019.

[66] Real Academia de la Lengua, «Diccionario de la lengua española,» [En línea]. Available: https://dle.rae.es/. [Último acceso: 10 April 2020].

[67] B. G. Dale, D. Bamford y T. V. Der Wiele, Edits., Managing Quality. An Essential Guide and Resource Gateway, John Wiley \& Sons Ldt, 2016.

[68] F. Al Obisat, Z. Alhalhouli, T. Alrawashdeh and T. Alshabatat, "Review of Literature on Software Quality," World of Computer Science and Information Technology, vol. 8, no. 5, 2018.

[69] J. Miguel, D. Mauricio y G. Rodríguez, "A Review of Software Quality Models for the Evaluation of Software Products, $)$ International Journal of Software Engineering \& Applications (IJSEA), vol. 5, no 6, 2014.

[70] B. Boehm, J. Brown and M. Lipow, "Quantitative Evaluation of Software Quality," in International Conference on Software Engineering, San Francisco, 1976.

[71] J. McCall, P. Richards y G. Walters, «Factors in Software Quality, TR-77-369,» RADC, 1977.

[72] R. Dromey, "A Model for Software Product Quality," IEEE Transactions on Software Engineering, vol. 21, no 2, 1995.

[73] I. Singh, "A Different Software Quality Model,» International Journal on Recent and Innovation Trends in Computing and Communication, vol. 1, no 5, p. 438-442, 2013.

[74] ISO/IEC, "Software Engineering Product Quality: Quality Model (Vol. 1) ISO/IEC 9126," 2001.

[75] ISO/IEC, «Quality Management System. Requirements ISO 9001 2000,» 2008.

[76] M. Paulk, B. Curtis, M. Chrissis y C. Weber, "Capability Maturity Model, Version 1.1,» IEEE Software, vol. 10, № 4, 1993.

[77] ISO/IEC, "System and Software Engineering. System and Software Quality Requirements and Evaluation. Measurement of Quality in Use ISO/IEC 25022,» 2016.

[78] ISO/IEC, "System and Software Engineering. System and Software Quality Requirements and Evaluation. Measurement of System and Software Product Quality ISO/IEC 25023,» 2016.

[79] Web Hypertext Application Technology Working Group (WHATWG), «DOM Standard Shadow Trees,» 2019. [En línea]. Available: http://bit.ly/2Hgkund. [Último acceso: January 2019].

[80] Web Hypertext Application Technology Working Group (WHATWG), «HTML Standard Custom Elements, » 2019. [En línea]. Available: http://bit.ly/2FDx3Gt. [Último acceso: January 2019]. 
[81] Web Hypertext Application Technology Working Group (WHATWG), «HTML Standard Template Element,» 2019. [En línea]. Available: http://bit.ly/2ANZzC0. [Último acceso: January 2019].

[82] O. W. Components, "Open Web Components," [Online]. Available: https://bit.ly/2BleuBg. [Accessed 08 June 2020].

[83] Hybrids Project, "Hybrids Library," 2019. [Online]. Available: http://bit.ly/2sznFMz. [Accessed January 2019].

[84] Snuggsi Project, "Snuggsi Library," 2019. [Online]. Available: http://bit.ly/2S2dwWO. [Accessed January 2019].

[85] Smart HTML Elements, "Smart.js," 2019. [Online]. Available: http://bit.ly/2TXXdrm. [Accessed January 2019].

[86] World Wide Web Consortium (W3C), «HTML Templates. Working Group Note 18 March 2014,» March 2014. [En línea]. Available: http://bit.ly/2CAL66. [Último acceso: January 2019].

[87] Mozilla Developer Network, «Polyfill - Glossary entry,» [En línea]. Available: https://mzl.la/2TgSdyq. [Último acceso: January 2019].

[88] ECMA International, "ECMAScript 2015 Language Specification," June 2015. [Online]. Available: http://bit.ly/2FO1MRA. [Accessed January 2019].

[89] W. Vorraber, M. Müller, S. Voessner y W. Slany, «Analyzing and Managing Complex Software Ecosystem, " IEEE Software, vol. 36, no 3, pp. 55-60, 2019.

[90] K. Beck y C. Andres, Extreme Programming Explained, Addison-Wesley, 2005.

[91] "WebComponents.org," [Online]. Available: http://bit.ly/2S8q52Q. [Accessed January 2019].

[92] Google, "Polymer Web Component Directory," [Online]. Available: http://bit.ly/2RI3n2e. [Accessed January 2019].

[93] K. Fogel, Producing Open Source Software: How to Run a Successful Free Software Project, O'Reilly Media, 2008.

[94] Free Software Foundation, "FSF Licensing \& Compliance Team," [Online]. Available: http://bit.ly/2Wi3pwy. [Accessed January 2019].

[95] Free Software Foundation, "What is free software? The Free Software Definition," [Online]. Available: http://bit.ly/2Rbaprj. [Accessed January 2019].

[96] Stack Over Flow, "StackOverFlow Developer Survey 2020," StackOverFlow, 2020. [Online]. Available: https://insights.stackoverflow.com/survey/2020. [Accessed 1509 2020].

[97] Google Developer, «Experts Program,» Google Inc, [En línea]. Available: https://developers.google.com/community/experts. [Último acceso: 20 April 2020].

[98] Google Inc., «Google Workspace,» [En línea]. Available: https://workspace.google.com. [Último acceso: 12 October 2020].

[99] C. Torrecilla-Salinas, M. Escalona, M. Mejias and O. De Troyer, "A Delphi-based expert judgment method applied to the validation of a mature Agile framework fo Web development projects," Information Tecnology and Management, vol. 20, pp. 9-40, 2019.

[100] The Comprehensive R Archive Network, "CRAN - Package psy," The Comprehensive R Archive Network, [En línea]. Available: https://bit.ly/3gO1Ob7. [Último acceso: 10 July 2020].

[101] The Comprehensive R Archive Network, "CRAN Package irr," The Comprehensive R Archive Network, [Online]. Available: https://bit.ly/3gO1Ob7. [Accessed 15 May 2020]. 
[102] M. Greenace, La Práctica de Análisis de Correspondencia., Madrid: Fundación BBVVA, 2008.

[103] The Comprehensive R Archive Network, «CRAN Package ca,» The Comprehensive $R$ Archive Network, [En línea]. Available: https://bit.ly/3eeUKmg. [Último acceso: 10 July 2020].

[104] A.-L. Martinez-Ortiz, «Web Components Metrics,» 2020. [En línea]. Available: https://github.com/WCMetrics/SurveyAnalysis. [Último acceso: 01 July 2020].

[105] P. Legendre, «Species Associations: The Kendall Coefficient of Concordance Revisited,» Journal of Agricultural, Biological, and Environmental Statistics, vol. 10, no 2, pp. 226245, 2005.

[106] D. St-Louis and W. Suryn, "Enhancing ISO/IEC 25021 quality measure elements for wider application within ISO 25000 series," in IECON 2012 - 38th Annual Conference on IEEE Industrial Electronics Society, Montreal, QC, Canada, 2012.

[107] J. Voas y R. Kuhn, "What Happened to Software Metrics?,» Computer, vol. 50, pp. 8898, May 2017.

[108] «International Software Benchmarking Standards Group,» ISBSG, [En línea]. Available: https://www.isbsg.org/. [Último acceso: May 2020].

[109] M. Halstead, Elements of Software Science, Amsterdam: Elsevier North-Holland, 1977.

[110] A. Abran, Software Metrics and Software Metrology, New Jersey: Wiley-IEEE Computer Society, 2010.

[111] N. Fenton y S. Pfleefer, Software Metrics. A Rigorous \& Practical Approach 2nd Edition, Thomson Computer Press, 1996.

[112] T. McCabe, "A Complexity Measure," IEEE Transactions on Software Engineering, vol. 2, no. 4, pp. 308-320, 1976.

[113] S. Kan, Metrics and Models in Software Quality Engineering, 2nd Edition ed., Addison Wesley, 2005.

[114] C. Kelton, J. Ryoo, A. Balasubramanian and S. Das, "Improving User Perceived Page Load Time Using Gaze," in Proceedings of the 14th USENIX Symposium on Networked Systems Design and Implementation, Boston, MA, USA, 2017.

[115] F. Reichheld, "The One Number You Need to Grow," Harvard Business Review, vol. 81, pp. 46-54, 2003.

[116] T. Menzies, C. Bird, T. Zimmermann, W. Schulte y E. Kocaganeli, «The Inductive Software Engineering Manifesto: Principles for Industrial Data Mining," de The International Workshop on Machine Learning Technologies in Software Engineering, Lawrence, Kansas, U.S.A., 2011.

[117] T. Menzies y T. Zimmermann, «Software Analytics: So What?,» IEEE Software, vol. 4, pp. 31-37, 2013.

[118] T. Mens, «Research trends in structural software complexity,» August 2016. [En línea]. Available: http://bit.ly/2RNv1ep. [Último acceso: January 2019].

[119] D. Lizcano, A.-L. Martinez-Ortiz, G. Lopez y A. Grignard, «End-user modeling of quality for web components," Journal of Software: Evolution and Process, no Special Issue Empirical Paper, 05 March 2020.

[120] H. A. Linstone y M. Turoff, The Delphi Method: Techniques and Applications, New Jersey: Self published online, 2002.

[121] B. Kitchenham, S. Pfleeger, L. Pickard, P. Jones, D. Hoaglin, K. El Emam y J. Rosenberg, « Preliminary guidelines for empirical research in software engineering," IEEE Transactions on Software Engineering, vol. 28, no 8, pp. 721-734, 2002. 
[122] B. Kitchenham, "Sofware Development Cost Models,» de Software Reliability Handbook, P. Rook, Ed., Elsevier, pp. 487-517.

[123] D. Hubbard, How To Measure Anything, New Jersey: Wiley, 2014.

[124] Hern, R. Hernandez Sampieri, C. Fernandez-Collado y P. Baptista Lucio, Metodologia de la Investigacion, 4th ed., Mc GrawHill, 2006.

[125] J. Hartmanis, "On Computational Complexity and the Nature of Computer Science," Communications of ACM, vol. 37, no 10, pp. 37-43, 1994.

[126] N. Gorla y R. Ramakrishnan, "Effect of Software Structure Attributes on Software Development Productivity," S. Systems and Software, vol. 36, no 2, pp. 191-199, 1997.

[127] D. Darcy, C. Kemerer, S. Slaughter y J. Tomayko, «The structural complexity of software: An experimental test," IEEE Transactions on Software Engineering, vol. 31, no 11, pp. 982-995, 2005.

[128] N. Bevan, "Quality in use: Meeting user needs for quality," J Systems and Software, vol. 49, no 1, pp. 89-96, 1999.

[129] N. Bevam, "Classifying and Selecting UX and Usability Measures, " de Proceeding of the International Workshop on Meaningful Measures, Reykjavik, 2008.

[130] R. Adamov y L. Ritcher, "A Proposal for Measuring the Structural Complexity, » J. System and Software, vol. 12, pp. 55-70, 1990.

[131] R. Kurnia, R. Ferdiana y S. Wibirama, «Software Metrics Classifications for Agile Scrum Process: A Literature Review, " de International Seminar on Research of Information Technology and Intelligent System, 2018.

[132] Google, "Polymer Project - lit-html Library," 2019. [Online]. Available:

http://bit.ly/2sBf8ZB. [Accessed January 2019].

[133] D. Izquierdo-Cortazar, J. Gonzalez-Barahona, S. Dueñas and G. Robles, "Towards Automated Quality Models for Software Development Communities: the QualOSS and FLOSSMetrics case," in Quality of Information and Communications Technology, Porto, Portugal, 2010.

[134] G. Robles, J. Gonzalez-Barahona, C. Cervigon, A. Capiluppi and D. Izquierdo-Cortazar, "Estimating Development Effort in Free/Open Source Software Projects by Mining Software Repositories," in Conference: Mining Software Repositories, Hyderabad, India, 2014.

[135] D. Zhang, S. Han, Y. Dang, J. Lou, H. Zhang y T. Xie, "Software Analytics in Practice,» IEEE Software, vol. 30, no 5, pp. 30-37, 2013.

[136] Twitter, "Bower A package manager for the web," 2012. [Online]. Available: http://bit.ly/2Mz1770. [Accessed January 2019].

[137] Vaadin, "Vaadin Web Component Directory," [Online]. Available: http://bit.ly/2sLB6Js. [Accessed January 2019].

[138] Wikipedia, "Delphi Method," [Online]. Available: https://en.wikipedia.org/wiki/Delphi_method. [Accessed 10 April 2020].

[139] Wikipedia, "Wikipedia - Lints," [Online]. Available: https://bit.ly/3flSLOi. [Accessed 10 July 2020]. 


\section{Apéndices}

\subsection{Datos Experimentales del Estudio Cualitativo}

En este apéndice se incluyen los datos experimentales del estudio cualitativo organizados en una tabla y agrupados por ronda. Los códigos de la primera fila corresponden a las unidades experimentales, es decir, cada experto. La segunda fila corresponde al nivel de experiencia autoasignado. El resto corresponden a las respuestas dentro de una escala ordinal de Likert de cinco niveles.

\begin{tabular}{|c|c|c|c|c|c|c|c|c|c|c|c|c|c|c|c|c|c|c|c|c|}
\hline Exp. & Z400A1 & $90 \mathrm{~A} 1$ & Z120A1 & Z500A1 & Z800A1 & Z100A1 & Z900A1 & Z240A1 & Z140A1 & Z230A1 & Z110A1 & Z200A1 & Z700A1 & Z300A1 & Z600A1 & Z210A1 & Z220A1 & Z180A1 & Z130A1 & Z150A1 \\
\hline Cat. & 4.00 & 4.00 & 4.00 & 3.00 & 5.00 & 4.00 & 2.00 & 4.00 & 5.00 & 5.00 & 4.00 & 4.00 & 5.00 & 4.00 & 4.00 & 4.00 & 4.00 & 5.00 & 4.00 & 5.00 \\
\hline 2D01 & 3.00 & 3.00 & 2.00 & 3.00 & 1.00 & 2.00 & 1.00 & 4.00 & 4.00 & 2.00 & 4.00 & 2.00 & 4.00 & 4.00 & 3.00 & 4.00 & .00 & 2.00 & .00 & 3.00 \\
\hline QD02 & 4.00 & 2.00 & 4.00 & 4.00 & 4.00 & 1.00 & 4.00 & 4.00 & 2.00 & 4.00 & 4.00 & 1.00 & 4.00 & 3.00 & 4.00 & 3.00 & 4.00 & 4.00 & 1.00 & 4.00 \\
\hline QD03 & 1.00 & 4.00 & 2.00 & 5.00 & 2.00 & 2.00 & 1.00 & 3.00 & 1.00 & 2.00 & 1.00 & 1.00 & 2.00 & 1.00 & 2.00 & 4.00 & 1.00 & 1.00 & 1.00 & 1.00 \\
\hline QD04 & 1.00 & 4.00 & 3.00 & 3.00 & 1.00 & 2.00 & 1.00 & 4.00 & 3.00 & 4.00 & 4.00 & 1.00 & 3.00 & 1.00 & 2.00 & 4.00 & 3.00 & 1.00 & 1.00 & 1.00 \\
\hline QD05 & 4.00 & 4.00 & 2.00 & 4.00 & 1.00 & 4.00 & 1.00 & 3.00 & 2.00 & 5.00 & 4.00 & 1.00 & 4.00 & 1.00 & 2.00 & 2.00 & 1.00 & 2.00 & 2.00 & 1.00 \\
\hline QD06 & 2.00 & 5.00 & 1.00 & 1.00 & 1.00 & 1.00 & 1.00 & 1.00 & 3.00 & 2.00 & 2.00 & 2.00 & 4.00 & 3.00 & 2.00 & 2.00 & 1.00 & 3.00 & 2.00 & 1.00 \\
\hline QD07 & 5.00 & 5.00 & 4.00 & 1.00 & 5.00 & 5.00 & 3.00 & 1.00 & 4.00 & 5.00 & 5.00 & 4.00 & 5.00 & 3.00 & 5.00 & 5.00 & 5.00 & 4.00 & 5.00 & 4.00 \\
\hline QD08 & 1.00 & 3.00 & 4.00 & 2.00 & 4.00 & 2.00 & 3.00 & 2.00 & 4.00 & 2.00 & 5.00 & 4.00 & 5.00 & 3.00 & 4.00 & 4.00 & 5.00 & 1.00 & 2.00 & 4.00 \\
\hline QD09 & 4.00 & 5.00 & 1.00 & 3.00 & 2.00 & 2.00 & 2.00 & 3.00 & 4.00 & 1.00 & 5.00 & 2.00 & 4.00 & 2.00 & 4.00 & 4.00 & 4.00 & 5.00 & 1.00 & 3.00 \\
\hline QD10 & 5.00 & 2.00 & 2.00 & 4.00 & 5.00 & 4.00 & 4.00 & 5.00 & 5.00 & 4.00 & 5.00 & 5.00 & 3.00 & 5.00 & 5.00 & 3.00 & 4.00 & 5.00 & 3.00 & 4.00 \\
\hline QD11 & 2.00 & 4.00 & 2.00 & 1.00 & 3.00 & 2.00 & 2.00 & 4.00 & 1.00 & 2.00 & 2.00 & 1.00 & 4.00 & 4.00 & 3.00 & 4.00 & 3.00 & 1.00 & 2.00 & 4.00 \\
\hline QD12 & 4.00 & 4.00 & 2.00 & 2.00 & 3.00 & 2.00 & 4.00 & 4.00 & 3.00 & 4.00 & 5.00 & 1.00 & 5.00 & 4.00 & 4.00 & 2.00 & 5.00 & 1.00 & .00 & 4.00 \\
\hline QD13 & 4.00 & 5.00 & 1.00 & 2.00 & 3.00 & 4.00 & 3.00 & 4.00 & 4.00 & 3.00 & 5.00 & 1.00 & 4.00 & 1.00 & 4.00 & 2.00 & 5.00 & 4.00 & 2.00 & 2.00 \\
\hline QD14 & 1.00 & 5.00 & 2.00 & 1.00 & 1.00 & 4.00 & 3.00 & 2.00 & 4.00 & 4.00 & 5.00 & 1.00 & 5.00 & 3.00 & 3.00 & 3.00 & 2.00 & 2.00 & 1.00 & 3.00 \\
\hline QD15 & 5.00 & 5.00 & 5.00 & 2.00 & 4.00 & 5.00 & 5.00 & 5.00 & 3.00 & 5.00 & 5.00 & 5.00 & 5.00 & 5.00 & 5.00 & 5.00 & 5.00 & 4.00 & 5.00 & 5.00 \\
\hline QD16 & 1.00 & 3.00 & 4.00 & 2.00 & 4.00 & 4.00 & 2.00 & 4.00 & 3.00 & 2.00 & 5.00 & 5.00 & 5.00 & 5.00 & 4.00 & 4.00 & 5.00 & 1.00 & 2.00 & 5.00 \\
\hline QD17 & 1.00 & 4.00 & 1.00 & 1.00 & 2.00 & 2.00 & 1.00 & 4.00 & 4.00 & 1.00 & 4.00 & 1.00 & 5.00 & 2.00 & 2.00 & 3.00 & 4.00 & 3.00 & 3.00 & 2.00 \\
\hline QD18 & 2.00 & 4.00 & 4.00 & 5.00 & 4.00 & 3.00 & 4.00 & 5.00 & 4.00 & 4.00 & 4.00 & 3.00 & 4.00 & 4.00 & 4.00 & 5.00 & 4.00 & 4.00 & 5.00 & 5.00 \\
\hline QD19 & 1.00 & 2.00 & 2.00 & 5.00 & 3.00 & 5.00 & 1.00 & 5.00 & 4.00 & 2.00 & 1.00 & 1.00 & 5.00 & 1.00 & 3.00 & 2.00 & 4.00 & 1.00 & .00 & 3.00 \\
\hline QD 20 & 1.00 & 3.00 & 2.00 & 3.00 & 2.00 & 2.00 & 1.00 & 4.00 & 2.00 & 4.00 & 4.00 & 1.00 & 5.00 & 1.00 & 3.00 & 2.00 & 2.00 & 1.00 & 2.00 & 2.00 \\
\hline QD21 & 1.00 & 4.00 & 5.00 & 4.00 & 2.00 & 5.00 & 1.00 & 5.00 & 5.00 & 4.00 & 4.00 & 3.00 & 3.00 & 1.00 & 4.00 & 2.00 & 4.00 & 3.00 & 5.00 & 2.00 \\
\hline QD22 & 1.00 & 4.00 & 5.00 & 3.00 & 3.00 & 4.00 & 3.00 & 4.00 & 4.00 & 4.00 & 2.00 & 1.00 & 4.00 & 4.00 & 5.00 & 4.00 & 1.00 & 1.00 & 2.00 & 1.00 \\
\hline QD23 & 4.00 & 4.00 & 5.00 & 2.00 & 5.00 & 5.00 & 3.00 & 3.00 & 4.00 & 5.00 & 4.00 & 4.00 & 5.00 & 4.00 & 5.00 & 4.00 & 5.00 & 5.00 & 4.00 & 3.00 \\
\hline QD24 & 1.00 & 5.00 & 5.00 & 4.00 & 4.00 & 4.00 & 4.00 & 4.00 & 4.00 & 4.00 & 4.00 & 5.00 & 5.00 & 5.00 & .00 & 5.00 & 5.00 & 2.00 & 4.00 & 5.00 \\
\hline QD25 & 5.00 & 4.00 & 5.00 & 3.00 & 5.00 & 4.00 & 4.00 & 4.0 & 3.00 & 5.00 & & 4.00 & 4.00 & 5.00 & & 5.00 & & 2.00 & & 4.00 \\
\hline QD26 & 4.00 & 4.00 & 1.00 & 2.00 & 2.00 & 4.00 & 3.00 & 3.00 & 4.00 & 4.00 & 2.00 & 1.00 & 5.00 & 3.00 & 5.00 & 4.00 & 4.00 & 4.00 & 1.00 & 4.00 \\
\hline QD27 & 5.00 & 4.00 & 5.00 & 4.00 & 5.00 & 4.00 & 4.00 & 4.00 & 3.00 & 4.00 & 4.00 & 5.00 & 5.00 & 4.00 & 3.00 & 5.00 & .00 & 5.00 & & 4.00 \\
\hline QD28 & 4.00 & 3.00 & 1.00 & 4.00 & 2.00 & 4.00 & 2.00 & 4.00 & 4.00 & 4.00 & 4.00 & 1.00 & 5.00 & 3.00 & 4.00 & 3.00 & 4.00 & 3.00 & 2.00 & 4.00 \\
\hline QD29 & 5.00 & 5.00 & 2.00 & 3.00 & 5.00 & 2.00 & 4.00 & 5.00 & 3.00 & 5.00 & 4.00 & 5.00 & 5.00 & 5.00 & 5.00 & 5.00 & .00 & 5.00 & .00 & 4.00 \\
\hline QD30 & 4.00 & & 5.00 & 1.00 & 5.00 & & 5.00 & & 5.00 & 4.00 & 4.00 & 5.00 & 5.00 & 3.00 & 3.00 & 4.00 & & 5.00 & & 4.00 \\
\hline QD31 & 3.00 & 4.00 & 1.00 & 2.00 & 5.00 & 4.00 & 2.00 & 4.00 & 4.00 & 2.00 & 4.00 & 4.00 & 4.00 & 4.00 & 4.00 & 3.00 & 2.00 & 4.00 & 2.00 & 4.00 \\
\hline QD32 & 1.00 & & & & & & & & & & & & .00 & 4.00 & 00 & 5.00 & & .00 & & 3.00 \\
\hline QD33 & 5.00 & 5.00 & 5.00 & 5.00 & 5.00 & 5.00 & 5.00 & 5.00 & 4.00 & 4.00 & 4.00 & 5.00 & 5.00 & 4.00 & 5.00 & 4.00 & 5.00 & 3.00 & 4.00 & 4.00 \\
\hline QD34 & 4.00 & 3.00 & 5.00 & 4.00 & 4.00 & & 3.00 & 4.00 & 2.00 & 4.00 & 4.00 & 4.00 & 4.00 & 4.00 & 4.00 & 5.00 & .00 & 1.00 & .00 & 2.00 \\
\hline QD35 & 2.00 & 4.00 & 5.00 & 5.00 & 3.00 & 4.00 & 3.00 & 5.00 & 4.00 & 4.00 & 4.00 & 3.00 & 5.00 & 3.00 & 4.00 & 4.00 & 4.00 & 4.00 & 3.00 & 3.00 \\
\hline QD36 & 5.00 & 5.00 & 5.00 & 4.00 & 4.00 & 5. & 2.00 & 4.00 & 5.00 & 5.00 & 4.00 & 5.00 & 5.00 & 5.00 & 5.00 & 5.00 & 00 & 5.00 & & 4.00 \\
\hline QD37 & 4.00 & 2.00 & 5.00 & 1.00 & 4.00 & 4.00 & 5.00 & 4.00 & 4.00 & 4.00 & 5.00 & 4.00 & 5.00 & 3.00 & 5.00 & 5.00 & 5.00 & 3.00 & 3.00 & 1.00 \\
\hline QD38 & 5.00 & 2.00 & 5.00 & 3.00 & 4.00 & 2.00 & 1.00 & 3.00 & 2.00 & 5.00 & 5.00 & 4.00 & 5.00 & 2.00 & 4.00 & 3.00 & 00 & 2.00 & 00 & 4.00 \\
\hline QD39 & 4.00 & 4.00 & 5.00 & 5.00 & 5.00 & 4.00 & 5.00 & 4.00 & 4.00 & 3.00 & 5.00 & 4.00 & 3.00 & 3.00 & 4.00 & 5.00 & 5.00 & 5.00 & 5.00 & 3.00 \\
\hline QD 40 & 2.00 & 5.00 & 1.00 & 4.00 & 2.00 & 4.00 & 5.00 & 4.0 & 5.00 & 2.00 & 3.00 & 1.00 & 5.00 & 4.00 & 4.00 & 2.00 & 4.00 & 4.00 & 3.00 & 4.00 \\
\hline QD41 & 4.00 & 4.00 & 5.00 & 5.00 & 5.00 & 5.00 & 3.00 & 4.00 & 4.00 & 4.00 & 5.00 & 5.00 & 4.00 & 4.00 & 4.00 & 5.00 & 5.00 & 4.00 & .00 & 4.00 \\
\hline QD42 & 4.00 & 5.00 & 1.00 & 4.00 & 2.00 & 5.0 & 2.00 & 4.00 & 3.00 & 3.00 & 3.00 & 5.00 & 5.00 & 5.00 & 4.00 & 4.00 & 4.00 & 3.00 & 2.00 & 3.00 \\
\hline QD43 & 5.00 & 5.00 & 5.00 & 4.00 & 5.00 & 5.00 & 3.00 & 3.00 & 4.00 & 4.00 & 5.00 & 5.00 & 5.00 & 5.00 & 5.00 & 5.00 & 5.00 & 4.00 & 5.00 & 4.00 \\
\hline QD44 & 4.00 & 3.00 & 5.00 & 2.00 & 4.00 & 5.00 & 5.00 & 4.00 & 5.00 & 3.00 & 5.00 & 5.00 & 5.00 & 4.00 & 4.00 & 5.00 & 4.00 & 5.00 & 4.00 & 4.00 \\
\hline QD45 & 4.00 & 3.00 & 5.00 & 5.00 & 4.00 & 4.00 & 1.00 & 3.00 & 4.00 & 4.00 & 5.00 & 3.00 & 5.00 & 3.00 & 4.00 & 2.00 & 3.00 & 3.00 & 4.00 & 4.00 \\
\hline
\end{tabular}

Ilustración 40: Datos Experimentales del Estudio Cualitativo, Ronda 1 


\begin{tabular}{|c|c|c|c|c|c|c|c|c|c|c|c|c|c|c|c|c|c|c|c|c|}
\hline Exp. & $\mathrm{Z100A2}$ & Z190A2 & Z140A2 & $\mathrm{Z180A2}$ & $\mathrm{Z230A2}$ & Z120A2 & $\mathrm{Z200A2}$ & $\mathrm{Z110A2}$ & $\mathrm{Z500A2}$ & Z210A2 & $\mathrm{Z} 600 \mathrm{A2}$ & Z300A2 & Z800A2 & Z400A2 & Z900A2 & $\mathrm{Z130A2}$ & Z220A2 & Z240A2 & $2700 A 2$ & $\mathrm{Z150A2}$ \\
\hline Cat. & 4.00 & 4.00 & 5.00 & 5.00 & 5.00 & 4.00 & 4.00 & 5.00 & 3.00 & 4.00 & 4.00 & 4.00 & 5.00 & 5.00 & 2.00 & 4.00 & 4.00 & 4.00 & 5.00 & 5.00 \\
\hline QD01 & 2.00 & 2.00 & 4.00 & 2.00 & 2.00 & 2.00 & 2.00 & 4.00 & 3.00 & 3.00 & 3.00 & 4.00 & 3.00 & 3.00 & 1.00 & 2.00 & 3.00 & 4.00 & 4.00 & 3.00 \\
\hline QD02 & 4.00 & 3.00 & 3.00 & 4.00 & 4.00 & 4.00 & 1.00 & 4.00 & 4.00 & 4.00 & 4.00 & 4.00 & 4.00 & 4.00 & 3.00 & 4.00 & 4.00 & 4.00 & 4.00 & 4.00 \\
\hline QD03 & 2.00 & 1.00 & 1.00 & 1.00 & 2.00 & 2.00 & 1.00 & 1.00 & 2.00 & 3.00 & 2.00 & 1.00 & 2.00 & 1.00 & 1.00 & 1.00 & .00 & 3.00 & .00 & 2.00 \\
\hline Q.D04 & 2.00 & 3.00 & 3.00 & 1.00 & 4.00 & 3.00 & 1.00 & 4.00 & 2.00 & 3.00 & 2.00 & 1.00 & 2.00 & 1.00 & 1.00 & 1.00 & 2.00 & 4.00 & 2.00 & 3.00 \\
\hline QD05 & 2.00 & 2.00 & 2.00 & 2.00 & 4.00 & 2.00 & 1.00 & 4.00 & 3.00 & 2.00 & 3.00 & 1.00 & 1.00 & 3.00 & 1.00 & 2.00 & 1.00 & 3.00 & 3.00 & 2.00 \\
\hline QD06 & 1.00 & 1.00 & 2.00 & 3.00 & 2.00 & 1.00 & 2.00 & 1.00 & 1.00 & 2.00 & 2.00 & 2.00 & 1.00 & 1.00 & 1.00 & 2.00 & 1.00 & 2.00 & 4.00 & 1.00 \\
\hline QD07 & 5.00 & 5.00 & 4.00 & 4.00 & 4.00 & 4.00 & 4.00 & 5.00 & 4.00 & 5.00 & 5.00 & 4.00 & 5.00 & 5.00 & 4.00 & 5.00 & 5.00 & 4.00 & 5.00 & 4.00 \\
\hline QD08 & 4.00 & 4.00 & 4.00 & 1.00 & 3.00 & 4.00 & 4.00 & 5.00 & 4.00 & 4.00 & 4.00 & 3.00 & 4.00 & 4.00 & 3.00 & 2.00 & 4.00 & 4.00 & 4.00 & 4.00 \\
\hline QD09 & 2.00 & 5.00 & 4.00 & 4.00 & 4.00 & 2.00 & 2.00 & 5.00 & 3.00 & 4.00 & 4.00 & 2.00 & 2.00 & 4.00 & 2.00 & 1.00 & 4.00 & 3.00 & 4.00 & 3.00 \\
\hline QD10 & 4.00 & 4.00 & 5.00 & 4.00 & 4.00 & 2.00 & 5.00 & 5.00 & 4.00 & 4.00 & 5.00 & 5.00 & 5.00 & 5.00 & 4.00 & 3.00 & 4.00 & 5.00 & 3.00 & 4.00 \\
\hline QD11 & 1.00 & 4.00 & 1.00 & 1.00 & 1.00 & 2.00 & 1.00 & 2.00 & 1.00 & 3.00 & 3.00 & 3.00 & 3.00 & 2.00 & 2.00 & 2.00 & 2.00 & 3.00 & 4.00 & 4.00 \\
\hline QD12 & 2.00 & 4.00 & 3.00 & 1.00 & 2.00 & 2.00 & 1.00 & 5.00 & 3.00 & 3.00 & 4.00 & 4.00 & 3.00 & 4.00 & 4.00 & 2.00 & 4.00 & 4.00 & 5.00 & 4.00 \\
\hline QD13 & 5.00 & 3.00 & 4.00 & 4.00 & 3.00 & 1.00 & 1.00 & 5.00 & 4.00 & 3.00 & 4.00 & 2.00 & 3.00 & 4.00 & 4.00 & 2.00 & 4.00 & 4.00 & 5.00 & 3.00 \\
\hline QD14 & 4.00 & 4.00 & 2.00 & 2.00 & 2.00 & 2.00 & 1.00 & 5.00 & 1.00 & 2.00 & 3.00 & 3.00 & 2.00 & 2.00 & 3.00 & 1.00 & 2.00 & 2.00 & 4.00 & 3.00 \\
\hline QD15 & 5.00 & 5.00 & 4.00 & 4.00 & 5.00 & 00 & 5.00 & 00 & 5.00 & 5.00 & 5.00 & 5.00 & 5.00 & 5.00 & .00 & 5.00 & .00 & 5.00 & .00 & 5.00 \\
\hline QD16 & 4.00 & 4.00 & 3.00 & 1.00 & 2.00 & 4.00 & 5.00 & 4.00 & 3.00 & 4.00 & 4.00 & 5.00 & 4.00 & 4.00 & 3.00 & 2.00 & 4.00 & 4.00 & 5.00 & 4.00 \\
\hline QD17 & 3.00 & 4.00 & 4.00 & 3.00 & 1.00 & 1.00 & 1.00 & 4.00 & 1.00 & 2.00 & 2.00 & 2.00 & 2.00 & 1.00 & 1.00 & 3.00 & 4.00 & 3.00 & 1.00 & 2.00 \\
\hline QD18 & 4.00 & 4.00 & 4.00 & 4.00 & 4.00 & 4.00 & 3.00 & 4.00 & 5.00 & 5.00 & 4.00 & 4.00 & 4.00 & 2.00 & 4.00 & 5.00 & 4.00 & 5.00 & 4.00 & 4.00 \\
\hline QD19 & 5.00 & 2.00 & 4.00 & 1.00 & 1.00 & 2.00 & 1.00 & 1.00 & 3.00 & 2.00 & 3.00 & 1.00 & 3.00 & 1.00 & 2.00 & 2.00 & 1.00 & 3.00 & 3.00 & 3.00 \\
\hline QD20 & 2.00 & 3.00 & 2. & 00 & 3.00 & & 1.00 & 0 & 3.00 & 2.00 & 3.00 & 1.00 & 2.00 & 2.00 & 1.00 & 2.00 & .00 & 3.00 & 00 & 2.00 \\
\hline QD21 & 4.00 & 1.00 & 5. & 3.00 & 4.00 & 5.00 & 3.00 & 4.00 & 4.00 & 2.00 & 4.00 & 2.00 & 3.00 & 2.00 & 4.00 & 5.00 & 4.00 & 5.00 & 3.00 & 4.00 \\
\hline QD22 & 4.00 & 4.00 & 4.00 & 2.00 & 4.00 & 5.00 & 1.00 & 2.00 & 3.00 & 4.00 & 5.00 & 4.00 & 3.00 & 2.00 & 3.00 & 2.00 & 2.00 & 4.00 & 3.00 & 3.00 \\
\hline QD23 & 5.00 & 4.00 & 4.00 & 5.00 & 5.00 & 5.00 & 4.00 & 4.00 & 4.00 & 4.00 & 5.00 & 4.00 & 5.00 & 4.00 & 4.00 & 4.00 & 5.00 & 4.00 & 5.00 & 4.00 \\
\hline QD24 & 5.00 & 5.00 & 5.00 & 3.00 & 5.00 & & 4.00 & 4.00 & 4.00 & 5.00 & 5.00 & 5.00 & 4.00 & 4.00 & 4.00 & 4.00 & .00 & 4.00 & .00 & 4.00 \\
\hline QD25 & 4.00 & 4.00 & 3.00 & 4.00 & 4.00 & .00 & 4.00 & 5.00 & 3.00 & 5.00 & 4.00 & 5.00 & 5.00 & 5.00 & 4.00 & 3.00 & .00 & 4.00 & .00 & 4.00 \\
\hline QD26 & 4.00 & & & & & & & & & & & 3.00 & & 4.00 & & & & 1.00 & & 4.00 \\
\hline QD27 & 4.00 & 4.00 & 3.00 & 5.00 & 4.00 & 5.00 & 5.00 & 4.00 & 4.00 & 5.00 & 4.00 & 4.00 & 5.00 & 5.00 & 4.00 & 3.00 & 5.00 & 3.00 & 5.00 & 4.00 \\
\hline QD28 & 4.00 & & & & 4.00 & & & & & & & 3.00 & 3.00 & 4.00 & 00 & 2.00 & 00 & 4.00 & & 4.00 \\
\hline QD29 & 4.00 & 5.00 & 3.00 & 5.00 & 5.00 & 4.00 & 5.00 & 4.00 & 4.00 & 5.00 & 5.00 & 5.00 & 5.00 & 5.00 & 4.00 & 4.00 & 5.00 & 5.00 & 5.00 & 4.00 \\
\hline QD30 & 5.00 & 5.00 & 5.00 & 5.00 & 4.00 & 5.00 & 5.00 & 4.00 & 4.00 & 4.00 & 5.00 & 4.00 & 5.00 & 4.00 & 5.00 & 2.00 & 00 & 5.00 & 00 & 4.00 \\
\hline QD31 & 4.00 & 4.00 & 4.00 & 4.00 & 4.00 & & 4.00 & 4.00 & 2.00 & 3.00 & 4.00 & 4.00 & 5.00 & 3.00 & 4.00 & 3.00 & 3.00 & 4.00 & .00 & 4.00 \\
\hline QD32 & 4.00 & 5.00 & 5.00 & 4.00 & 5.00 & 5.00 & 4.00 & 4.00 & 5.00 & 4.00 & 5.00 & 4.00 & 3.00 & 2.00 & .00 & 4.00 & 00 & 4.00 & 00 & 3.00 \\
\hline QD33 & 5.00 & & & & 4.00 & & 5.00 & & & & 5.00 & 5.00 & 3.00 & 5.00 & & 0.00 & & 3.00 & & 4.00 \\
\hline QD34 & 4.00 & 5.00 & 2.0 & 1.0 & 4.00 & & 4.00 & 4.0 & 4.00 & 5.00 & 4.00 & 4.00 & 4.00 & 4.00 & 3.00 & 4.00 & 4.00 & 4.00 & 00 & 4.00 \\
\hline QD35 & 4.00 & 4.00 & & 4.00 & 4.00 & & 3.00 & & 5.00 & & 4.00 & 3.00 & 3.00 & 2.00 & 4.00 & 4.00 & .00 & 4.00 & & 4.00 \\
\hline QD36 & 5.00 & 5.00 & 4. & 5.0 & 5.00 & & 5.00 & 4. & 5.00 & 5.00 & 5.00 & 5.00 & 4.00 & 5.00 & 4.00 & 5.00 & 5.00 & 5.00 & .00 & 4.00 \\
\hline QD37 & 4.00 & 4.00 & & & 4.00 & & 4.00 & & 5.00 & 5.00 & 5.00 & 4.00 & 4.00 & 4.00 & 5.00 & 4.00 & .00 & 4.00 & .00 & 4.00 \\
\hline QD38 & 3.00 & 4.00 & 2.00 & 2.00 & 4.00 & 5.0 & 4.00 & 4.00 & 3.00 & 4.00 & 4.00 & 3.00 & 4.00 & 4.00 & 4.00 & 4.00 & 4.00 & 3.00 & 5.00 & 4.00 \\
\hline QD39 & 4.00 & 4.00 & 4.00 & 5.0 & 4.00 & & 4.00 & & 5.00 & 5.00 & 4.00 & 4.00 & 5.00 & 4.00 & 5.00 & 5.00 & & 4.00 & & 4.00 \\
\hline QD40 & 4.00 & 4.00 & 5.00 & 4.00 & 2.00 & 4.00 & 2.00 & 3.00 & 4.00 & 2.00 & 4.00 & 4.00 & 3.00 & 3.00 & 5.00 & 3.00 & 4.00 & 4.00 & 5.00 & 4.00 \\
\hline QD41 & 5.00 & 5.00 & 4.00 & 4.00 & 4.00 & 5.00 & 5.00 & 5.00 & 5.00 & 5.00 & 4.00 & 4.00 & 5.00 & 4.00 & 3.00 & 5.00 & 5.00 & 4.00 & .00 & 4.00 \\
\hline QD42 & 4.00 & 4.00 & 3.00 & 3.00 & 3.00 & 4.00 & 4.00 & 3.00 & 4.00 & 4.00 & 4.00 & 5.00 & 3.00 & 4.00 & 3.00 & 3.00 & 4.00 & 4.00 & 5.00 & 3.00 \\
\hline QD43 & 5.00 & 5.0 & 4.0 & & 4.0 & & 5.0 & & 4.0 & & 5.00 & 5.00 & 5.00 & 5.00 & & 5.00 & 5.00 & 4.00 & .00 & 4.00 \\
\hline QD44 & 5.00 & 5.00 & 5.00 & 5.00 & 4.00 & 3.00 & 5.00 & 5.00 & 5.00 & 5.00 & 4.00 & 4.00 & 4.00 & 4.00 & 5.00 & 4.00 & 4.00 & 4.00 & 5.00 & 4.00 \\
\hline 245 & 4.00 & 4.00 & 3.00 & & 4.00 & 4.00 & 3.00 & 500 & 5.00 & 3.00 & 4.00 & 3.00 & 4.00 & 4.00 & 1.00 & 4.00 & 3.00 & 3.00 & 5.00 & 4.00 \\
\hline
\end{tabular}

Ilustración 41: Datos Experimentales del Estudio Cualitativo, Ronda 2 


\subsection{Distribuciones de Consenso}

En este apéndice se incluyen las distribuciones de consenso para la primera y la segunda ronda de entrevistas.

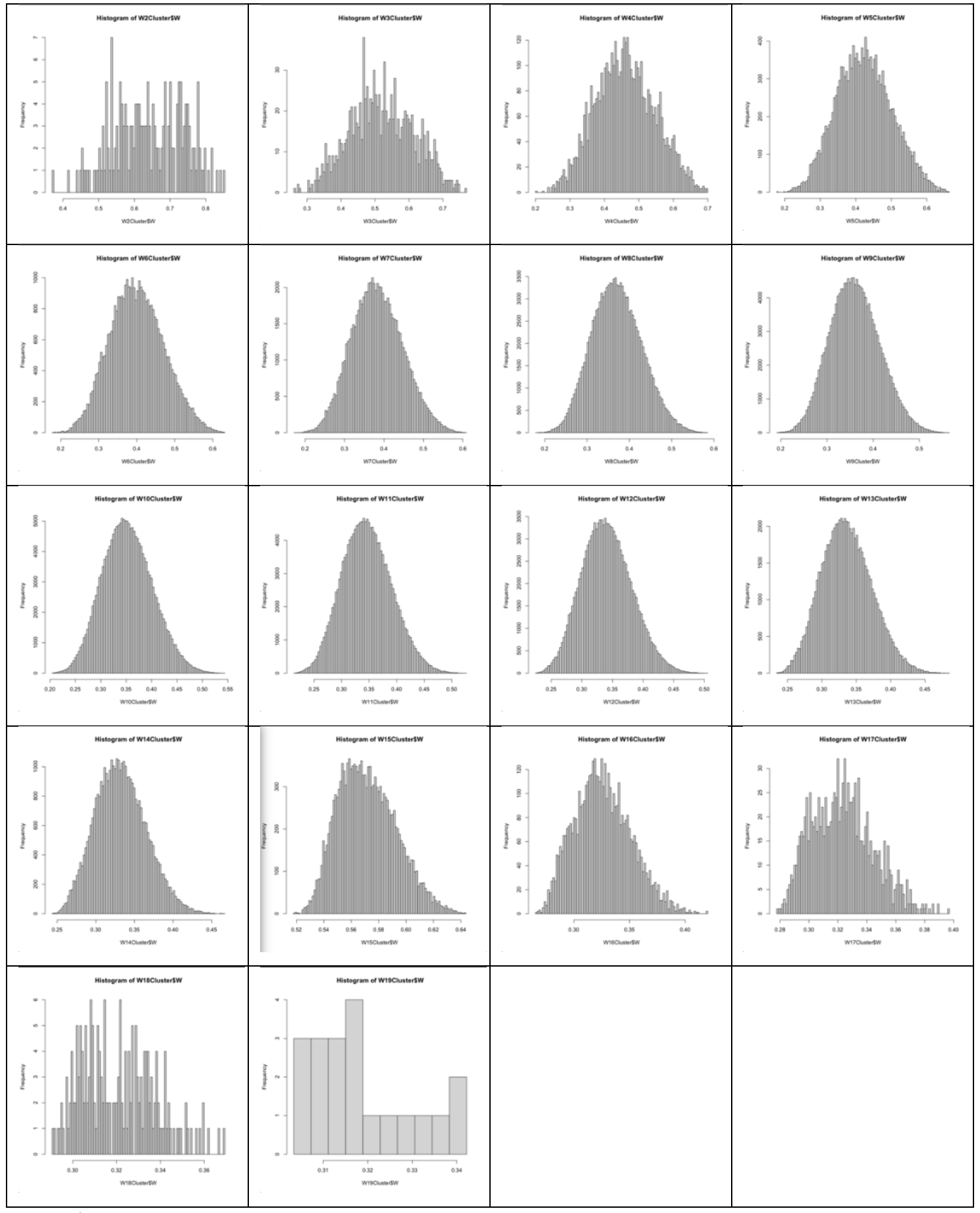

Ilustración 42: Distribuciones de Consenso, ronda 1 
Y a continuación la tabla con las distribuciones de consenso obtenidas durante la segunda ronda de entrevistas.

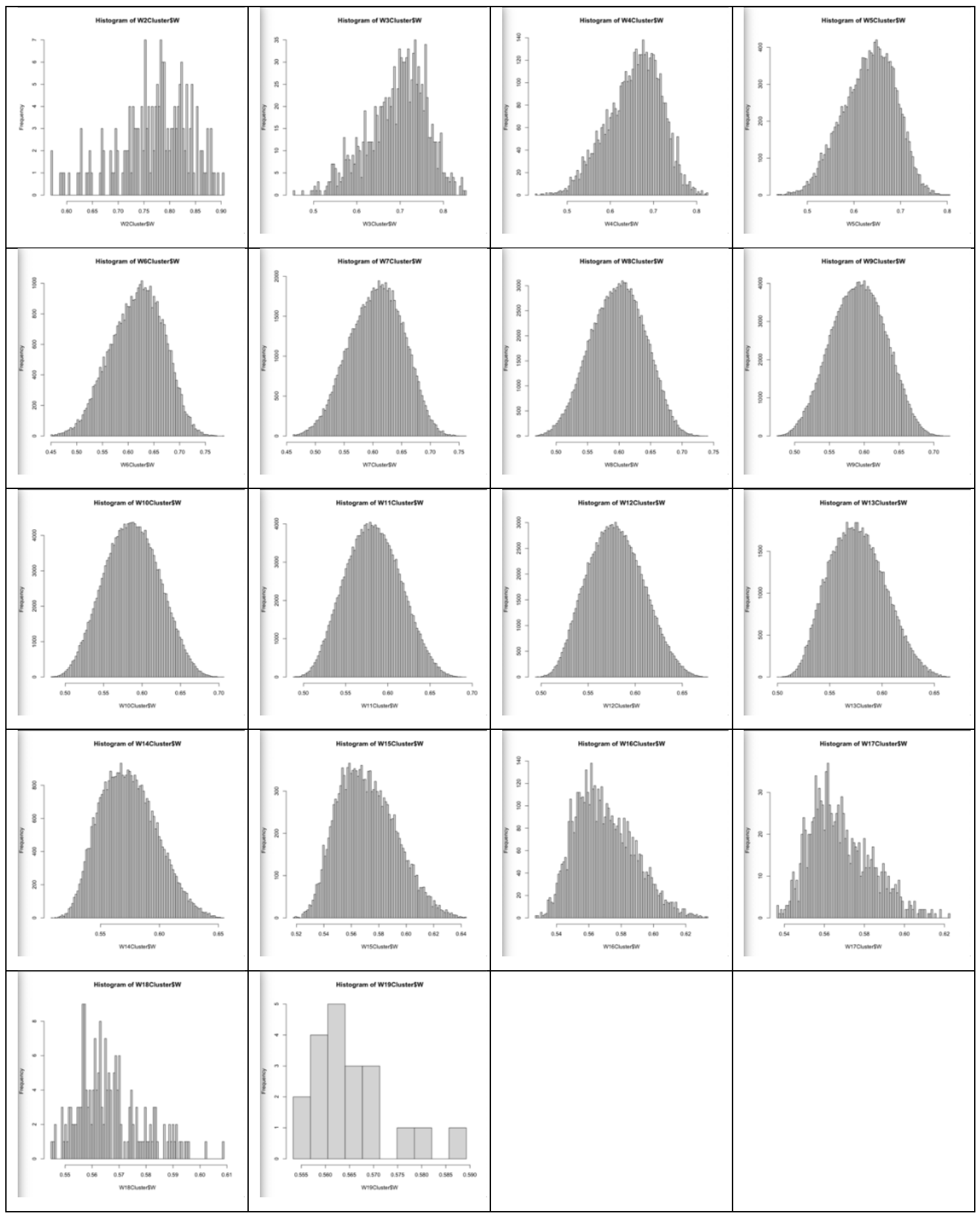

Ilustración 43: Distribuciones de Consenso, ronda 2 


\subsection{Datos Experimentales del Estudio Cuantitativo I}

En este apéndice se incluyen los datos resultado del estudio cuantitativo, organizados de forma tabular y agrupados por escenario.

\begin{tabular}{|c|c|c|c|c|c|c|c|c|}
\hline \multirow{9}{*}{ 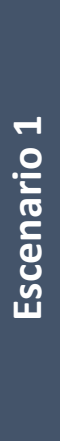 } & & \multicolumn{3}{|c|}{ Atributos Internos / Estáticos } & \multicolumn{3}{|c|}{ Atributos Externos / Dinámicos } & \multirow{2}{*}{ Valoración } \\
\hline & & Tamaño & C. Interna & C. Externa & Completitud & Latencia & Refresco & \\
\hline & \multirow{5}{*}{$\begin{array}{l}\text { Google+ } \\
\text { Twitter } \\
\text { Facebook } \\
\text { Pinterest } \\
\text { Bolsa }\end{array}$} & 2.76 & 5.00 & 36.00 & 5.00 & 1210.42 & 50.41 & 4.33 \\
\hline & & 3.53 & 5.00 & 25.00 & 5.00 & 1433.48 & 51.10 & 3.83 \\
\hline & & 3.40 & 5.00 & 29.00 & 5.00 & 665.95 & 56.81 & 2.83 \\
\hline & & 3.52 & 5.00 & 62.00 & 5.00 & 117.19 & 53.10 & 3.17 \\
\hline & & 3.90 & 5.00 & 53.00 & 5.00 & 833.45 & 53.82 & 2.50 \\
\hline & \multirow{2}{*}{$\begin{array}{l}\text { Tiempo } \\
\text { Tráfico }\end{array}$} & 3.03 & 5.00 & 12.00 & 5.00 & 1876.99 & 56.34 & 2.33 \\
\hline & & 3.79 & 4.00 & 30.00 & 5.00 & 499.60 & 59.26 & 2.33 \\
\hline
\end{tabular}

Ilustración 44: Datos Experimentales del Estudio Cuantitativo, Escenario 1

\begin{tabular}{|c|c|c|c|c|c|c|c|c|}
\hline \multirow{9}{*}{ 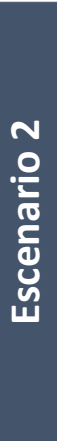 } & & Atributos & Internos / & Estáticos & Atributos Ex & xternos / Dir & námicos & Valoración \\
\hline & & Tamaño & C. Interna & C. Externa & Completitud & Latencia & Refresco & 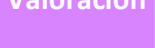 \\
\hline & \multirow{7}{*}{$\begin{array}{l}\text { Google+ } \\
\text { Twitter } \\
\text { Facebook } \\
\text { Pinterest } \\
\text { Bolsa } \\
\text { Tiempo } \\
\text { Tráfico }\end{array}$} & 3.10 & 4.00 & 36.00 & 5.00 & 1210.42 & 50.41 & 3.33 \\
\hline & & 3.53 & 5.00 & 25.00 & 5.00 & 3053.26 & 53.54 & 4.00 \\
\hline & & 3.40 & 5.00 & 29.00 & 4.22 & 665.95 & 56.81 & 3.83 \\
\hline & & 2.98 & 5.00 & 62.00 & 5.00 & 117.19 & 53.10 & 2.17 \\
\hline & & 3.90 & 5.00 & 42.00 & 5.00 & 5059.94 & 59.01 & 2.83 \\
\hline & & 3.03 & 5.00 & 12.00 & 4.34 & 151.47 & 53.86 & 2.83 \\
\hline & & 3.79 & 5.00 & 55.00 & 5.00 & 499.60 & 59.26 & 3.83 \\
\hline
\end{tabular}

Ilustración 45: Datos Experimentales del Estudio Cuantitativo, Escenario 2

\begin{tabular}{|c|c|c|c|c|c|c|c|c|}
\hline \multirow{9}{*}{ 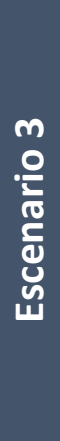 } & & Atributos & Internos / & Estáticos & Atributos Ex & xternos / Dir & inámicos & Valoración \\
\hline & & Tamaño & C. Interna & C. Externa & Completitud & Latencia & Refresco & \\
\hline & \multirow{7}{*}{$\begin{array}{l}\text { Google+ } \\
\text { Twitter } \\
\text { Facebook } \\
\text { Pinterest } \\
\text { Bolsa } \\
\text { Tiempo } \\
\text { Tráfico }\end{array}$} & 3.10 & 5.00 & 36.00 & 4.25 & 1210.42 & 50.41 & 2.50 \\
\hline & & 3.53 & 5.00 & 25.00 & 5.00 & 1433.48 & 51.10 & 4.67 \\
\hline & & 3.40 & 5.00 & 45.00 & 5.00 & 665.95 & 56.81 & 3.33 \\
\hline & & 3.52 & 5.00 & 62.00 & 5.00 & 1939.39 & 53.39 & 3.33 \\
\hline & & 3.90 & 5.00 & 42.00 & 5.00 & 833.45 & 53.82 & 4.00 \\
\hline & & 3.03 & 5.00 & 12.00 & 5.00 & 151.47 & 53.86 & 4.17 \\
\hline & & 3.79 & 5.00 & 30.00 & 5.00 & 499.60 & 59.26 & 4.83 \\
\hline
\end{tabular}

Ilustración 46: Datos Experimentales del Estudio Cuantitativo, Escenario 3

\begin{tabular}{|c|c|c|c|c|c|c|c|c|}
\hline \multirow{9}{*}{ 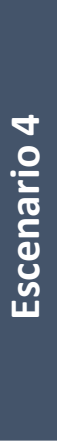 } & & Atributos & Internos / & Estáticos & Atributos Ex & xternos / Dir & námicos & Yalamción \\
\hline & & Tamaño & C. Interna & C. Externa & Completitud & Latencia & Refresco & \\
\hline & \multirow{7}{*}{$\begin{array}{l}\text { Google+ } \\
\text { Twitter } \\
\text { Facebook } \\
\text { Pinterest } \\
\text { Bolsa } \\
\text { Tiempo } \\
\text { Tráfico }\end{array}$} & 3.10 & 5.00 & 36.00 & 5.00 & 3579.17 & 53.14 & 4.67 \\
\hline & & 3.05 & 5.00 & 25.00 & 5.00 & 1433.48 & 51.10 & 2.67 \\
\hline & & 3.40 & 4.90 & 29.00 & 5.00 & 665.95 & 56.81 & 4.67 \\
\hline & & 3.52 & 5.00 & 84.00 & 5.00 & 117.19 & 53.10 & 4.67 \\
\hline & & 3.90 & 5.00 & 42.00 & 5.00 & 833.45 & 53.82 & 4.33 \\
\hline & & 3.03 & 5.00 & 12.00 & 5.00 & 151.47 & 53.86 & 4.67 \\
\hline & & 3.79 & 5.00 & 30.00 & 4.05 & 499.60 & 59.26 & 4.67 \\
\hline
\end{tabular}

Ilustración 47: Datos Experimentales del Estudio Cuantitativo, Escenario 4 


\begin{tabular}{|c|c|c|c|c|c|c|c|c|}
\hline \multirow{9}{*}{ 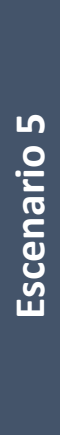 } & & Atributos & Internos / & Estáticos & Atributos Ex & xternos / Di & námicos & Valaración \\
\hline & & Tamaño & C. Interna & C. Externa & Completitud & Latencia & Refresco & \\
\hline & \multirow{7}{*}{$\begin{array}{l}\text { Google+ } \\
\text { Twitter } \\
\text { Facebook } \\
\text { Pinterest } \\
\text { Bolsa } \\
\text { Tiempo } \\
\text { Tráfico }\end{array}$} & 3.10 & 5.00 & 36.00 & 5.00 & 1210.42 & 50.41 & 2.67 \\
\hline & & 3.53 & 5.00 & 25.00 & 5.00 & 1433.48 & 51.10 & 4.17 \\
\hline & & 3.40 & 5.00 & 29.00 & 5.00 & 665.95 & 56.81 & 4.00 \\
\hline & & 3.52 & 5.00 & 62.00 & 5.00 & 117.19 & 53.10 & 4.33 \\
\hline & & 2.53 & 5.00 & 42.00 & 5.00 & 833.45 & 53.82 & 2.50 \\
\hline & & 3.03 & 4.00 & 12.00 & 5.00 & 151.47 & 53.86 & 2.67 \\
\hline & & 3.79 & 5.00 & 30.00 & 5.00 & 499.60 & 59.26 & 3.33 \\
\hline
\end{tabular}

Ilustración 48: Datos Experimentales del Estudio Cuantitativo, Escenario 5

\begin{tabular}{|c|c|c|c|c|c|c|c|c|}
\hline \multirow{9}{*}{ 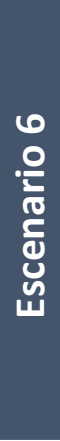 } & & Atributos & Internos / & Estáticos & Atributos Ex & xternos / Di & inámicos & Valoración \\
\hline & & Tamaño & C. Interna & C. Externa & Completitud & Latencia & Refresco & \\
\hline & \multirow{7}{*}{$\begin{array}{l}\text { Google+ } \\
\text { Twitter } \\
\text { Facebook } \\
\text { Pinterest } \\
\text { Bolsa } \\
\text { Tiempo } \\
\text { Tráfico }\end{array}$} & 3.10 & 5.00 & 36.00 & 5.00 & 1210.42 & 50.41 & 2.83 \\
\hline & & 3.53 & 5.00 & 25.00 & 5.00 & 1433.48 & 51.10 & 3.83 \\
\hline & & 3.40 & 5.00 & 29.00 & 5.00 & 665.95 & 56.81 & 2.50 \\
\hline & & 3.52 & 5.00 & 62.00 & 5.00 & 117.19 & 53.10 & 2.50 \\
\hline & & 3.90 & 5.00 & 42.00 & 5.00 & 833.45 & 53.82 & 1.83 \\
\hline & & 2.63 & 5.00 & 12.00 & 5.00 & 151.47 & 53.86 & 3.50 \\
\hline & & 3.79 & 5.00 & 30.00 & 5.00 & 499.60 & 59.26 & 2.33 \\
\hline
\end{tabular}

Ilustración 49: Datos Experimentales del Estudio Cuantitativo, Escenario 6

\begin{tabular}{|c|c|c|c|c|c|c|c|c|}
\hline \multirow{9}{*}{ 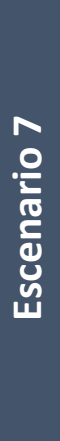 } & & \multicolumn{3}{|c|}{ Atributos Internos / Estáticos } & \multicolumn{3}{|c|}{ Atributos Externos / Dinámicos } & \multirow{2}{*}{ Valoración } \\
\hline & & Tamaño & C. Interna & C. Externa & Completitud & Latencia & Refresco & \\
\hline & \multirow{5}{*}{$\begin{array}{l}\text { Google+ } \\
\text { Twitter } \\
\text { Facebook } \\
\text { Pinterest } \\
\text { Bolsa }\end{array}$} & \begin{tabular}{|r|}
3.10 \\
\end{tabular} & 5.00 & 53.00 & 5.00 & \begin{tabular}{|l|}
1210.42 \\
\end{tabular} & \begin{tabular}{|r|}
50.41 \\
\end{tabular} & 2.17 \\
\hline & & 3.53 & 5.00 & 25.00 & 3.71 & 1433.48 & 51.10 & 2.83 \\
\hline & & 3.07 & 5.00 & 29.00 & 5.00 & 665.95 & 56.81 & 2.33 \\
\hline & & 3.52 & 5.00 & 62.00 & 5.00 & 117.19 & 53.10 & 4.50 \\
\hline & & 3.90 & 5.00 & 42.00 & 2.78 & 833.45 & 53.82 & 2.17 \\
\hline & \multirow{2}{*}{$\begin{array}{l}\text { Tiempo } \\
\text { Tráfico }\end{array}$} & 3.03 & 5.00 & 12.00 & 5.00 & 151.47 & 53.86 & 2.50 \\
\hline & & 3.79 & 5.00 & 30.00 & 5.00 & 1359.25 & 63.13 & 4.50 \\
\hline
\end{tabular}

Ilustración 50: Datos Experimentales del Estudio Cuantitativo, Escenario 7

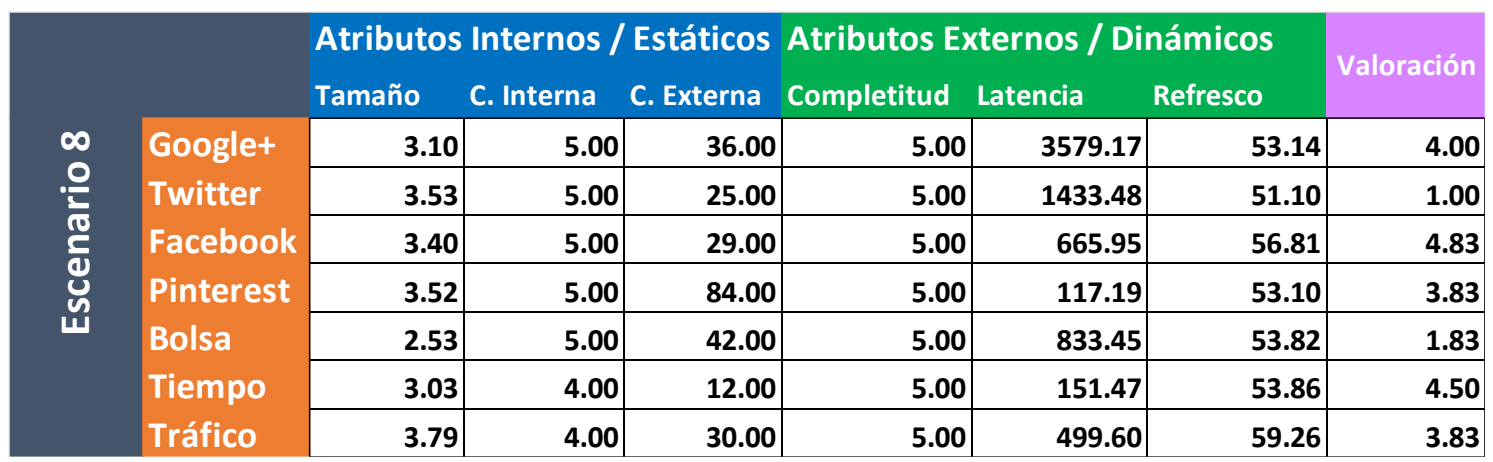

Ilustración 51: Datos Experimentales del Estudio Cuantitativo, Escenario 8 


\begin{tabular}{|c|c|c|c|c|c|c|c|c|}
\hline \multirow{9}{*}{ 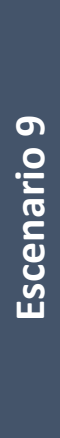 } & & Atributos & Internos / & Estáticos & Atributos Ex & xternos / Dir & inámicos & Valoración \\
\hline & & Tamaño & C. Interna & C. Externa & Completitud & Latencia & Refresco & \\
\hline & \multirow{7}{*}{$\begin{array}{l}\text { Google+ } \\
\text { Twitter } \\
\text { Facebook } \\
\text { Pinterest } \\
\text { Bolsa } \\
\text { Tiempo } \\
\text { Tráfico }\end{array}$} & 3.10 & 5.00 & 36.00 & 5.00 & 1210.42 & 50.41 & 3.50 \\
\hline & & 3.53 & 4.90 & 25.00 & 5.00 & 3053.26 & 53.54 & 4.67 \\
\hline & & 3.40 & 5.00 & 29.00 & 4.22 & 665.95 & 56.81 & 4.00 \\
\hline & & 3.52 & 5.00 & 62.00 & 5.00 & 117.19 & 53.10 & 2.67 \\
\hline & & 3.90 & 5.00 & 42.00 & 5.00 & 833.45 & 53.82 & 1.67 \\
\hline & & 3.03 & 5.00 & 12.00 & 5.00 & 151.47 & 53.86 & 2.00 \\
\hline & & 3.79 & 5.00 & 30.00 & 5.00 & 499.60 & 59.26 & 2.67 \\
\hline
\end{tabular}

Ilustración 52: Datos Experimentales del Estudio Cuantitativo, Escenario 9

\begin{tabular}{|c|c|c|c|c|c|c|c|c|}
\hline \multirow{9}{*}{ 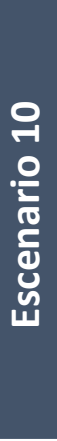 } & & \multicolumn{3}{|c|}{ Atributos Internos / Estáticos } & \multicolumn{3}{|c|}{ Atributos Externos / Dinámicos } & \multirow{2}{*}{ Valoración } \\
\hline & & Tamaño & C. Interna & C. Externa & Completitud & Latencia & Refresco & \\
\hline & \multirow{7}{*}{$\begin{array}{l}\text { Google+ } \\
\text { Twitter } \\
\text { Facebook } \\
\text { Pinterest } \\
\text { Bolsa } \\
\text { Tiempo } \\
\text { Tráfico }\end{array}$} & 3.10 & 5.00 & 36.00 & 5.00 & 1210.42 & 50.41 & 3.83 \\
\hline & & 3.53 & 5.00 & 25.00 & 5.00 & 1433.48 & 51.10 & 4.33 \\
\hline & & 3.40 & 5.00 & 29.00 & 5.00 & 665.95 & 56.81 & 4.50 \\
\hline & & 3.52 & 4.99 & 62.00 & 5.00 & 117.19 & 53.10 & 3.17 \\
\hline & & 3.90 & 3.00 & 42.00 & 5.00 & 833.45 & 53.82 & 4.33 \\
\hline & & 3.03 & 5.00 & 32.00 & 5.00 & 151.47 & 53.86 & 4.83 \\
\hline & & 2.88 & 5.00 & 30.00 & 5.00 & 499.60 & 59.26 & 4.33 \\
\hline
\end{tabular}

Ilustración 53: Datos Experimentales del Estudio Cuantitativo, Escenario 10

\begin{tabular}{|c|c|c|c|c|c|c|c|c|}
\hline \multirow{9}{*}{ 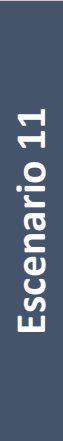 } & & \multicolumn{3}{|c|}{ Atributos Internos / Estáticos } & \multicolumn{3}{|c|}{ Atributos Externos / Dinámicos } & \multirow{2}{*}{ Valoración } \\
\hline & & Tamaño & C. Interna & C. Externa & Completitud & Latencia & Refresco & \\
\hline & \multirow{5}{*}{$\begin{array}{l}\text { Googlet } \\
\text { Twitter } \\
\text { Facebook } \\
\text { Pinterest } \\
\text { Bolsa }\end{array}$} & \begin{tabular}{r|}
3.10 \\
\end{tabular} & 4.00 & 36.00 & $\begin{array}{r}5.00 \\
\end{array}$ & 1210.42 & \begin{tabular}{|r|}
50.41 \\
\end{tabular} & 3.83 \\
\hline & & 3.53 & 5.00 & 25.00 & 5.00 & 1433.48 & 51.10 & 3.33 \\
\hline & & 3.40 & 5.00 & 29.00 & 5.00 & 665.95 & 56.81 & 4.33 \\
\hline & & 2.98 & 5.00 & 62.00 & 5.00 & 117.19 & 53.10 & 4.33 \\
\hline & & 3.90 & 5.00 & 42.00 & 5.00 & 5059.94 & 59.01 & 2.17 \\
\hline & \multirow{2}{*}{$\begin{array}{l}\text { Tiempo } \\
\text { Tráfico }\end{array}$} & 3.03 & 5.00 & 12.00 & 4.34 & 151.47 & 53.86 & 3.83 \\
\hline & & 3.79 & 5.00 & 55.00 & 5.00 & 499.60 & 59.26 & 4.67 \\
\hline
\end{tabular}

Ilustración 54: Datos Experimentales del Estudio Cuantitativo, Escenario 11

\begin{tabular}{|c|c|c|c|c|c|c|c|c|}
\hline \multirow{9}{*}{ 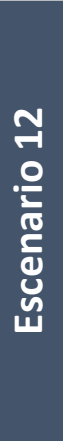 } & & \multicolumn{3}{|c|}{ Atributos Internos / Estáticos } & \multicolumn{3}{|c|}{ Atributos Externos / Dinámicos } & \multirow{2}{*}{ Valoración } \\
\hline & & Tamaño & C. Interna & C. Externa & Completitud & Latencia & Refresco & \\
\hline & \multirow{5}{*}{$\begin{array}{l}\text { Google+ } \\
\text { Twitter } \\
\text { Facebook } \\
\text { Pinterest } \\
\text { Bolsa }\end{array}$} & 3.10 & 5.00 & 36.00 & 5.00 & 1210.42 & \begin{tabular}{|r|}
50.41 \\
\end{tabular} & 5.00 \\
\hline & & 3.53 & 5.00 & 49.00 & 5.00 & 1433.48 & 51.10 & 4.33 \\
\hline & & 3.40 & 5.00 & 29.00 & 5.00 & 1684.85 & 61.36 & 4.67 \\
\hline & & 3.52 & 5.00 & 62.00 & 4.03 & 117.19 & 53.10 & 2.33 \\
\hline & & 3.90 & 5.00 & 42.00 & 5.00 & 833.45 & 53.82 & 3.67 \\
\hline & \multirow{2}{*}{$\begin{array}{l}\text { Tiempo } \\
\text { Tráfico }\end{array}$} & 3.03 & 5.00 & 12.00 & 5.00 & 151.47 & 53.86 & 5.00 \\
\hline & & 3.79 & 5.00 & 30.00 & 5.00 & 499.60 & 59.26 & 5.00 \\
\hline
\end{tabular}

Ilustración 55: Datos Experimentales del Estudio Cuantitativo, Escenario 12 


\begin{tabular}{|c|c|c|c|c|c|c|c|c|}
\hline \multirow{9}{*}{ 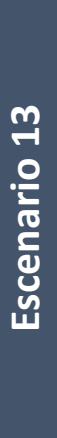 } & & Atributos & Internos / & Estáticos & Atributos Ex & xternos / Di & námicos & Valaración \\
\hline & & Tamaño & C. Interna & C. Externa & Completitud & Latencia & Refresco & \\
\hline & \multirow{7}{*}{$\begin{array}{l}\text { Google+ } \\
\text { Twitter } \\
\text { Facebook } \\
\text { Pinterest } \\
\text { Bolsa } \\
\text { Tiempo } \\
\text { Tráfico }\end{array}$} & 3.10 & 5.00 & 53.00 & 5.00 & 1210.42 & 50.41 & 3.83 \\
\hline & & 3.53 & 5.00 & 25.00 & 5.00 & 1433.48 & 51.10 & 3.83 \\
\hline & & 3.07 & 5.00 & 29.00 & 5.00 & 665.95 & 56.81 & 3.67 \\
\hline & & 3.52 & 5.00 & 62.00 & 5.00 & 117.19 & 53.10 & 3.67 \\
\hline & & 3.90 & 5.00 & 42.00 & 2.78 & 833.45 & 53.82 & 3.33 \\
\hline & & 2.63 & 5.00 & 12.00 & 5.00 & 151.47 & 53.86 & 5.00 \\
\hline & & 3.79 & 5.00 & 30.00 & 5.00 & 1359.25 & 63.13 & 4.33 \\
\hline
\end{tabular}

Ilustración 56: Datos Experimentales del Estudio Cuantitativo, Escenario 13

\begin{tabular}{|c|c|c|c|c|c|c|c|c|}
\hline \multirow{9}{*}{ 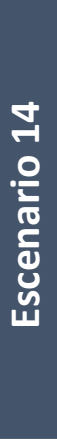 } & & \multicolumn{3}{|c|}{ Atributos Internos / Estáticos } & \multicolumn{3}{|c|}{ Atributos Externos / Dinámicos } & \multirow{2}{*}{ Valoración } \\
\hline & & Tamaño & C. Interna & C. Externa & Completitud & Latencia & Refresco & \\
\hline & \multirow{7}{*}{$\begin{array}{l}\text { Google+ } \\
\text { Twitter } \\
\text { Facebook } \\
\text { Pinterest } \\
\text { Bolsa } \\
\text { Tiempo } \\
\text { Tráfico }\end{array}$} & 2.76 & 5.00 & 36.00 & 5.00 & 1210.42 & 50.41 & 2.83 \\
\hline & & 3.53 & 5.00 & 49.00 & 5.00 & 1433.48 & 51.10 & 4.17 \\
\hline & & 3.40 & 5.00 & 29.00 & 5.00 & 1684.85 & 61.36 & 2.83 \\
\hline & & 3.52 & 5.00 & 62.00 & 4.03 & 117.19 & 53.10 & 4.50 \\
\hline & & 3.90 & 3.00 & 42.00 & 5.00 & 833.45 & 53.82 & 2.33 \\
\hline & & 3.03 & 5.00 & 32.00 & 5.00 & 151.47 & 53.86 & 2.83 \\
\hline & & 3.79 & 5.00 & 30.00 & 4.05 & 499.60 & 59.26 & 4.33 \\
\hline
\end{tabular}

Ilustración 57: Datos Experimentales del Estudio Cuantitativo, Escenario 14

\begin{tabular}{|c|c|c|c|c|c|c|c|c|}
\hline \multirow{9}{*}{ 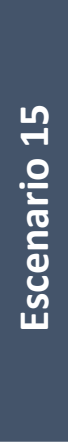 } & & \multicolumn{3}{|c|}{ Atributos Internos / Estáticos } & \multicolumn{3}{|c|}{ Atributos Externos / Dinámicos } & \multirow{2}{*}{ Valoración } \\
\hline & & Tamaño & C. Interna & C. Externa & Completitud & Latencia & Refresco & \\
\hline & \multirow{5}{*}{$\begin{array}{l}\text { Google+ } \\
\text { Twitter } \\
\text { Facebook } \\
\text { Pinterest } \\
\text { Bolsa }\end{array}$} & \begin{tabular}{r|}
3.10 \\
\end{tabular} & 5.00 & 36.00 & $\begin{array}{r}5.00 \\
\end{array}$ & 1210.42 & 50.41 & 4.33 \\
\hline & & 3.53 & 5.00 & 25.00 & 3.71 & 1433.48 & 51.10 & 4.33 \\
\hline & & 3.40 & 5.00 & 29.00 & 5.00 & 665.95 & 56.81 & 4.33 \\
\hline & & 3.52 & 5.00 & 62.00 & 5.00 & 117.19 & 53.10 & 4.33 \\
\hline & & 3.90 & 5.00 & 42.00 & 5.00 & 833.45 & 53.82 & 4.33 \\
\hline & \multirow{2}{*}{$\begin{array}{l}\text { Tiempo } \\
\text { Tráfico }\end{array}$} & 3.03 & 5.00 & 12.00 & 5.00 & 151.47 & 53.86 & 4.33 \\
\hline & & 3.79 & 5.00 & 30.00 & 5.00 & 499.60 & 59.26 & 4.33 \\
\hline
\end{tabular}

Ilustración 58: Datos Experimentales del Estudio Cuantitativo, Escenario 15

\begin{tabular}{|c|c|c|c|c|c|c|c|c|}
\hline \multirow{9}{*}{ 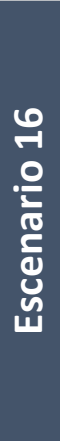 } & & \multicolumn{3}{|c|}{ Atributos Internos / Estáticos } & \multicolumn{3}{|c|}{ Atributos Externos / Dinámicos } & \multirow{2}{*}{ Valoración } \\
\hline & & Tamaño & C. Interna & C. Externa & Completitud & Latencia & Refresco & \\
\hline & \multirow{5}{*}{$\begin{array}{l}\text { Google+ } \\
\text { Twitter } \\
\text { Facebook } \\
\text { Pinterest } \\
\text { Bolsa }\end{array}$} & \begin{tabular}{|r|}
3.10 \\
\end{tabular} & 5.00 & 36.00 & \begin{tabular}{r|}
5.00 \\
\end{tabular} & 1210.42 & 50.41 & 5.00 \\
\hline & & 3.53 & 5.00 & 25.00 & 5.00 & 1433.48 & 51.10 & 5.00 \\
\hline & & 3.40 & 5.00 & 29.00 & 5.00 & 665.95 & 56.81 & 4.50 \\
\hline & & 3.52 & 5.00 & 62.00 & 5.00 & 117.19 & 53.10 & 2.67 \\
\hline & & 3.90 & 5.00 & 42.00 & 5.00 & 833.45 & 53.82 & 3.50 \\
\hline & \multirow{2}{*}{$\begin{array}{l}\text { Tiempo } \\
\text { Tráfico }\end{array}$} & 3.03 & 5.00 & 12.00 & 5.00 & 151.47 & 53.86 & 5.00 \\
\hline & & 3.79 & 5.00 & 30.00 & 5.00 & 499.60 & 59.26 & 3.83 \\
\hline
\end{tabular}

Ilustración 59: Datos Experimentales del Estudio Cuantitativo, Escenario 16 


\subsection{Datos Experimentales del Estudio Cuantitativo II}

En este apéndice se incluyen los datos resultado del estudio cuantitativo, organizados de forma tabular y agrupados por componente.

\begin{tabular}{|c|c|c|c|c|c|c|c|c|}
\hline & & \multicolumn{3}{|c|}{ Atributos Internos / Estáticos } & \multicolumn{3}{|c|}{ Atributos Externos / Dinámicos } & \multirow{3}{*}{$\begin{array}{c}\text { Valoración } \\
\text { V }\end{array}$} \\
\hline & & Tamaño & C. Interna & C. Externa & Completitud & Latencia & Refresco & \\
\hline & & 11 & 12 & 13 & E1 & E2 & E3 & \\
\hline \multirow{16}{*}{$\begin{array}{l}\frac{ \pm}{\varpi 0} \\
8 \\
8\end{array}$} & Escenario 1 & 2.76 & 5.00 & 36.00 & 5.00 & 1210.42 & 50.41 & 4.33 \\
\hline & Escenario 2 & 3.10 & 4.00 & 36.00 & 5.00 & 1210.42 & 50.41 & 3.33 \\
\hline & Escenario 3 & 3.10 & 5.00 & 36.00 & 4.25 & 1210.42 & 50.41 & 2.50 \\
\hline & Escenario 4 & 3.10 & 5.00 & 36.00 & 5.00 & 3579.17 & 53.14 & 4.67 \\
\hline & Escenario 5 & 3.10 & 5.00 & 36.00 & 5.00 & 1210.42 & 50.41 & 2.67 \\
\hline & Escenario 6 & 3.10 & 5.00 & 36.00 & 5.00 & 1210.42 & 50.41 & 2.83 \\
\hline & Escenario 7 & 3.10 & 5.00 & 53.00 & 5.00 & 1210.42 & 50.41 & 2.17 \\
\hline & Escenario 8 & 3.10 & 5.00 & 36.00 & 5.00 & 3579.17 & 53.14 & 4.00 \\
\hline & Escenario 9 & 3.10 & 5.00 & 36.00 & 5.00 & 1210.42 & 50.41 & 3.50 \\
\hline & Escenario 10 & 3.10 & 5.00 & 36.00 & 5.00 & 1210.42 & 50.41 & 3.83 \\
\hline & Escenario 11 & 3.10 & 4.00 & 36.00 & 5.00 & 1210.42 & 50.41 & 3.83 \\
\hline & Escenario 12 & 3.10 & 5.00 & 36.00 & 5.00 & 1210.42 & 50.41 & 5.00 \\
\hline & Escenario 13 & 3.10 & 5.00 & 53.00 & 5.00 & 1210.42 & 50.41 & 3.83 \\
\hline & Escenario 14 & 2.76 & 5.00 & 36.00 & 5.00 & 1210.42 & 50.41 & 2.83 \\
\hline & Escenario 15 & 3.10 & 5.00 & 36.00 & 5.00 & 1210.42 & 50.41 & 4.33 \\
\hline & Escenario 16 & 3.10 & 5.00 & 36.00 & 5.00 & 1210.42 & 50.41 & 5.00 \\
\hline
\end{tabular}

Ilustración 60:Datos Experimentales del Estudio Cuantitativo, Componente Google+

\begin{tabular}{|c|c|c|c|c|c|c|c|c|}
\hline & & \multicolumn{3}{|c|}{ Atributos Internos / Estáticos } & \multicolumn{3}{|c|}{ Atributos Externos / Dinámicos } & \multirow{3}{*}{$\begin{array}{c}\text { Valoración } \\
\qquad \mathrm{V}\end{array}$} \\
\hline & & Tamaño & C. Interna & C. Externa & Completitud & Latencia & Refresco & \\
\hline & & I1 & 12 & 13 & E1 & E2 & E3 & \\
\hline \multirow{16}{*}{$\frac{\text { 递 }}{\frac{2}{3}}$} & Escenario 1 & 3.53 & 5.00 & 25.00 & 5.00 & 1433.48 & 51.10 & 3.83 \\
\hline & Escenario 2 & 3.53 & 5.00 & 25.00 & 5.00 & 3053.26 & 53.54 & 4.00 \\
\hline & Escenario 3 & 3.53 & 5.00 & 25.00 & 5.00 & 1433.48 & 51.10 & 4.67 \\
\hline & Escenario 4 & 3.05 & 5.00 & 25.00 & 5.00 & 1433.48 & 51.10 & 2.67 \\
\hline & Escenario 5 & 3.53 & 5.00 & 25.00 & 5.00 & 1433.48 & 51.10 & 4.17 \\
\hline & Escenario 6 & 3.53 & 5.00 & 25.00 & 5.00 & 1433.48 & 51.10 & 3.83 \\
\hline & Escenario 7 & 3.53 & 5.00 & 25.00 & 3.71 & 1433.48 & 51.10 & 2.83 \\
\hline & Escenario 8 & 3.53 & 5.00 & 25.00 & 5.00 & 1433.48 & 51.10 & 1.00 \\
\hline & Escenario 9 & 3.53 & 4.90 & 25.00 & 5.00 & 3053.26 & 53.54 & 4.67 \\
\hline & Escenario 10 & 3.53 & 5.00 & 25.00 & 5.00 & 1433.48 & 51.10 & 4.33 \\
\hline & Escenario 11 & 3.53 & 5.00 & 25.00 & 5.00 & 1433.48 & 51.10 & 3.33 \\
\hline & Escenario 12 & 3.53 & 5.00 & 49.00 & 5.00 & 1433.48 & 51.10 & 4.33 \\
\hline & Escenario 13 & 3.53 & 5.00 & 25.00 & 5.00 & 1433.48 & 51.10 & 3.83 \\
\hline & Escenario 14 & 3.53 & 5.00 & 49.00 & 5.00 & 1433.48 & 51.10 & 4.17 \\
\hline & Escenario 15 & 3.53 & 5.00 & 25.00 & 3.71 & 1433.48 & 51.10 & 4.33 \\
\hline & Escenario 16 & 3.53 & 5.00 & 25.00 & 5.00 & 1433.48 & 51.10 & 5.00 \\
\hline
\end{tabular}

Ilustración 61: Datos Experimentales del Estudio Cuantitativo, Componente Twitter 


\begin{tabular}{|c|c|c|c|c|c|c|c|c|}
\hline & & \multicolumn{3}{|c|}{ Atributos Internos / Estáticos } & \multicolumn{3}{|c|}{ Atributos Externos / Dinámicos } & \multirow{3}{*}{$\begin{array}{c}\text { Valoración } \\
\text { V }\end{array}$} \\
\hline & & Tamaño & C. Interna & C. Externa & Completitud $\mathrm{L}$ & Latencia & Refresco & \\
\hline \multirow{17}{*}{ 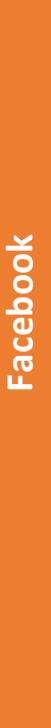 } & & 11 & 12 & 13 & E1 $\quad 1$ & E2 & E3 & \\
\hline & Escenario 1 & 3.40 & 5.00 & 29.00 & 5.00 & 665.95 & 56.81 & 2.83 \\
\hline & Escenario 2 & 3.40 & 5.00 & 29.00 & 4.22 & 665.95 & 56.81 & 3.83 \\
\hline & Escenario 3 & 3.40 & 5.00 & 45.00 & 5.00 & 665.95 & 56.81 & 3.33 \\
\hline & Escenario 4 & 3.40 & 4.90 & 29.00 & 5.00 & 665.95 & 56.81 & 4.67 \\
\hline & Escenario 5 & 3.40 & 5.00 & 29.00 & 5.00 & 665.95 & 56.81 & 4.00 \\
\hline & Escenario 6 & 3.40 & 5.00 & 29.00 & 5.00 & 665.95 & 56.81 & 2.50 \\
\hline & Escenario 7 & 3.07 & 5.00 & 29.00 & 5.00 & 665.95 & 56.81 & 2.33 \\
\hline & Escenario 8 & 3.40 & 5.00 & 29.00 & 5.00 & 665.95 & 56.81 & 4.83 \\
\hline & Escenario 9 & 3.40 & 5.00 & 29.00 & 4.22 & 665.95 & 56.81 & 4.00 \\
\hline & Escenario 10 & 3.40 & 5.00 & 29.00 & 5.00 & 665.95 & 56.81 & 4.50 \\
\hline & Escenario 11 & 3.40 & 5.00 & 29.00 & 5.00 & 665.95 & 56.81 & 4.33 \\
\hline & Escenario 12 & 3.40 & 5.00 & 29.00 & 5.00 & 1684.85 & 61.36 & 4.67 \\
\hline & Escenario 13 & 3.07 & 5.00 & 29.00 & 5.00 & 665.95 & 56.81 & 3.67 \\
\hline & Escenario 14 & 3.40 & 5.00 & 29.00 & 5.00 & 1684.85 & 61.36 & 2.83 \\
\hline & Escenario 15 & 3.40 & 5.00 & 29.00 & 5.00 & 665.95 & 56.81 & 4.33 \\
\hline & Escenario 16 & 3.40 & 5.00 & 29.00 & 5.00 & 665.95 & 56.81 & 4.50 \\
\hline
\end{tabular}

Ilustración 62: Datos Experimentales del Estudio Cuantitativo, Componente Facebook

\begin{tabular}{|c|c|c|c|c|c|c|c|c|}
\hline & & \multicolumn{3}{|c|}{ Atributos Internos / Estáticos } & \multicolumn{3}{|c|}{ Atributos Externos / Dinámicos } & \multirow{3}{*}{ 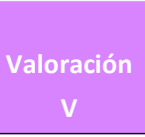 } \\
\hline & & Tamaño & C. Interna & C. Externa & Completitud & Latencia & Refresco & \\
\hline \multirow{17}{*}{ 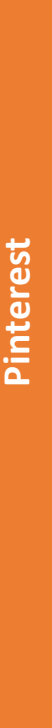 } & & 11 & 12 & 13 & E1 & E2 & E3 & \\
\hline & Escenario 1 & 3.52 & 5.00 & 62.00 & 5.00 & 117.19 & 53.10 & 3.17 \\
\hline & Escenario 2 & 2.98 & 5.00 & 62.00 & 5.00 & 117.19 & 53.10 & 2.17 \\
\hline & Escenario 3 & 3.52 & 5.00 & 62.00 & 5.00 & 1939.39 & 53.39 & 3.33 \\
\hline & Escenario 4 & 3.52 & 5.00 & 84.00 & 5.00 & 117.19 & 53.10 & 4.67 \\
\hline & Escenario 5 & 3.52 & 5.00 & 62.00 & 5.00 & 117.19 & 53.10 & 4.33 \\
\hline & Escenario 6 & 3.52 & 5.00 & 62.00 & 5.00 & 117.19 & 53.10 & 2.50 \\
\hline & Escenario 7 & 3.52 & 5.00 & 62.00 & 5.00 & 117.19 & 53.10 & 4.50 \\
\hline & Escenario 8 & 3.52 & 5.00 & 84.00 & 5.00 & 117.19 & 53.10 & 3.83 \\
\hline & Escenario 9 & 3.52 & 5.00 & 62.00 & 5.00 & 117.19 & 53.10 & 2.67 \\
\hline & Escenario 10 & 3.52 & 4.99 & 62.00 & 5.00 & 117.19 & 53.10 & 3.17 \\
\hline & Escenario 11 & 2.98 & 5.00 & 62.00 & 5.00 & 117.19 & 53.10 & 4.33 \\
\hline & Escenario 12 & 3.52 & 5.00 & 62.00 & 4.03 & 117.19 & 53.10 & 2.33 \\
\hline & Escenario 13 & 3.52 & 5.00 & 62.00 & 5.00 & 117.19 & 53.10 & 3.67 \\
\hline & Escenario 14 & 3.52 & 5.00 & 62.00 & 4.03 & 117.19 & 53.10 & 4.50 \\
\hline & Escenario 15 & 3.52 & 5.00 & 62.00 & 5.00 & 117.19 & 53.10 & 4.33 \\
\hline & Escenario 16 & 3.52 & 5.00 & 62.00 & 5.00 & 117.19 & 53.10 & 2.67 \\
\hline
\end{tabular}

Ilustración 63: Datos Experimentales del Estudio Cuantitativo, Componente Pinterest 


\begin{tabular}{|c|c|c|c|c|c|c|c|c|}
\hline & & \multicolumn{3}{|c|}{ Atributos Internos / Estáticos } & \multicolumn{3}{|c|}{ Atributos Externos / Dinámicos } & \multirow{3}{*}{ 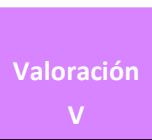 } \\
\hline & & Tamaño & C. Interna & C. Externa & Completitud $\mathrm{L}$ & Latencia & Refresco & \\
\hline & & I1 & 12 & 13 & E1 $\quad 1$ & E2 & E3 & \\
\hline \multirow{16}{*}{$\frac{\mathscr{8}}{\circ}$} & Escenario 1 & 3.90 & 5.00 & 53.00 & 5.00 & 833.45 & 53.82 & 2.50 \\
\hline & Escenario 2 & 3.90 & 5.00 & 42.00 & 5.00 & 5059.94 & 59.01 & 2.83 \\
\hline & Escenario 3 & 3.90 & 5.00 & 42.00 & 5.00 & 833.45 & 53.82 & 4.00 \\
\hline & Escenario 4 & 3.90 & 5.00 & 42.00 & 5.00 & 833.45 & 53.82 & 4.33 \\
\hline & Escenario 5 & 2.53 & 5.00 & 42.00 & 5.00 & 833.45 & 53.82 & 2.50 \\
\hline & Escenario 6 & 3.90 & 5.00 & 42.00 & 5.00 & 833.45 & 53.82 & 1.83 \\
\hline & Escenario 7 & 3.90 & 5.00 & 42.00 & 2.78 & 833.45 & 53.82 & 2.17 \\
\hline & Escenario 8 & 2.53 & 5.00 & 42.00 & 5.00 & 833.45 & 53.82 & 1.83 \\
\hline & Escenario 9 & 3.90 & 5.00 & 42.00 & 5.00 & 833.45 & 53.82 & 1.67 \\
\hline & Escenario 10 & 3.90 & 3.00 & 42.00 & 5.00 & 833.45 & 53.82 & 4.33 \\
\hline & Escenario 11 & 3.90 & 5.00 & 42.00 & 5.00 & 5059.94 & 59.01 & 2.17 \\
\hline & Escenario 12 & 3.90 & 5.00 & 42.00 & 5.00 & 833.45 & 53.82 & 3.67 \\
\hline & Escenario 13 & 3.90 & 5.00 & 42.00 & 2.78 & 833.45 & 53.82 & 3.33 \\
\hline & Escenario 14 & 3.90 & 3.00 & 42.00 & 5.00 & 833.45 & 53.82 & 2.33 \\
\hline & Escenario 15 & 3.90 & 5.00 & 42.00 & 5.00 & 833.45 & 53.82 & 4.33 \\
\hline & Escenario 16 & 3.90 & 5.00 & 42.00 & 5.00 & 833.45 & 53.82 & 3.50 \\
\hline
\end{tabular}

Ilustración 64: Datos Experimentales del Estudio Cuantitativo, Componente Bolsa

\begin{tabular}{|c|c|c|c|c|c|c|c|c|}
\hline & & \multicolumn{3}{|c|}{ Atributos Internos / Estáticos } & \multicolumn{3}{|c|}{ Atributos Externos / Dinámicos } & \multirow{3}{*}{ 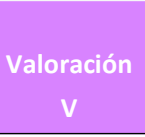 } \\
\hline & & Tamaño & C. Interna & C. Externa & Completitud & Latencia & Refresco & \\
\hline \multirow{17}{*}{$\frac{8}{\frac{8}{E}}$} & & 11 & 12 & 13 & E1 & E2 & E3 & \\
\hline & Escenario 1 & 3.03 & 5.00 & 12.00 & 5.00 & 1876.99 & 56.34 & 2.33 \\
\hline & Escenario 2 & 3.03 & 5.00 & 12.00 & 4.34 & 151.47 & 53.86 & 2.83 \\
\hline & Escenario 3 & 3.03 & 5.00 & 12.00 & 5.00 & 151.47 & 53.86 & 4.17 \\
\hline & Escenario 4 & 3.03 & 5.00 & 12.00 & 5.00 & 151.47 & 53.86 & 4.67 \\
\hline & Escenario 5 & 3.03 & 4.00 & 12.00 & 5.00 & 151.47 & 53.86 & 2.67 \\
\hline & Escenario 6 & 2.63 & 5.00 & 12.00 & 5.00 & 151.47 & 53.86 & 3.50 \\
\hline & Escenario 7 & 3.03 & 5.00 & 12.00 & 5.00 & 151.47 & 53.86 & 2.50 \\
\hline & Escenario 8 & 3.03 & 4.00 & 12.00 & 5.00 & 151.47 & 53.86 & 4.50 \\
\hline & Escenario 9 & 3.03 & 5.00 & 12.00 & 5.00 & 151.47 & 53.86 & 2.00 \\
\hline & Escenario 10 & 3.03 & 5.00 & 32.00 & 5.00 & 151.47 & 53.86 & 4.83 \\
\hline & Escenario 11 & 3.03 & 5.00 & 12.00 & 4.34 & 151.47 & 53.86 & 3.83 \\
\hline & Escenario 12 & 3.03 & 5.00 & 12.00 & 5.00 & 151.47 & 53.86 & 5.00 \\
\hline & Escenario 13 & 2.63 & 5.00 & 12.00 & 5.00 & 151.47 & 53.86 & 5.00 \\
\hline & Escenario 14 & 3.03 & 5.00 & 32.00 & 5.00 & 151.47 & 53.86 & 2.83 \\
\hline & Escenario 15 & 3.03 & 5.00 & 12.00 & 5.00 & 151.47 & 53.86 & 4.33 \\
\hline & Escenario 16 & 3.03 & 5.00 & 12.00 & 5.00 & 151.47 & 53.86 & 5.00 \\
\hline
\end{tabular}

Ilustración 65: Datos Experimentales del Estudio Cuantitativo, Componente Tiempo 


\begin{tabular}{|c|c|c|c|c|c|c|c|c|}
\hline & & \multicolumn{3}{|c|}{ Atributos Internos / Estáticos } & \multicolumn{3}{|c|}{ Atributos Externos / Dinámicos } & \multirow{3}{*}{$\begin{array}{c}\text { Valoración } \\
\qquad \text { V }\end{array}$} \\
\hline & & Tamaño & C. Interna & C. Externa & Completitud & Latencia & Refresco & \\
\hline \multirow{17}{*}{ 언 } & & 11 & 12 & 13 & E1 & E2 & E3 & \\
\hline & Escenario 1 & 3.79 & 4.00 & 30.00 & 5.00 & 499.60 & 59.26 & 2.33 \\
\hline & Escenario 2 & 3.79 & 5.00 & 55.00 & 5.00 & 499.60 & 59.26 & 3.83 \\
\hline & Escenario 3 & 3.79 & 5.00 & 30.00 & 5.00 & 499.60 & 59.26 & 4.83 \\
\hline & Escenario 4 & 3.79 & 5.00 & 30.00 & 4.05 & 499.60 & 59.26 & 4.67 \\
\hline & Escenario 5 & 3.79 & 5.00 & 30.00 & 5.00 & 499.60 & 59.26 & 3.33 \\
\hline & Escenario 6 & 3.79 & 5.00 & 30.00 & 5.00 & 499.60 & 59.26 & 2.33 \\
\hline & Escenario 7 & 3.79 & 5.00 & 30.00 & 5.00 & 1359.25 & 63.13 & 4.50 \\
\hline & Escenario 8 & 3.79 & 4.00 & 30.00 & 5.00 & 499.60 & 59.26 & 3.83 \\
\hline & Escenario 9 & 3.79 & 5.00 & 30.00 & 5.00 & 499.60 & 59.26 & 2.67 \\
\hline & Escenario 10 & 2.88 & 5.00 & 30.00 & 5.00 & 499.60 & 59.26 & 4.33 \\
\hline & Escenario 11 & 3.79 & 5.00 & 55.00 & 5.00 & 499.60 & 59.26 & 4.67 \\
\hline & Escenario 12 & 3.79 & 5.00 & 30.00 & 5.00 & 499.60 & 59.26 & 5.00 \\
\hline & Escenario 13 & 3.79 & 5.00 & 30.00 & 5.00 & 1359.25 & 63.13 & 4.33 \\
\hline & Escenario 14 & 3.79 & 5.00 & 30.00 & 4.05 & 499.60 & 59.26 & 4.33 \\
\hline & Escenario 15 & 3.79 & 5.00 & 30.00 & 5.00 & 499.60 & 59.26 & 4.33 \\
\hline & Escenario 16 & 3.79 & 5.00 & 30.00 & 5.00 & 499.60 & 59.26 & 3.83 \\
\hline
\end{tabular}

Ilustración 66: Datos Experimentales del Estudio Cuantitativo, Componente Tráfico 


\subsection{Datos Experimentales del Estudio Cuantitativo III}

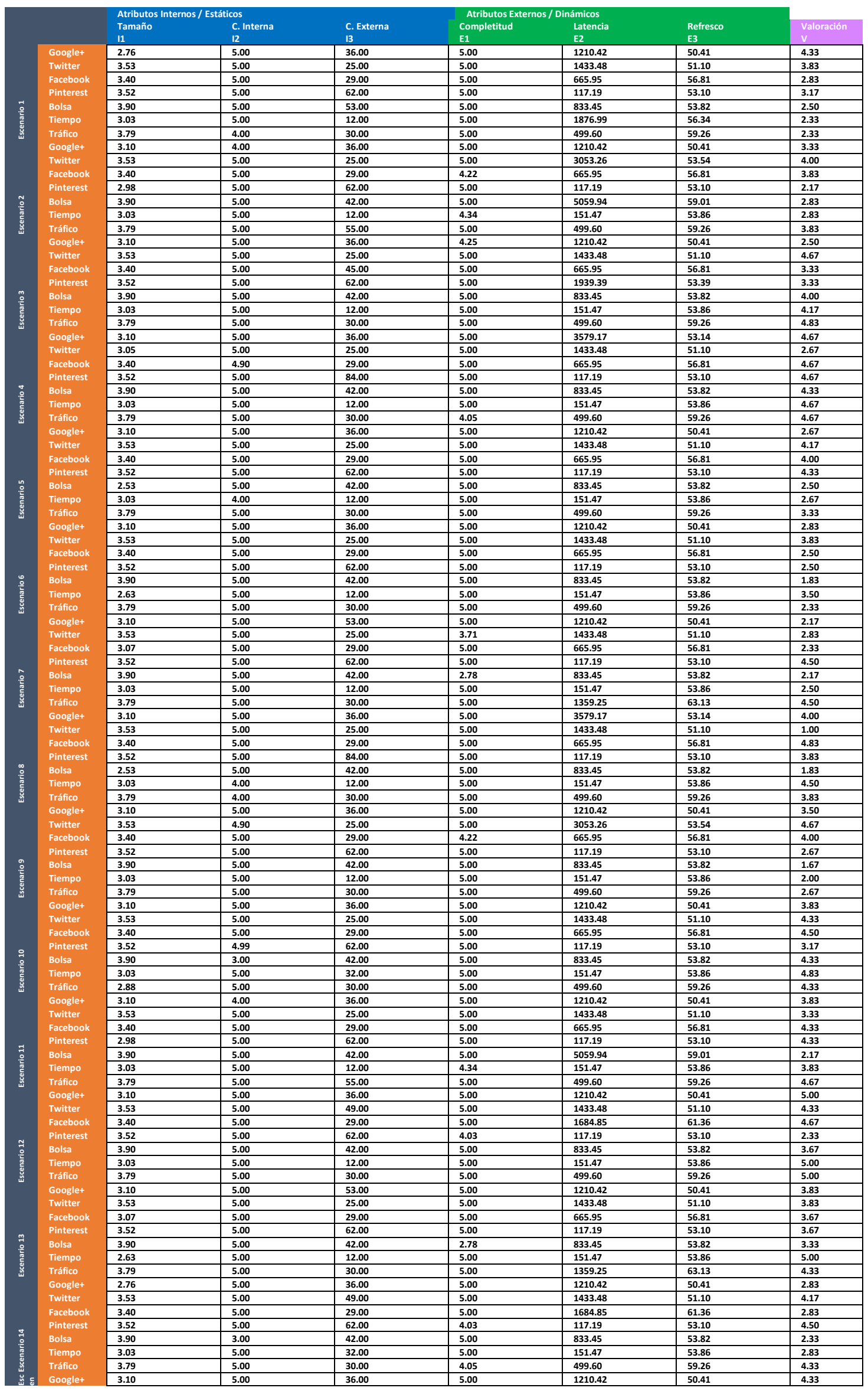




\begin{tabular}{|c|c|c|c|c|c|c|c|}
\hline Twitter & 3.53 & 5.00 & 25.00 & 3.71 & 1433.48 & 51.10 & 4.33 \\
\hline Facebook & 3.40 & 5.00 & 29.00 & 5.00 & 665.95 & 56.81 & 4.33 \\
\hline Pinterest & 3.52 & 5.00 & 62.00 & 5.00 & 117.19 & 53.10 & 4.33 \\
\hline Bolsa & 3.90 & 5.00 & 42.00 & 5.00 & 833.45 & 53.82 & 4.33 \\
\hline Tiempo & 3.03 & 5.00 & 12.00 & 5.00 & 151.47 & 53.86 & 4.33 \\
\hline Tráfico & 3.79 & 5.00 & 30.00 & 5.00 & 499.60 & 59.26 & 4.33 \\
\hline Google+ & 3.10 & 5.00 & 36.00 & 5.00 & 1210.42 & 50.41 & 5.00 \\
\hline Twitter & 3.53 & 5.00 & 25.00 & 5.00 & 1433.48 & 51.10 & 5.00 \\
\hline Facebook & 3.40 & 5.00 & 29.00 & 5.00 & 665.95 & 56.81 & 4.50 \\
\hline Pinterest & 3.52 & 5.00 & 62.00 & 5.00 & 117.19 & 53.10 & 2.67 \\
\hline Bolsa & 3.90 & 5.00 & 42.00 & 5.00 & 833.45 & 53.82 & 3.50 \\
\hline Tiempo & 3.03 & 5.00 & 12.00 & 5.00 & 151.47 & 53.86 & 5.00 \\
\hline Tráfico & 3.79 & 5.00 & 30.00 & 5.00 & 499.60 & 59.26 & 3.83 \\
\hline
\end{tabular}

Ilustración 67: Resultados Experimentales Cuantitativos Agrupados a Nivel de Estudio 


\subsection{Categorización del Panel de Expertos}

En este apéndice se incluyen los resultados individuales de la categorización de expertos. Estos datos permitirán un mayor entendimiento y análisis de los resultados presentados en esta

tesis.

\begin{tabular}{|c|c|c|c|c|c|c|c|c|c|c|}
\hline Codigo Experto & E055 & E014 & E072 & E205 & E194 & E064 & E114 & E034 & E105 & E154 \\
\hline ECOO Expertise & 5 & 4 & 2 & 5 & 4 & 4 & 4 & 4 & 5 & 4 \\
\hline $\begin{array}{l}\text { EC01 Year of experiences } \\
\text { with Web Technologies }\end{array}$ & More than 7 years & More than 7 years & More than 7 years & More than 7 years & More than 7 years & $\begin{array}{c}\text { Between } 3 \text { and } 5 \\
\text { years }\end{array}$ & More than 7 years & More than 7 years & More than 7 years & $\begin{array}{c}\text { Between } 5 \text { and } 7 \\
\text { years }\end{array}$ \\
\hline $\begin{array}{l}\text { EC02 Do you have formal } \\
\text { education on Computer } \\
\text { Science? }\end{array}$ & Others & Others & $\begin{array}{l}\text { Bachelor Degree } \\
\text { on Computer } \\
\text { Science }\end{array}$ & $\begin{array}{l}\text { Master Degree on } \\
\text { Computer Science }\end{array}$ & $\begin{array}{l}\text { PhD on Computer } \\
\text { Science }\end{array}$ & $\begin{array}{l}\text { Bachelor Degree } \\
\text { on Computer } \\
\text { Science }\end{array}$ & Others & Others & Others & Others \\
\hline $\begin{array}{l}\text { ECO3 Are you actively } \\
\text { contributing to open } \\
\text { source projects? }\end{array}$ & Yes & Yes & Yes & Yes & Yes & No & Yes & Yes & Yes & Yes \\
\hline EC04 Professional Sector & $\begin{array}{l}\text { IT Services / } \\
\text { Software } \\
\text { Development }\end{array}$ & $\begin{array}{l}\text { IT Services / } \\
\text { Software } \\
\text { Development }\end{array}$ & $\begin{array}{l}\text { IT Services / } \\
\text { Software } \\
\text { Development }\end{array}$ & $\begin{array}{l}\text { IT Services / } \\
\text { Software } \\
\text { Development }\end{array}$ & $\begin{array}{l}\text { Research / } \\
\text { Academy }\end{array}$ & $\begin{array}{l}\text { IT Services / } \\
\text { Software } \\
\text { Development }\end{array}$ & $\begin{array}{l}\text { IT Services / } \\
\text { Software } \\
\text { Development }\end{array}$ & $\begin{array}{l}\text { IT Services / } \\
\text { Software } \\
\text { Development }\end{array}$ & $\begin{array}{l}\text { IT Services / } \\
\text { Software } \\
\text { Development }\end{array}$ & $\begin{array}{l}\text { IT Services / } \\
\text { Software } \\
\text { Development }\end{array}$ \\
\hline $\begin{array}{l}\text { EC05 Web Components } \\
\text { Technology }\end{array}$ & Lit Element & Lit Element & $\begin{array}{c}\text { Angular } \\
\text { Components }\end{array}$ & Lit Element & $\begin{array}{c}\text { Angular } \\
\text { Components }\end{array}$ & $\begin{array}{l}\text { React, Vue.js (non } \\
\text { native } \\
\text { components). } \\
\text { Previously } \\
\text { Polymer. }\end{array}$ & Hybrids & $\begin{array}{l}\text { Angular } \\
\text { Components }\end{array}$ & Lit Element & Hybrids \\
\hline $\begin{array}{c}\text { ECO6 is there a QA role / } \\
\text { group in your team? }\end{array}$ & Yes & No & Yes & Yes & No & No & Yes & Yes & Yes & No \\
\hline $\begin{array}{l}\text { EC07 Does you } \\
\text { development process } \\
\text { include any quality test? }\end{array}$ & Yes & Yes & Yes & Yes & Yes & No & Yes & Yes & Yes & Yes \\
\hline $\begin{array}{l}\text { EC08 Does your team run } \\
\text { quality test with } \\
\text { customers or users? }\end{array}$ & No & No & Yes & No & Yes & No & Yes & Yes & Yes & No \\
\hline $\begin{array}{l}\text { ECO9 Does your team use } \\
\text { any static analysis tool? }\end{array}$ & Yes & Yes & Yes & Yes & Yes & Yes & Yes & Yes & Yes & Yes \\
\hline $\begin{array}{l}\text { EC10 Do you know ISO } \\
25000 \text { quality standards? }\end{array}$ & Yes & No & No & No & No & No & Yes & No & No & No \\
\hline EP11 Further comments & $\begin{array}{c}\text { PhD and Master in } \\
\text { Telecommunicati } \\
\text { ons }\end{array}$ & 0 & 0 & 0 & 0 & 0 & $\begin{array}{l}\text { Master in } \\
\text { Industrial } \\
\text { Engineering }\end{array}$ & 0 & 0 & $\begin{array}{l}\text { Can't wait to see } \\
\text { this published:) }\end{array}$ \\
\hline
\end{tabular}

Ilustración 68: Resultados Individuales de la Categorización de Expertos I

\begin{tabular}{|c|c|c|c|c|c|c|c|c|c|c|}
\hline Codigo Experto & E043 & E144 & E185 & E174 & E084 & E095 & E124 & E135 & E024 & E164 \\
\hline ECOO Expertise & 3 & 4 & 5 & 4 & 4 & 5 & 4 & 5 & 4 & 4 \\
\hline $\begin{array}{l}\text { EC01 Year of experiences } \\
\text { with Web Technologies }\end{array}$ & More than 7 years & $\begin{array}{c}\text { Between } 5 \text { and } 7 \\
\text { years }\end{array}$ & $\begin{array}{c}\text { Between } 3 \text { and } 5 \\
\text { years }\end{array}$ & More than 7 years & More than 7 years & More than 7 years & $\begin{array}{c}\text { Between } 5 \text { and } 7 \\
\text { years }\end{array}$ & More than 7 years & $\begin{array}{c}\text { Between } 3 \text { and } 5 \\
\text { years }\end{array}$ & $\begin{array}{c}\text { Between } 5 \text { and } 7 \\
\text { years }\end{array}$ \\
\hline $\begin{array}{l}\text { EC02 Do you have formal } \\
\text { education on Computer } \\
\text { Science? }\end{array}$ & $\begin{array}{l}\text { Bachelor Degree } \\
\text { on Computer } \\
\text { Science }\end{array}$ & Others & $\begin{array}{l}\text { Bachelor Degree } \\
\text { on Computer } \\
\text { Science }\end{array}$ & $\begin{array}{l}\text { Bachelor Degree } \\
\text { on Computer } \\
\text { Science }\end{array}$ & $\begin{array}{l}\text { Bachelor Degree } \\
\text { on Computer } \\
\text { Science }\end{array}$ & $\begin{array}{l}\text { Master Degree on } \\
\text { Computer Science }\end{array}$ & Others & $\begin{array}{l}\text { Master Degree on } \\
\text { Computer Science }\end{array}$ & $\begin{array}{l}\text { Master Degree on } \\
\text { Computer Science }\end{array}$ & Others \\
\hline $\begin{array}{l}\text { EC03 Are you actively } \\
\text { contributing to open } \\
\text { source projects? }\end{array}$ & No & Yes & Yes & Yes & No & Yes & No & Yes & Yes & Yes \\
\hline EC04 Professional Sector & $\begin{array}{l}\text { IT Services / } \\
\text { Software } \\
\text { Development }\end{array}$ & $\begin{array}{l}\text { IT Services / } \\
\text { Software } \\
\text { Development }\end{array}$ & $\begin{array}{l}\text { IT Services / } \\
\text { Software } \\
\text { Development }\end{array}$ & $\begin{array}{l}\text { IT Services / } \\
\text { Software } \\
\text { Development }\end{array}$ & $\begin{array}{l}\text { IT Services / } \\
\text { Software } \\
\text { Development }\end{array}$ & $\begin{array}{l}\text { IT Services / } \\
\text { Software } \\
\text { Development }\end{array}$ & $\begin{array}{l}\text { IT Services / } \\
\text { Software } \\
\text { Development }\end{array}$ & $\begin{array}{l}\text { IT Services / } \\
\text { Software } \\
\text { Development }\end{array}$ & $\begin{array}{l}\text { IT Services / } \\
\text { Software } \\
\text { Development }\end{array}$ & $\begin{array}{l}\text { IT Services / } \\
\text { Software } \\
\text { Development }\end{array}$ \\
\hline $\begin{array}{l}\text { EC05 Web Components } \\
\text { Technology }\end{array}$ & Hybrids & Lit Element & Stencills & $\begin{array}{l}\text { Angular } \\
\text { Components }\end{array}$ & Vanilla & Lit Element & $\begin{array}{l}\text { Angular } \\
\text { Components }\end{array}$ & Lit Element & Lit Element & Lit Element \\
\hline $\begin{array}{l}\text { ECO6 is there a QA role / } \\
\text { group in your team? }\end{array}$ & No & No & Yes & No & No & Yes & Yes & Yes & No & No \\
\hline $\begin{array}{l}\text { EC07 Does you } \\
\text { development process } \\
\text { include any quality test? }\end{array}$ & No & No & Yes & Yes & Yes & Yes & Yes & Yes & Yes & Yes \\
\hline $\begin{array}{l}\text { EC08 Does your team run } \\
\text { quality test with } \\
\text { customers or users? }\end{array}$ & Yes & No & Yes & Yes & Yes & Yes & Yes & Yes & Yes & Yes \\
\hline $\begin{array}{l}\text { EC09 Does your team use } \\
\text { any static analysis tool? }\end{array}$ & Yes & Yes & Yes & No & Yes & Yes & Yes & Yes & Yes & Yes \\
\hline $\begin{array}{l}\text { EC10 Do you know ISO } \\
25000 \text { quality standards? }\end{array}$ & No & No & No & No & No & Yes & No & Yes & Yes & No \\
\hline EP11 Further comments & 0 & $\begin{array}{l}\text { I studied a higher } \\
\text { cycle in Spain. }\end{array}$ & 0 & 0 & 0 & 0 & 0 & 0 & 0 & 0 \\
\hline
\end{tabular}

Ilustración 69: Resultados Individuales de la Categorización de Expertos II 